IZADP No. 1640

\title{
Workplace Training in Europe
}

Andrea Bassanini

Alison Booth

Giorgio Brunello

Maria De Paola

Edwin Leuven

J une 2005 


\title{
Workplace Training in Europe
}

\author{
Andrea Bassanini \\ OECD and University of Evry \\ Alison Booth \\ Australian National University, University of Essex \\ and IZA Bonn \\ Giorgio Brunello \\ University of Padova, CESifo \\ and IZA Bonn \\ Maria De Paola \\ University of Calabria \\ Edwin Leuven \\ University of Amsterdam and CREST
}

Discussion Paper No. 1640

June 2005

IZA

P.O. Box 7240

53072 Bonn

Germany

Phone: +49-228-3894-0

Fax: +49-228-3894-180

Email: iza@iza.org

\begin{abstract}
Any opinions expressed here are those of the author(s) and not those of the institute. Research disseminated by IZA may include views on policy, but the institute itself takes no institutional policy positions.

The Institute for the Study of Labor (IZA) in Bonn is a local and virtual international research center and a place of communication between science, politics and business. IZA is an independent nonprofit company supported by Deutsche Post World Net. The center is associated with the University of Bonn and offers a stimulating research environment through its research networks, research support, and visitors and doctoral programs. IZA engages in (i) original and internationally competitive research in all fields of labor economics, (ii) development of policy concepts, and (iii) dissemination of research results and concepts to the interested public.
\end{abstract}

IZA Discussion Papers often represent preliminary work and are circulated to encourage discussion. Citation of such a paper should account for its provisional character. A revised version may be available directly from the author. 
IZA Discussion Paper No. 1640

June 2005

\section{ABSTRACT}

\section{Workplace Training in Europe*}

This paper reviews the existing evidence on workplace training in Europe in different data sources - the CVTS, OECD data and the European Community Household Panel. We outline the differences in training incidence and relate these differences to the private costs and benefits of training, and to institutional factors such as unions, employment protection and product market competition. We ask whether there is a case for under-provision of training in Europe and examine alternative policies aiming both at raising training incidence and at reducing inequalities in the provision of skills.

JEL Classification: J24

Keywords: $\quad$ training, Europe, training policies

Corresponding author:

Giorgio Brunello

Università di Padova

Dipartimento di Scienze Economiche

Via del Santo 33

35100 Padova

Italy

Email: giorgio.brunello@unipd.it

\footnotetext{
* Paper presented at the Annual Conference of the Fondazione Rodolfo De Benedetti, Venice June 2005. The views expressed here are those of the authors and cannot be held to represent those of their institutions. We are grateful to our discussants Giuseppe Bertola and Steve Pischke, to Pietro Garibaldi, Michele Pellizzari and to the audiences in Venice and Rome for comments.
} 


\section{Introduction}

A major strategic goal set by the European Heads of Government in the Lisbon summit at the beginning of the new millennium was to make of Europe by 2010 the most competitive and dynamic knowledge - based economy in the world. Education and training are key ingredients of the strategy, which recommends to several European countries the modernization of their education systems and the increase in the percentage of individuals participating in lifelong education ad training. The emphasis on education and training is common to all advanced industrial societies, because of the widespread belief that the challenges posed by the rise of the new low-cost producers in Asia can only be met if labour attains high levels of skill, in a continuous up-skilling process ${ }^{1}$. Almost halfway through, however, it seems clear that attaining the very ambitious goals of the Lisbon strategy is out of question for most European countries (see European Commission, 2005)2.

When macroeconomists talk about human capital, most of the time they focus on education. However, the accumulation of human capital does not end with schools, and training is key to augment and adapt existing skills to the changes of technology. Training is particularly important for senior workers, whose skills accumulated at school are likely to be substantially depreciated, and for the less educated, who run the risk of social exclusion.

One could argue that the attention paid to education is justified by the fact that learning begets learning: getting a better educated labour force guarantees that workers and firms invest more in training. But do they invest enough? The almost ubiquitous diffusion of training policies seem to suggest the contrary, as these policies often provide subsidies to the parties to encourage more company training. Economists have often pointed out that the market for training is characterized by several market failures, which include imperfections in labour, product and capital markets, and both positive and negative externalities. But what is the evidence? And can we say that the difference in the intensity of training across Europe is due to the different importance of these failures?

Efficiency is not the only criterion which justifies government intervention in the market for training. The simple observation that learning begets learning suggests that those individuals who are disadvantaged in the education process are also likely to be at a disadvantage in their labour market learning. If access to schooling is not

\footnotetext{
${ }^{1}$ See Crouch, 1998.

${ }^{2}$ See Addison and Siebert, 1994, for a description of EU training policy before Lisbon.
} 
open to all according to talent and effort because of market failures in the market for education, the disadvantage accumulated at school is going to be amplified by poor training in the labour market. If individuals mature differently and this affects their responses to education, this too could be amplified by training subsequently. A reinforcing factor here is that inequalities of opportunity could affect not only schooling, but also training conditional on schooling.

Even if labour markets were perfectly efficient and equal, government policies which transfer resources from the taxpayer to workers and firms via training subsidies could be explained because of political economy considerations: skilled workers and firms usually are better organized than the ordinary taxpayer, and can lobby politicians for subsidies as a form of redistribution. If the positive effect of training on productivity spills over on the productivity of unskilled workers, the latter too may find it convenient to support training subsidies.

This report examines in comparative perspective workplace training in Europe. Compared to training in general, workplace training is received while in employment, and is usually but not exclusively provided by the employer. This is an important area, not only because company training covers a substantial part of education after labour market entry, but because of the perception - rather widespread in the documents by the European Commissions on the Lisbon Strategy - that European employers do not spend enough in increasing the skills and competencies of their employees.

This tension between policy targets at the European level and the behaviour of firms is well described by Colin Crouch in the following quotation:

"Business firms are equipped to maximize, not collective objectives, but their own profitability. In doing this they will certainly provide training and retraining for large numbers of employees; there is however no reason why company decisions and market forces should maximize the level of vocational ability for a whole society except through a largely serendipitous fall-out..." (Crouch, 1998, p.370)

We start by looking at the facts. Chart I.1 shows the differences in average training incidence across European countries, Anglo-Saxon countries and some countries of Eastern Europe. The Chart plots both average training participation and average annual hours of training per employee. We notice that the US - a key competitor - does not perform "better" than all European countries, because the UK, France and Scandinavian countries have both higher participation and higher annual hours of training. The rest of Europe, including the countries in the "olive belt" 
(Greece, Italy, Portugal and Spain), does "worse" than the US, and is somewhat closer to the new entries from Eastern Europe ${ }^{3}$. While these indicators need to be considered with care, due to the measurement problems discussed at length in the report, they reveal that Europe is very heterogeneous when it comes to training outcomes.

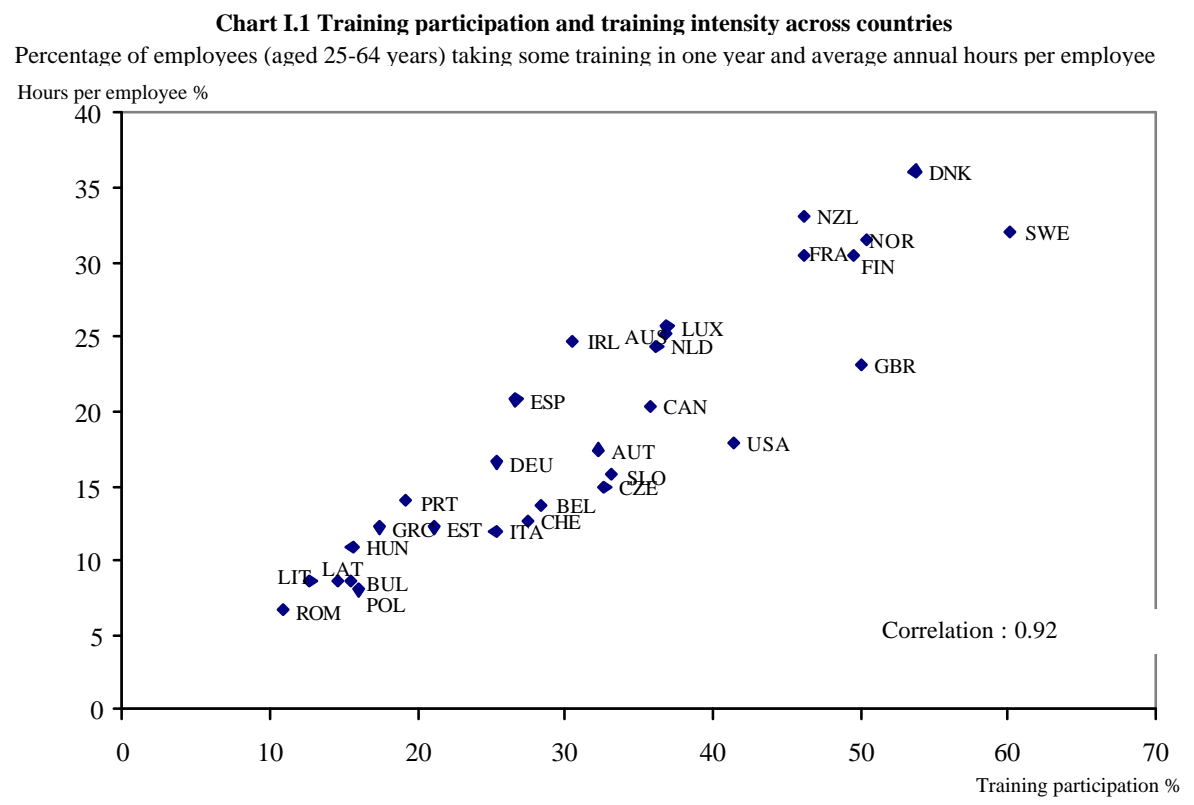

Note: the data refer to the second half of the 1990

Source: OECD (2004).

The Chart also suggests that the concern voiced across the Atlantic on the "poor" performance of US education and training might seem somewhat inflated from the perspective of Southern European countries. In a well known review of company training in the US, which dates back to the early 1990s, Lisa Lynch, 1994, talks of an emerging consensus that US workers' skills are not on par with those of European and Japanese workers. She quotes a report by the US Commission on Workforce Quality and Labour Market Efficiency, which concludes that for US firms to compete internationally a reform of the education and training system is in order. An equally pessimistic view has been voiced, almost contemporaneously, by Bishop, 1993.

Whether this pessimistic view still holds after the very good performance of US productivity growth since the mid 1990s is an open question. Such performance also throws some doubts on the prevailing mantra - more education, more training - in many policy circles: labour productivity in the business sector grew on average by

\footnotetext{
${ }^{3}$ The somewhat surprising relative position of Germany in this diagram could be explained with the fact that we are considering only individuals aged 25-64; by so doing, we exclude most apprenticeship training.
} 
2.10 percent in the US during 1995-2002, in spite of the perception that education and training in that country was not on par with Germany or Japan, which grew instead at a significantly lower rate. Interestingly, only three European countries have had higher labour productivity growth than the US during the same period: I reland (3.92 percent), Greece (3.50 percent) and Finland (2.42 percent). Of these, only Finland has an unambiguously higher training participation and better indicators on schooling performance than the US.

We show that most workplace training is done by employers, independently of whether the accumulated skills can be transferred to other employers. On average, the entire cost of $3 / 4$ of the training courses is directly paid by employers, and there is little evidence that employees indirectly pay through lower wages. Large and innovative firms ${ }^{4}$ train more than small and non-innovative firms, with the UK being the only European country where this does not hold. Cross-country variation among large and innovative firms is, however, small. Therefore, the lower average training incidence in countries located in the Southern "olive belt" is correlated both to their larger share of small firms and to the fact that these firms train relatively less than firms of similar size in Northern Europe.

In Europe, as in the US, training increases with educational attainment and the skill-intensity of occupations, and decreases with age. The age-training gap is negatively correlated with the employment rate of older workers, reflecting either the impact of training on older workers' employability or their incentive to stay on rather than retire, and invest in their skills. Women take more training than men, but essentially because they pay for their own training more often, while firms do not appear to accommodate their greater demand for training. Importantly, women tend to receive less employer-sponsored training than men when they are young and have more frequent career interruptions due to childrearing. On average, temporary workers get trained less often.

After netting out observable individual characteristics, country effects account for almost $1 / 2$ of the explained variation in training participation across Europe - net of Germany $^{5}$. Without doubt, part of this variation reflects measurement error and cross-country differences in definitions and perceptions of training. For instance, since training registered in employer and employee surveys is typically formal, significant episodes of informal training are not counted, which is especially problematic for small firms, where a lot of informal training arguably takes place.

\footnotetext{
${ }^{4}$ Innovative firms are those firm which have introduced at least a new product or process during the reference period.

${ }^{5}$ Germany excluded because of the quality of the data.
} 
However, this residual cross - country variation also includes differences in the institutional and social framework, in government policies and in the macroeconomic conditions.

It is rather difficult to sort out the relative importance of each potential candidate, because some variables are hard to measure, and because of a large host of confounding factors. Yet we find the strong positive correlation between investment in R\&D as percentage of GDP and training incidence showed in Figure 12 quite suggestive of the interactions between skill development and innovative effort at the country level. While we cannot tell whether this relationship reflects a causal link, we remark that the large difference in average training incidence between Northern and Southern European countries is also mirrowed by a large difference in their ability to invest in research and development. An analogous correlation emerges when we measure innovative activity with the share of expenditure in ICT over GDP.

\section{Figure I2. R\&D investment and training, by country}

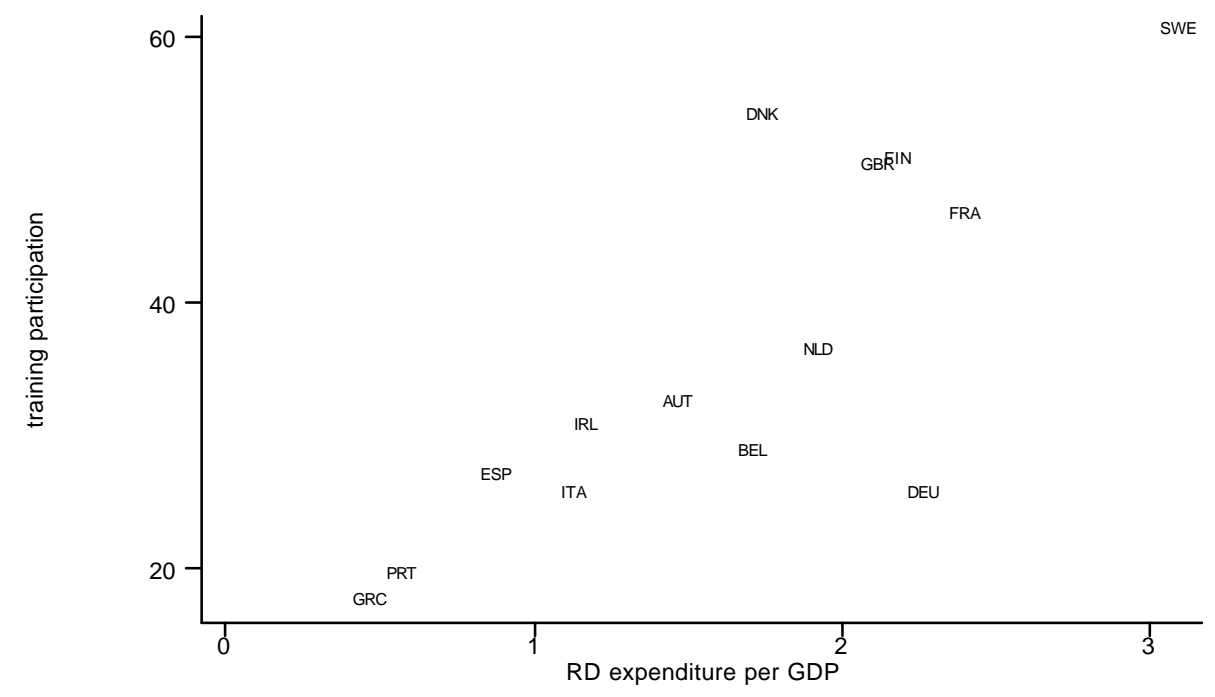

Similarly, Figure 13 shows that there is a negative correlation between an index of stringency of anti-competitive product market regulation - due to Nicoletti and Scarpetta, 2003: training participation is low in Southern European countries, which invest less in $R \& D$ and have more regulated product markets. Conversely, no significant correlation exists between training participation - at the country level and the percentage of workers on a temporary contract. As illustrated by Figure 14, if we exclude the case of Spain - an obvious outlier because of the very high share of temporary labour - countries with a similar share of temporary workers have vastly different levels of training participation. 
Product and labour market institutions have been changing in Europe under the widespread pressure to develop more competitive markets. Did these changes affect training outcomes? We show that the decrease in product market regulation across Europe has facilitated average training investment. Labour market flexibility, on the other hand, has had mixed effects: while the diffusion of temporary work has been associated with a reduction of training incidence, the opposite has occurred with the slow but almost general reduction in the employment protection of regular labour. These results suggest that the progressive deregulation of product and labour markets does not necessarily have a negative impact on the accumulation of human capital in firms, as some have suggested (see Acemoglu and Pischke, 1999a).

\section{Figure I 3. Product market regulation and training, by country}

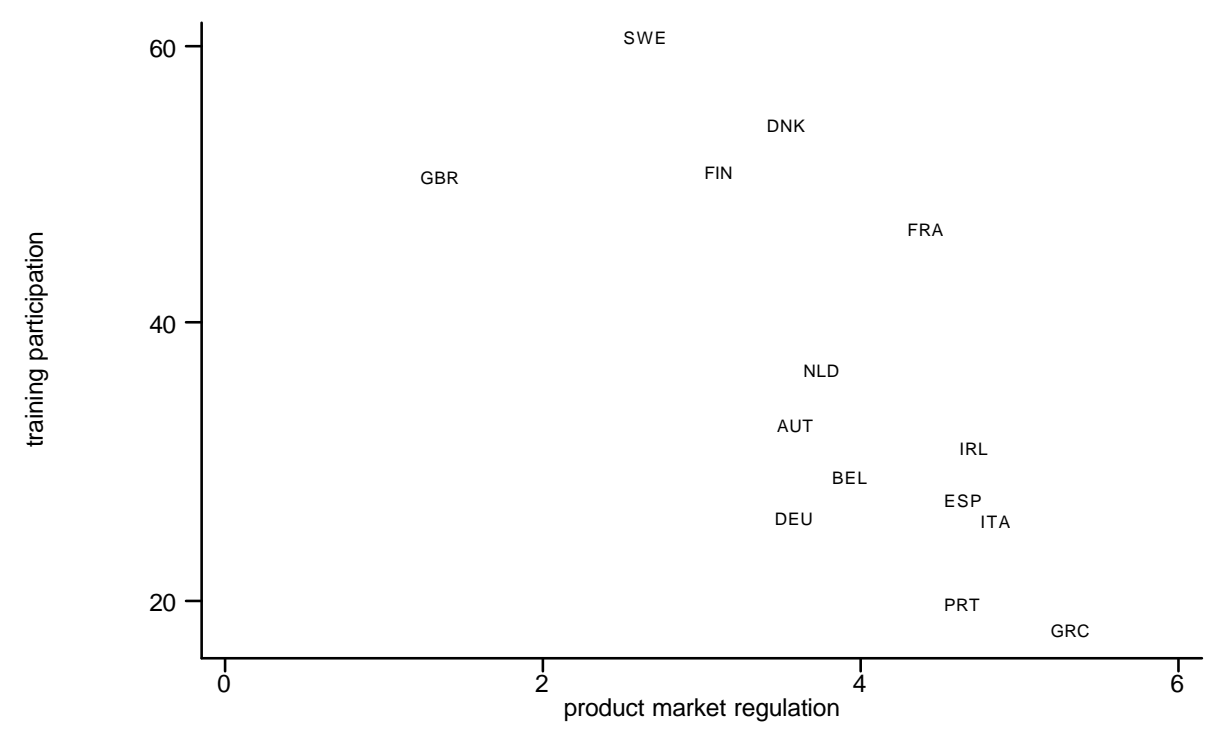

Do the cross - country differences in training incidence across European countries also reflect differences in the deviation of the private from the social optimum? This is a difficult question for at least two reasons: frst, government policies are in place. Assuming that these policies are effective in changing training participation, the observed outcome is different from the one that would prevail without any policy. Second, there are other distortions in the labour and product markets, which place us in a second best environment. When we consider whether government intervention in the training market is desirable, the natural question to ask is how the level of training attained by private agents compares with the socially optimum level of training. While the former is defined by the equality of private benefits and costs, the latter requires that we also consider social benefits and costs. 
We argue that answering this question is particularly hard with the statistical data at hand. First of all, we rarely have information on training costs. Second, private benefits are related to the increase in productivity after training. Since productivity is measured only in special surveys and case studies, our knowledge of training benefits is also limited ${ }^{6}$.

\section{Figure I 4. Temporary workers and training, by country}

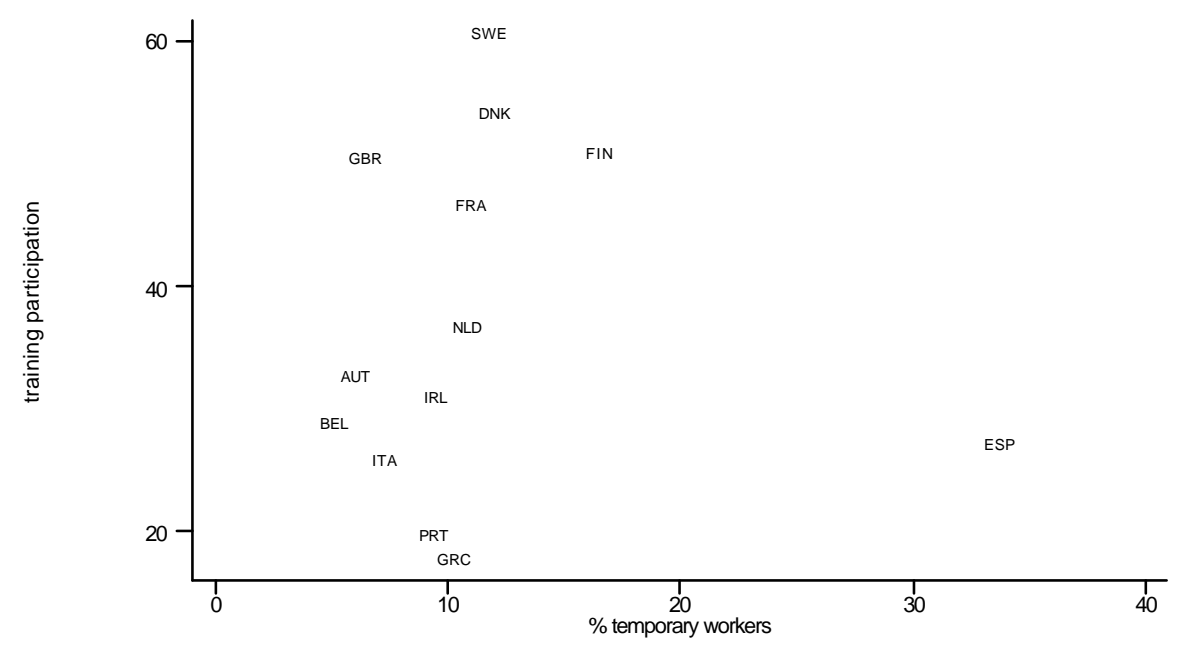

The closest we can get to the private benefits to training is by looking at the wage returns. Even in this case, however, we need to be aware that wages do not correspond to productivity if labour markets are not perfectly competitive. Broadly, the empirical evidence suggests that these returns are substantial, and significantly higher than the returns to education. It also shows that estimated returns are highest in countries where training incidence is lowest, such as Portugal. An implication of this is that cross - country differences in training participation could depend more on differences in supply than in demand. Are these uncovered high returns to training a genuine aspect of the investment in human capital after schooling or instead a statistical artefact driven by our inability to eliminate confounding factors such as individual talent? It might be too early to provide a definite answer to this question, but there are some signs that the estimated wage returns to training might be over-valued.

While we know a lot about private returns - even though some of what we know

\footnotetext{
${ }^{6}$ Policy reports have sometimes less blurred views. In a recent report by the European Commission, for instance, it is stated that "a strong link exists between human capital and productivity in businesses. Investment in human capital increases productivity and is a direct source of innovation and competitiveness" (European Commission, 2005, p.3)
} 
may be open to question - we are basically in the dark when it comes to social returns. In theory, we can think of a number of positive and negative externalities affecting training decisions: poaching externalities due to turnover, positive spillovers on unskilled labour, and positive externalities originated by the complementarity between training and innovation. In practice, there is no measure telling us whether such effects exist and how relevant they are. Little help comes also from the large and growing empirical literature on human capital and growth, because the standard measures of human capital used in that literature include the quantity and quality of education, but exclude training. In this literature, since education and training are complements, the contribution of education to growth includes also the contribution of training, but we have no way to tell the contribution of each of these two variables apart.

Lack of evidence on under-provision is a reason to be prudent when advocating training measures to eliminate the inefficiencies of private markets. Such measures include regulatory interventions - such as payback clauses, apprenticeship contracts, the certification of training and its recognition on a European basis - as prescribed by the Copenhagen declaration, and co-financing measures which fund employers and employees who invest in training.

Training policies, however, can also be motivated by considerations of equity. The European Union gives to equity a prominent role in its Lisbon Strategy, using such keywords as "equal opportunity" and "social inclusion" when advocating more education and more training. When individuals cannot attain desirable outcomes because of circumstances that are independent of their actions, policies that try to restore equality of opportunity are warranted even in the absence of efficiency reasons. Examples of such circumstances include family privilege and / or disadvantage, which we capture with measures of family background. We show that, contrary to the case of the United States, training outcomes in Europe depend in a significant way on parental background, even after netting out education, and that this dependence is particularly significant in Southern European countries. Therefore, individuals who come from disadvantaged European households not only are less likely to attain higher and better education, but also fail to become recipients of company training. Importantly, differences in family background correlate closely in some countries - Italy and Spain are typical examples here with regional disparities: poorer regions have both an average poor family background and lower training incidence.

When equity is the issue, training policies should be targeted at the 
disadvantaged. But are they? Since some co-financing schemes prescribe an active role of the social parties, union concern for equality can help in directing some of these resources to the right targets. An alternative is provided by tax and subsidies to individuals, which include vouchers and learning accounts. Equality as a motivator for policy, however, runs into problems when we consider that the private benefits of the investment may be particularly low among the disadvantaged. Our empirical evidence confirms that workers with lower educational attainment who receive training have significantly lower returns than workers with higher education. This evidence might suggest that an alternative policy which trains the skilled, tax them and redistribute to the less skilled, is desirable - see Heckman, 1999. The problem, of course, is that such policy would breed a culture of social exclusion and dependence, which might be less acceptable in Europe than in the other side of the Atlantic.

Since employers, unlike governments and unions, should not be expected to select the recipients of workplace training with an eye to undo the disadvantages created before labour market entry, policies aiming at the equality of opportunities need also to consider schooling, because of its complementarity with training, and because most of the pre-college schooling in Europe is public. Schooling clearly matters: in the European Union early school leavers - defined as the share of the population aged 18 to 24 with only lower secondary education and not in education or training - were over 20 percent in 2004 in Italy, Spain and Portugal, more than twice the percentage in the Scandinavian countries. As shown by Figure 15, average training incidence is higher in countries where the percentage of the active population with at least upper secondary education is higher ${ }^{7}$. By increasing the average quantity - and quality - of education, governments can also increase training incidence.

Employers may prefer to respond to technical progress and innovation not by retraining existing employees but by replacing them with new generations of school leavers, who have better and more updated general education. This is clearly a problem for senior employees, especially when they lose their jobs. In these circumstances, government action tends to become associated with the care of social casualties and with failures to cope. Some have also voiced concern that pension reforms in Europe, which reduce the implicit tax on continuing work and delay retirement age may damage the prospects of senior workers, who are less

\footnotetext{
${ }^{7}$ Nickell, Redding and Swaffield, 2002, study the interaction between educational attainment, labour market institutions and the structure of production.
} 
employable and more likely to end up in the unemployment pool. Our empirical evidence shows that this concern might be partly inflated, because workers over 50s tend to train more where the implicit tax on continuing work is lower.

\section{Figure I5. Training incidence and schooling}

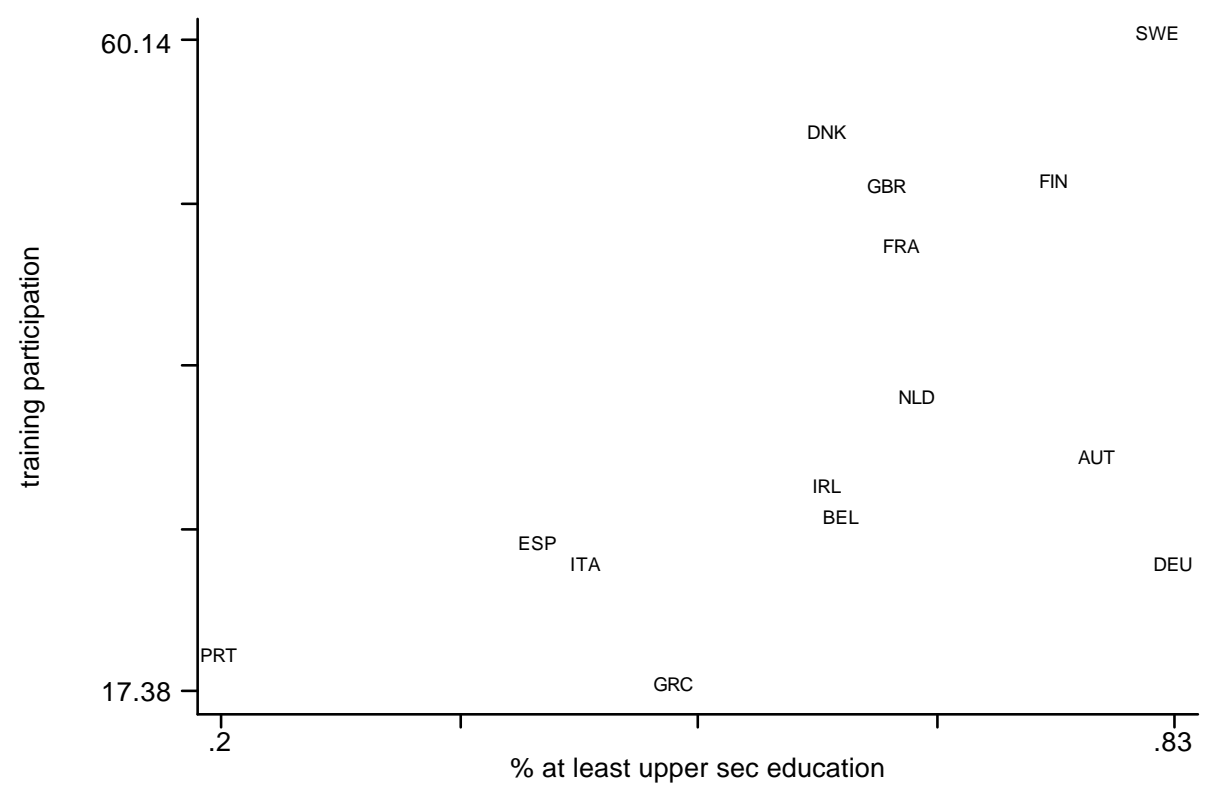

More generally our evidence suggests that training outcomes can be improved also indirectly. The Lisbon agenda includes among its goals: a) investments in research and development to be 3 percent of GDP in 2010 (only Sweden was above the target in the mid 1990s); 55 percent of the labour force aged 55-64 to be in work in 2010; 70 percent of the labour force to be in work in 2010. Our empirical results suggest that policies which try to attain these targets are likely to favour investment in workplace training, with reinforcing effects on the targets themselves. For instance, policies increasing female commitment to the labour market - e.g. during childrearing years, including child care policies and maternity leave provisions - should lead to more training. Moreover, measures that help deregulating the product market and that reduce the incentives to retire are also expected to increase training incidence ${ }^{8}$.

When thinking of policy, it is probably a good idea to realize that Europe is not a homogeneous entity when education and training are considered. Some European countries - most notably the Scandinavian area - are investing more that the US, our key competitor. Others, and typically those in the "olive belt" area, lag

\footnotetext{
${ }^{8}$ On the other hand, measures that increase the portfolio of available labour contracts can increase labour force participation, with less clear-cut effects on training investments.
} 
substantially behind. Our report shows that what we know about training in Europe is not yet enough to answer questions of pressing importance for policy design. Many training policies provide resources to employers and employees, but do they work? Do they have a real or a cosmetic effect? What are the deadweight losses? Compared to the US, evaluation studies of training policies in Europe are few. More needs to be done, both in terms of access to data and in terms of serious policy evaluation.

To conclude, why is Finland investing in training much more than Italy? While we are aware that the answer to this question is complex, a first try is shown in Figure 16 below. Let the demand for and supply of trained employees be a negative and a positive function of the training wage premium $w_{T}$, respectively, and let training participation in each country be determined at the intersection of demand and supply. In this report we show that participation is much higher in Finland than in Italy, in spite of the fact that the expected wage premium is similar - see Chapter 4. Our tentative explanation relies on the fact that both the supply of and the demand for trained employees is higher in Finland than in Italy. The supply is higher at any price in the former country because the higher quantity and quality of education reduces training costs; the demand is higher in Finland than in Italy because of the substantially higher R\&D expenditure and lower product market regulation in the former country, which increase the productivity of trained employees.

Finland turned around the recession of 1990-91 by rapidly converting from natural resources to high-tech production, and so did Sweden. One could conclude that Italy needs another Nokia - or Ericsson. But does it have the right conditions for this to happen? As argued by Blomstrom and Kokko, 2003, “.. in - house training and education have been of central importance for Nokia's ability to absorb new technologies. Both companies - Nokia and Ericsson - have also benefited greatly from public investments in high education and research..." (p.30). Education policies, which affect both the quantity and the quality of I talian education, might require time but are perhaps a key factor in avoiding economic decline.

This report is organized as follows. Chapter 1 reviews the basic theory of workplace training in imperfectly competitive - or oligopsonistic - labour markets. Chapter 2 looks at the data we have and at the main facts concerning training participation. Chapter 3 investigates the relationship between average training participation and country - specific labour and product market institutions. Chapter 4 looks at the private and social costs and benefits of training. Finally, Chapter 5 considers policy issues and reviews the main policies adopted in Europe. 
Figure I6. Training participation and returns in I taly and Finland

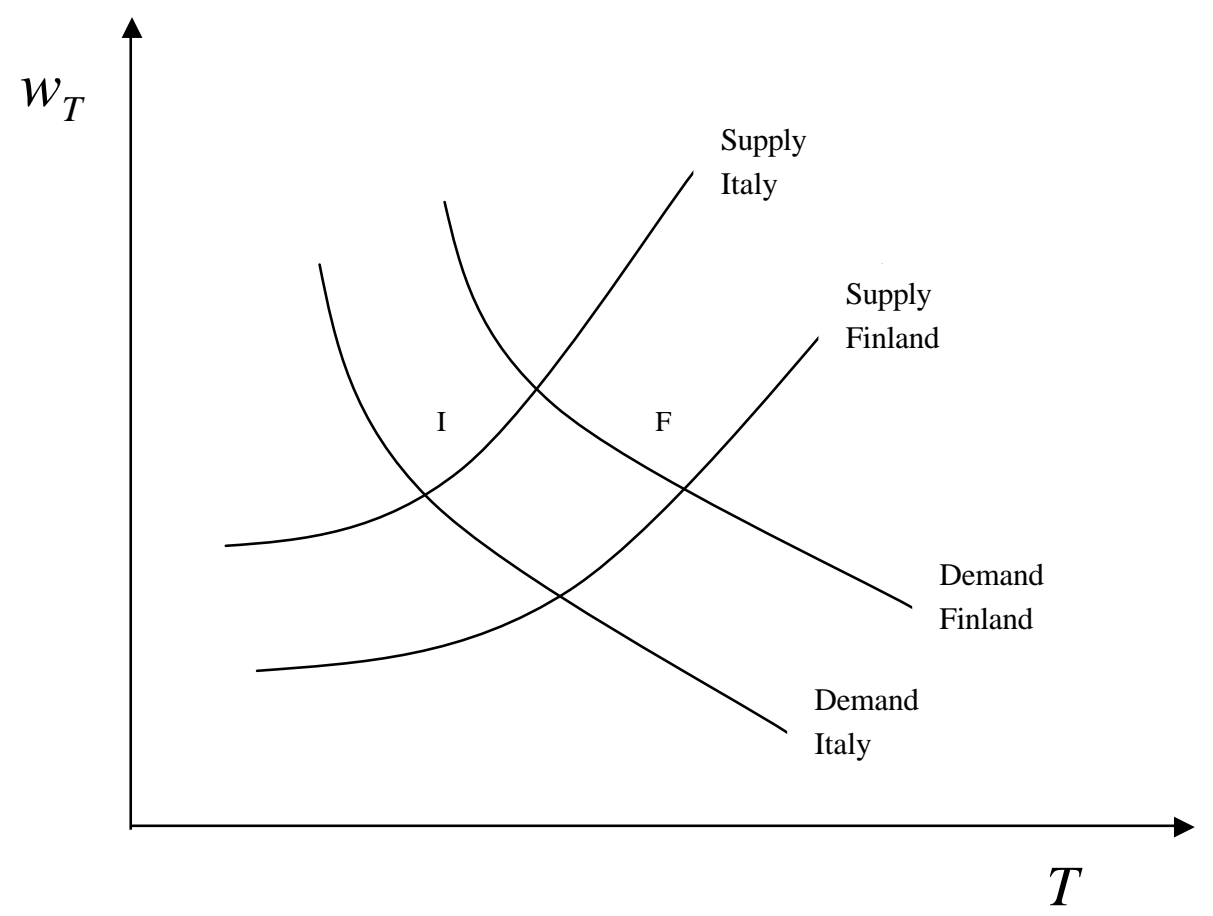




\section{Chapter 1: An Overview of the Theoretical Framework}

Investments in human capital are central to economic performance and growth. When tastes and technologies are changing rapidly, human capital investments are important in maintaining high levels of competitiveness and of employment. Without a workforce that is continually acquiring new skills, it is difficult to reap all the returns from technological progress. In this second half of the volume, we focus on a particular component of human capital - training. Throughout we use the term training to refer to work-related training received while in employment. Thus we exclude from our analysis training received while unemployed or training provided by governments through, for example, active labour market policy.

\subsection{The Received Wisdom}

According to orthodox human capital theory, formalized by Becker, 1964, and Oi, 1962, among others, human capital is an investment that raises expected future productivity, albeit at a cost. Training costs comprise the opportunity costs of foregone earnings as well as the direct costs of training (such as course enrolment costs, materials used while learning, training personnel and the like). Investment in human capital is thus very similar to investment in physical capital but with one crucial distinction. In the absence of slavery, workers retain ownership - and thus control - of their embodied human capital.

Training can be either general or specific in nature (although training is in practice likely to combine a mix of both types, and we will return to this later). In a competitive economy, general training represents skills that can be used at countless other firms, and hence the training is general or portable across companies as individuals change jobs. According to human capital theory, general training would therefore be financed by the worker through the receipt of lowered wages during training, although it could be provided by the firm. The reason for this is that training is embodied in the worker, who could leave at any time to another job where she would be equally as productive. No firm would ever finance such training, since its returns are uncertain and could well be zero. In contrast, specific training is by definition only valuable to the firm providing the training. Hence, to reduce potential hold-up problems, both parties would contribute to the financing of training. This sharing mechanism ensures that both firm and worker have the 
incentive to maintain the relationship after training and thereby to reap the returns. Thus both forms of training - general and specific - are associated with clear predictions, first with regard to their financing, and second with regard to who gets the returns. In the general training case the worker reaps all the returns. In the specific training case, the returns are shared.

For three decades, it was thought that human capital theory, based on the assumption of a perfectly competitive labour market, fully explained who would pay for general training. Any stylized facts diverging from the theory's predictions were believed to be due to imperfections such as credit market constraints. And yet there remained some puzzles that could not be explained within this framework. First, survey evidence showed employers paying for general training in spite of potential poaching of trained workers. And second, there did not seem to be evidence of workers receiving wage cuts during training ${ }^{9}$.

\subsection{Challenges to this Orthodoxy}

More recently, a number of published papers have challenged this orthodoxy. Bhaskar, Manning and To, 2002, note that, just as in international trade the introduction of product market imperfections revolutionised our understanding of trade policies and comparative advantage, while in macroeconomics models of monopolistic competition explained how small adjustment costs could lead to business fluctuations, so too in labour economics has imperfect competition begun to transform our way of thinking. And this is not just through institutions such as trade unions, which are an obvious labour market imperfection. A growing literature argues that employers actually have market power in setting wages - what we might term the new oligopsony. This oligopsony can arise through product differentiation and through imperfect information (rather than through the old definition of a monopsonist as being a single employer in a labour market). And its proponents demonstrate that it can lead to simple and plausible explanations of labour market phenomena that are otherwise regarded as puzzles.

Oligopsony is when the labour supply curve facing a firm is not completely elastic. How can oligopsony arise? There are many potential avenues. Examples include search frictions that emerge when there is imperfect information on job opportunities elsewhere, mobility costs for employees in changing jobs; and

\footnotetext{
${ }^{9}$ For evidence of these puzzles, see for example Bishop, 1997; Leuven and Oosterbeek, 1999; Acemoglu and Pischke, 1999a; and Booth and Bryan, 2005b.
} 
heterogeneous preferences over the non-wage characteristics associated with various jobs (such as their location, work culture, colleague sociability, flexibility of hours, environment, distance from home). ${ }^{10}$

The new training approach uses the insights of new oligopsony theory to generate important new results. Recent papers show that, if the labour market is actually characterised by oligopsonistic wage-setting, some of the predictions of the human capital model are overturned. For example, the wage returns to general training may be less than the productivity returns and firms may find it profitable to pay for training even though it is general.

In the next section, we briefly outline the principal hypotheses regarding training and summarize their predictions as to who pays for general training and the returns to training (at both the training firms and at subsequent firms). For the moment we leave aside the role of institutions, although we will return to this later in the chapter.

\subsection{An overview of the various approaches and their empirical predictions}

i. General training in a perfectly competitive labour market

According to standard human capital theory, workers in perfectly competitive labour markets will pay for general work-related training by receiving low training wages. They will reap the returns to this investment by receiving higher wages afterwards and their post-training wages will be the same across firms, ceteris paribus (Becker, 1964). These predictions are summarised in the first row of Table 1.1, reproduced from Booth and Bryan, 2005a.

\section{ii. Imperfect capital markets and general training}

Workers who cannot afford to accept low wages during general training will be adversely affected by any credit market constraints that disbar them from borrowing

\footnotetext{
${ }^{10}$ This can be thought of as horizontal job differentiation. In Booth and Zoega, 1999, horizontal differentiation arises because jobs differ in terms of their non-wage characteristics, over which workers have varying preferences. This generates an imperfectly elastic labor supply to the firm. Bhaskar and To, 1999, also assume that workers have heterogenous preferences for nonwage job characteristics (and cite various empirical studies supporting this assumption). Bhaskar, Manning and To, 2002, note that these can usefully summarize the variety of reasons for imperfect competition in the labor market.
} 
to finance their investment. However, should the firm be willing to act as lender, it can pay workers more than their marginal product during training and less afterwards. The firm would only agree to such a contract if some mechanism can be devised to bind workers to the firm after training until the loan has been paid back. (Malcomson, Maw and McCormick, 2003). A binding contract - such as an apprenticeship contract or a minimum employment guarantee - is one means of so doing. The predictions of this model are that firms will pay for general training, and workers' wages will be above marginal productivity during training and below marginal productivity after training. The magnitude of this wedge will reflect the degree of cost-sharing. The training will be transferable across firms, and after changing employers workers should get a greater return to their training than they received in the firm that provided the training and the loan. These predictions are summarised in the second row of Table 1.1.

\section{iii. Pure specific training}

Now consider the predictions of the pure specific training model. For specific human capital - of value only to the one firm - it is efficient for the firm and the worker to share both the costs and the returns of the training investment to avoid hold-up problems (Hashimoto, 1981; Leuven and Oosterbeck, 2001). Consequently workers' wages will be above marginal productivity during training and below marginal productivity after training. The magnitude of this wedge will reflect the degree of cost-sharing. The training will not be transferable across firms by definition (in contrast to the model of credit constrained workers seeking general training outlined above). These predictions are summarised in the third row of Table 1.1 .

iv. Mixture of training types

Suppose that, while the labour market is perfectly competitive, training comprises a mix of general and specific components. Here workers will finance their general training and firms will share the costs of the specific training. Since there will be some sharing of costs, wages at the training firm will be greater than productivity during training and less than productivity after training. Wages at subsequent firms will reflect returns only to the general component of training, and consequently will be less than wages at the training firm (in which there is some 
return to the worker to the shared investment in specific training). These predictions are summarised in the fourth row of Table 1.1.

\section{v. Oligopsonistic wage setting}

Now consider a labour market characterised by oligopsonistic wage-setting, as in the 'new' training literature. ${ }^{11}$ It can be shown that the wage 'compression' associated with imperfectly competitive labour markets may increase the incentive for firms to invest in general training, where we will explain in detail in a subsequent section precisely what is meant by the term wage compression. The necessary condition for this result is that post-training productivity is increasing in training intensity at a faster rate than are wages, as illustrated in Figure 1.1. However, the amount of training provided in equilibrium may be sub-optimal from the viewpoint of society. ${ }^{12}$

In Figure 1.1, reproduced from Acemoglu and Pischke, 1999b, $f(\tau)$ denotes a worker's productivity as a concave function of training intensity $\tau$, and $w$ denotes wages. Suppose that $\Delta$ represents the costs of moving between jobs and notice that $f(\tau)-w(\tau)=\Delta$. If $\Delta$ were a constant, then $f^{\prime}(\tau)-w^{\prime}(\tau)=0$. Thus the firm would not benefit from training, as profits would be the same at any level of training intensity. However if mobility costs are increasing in the level of training $\Delta^{\prime}(\tau)>0$, the wage schedule will be flatter than the productivity schedule, since firms pay workers their outside options. Thus profits change by $f^{\prime}-w^{\prime}=\Delta^{\prime}(\tau)>0$, and the firm benefits from giving the worker more training.

The predictions of this simple model - and indeed all the models in this genre are that the firm may finance general training, and that the wages at the training

\footnotetext{
${ }^{11}$ See inter alia, Katz and Ziderman, 1990; Stevens, 1994, 1996; Chang and Wang, 1996; Loewenstein and Spletzer, 1998; Acemoglu and Pischke, 1999b, and Booth and Zoega, 1999.

12 Acemoglu and Pischke, 1999b, isolate four conditions that have to be satisfied for firms to be willing to pay for general training when workers are either credit constrained or would choose a lower level of training. (1) Labourmarket frictions making the productivity of a worker exceed his or her outside option and generating economic rents; (2) The propensity to quit is strictly less than one (in discrete time). When the firm is certain that a worker will leave once trained, it is not willing to sponsor the training. (3) The firm's share of the joint surplus due to labourmarket frictions is nonzero, i.e. the workers' bargaining power is less than one. If the firm cannot capture a part of the surplus from a job match so that the worker gets all the return to training, it is again not willing to pay for the training. (4) The marginal effect of training on productivity has to exceed (in absolute terms) the marginal effect of training on the outside wage. The implication is that the former also exceeds the marginal effect on the firm's own wage, since firms pay workers their outside options. This phenomenon should be referred to as absolute wage compression, to distinguish it from the more commonly used definition of the term wage compression that refer to relative wage compression.
} 
firm will be less than marginal product. However, there are some differences in the other predictions of this class of models. For example, according to the contracting model of Loewenstein and Spletzer, 1998, there may be a greater wage return to training in future firms than in the current firm depending on whether or not a minimum wage guarantee binds in the current job. If it does bind, the employer can extract rents from providing general training.

Figure 1: Wage Structure and Training

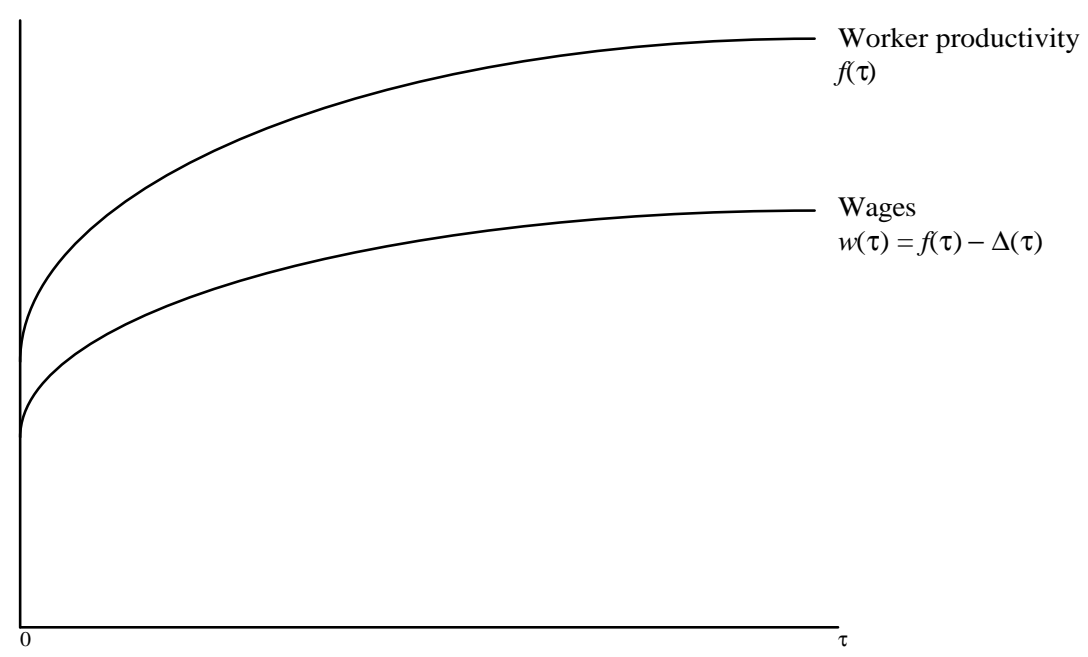

vi. Asymmetric information

Next we consider the impact of asymmetric information on the predictions of the orthodox human capital model. Asymmetry of information about the value of employer - provided training (for example where the firm providing general training knows its value but other firms do not) can affect the transferability of training in an otherwise competitive labour market with identical ability workers. If outside firms assign a value of zero to the training - as they might if they have no information such training is in effect specific to the training firm. Consequently the firm may be willing to share in the costs of its provision and the pay returns in other firms will be non- existent or small. The predictions of this model are as for Row [3] of Table 1.1. 
Table 1.1: Some Predictions of Human Capital Theory

\begin{tabular}{|c|c|c|c|c|}
\hline $\begin{array}{l}\text { Row } \\
\text { No. }\end{array}$ & Model & $\begin{array}{l}\text { Who } \\
\text { Pays }\end{array}$ & $\begin{array}{l}\text { Divergence between } \\
\text { Wages } \\
\text { (w) and Net Marginal } \\
\text { Productivity (MP) at } \\
\text { Training } \\
\text { Firm }\end{array}$ & $\begin{array}{l}\text { Transferability of } \\
\text { Training }\end{array}$ \\
\hline [1] & $\begin{array}{l}\text { Perfect competition, } \\
\text { general training }\end{array}$ & Worker & None & Fully transferable \\
\hline [2] & $\begin{array}{l}\text { As above but with } \\
\text { credit constraints }\end{array}$ & Sharing & $\begin{array}{l}\mathrm{w}>\mathrm{MP} \text { during training and } \\
\mathrm{w}<\mathrm{MP} \text { after training }\end{array}$ & $\begin{array}{l}\text { Transferable but wage } \\
\text { returns elsewhere } \\
\text { greater than returns } \\
\text { at firm providing training }\end{array}$ \\
\hline [3] & $\begin{array}{l}\text { Perfect competition, } \\
\text { specific training }\end{array}$ & Sharing & $\begin{array}{l}\mathrm{w}>\mathrm{MP} \text { during training and } \\
\mathrm{w}<\mathrm{MP} \text { after training }\end{array}$ & Non-transferable \\
\hline [4] & $\begin{array}{l}\text { Perfect competition, } \\
\text { mix of general and } \\
\text { specific training }\end{array}$ & Sharing & $\begin{array}{l}\mathrm{w}>\mathrm{MP} \text { during training and } \\
\mathrm{w}<\mathrm{MP} \text { after training }\end{array}$ & $\begin{array}{l}\text { Partially transferable; wage } \\
\text { returns elsewhere less than } \\
\text { returns at firm providing training }\end{array}$ \\
\hline [5] & $\begin{array}{l}\text { Oligopsonistic labor } \\
\text { market, general } \\
\text { training }\end{array}$ & Firm & $\begin{array}{l}\mathrm{w}<\mathrm{MP} \text { during and after } \\
\text { training, implying rents } \\
\text { for the firm }\end{array}$ & $\begin{array}{l}\text { Fully transferable, wage returns } \\
\text { elsewhere greater than returns } \\
\text { at firm providing training }\end{array}$ \\
\hline
\end{tabular}


However, a formal qualification associated with a training course is a means of conveying to outsiders the value of the employer-provided general training. For this reason one would expect accredited training to have a larger impact on wages in future firms than non-accredited training ceteris paribus. One would also expect it to be financed by the individual, since it is transferable or general. The predictions of the model with accreditations for training are therefore the same as for Row [1] of Table 1.1 - the individual will pay and will get all the pay returns.

An alternative approach is found in the asymmetric information model of Acemoglu and Pischke, 1998, in which workers are characterised by heterogeneous abilities. Here training is rewarded more in the current firm than in outside firms because the current firm will pay higher wages to retain high ability workers, whereas low-ability workers will be dismissed. Some of the high ability workers who need to leave their jobs will be treated as low ability workers in the outside market. Since training and ability are complements, training will be valued less for workers who have been laid off or who have quit. Consequently in the outside market these workers will receive lower returns to their training. The predictions of this model are as for Row [4].

\subsection{Comparisons of predictions of these models}

Of course, the predictions of some of these hypotheses are observationally equivalent. Two models predict that transferable training might have bigger returns to subsequent firms than to the training firm, as inspection of Rows [2] and [5] shows. On the other hand, some predictions are quite distinct. For example, while both models in Rows [1] and [5] predict that training is transferable, the first predicts that workers pay for it while the fifth predicts that firms do. ${ }^{13}$

\subsection{A Clarification of Wage Compression}

The new oligopsony theory emphasises that post-training productivity must increasing in training intensity at a faster rate than wages in order for firms to be willing to finance general training. In much of the literature subsequent to earlier

\footnotetext{
${ }^{13}$ Booth and Bryan, 2005a, distinguished between these hypotheses by (i) using information about who pays directly for work-related training, and (ii) comparing the pay returns to such training at the current and subsequent firms. Booth and Bryan, 2005b, analyse survey data about the extent and financing of various types of training in Britain using the newer training questions from the BHPS.
} 
work by Acemoglu and Pischke - especially in empirical studies - there has been a tendency to use the term 'wage compression' as shorthand for this necessary condition. Following Booth and Zoega, 2004, we emphasise that wage compression in the normal usage of the term (Kaldor, 1963; and Katz and Murphy, 1992) is not a necessary condition for firm-sponsored general training. Below we briefly explain why, and in the Appendix 1.A to this chapter we explain this formally.

Assume that $\mathrm{y}(\tau)$ is output of a worker with training $\tau, w(\tau)$ is his or her wage, $P(\tau)$ denotes the difference between the two $(y-w)$ and $p(\tau)$ denotes the ratio of the two $(y / w)$.

\section{Definition 1}

Absolute wage compression occurs when $\mathrm{P}^{\prime}(0)=\mathrm{y}^{\prime}(0)-\mathrm{w}^{\prime}(0)>0$. This implies that profits per worker in absolute terms are increasing in $\tau$ over some range.

\section{Definition 2}

Relative wage compression occurs when $p^{\prime}(0)>0$. This implies that the ratio of output to wages is increasing (decreasing) in $\tau$. By taking logs we get

$$
\frac{d \log p(0)}{d \tau}=\frac{d \log y(0)}{d \tau}-\frac{d \log w(0)}{d \tau}>0(<0)
$$

that is the derivative of the log difference with respect to $\tau$ is increasing (decreasing) in $\tau$. In this case training increases output proportionately more (less) than wages. ${ }^{14}$

In Appendix 1A, we show that the departure from the Becker framework highlighted in the contribution of Acemoglu and Pischke is more general than implied by their analysis. Their additive formulation of the way that training affects workers productivity and wages focuses attention on just one set of institutional arrangements - those with absolute wage compression. While such an additive formulation has the attraction of simplicity, it can be interpreted as suggesting that

${ }^{14}$ To illustrate the difference between the two definitions, assume that, as a result of increased training, the productivity and wages of every worker doubles. Here there is no change in the ratio of output to wages for any worker and no change in relative wages or relative productivity levels. However, there is absolute wage compression, since the difference between output and wages is now higher for those who have received training compared to those who have not. The second definition - relative wage compression - comes closer to what is usually understood as wage compression in the macro/labour literature, where what matters is the ratio of the wage income of different income groups. Changes in the income distribution are thus conventionally measured by changes in wage- or income ratios. 
firms will only pay for general training under a rather narrower set of institutional arrangements than is actually the case. The model can also be set up such that training affects productivity and wages in a multiplicative (or log-additive) way. This multiplicative formulation has the advantage of being more plausible, since it assumes that inherent ability and trained productivity are imperfect rather than perfect substitutes. ${ }^{15}$ But more importantly, this formulation also encompasses a wider range of institutional arrangements, including piece rates. In the appendix we show that firms are willing to pay for general training even in the absence of relative wage compression, although the latter does increase the level of training chosen by firms.

\subsection{Is There Under-Provision of Training?}

According to human capital theory, which assumes perfectly competitive labour markets, there is no role for policy intervention, because the first best allocation is attained by the interaction of market forces and the Invisible Hand leads to optimal provision of general work-related training. Only if there are imperfect capital markets, where workers might be credit constrained and therefore unable to accept lower wages during training, under-provision occurs with respect to the first best and there is a potential role for policy. Here training contracts, pay-back contracts and the like - extensively discussed in Chapter 5 - may be appropriate policy tools.

However if labour markets are not perfectly competitive, there may potentially be an additional role for policy. As we emphasised earlier in this chapter, provided that the productivity returns from training are increasing in training more rapidly than the wage returns, then firms will be willing to pay for general training. But there is no guarantee that the amount of training they provide will be optimal from society's viewpoint.

The argument here is that firms which bear training costs cannot fully appropriate the benefits of training, which are shared either with trained employees or with future employers. The former type of sharing occurs because workers and firms can bargain over wages after training has taken place, which creates a hold-up

\footnotetext{
15 A simple example clarifies the distinction. Suppose that two individuals with different levels of inherent abilities enter a training programme. According to the additive formulation, their productivities will converge the longer they stay in the programme. But according to the multiplicative formulation, the ratio of their productivities will stay constant while their absolute productivities rise. Thus according to the additive formulation, we can put a novice into a computer class and sit himnext to Bill Gates, and the abilities of the two will gradually converge since the latter will learn no faster. According to the multiplicative formulation, Mr. Gates will maintain his relative lead.
} 
problem (Leuven, 2003). The second type occurs when quit rates are positive and new employers pay trained employees less than their productivity. Since their profits are not explicitly considered by training firms when deciding whether and how much to invest, there is a poaching externality which reduces training below its social optimum level (Stevens, 1996).

Other externalities mentioned in the literature - network effects and the spillovers originated by the complementarity between training and innovation (Acemoglu, 1997) - can generate multiple equilibria and private levels of training different from the social optimum (see for example Burdett and Smith, 1996; Brunello and Medio, 1996, Snower, 1996; Redding, 1996; Acemoglu and Pischke, 1998). In these environments, under-provision of training is one possible equilibrium, and intervention might be desirable to shift the economy to a high skilled job creation and high training equilibrium. ${ }^{16}$

While poaching and hold-up can produce under-provision of training, they are also consistent with over-provision and with the social optimum, as discussed for instance by Moen and Rosen, 2002. Appendix 1B presents a simple example where this is the case. Unfortunately as yet there is generally little guidance from available models as to whether there is under-provision or over-provision of training. And thus these models provide little guidance for policy. The asymmetric information approach is an exception, since accreditation of training programmes is an obvious policy response to imperfect information about the quality of a training course. ${ }^{17}$

To shed further light on the important issue of under - or over-provision of training, we have devised a simple test of the hypothesis of under-provision or overprovision of training in an imperfectly competitive framework. The theoretical basis for this test is shown in Appendix 1B in this chapter. This test aims to establish whether or not voluntary turnover declines with training, and the results of its empirical implementation are presented in Chapter 5. If turnover does declines with

\footnotetext{
${ }^{16}$ For example, Snower, 1996, models a 'low skill, bad job trap', in which the social returns to posting skilled job vacancies and investing in training are higher than the private returns. This is because a skilled job vacancy increases the probability that a skilled worker finds a good job and consequently aises the expected return to training. On the other hand, investing in training increases the probability of filling a skilled vacancy and therefore raises the returns from creating skilled jobs. This creates the possibility of multiple equilibria - a high equilibrium with high job creation and high levels of training, and a low equilibrium with low job creation and low training levels - the low skills, bad job trap. Laing, Palivos and Wang, 1995, develop a model in which the level of education affects economic growth by influencing workers' ability to accumulate skills on the job, and there can be multiple steady-state growth paths.

${ }^{17}$ Some types of training are harder to verify, or to write contracts about, than others. The lack of contractibility of some forms of training, deriving from the sometimes intangible nature of skills investment and the impossibility of complete contracts, may make accreditation difficult, especially for the more informal types of training. See also Acemoglu and Pischke, 1998, and Malcomson, Maw and McCormick, 2002, who make the case for apprenticeship contracts.
} 
training, this confirms that we cannot say much about under-provision of training. If not, then there is under-provision, but we still don't know how far the private optimum is from the first best ${ }^{18}$. This test is not invalidated by the presence of positive externalities.

So far we have discussed only the models in the microeconomic literature, but human capital also plays an important role in affecting growth, as highlighted in the macroeconomic growth literature. ${ }^{19}$ The importance of skills acquired on the job, and through training institutions, is emphasised in the learning by doing approach developed by Romer, 1986, by the human capital approach proposed by Lucas, 1988, and by the combination of education and learning on-the-job in Laing, Palivos and Wang, 1995. Since skills investments in these models have positive externalities, their financing could in principle involve employers, workers and government. But given the elusive nature of the externalities and the difficulties in their measurement, it is difficult to reach any compelling conclusion. In addition, the more narrowly conceived is the training the weaker are the social benefits and the less justified is state intervention ${ }^{20}$.

\subsection{Is There an Equity I ssue?}

Government intervention in the provision of workplace training may be difficult to justify on efficiency grounds, but could be motivated by equity considerations. Following Roemer, 1998, equal opportunity policies need to distinguish between differences in outcomes that arise from different individual expenditure of effort and differences arising from circumstances for which society believe individuals should not be held accountable - such as race, gender, and family background. Since firms can exclude individuals from the provision of workplace training, an important

\footnotetext{
${ }^{18}$ Booth and Zoega, 1999, expand the quitting externality approach of Stevens, 1994, 1996, by incorporating quits into a continuous time framework with demand uncertainty. They show conditions under which higher quit rates will lead to firms being more willing to finance training. High quit rates can encourage firms to wait less for information about future productivity before training new workers. This effect can offset the usual under-investment effect, in a world of certainty, of quits.

${ }^{19}$ In Acemoglu, 1996, firms have constant returns to scale production functions and an interaction between ex ante human capital investments and bilateral search, resulting in social increasing returns to average human capital. A similar result is found in Booth and Coles, 2005, where the increasing returns to education arise at the participation margin, in a model allowing for the interaction of home and market productivities and the tax system.

${ }^{20}$ So far very little growth theory that has looked exclusively at work-related training separately from education. Indeed, the only paper to our knowledge is that of Sepulveda, 2002. However there is a considerable literature looking at externalities associated with general education, as will have been discussed in the first part of this book. Through this avenue there may be a role for policy.
} 
question is whether the recipients of training are favoured because of their higher effort or because of circumstances outside their control. In the latter case, government intervention is warranted.

Carneiro and Heckman, 2003, examine whether the provision of company training in the US is affected by family background, measured by the father's education and family income. Their empirical analysis on the NLSY79 shows that, conditional on ability - measured by the scores of the AFQT test - and education, family background has a negative effect on company training, and conclude that "..private financing arrangements between workers and firms appear to offset family income constraints and partially offset initial disadvantages." Since the unconditional effect of parental background on company training is in their estimates not significantly different from zero, there is little support for the US of training policies addressing equality of opportunity.

\subsection{Institutions}

Training outcomes differ significantly across countries, as well as within countries (OECD, 2003a). This heterogeneity relates to differences in institutions - in the labour, product and education markets - affecting marginal benefits and costs. Institutions play an important role in the new training theory, because minimum wages and trade unions - inter alia - can affect the wedge between wages and marginal productivity. In Appendix $1 \mathrm{C}$ of this chapter, we develop an illustrative 'wage compression' model to show how institutions in the labour and product market can affect training provision. In the discussion below we consider the effects of trade unions, followed by minimum wages, product market regulation, and then the tax system. All of these institutions are likely to vary across OECD countries.

\subsubsection{Trade Unions}

The channels through which union collective bargaining can affect training and pay are potentially quite complex, and it is not immediately obvious that unionism will be associated with positive or negative returns to training. In this section we discuss some of the channels through which unions can affect training and training returns, drawing on the survey at the start of Booth, Francesconi and Zoega, 2003. 

Table 1.2 Predictions about Unions and Training

\begin{tabular}{|c|c|c|c|}
\hline & Model & Description & Empirical Predictions for Individual-level Data \\
\hline [1] & $\begin{array}{l}\text { Otherwise } \\
\text { competitive }\end{array}$ & $\begin{array}{l}\text { Unions flatten wage profiles, } \\
\text { reducing wage dispersion and } \\
\text { distorting workers' incentives to } \\
\text { invest in training. }\end{array}$ & $\begin{array}{l}\text { Negative correlation between union presence and training. Training returns } \\
\text { lower for union-covered than non union covered workers. }\end{array}$ \\
\hline [2] & $\begin{array}{l}\text { Oligopsonistic } \\
\text { labor market }\end{array}$ & $\begin{array}{l}\text { [i] Wage compression associated } \\
\text { with unions means that firms are } \\
\text { more likely to finance training. } \\
\text { [ii] Unions bargain at industry } \\
\text { level directly over wages and } \\
\text { training. }\end{array}$ & $\begin{array}{l}\text { Union-covered workers receive sub- optimal levels of training. Ambiguous } \\
\text { predictions as to the training returns of union-covered than non-union } \\
\text { covered workers. } \\
\text { Union-covered workers receive more training and higher training returns } \\
\text { relative to uncovered workers. }\end{array}$ \\
\hline [3] & $\begin{array}{l}\text { Union concern } \\
\text { over the wage } \\
\text { and } \\
\text { employment } \\
\text { package }\end{array}$ & $\begin{array}{l}\text { Unions directly negotiate better } \\
\text { training opportunities for } \\
\text { covered workers, especially in } \\
\text { non-competitive product markets } \\
\text { where the available surplus is larger }\end{array}$ & $\begin{array}{l}\text { Union-covered workers receive more training and higher training returns } \\
\text { relative to uncovered workers. }\end{array}$ \\
\hline [4] & Turnover & $\begin{array}{l}\text { Because unions reduce turnover, } \\
\text { they have an indirect effect: union } \\
\text { firms train more workers and each } \\
\text { worker gets more training. }\end{array}$ & $\begin{array}{l}\text { Union-covered workers receive more training, and also higher training } \\
\text { returns relative to uncovered workers, owing to their greater training } \\
\text { intensity. }\end{array}$ \\
\hline [5] & $\begin{array}{l}\text { Union control } \\
\text { over supply of } \\
\text { labor }\end{array}$ & $\begin{array}{l}\text { [i] Control over the number of } \\
\text { trainees reduces the supply of } \\
\text { trained workers, lowering } \\
\text { incidence but increasing returns. } \\
\text { [ii] Control over the quality of } \\
\text { trainees may more and better } \\
\text { training per worker to sustain } \\
\text { occupational standards. }\end{array}$ & $\begin{array}{l}\text { Negative correlation between unions and training incidence. Training returns } \\
\text { for union-covered workers are greater } \\
\text { than for non-union workers. } \\
\text { A positive association between unions and training intensity and also higher } \\
\text { wage growth. }\end{array}$ \\
\hline [6] & $\begin{array}{l}\text { Selection } \\
\text { models }\end{array}$ & $\begin{array}{l}\text { Union firms more carefully vet } \\
\text { new hires who are thus on } \\
\text { average of better quality. }\end{array}$ & $\begin{array}{l}\text { More tra ining and greater pay returns for union-covered workers but this } \\
\text { reflects their higher unobserved ability/quality. Controlling for unobserved } \\
\text { ability should eliminate this effect. }\end{array}$ \\
\hline
\end{tabular}


The implications of unionism for training and pay depend, inter alia, on the degree of competition in the labour market and on whether the union effect on training is indirect (through the wage structure) or direct (through the negotiation of training). In Appendix 1C of this chapter, we also explicitly incorporate trade unions into our illustrative 'wage compression' model, which produces similar implications to the Booth, Francesconi and Zoega, 2005, framework concerning wages, training and turnover.

\section{i. Otherwise Competitive Labour Markets}

We define as 'otherwise competitive' the situation where the labour market is perfectly competitive except for union presence. The benchmark case is a perfectly competitive labour market without any trade union presence. A necessary condition for efficient training investment in competitive labour markets is that wages are set to facilitate such training investments. Some studies (for example, see Mincer 1983) therefore argue that, where wages are set collectively by trade unions in an otherwise competitive labour market, wage dispersion is reduced and incentives to invest in general training at the workplace are distorted. This is because union wages cannot be lowered during training and increased after training to allow workers to bear the costs and benefits of general training. Workers and firms will not efficiently invest in such training, and there will be a negative correlation between union presence and work-related training (Duncan and Stafford 1980; Barron, Fuess, and Loewenstein 1987). In addition, the pay returns to training for union-covered workers will be lower than the pay returns to training for uncovered workers. These predictions are summarized in the first row of Table 1.2.

\section{ii. Imperfectly Competitive Labour Markets}

Next, we define an imperfectly competitive labour market as one characterized by some degree of oligopsony, which may arise through search frictions, workers' stochastic preferences for different firms, and the like. In oligopsonistic labour markets - as we discussed earlier in this chapter - workers receive wages below their marginal product, and thus workers' incentives to invest optimally in general training will be lowered. Some of the returns to training will accrue to the training 
firms, whose incentives to invest are increased. But the amount of training provided in equilibrium will be sub-optimal from society's viewpoint.

In imperfectly competitive labour markets, unions will have ambiguous effects on the pay returns to training. Acemoglu and Pischke, 1999b, argue that unions cause wage compression in imperfectly competitive labour markets. In their model, unions set wages and the firm determines training. The model predicts that unionism will be associated with increased firm-financed transferable training. However the pay returns to union-covered workers from such training may be lower if the direct (adverse) effect of unions on wages is stronger than the indirect effect through more training. In contrast, Booth, Francesconi, and Zoega, 2005, model the source of wage compression as workers' stochastic preferences for different firms or heterogeneous mobility costs. In this framework, industry-wide unions that bargain directly over training and wages can extract a share of the surplus and hand it to workers in the form of more training and higher wages. Consequently industry-wide unionism will be associated with more transferable training and with higher pay returns from training. This is because the union is effectively internalizing the friction. ${ }^{21}$ These various predictions are summarized in the second row of Table 1.2.

\section{iii. Union Concern over the Wage-Employment Package}

Assume that union utility is increasing in the wages and job security or employment of its members, as is usual in most models of union behaviour. Unions may ensure that covered workers receive higher wages and greater job security by directly intervening in training provision, for example by making sure that workers' skills are enhanced through more training. Thus training is an instrument through which union goals of increasing employment and job security are attained. Strong unions might therefore be more willing to negotiate better training opportunities for covered workers, especially in non-competitive product markets in which the available surplus is larger. Testable predictions from this hypothesis - summarized in Row [3] of Table 1.2 - are that union-covered firms will provide more training and higher returns for such training, relative to uncovered firms.

iv. Labour Turnover

\footnotetext{
21 In another context, Booth and Chatterji, 1998, show that union-firm wage bargaining can prevent ex-post monopsonistic wage-setting by firms and can thereby reduce inefficient quits.
} 
Where unions improve worker morale and organisation the workplace, labour turnover may be reduced (Blau and Kahn 1983; Freeman and Medoff 1984). Union-covered firms may therefore have greater incentives to provide training because they are less likely to lose highly productive trained workers. ${ }^{22}$ Through this mechanism, unionism may be associated with increased training and productivity, and consequently wages..$^{23}$ The testable predictions of this hypothesis are that union-covered firms train a greater proportion of their workers and give each worker more training, because covered workers are characterized by lower turnover. Thus the training returns for covered workers will be higher than for uncovered workers because of their greater training intensity (holding tenure and all else constant). These predictions are summarized in the fourth row of Table 1.2 .

\section{v. Unions' Use of Training to Control Labour Supply}

Union organization in a number of European countries initially developed on a craft (or occupational) basis and only later along industrial lines. A traditional strategy of craft unions in countries such as Britain and Germany was to influence access to training (typically youth access to apprenticeship) as a means of determining labour supply, as well as to monitor the quality of training provided (Ryan 1994). If this strategy has persisted over time, we may still observe this channel of influence for specific groups of workers such as apprentices or young and inexperienced employees. However its predictions for training and training returns are ambiguous. For example, union control over the number of trainees might result in a negative association between unions and training receipt. Trainee numbers might be restricted to increase labour scarcity, thereby lowering incidence but increasing training returns. Conversely, union control over the quality of training might result in a positive association between unions and training incidence and intensity (more and better training per worker to sustain occupational standards) and also for wage growth. These various predictions are summarized in the fifth row of Table 1.2 .

\footnotetext{
${ }^{22}$ Booth, Francesconi, and Zoega, 2005, provide a formal model.

${ }^{23}$ Analysing a panel of British industries between 1983 and 1996, Dearden, Reed, and Van Reenen (2000) find that higher training is systematically associated with higher productivity.
} 
vi. Selectivity and Other Issues

In firms that become unionized, management may respond to higher union wages by more carefully vetting new hires to obtain a better quality workforce. This vetting might also involve induction training. From the supply side, better quality or more motivated workers might self-select into unions jobs if the training opportunities and returns are higher in the union-covered sector. If unions bargain directly over training as well as wages, only workers able to benefit from such training will wish to queue for union jobs, or will be offered such jobs. These predictions are summarized in the last row of Table 1.2. They suggest that any observed link between unions, training and training returns may be spurious. ${ }^{24}$

Some of these hypotheses as to the impact of unionism on training and training returns are observationally equivalent, as inspection of the last column of Table 1.2 makes clear. The hypotheses summarized in Rows [2.ii], [3], [4] and [5.ii] all predict that union-covered workers will receive more training and higher training returns relative to uncovered workers. On the other hand, the "otherwise competitive" model (see Row [1] of Table 1.2) is the only hypothesis predicting a negative correlation between union presence and training and lower training returns for union-covered compared with non-union-covered workers. Moreover the hypotheses are not mutually exclusive. Higher job retention of union-covered workers may be at work in imperfectly competitive labour markets. And apprenticeships may go hand in hand with oligopsonistic labour markets.

\subsubsection{Minimum wages}

With competitive labour markets, human capital theory predicts that the introduction of a minimum wage will reduce investment in training by covered workers who can no longer contribute to training costs through lower wages (see Rosen, 1972). If the labour market for the low paid is competitive and workers are not credit constrained, a minimum wage will reduce training. In the absence of binding training contracts for workers, a minimum wage provides a floor below which wages cannot fall. Thus lower wages cannot be used as a means of allowing workers to finance general training, or to facilitate worker-firm sharing in specific training investments.

\footnotetext{
${ }^{24}$ This emphasizes the importance in empirical work to control for potential self-selection into training as well as potential self-selection into union coverage. However, in many EU countries union coverage is attached to the job rather than the individual, and thus the issue of selection is somewhat mitigated.
} 
But if the labour market for the low paid is imperfectly competitive or workers are credit constrained, a minimum wage can increase investment in the general component of training. Why is this the case? The basic rationale is provided by oligopsonistic models - some of which were outlined earlier in this chapter predicting that firms may pay for general training. The oligopsonistic labour market introduces a 'wedge' between wages and marginal product. And it can be shown that the introduction of a minimum wage also acts as a type of wedge between wages and marginal productivity. Thus it can actually increase general training over a range of human capital and induce employers to train their unskilled workers (Acemoglu and Pischke, 2003).

It is an empirical question as to which, if any, of these effects dominates training incidence and volumes in the real world. The answer will depend on the general-specific training mix, the existence of credit constraints on low paid workers, and the degree of imperfect competition in the labour market.

\subsubsection{Taxes and Social Security Systems}

Average income and payroll taxes create a wedge between the gross wage paid by the employer and the pay taken home by employees. The effect of the wedge on training is likely to depend on whether the cost is borne by the employer or by the employee. The simple bargaining model in Appendix 1C shows that - when the outside option is not taxed- an increase in the average and marginal tax wedge reduces the employer's incentives to train.

\subsubsection{Product market competition and deregulation}

Deregulation increases competition in the product market and can affect training in a number of ways. First, deregulation influences real wages and profits after training, and reduces rents. Second, the higher competition induced by deregulation increases productivity by forcing firms to improve efficiency and to innovate. If innovation and skills are complements - see Acemoglu, 1997 - firms have a higher incentive to train. By affecting the entry of firms, deregulation also contributes to local agglomeration effects, which encourage the investment in training ${ }^{25}$. Third, the relative bargaining power of workers can fall, because of the higher risk of involuntary turnover and plant closure associated to more product market competition. We illustrate the relationship between training and

\footnotetext{
${ }^{25}$ See Brunello and Gambarotto, 2004, and Brunello and De Paola, 2004.
} 
deregulation by using the model of imperfect competition developed by Blanchard and Giavazzi, 2003, in the Dixit - Stiglitz tradition. We use as a measure of product market competition a parameter reflecting the degree of substitutability between available products. The greater this degree, the more competitive the product market.

We show that, in the general symmetric equilibrium with no entry, when the bargaining power of workers is constant and we ignore its effects on productivity, more deregulation reduces the marginal benefits of training by reducing rents. Therefore, training falls. Deregulation, however, affects productivity. By inducing more competition, innovation and a stronger quest for efficiency, deregulation also contributes to increasing the marginal returns to training. Moreover, if the higher risk of dismissal associated to deregulation induces workers to accept wage concessions, then the bargaining power of workers declines. These two effects can compensate the negative impact of lower rents and contribute to generate an overall increase of training ${ }^{26}$.

\subsubsection{Schooling institutions}

The variation of school design - especially of secondary schools - can affect training outcomes, given the complementarity between education and training. Countries differ in the degree of stratification of secondary education and in the importance of tracking. The design of secondary schooling systems varies considerably across European countries, and an important dimension of such variation is the relative importance of vocational and general education. While comprehensive schooling systems which mix general and vocational education are typical of the UK, stratified systems, with a much more marked separation of the vocational and general track, are widespread in Germany. The rest of the major European countries lie somewhere in between ${ }^{27}$. It is an open question as to whether a more stratified schooling system is conducive to higher training outcomes than a more comprehensive system. If vocational schools in stratified educational systems produce very specialized skills that become rapidly obsolete in the presence of technical progress, more training might be required to update existing skills to match the new technical blueprints. On the other hand,

\footnotetext{
26 In contrast, the model in Gersbach and Schmutzler, 2004, predicts that training incidence is higher if concentration is high, or competitive intensity is relatively low, or product differentiation is strong. The reason is that they assume that the slope of the outside option function (and therefore of the wage function) increases with product market competition.

${ }^{27}$ See Brunello and Giannini, 2004, and Brunello, Giannini and Ariga, 2004, for a discussion of these issues.
} 
comprehensive schools could produce skills that are too general, and which require additional training to become operational.

\section{Summary}

For many years it was thought that human capital theory, based on the assumption of a perfectly competitive labour market, fully explained who would pay for general training. Stylized facts diverging from the theory's predictions were believed to be due to imperfections such as credit market constraints. And yet some puzzles remained that could not be explained within this framework; puzzles such as employers paying for general training in spite of potential poaching of trained workers, and the lack of evidence of workers receiving wage cuts during training.

Over the last decade, new ways of thinking in labour economics have challenged this orthodoxy and begun to transform our ways of thinking about work-related training. A growing literature argues that employers have market power in setting wages - what is termed the new oligopsony. This oligopsony can arise through product differentiation and through imperfect information (rather than through the old definition of a monopsonist as being a single employer in a labour market). And its proponents demonstrate that it can lead to simple and plausible explanations of labour market phenomena that are otherwise regarded as puzzles.

In the remainder of this book we use this framework to inform our empirical investigation. We would emphasise that the traditional human capital approach assuming perfectly competitive labour markets forms a useful and powerful benchmark model. However, although the imperfectly competitive approach is still being developed, it offers important new insights about work-related training and conditions under which intervention in the labour market might be justified. In the next chapter, we turn to an investigation of the extent and outcomes of training across a number of countries, and document stylised facts across a number of OECD countries. 


\section{APPENDIX 1A}

In two recent contributions, Acemoglu and Pischke, 1999a, 1999b, - AP from now on - argue that it is through wage compression that trade unions and other labour-market institutions induce firms to invest in general training. Using the results in Booth-Zoega, 2004, we demonstrate that this condition is satisfied in a much wider range of conditions even including compensation schemes - such as piece rates - that are not commonly associated with wage compression.

Denote a worker's inherent ability or productivity by $\bar{y}$. Then assume that training adds to workers' productivity $(y)$ in an additive fashion where $f(\tau)$ is a strictly concave function:

$$
y(\tau)=\bar{y}+f(\tau)
$$

Similarly assume that wages $\mathrm{w}$, in the absence of training, can be denoted by $\bar{w}$ where $\lambda(\tau)$ is again a strictly concave function;

$$
w(\tau)=\bar{w}+\lambda(\tau)
$$

and $\bar{y}$ and $\bar{w}$ can take any value. Profits from a worker having received training $\tau$ can then be written as

$$
P(\tau)=y(\tau)-w(\tau)=\bar{y}-\bar{w}+(f(\tau)-\lambda(\tau))
$$

Here, absolute wage compression occurs if $\mathrm{P}^{\prime}(0)>0$. Now denote the probability that a worker stays on after training as $(1-q)$, where $q$ is the propensity to quit and is taken to be a constant and independent of relative wages. The equality of the expected marginal profit from training - given by $(1-q) P^{\prime}(\tau)$ - and the marginal training costs $c^{\prime}(\tau)$ - where $c(\tau)$ is a strictly convex function and $c(0)=0$ - gives the optimal level of training $\tau^{*}$ :

$$
P^{\prime}(\tau)=y^{\prime}(\tau)-w^{\prime}(\tau)=(1-q)\left[f^{\prime}(\tau *)-\lambda^{\prime}(\tau *)\right]=c^{\prime}(\tau *)
$$


It follows that $\tau^{*}>0$ if and only if $P^{\prime}(0)>0$ which implies $f^{\prime}(0)>\lambda^{\prime}(0)$.

Now, instead of assuming that training adds to both productivity and wages in an additive fashion, suppose that it adds in a multiplicative or log-additive way. We now change equations ( $1 \mathrm{~A}-1)$ and (1A-2) so they become

$$
\begin{aligned}
& y(\tau)=\bar{y} f(\tau) \\
& w(\tau)=\bar{w} f(\tau)
\end{aligned}
$$

where we have set $f(\tau)=\lambda(\tau)$ to emphasise that $f^{\prime}(\tau)=\lambda^{\prime}(\tau)$ for all values of $\tau$. This makes the ratio of output to wages $\mathrm{p}(\tau)$ a constant and equal to $\bar{y} / \bar{w}$ and there is no relative wage compression by definition.

Booth and Zoega, 2004, argue that it is less plausible for inherent ability (or skills) and acquired productivity through training to appear in an additive (equations (1A-1) and (1A-2)) or a multiplicative fashion (equations (1A-1') and $\left.\left(1 \mathrm{~A}-2^{\prime}\right)\right)$. The difference between $(1 \mathrm{~A}-1)$ and $\left(1 \mathrm{~A}-1^{\prime}\right)$ is simple. The first formulation implies that inherent abilities and trained productivity are perfect substitutes, so that the isoquants in the inherent ability-trained productivity $(\bar{y}, f(\tau))$ space are downward-sloping lines. This is unlikely to be the case. The alternative multiplicative formulation implies that they are imperfect substitutes, so that the upper-contour set becomes strictly convex.

The firm's profits from employing the worker become, under the multiplicative formulation

$$
P(\tau)=y(\tau)-w(\tau)=(\bar{y}-\bar{w}) f(\tau)
$$

and the first-order conditions with respect to training are now

$$
(1-q)(\bar{y}-\bar{w}) f^{\prime}(\tau *)=c^{\prime}(\tau *)
$$

It again follows that $\tau^{*}>0$ if and only if $P^{\prime}(0)>0$ - there is absolute wage compression as emphasized by AP - but which now only implies $\bar{y}>\bar{w}$. Thus the firm would benefit from increased training in the absence of relative wage compression, and would be willing to pay for it. It follows that absolute wage compression does not imply relative wage compression. Firms may be willing to 
train in the absence of relative wage compression - relative wage decompression $\mathrm{p}^{\prime}(0)<0$ not excluded.

We can make this point more succinctly as follows. Relative wage compression is defined as $d p(\tau) / d \tau>0$ where $p=\frac{y(\tau)}{w(\tau)}$ which implies that

$$
\frac{w y^{\prime}-w^{\prime} y}{w^{2}}=\frac{w\left(y^{\prime}-w^{\prime}\right)-w^{\prime}(y-w)}{w^{2}}
$$

Since $w^{\prime}(\tau) \geq 0$ and $y(\tau) \geq w(\tau)$ it follows that relative wage compression implies absolute wage compression: $y^{\prime}>w^{\prime}$. However, absolute wage compression does not have to imply relative wage compression.

While relative wage compression increases the level of general training desired by employers, by no means does it constitute a necessary condition. To see this, return to equations $\left(1 A-1^{\prime}\right)$ and $\left(1 A-2^{\prime}\right)$. First substitute $\lambda(\tau)$ for $f(\tau)$ in equation $\left(1 A-2^{\prime}\right)$ and then insert the multiplicative functions of $\left(1 A-1^{\prime}\right)$ and $\left(1 A-2{ }^{\prime}\right)$ into the expression for profits. This yields the firm's maximand as:

$$
\max _{\tau}(1-q)[\overline{\mathrm{y}} f(\tau)-\bar{w} \lambda(\tau)]-c(\tau)
$$

The first order condition now becomes, after adding and subtracting the term $\bar{w} f^{\prime}(\tau):$

$$
(1-q)\left[(\bar{y}-\bar{w}) f^{\prime}\left(\tau^{*}\right)+\bar{w}\left(f^{\prime}(\tau *)-\lambda^{\prime}(\tau *)\right)\right]=c^{\prime}\left(\tau^{*}\right)
$$

where we assume that $\bar{y}>\bar{w}$ and $f^{\prime}(\tau)>\lambda^{\prime}(\tau)$. Relative wage compression now appears as the last term on the left-hand side of equation (1A-6). It is clear that, while relative wage compression increases the level of general training desired by employers, it by no means implies a necessary condition. This is because, even when $f^{\prime}(0)=\lambda^{\prime}(0)$ and there is no relative wage compression, there will still be absolute wage compression since $\mathrm{P}^{\prime}(0)>0$ through $(\bar{y}-\bar{w}) f^{\prime}(\tau)$. Therefore the firm will still be willing to pay for general training even with no relative wage compression. However it is clear that, with relative wage compression $f^{\prime}(0)>\lambda^{\prime}(0)$, the profitability of paying for workers' training is increased. 
Relative wage compression is thus not a necessary condition for firms' willingness to pay for general training, but instead a factor affecting how much they are willing to pay. How important this factor is depends on the shape of the training function $\mathrm{f}(\tau)$, the level of labour-market rigidity $\bar{y}-\bar{w}$, and the effect of training on wages $\lambda^{\prime}(\tau)$. In contrast, absolute wage compression does constitute such a necessary condition. However, absolute wage compression is a feature of compensation systems such as piece rates, which one does not usually associate with any form of wage compression. 


\section{APPENDIX 1B}

Consider a static model of training investment with the following sequence of events (see Acemoglu and Pischke, 1998, 1999a): in the first stage the firm decides how much to invest in (general) training $\tau$ and bears the training cost; in the second stage the firm and the worker bargain over the wage $w(\tau)$; in the third stage a random event $\varepsilon$ occurs, drawn from the distribution $\varepsilon \sim G(0, \sigma)$, which affects the outside option available to the worker, $v(\tau)$. Based on this event and the previous stages of the game, the worker decides whether to quit or stay. If she quits, the training firm cannot recoup the training costs. Both the firm and the worker are risk - neutral. Since the labour market is frictional, $f(\tau)>v(\tau)+\varepsilon$. Turnover can only be voluntary and occurs when $w(\tau) \leq v(\tau)+\varepsilon$. Therefore we have

$$
q(\tau)=\lambda(\tau)[1-G(w(\tau)-v(\tau))]
$$

where $\lambda$ is the rate of job offers, which we assume to be increasing in training because training has a positive signalling effect (see Autor 2001).

Using primes for first derivatives, the effect of training on turnover is

$$
\frac{\partial q}{\partial \tau}=-\lambda g\left[w^{\prime}(\tau)-v^{\prime}(\tau)\right]+\lambda^{\prime}(\tau)[1-G(w(\tau)-v(\tau))]
$$

Wages are set by Nash bargaining before the random draw on $\varepsilon$. Since $\varepsilon$ is not observed at the time of the bargain, the wage $w$ cannot be indexed to the draw. The worker earns expected wages $w(\tau)$ if employed and has an expected outside option $v(\tau)$ in the event of separation. The outcome of the Nash bargain is

$$
w(\tau)=(1-\beta) f(\tau)+\beta v(\tau)
$$

where $\beta$ is the bargaining power of the firm, from which we obtain

$$
w^{\prime}(\tau)-v^{\prime}(\tau)=(1-\beta)\left[f^{\prime}(\tau)-v^{\prime}(\tau)\right]
$$


Replacing (1B-4) into (1B-2), we notice that the first element in the right hand side of ( $1 \mathrm{~B}-2)$ is negative if $1-\beta>0$ and there is absolute wage compression, defined as $\left[f^{\prime}(\tau)-v^{\prime}(\tau)\right]>0$. The overall derivative, however, cannot be signed a priori.

Next consider the training decision taken by the firm to maximize expected profits

$$
P(\tau)=[1-q(\tau)] \beta[f(\tau)-v(\tau)]-c(\tau)
$$

where $c(\tau)$ is the total cost of training, which is paid by the firm when there is absolute wage compression. The optimal choice of $\tau$ yields

$$
(1-q) \beta\left[f^{\prime}(\tau)-v^{\prime}(\tau)\right]-q^{\prime}(\tau) \beta[f(\tau)-v(\tau)]=c^{\prime}(\tau)
$$

In the absence of positive externalities, the first best is attained if

$$
f^{\prime}(\tau)=c^{\prime}(\tau)
$$

The private optimum (1B-7) corresponds to the first best if

$$
-q^{\prime}(\tau) \beta[f(\tau)-v(\tau)]=(1-q) \beta v^{\prime}(\tau)+[1-\beta+q \beta] f^{\prime}(\tau)
$$

which cannot be excluded if $q(\tau)<0$.

The presence of positive spillovers - due for instance to the complementarity between training and innovation - affects the first best outcome. Letting $f^{\prime}(\tau)+F^{\prime}(\tau)$ be the sum of private and social returns to training, the condition above becomes

$$
-q^{\prime}(\tau) \beta[f(\tau)-v(\tau)]=(1-q) \beta v^{\prime}(\tau)+[1-\beta+q \beta] f^{\prime}(\tau)+F^{\prime}(\tau)
$$


Perhaps more importantly, the private optimum can be higher than the social optimum if the left hand side of the above expression is larger than the right hand side. We summarize the implications of the model as follows

- if $q=0 ; \quad \beta=1 ; \quad v^{\prime}(\tau)=0 ; \quad q^{\prime}(\tau)=0$, there is no under-provision of training;

- if $q \geq 0, \quad \beta \leq 1, \quad v(\tau) \geq 0$ and $q(\tau) \geq 0$ there is under-provision of training. We have ruled out the case $\beta=1$, because in that case no firm would invest in training. Since training is general, we can exclude $v(\tau)=0$ and the former case. Therefore, a sufficient condition for under-provision is $q(\tau) \geq 0$, which can be tested on data. If $q(\tau) \geq 0$, private optimum yields a level of training lower than the first best. How much lower? It depends on the shape of the cost, turnover, productivity and outside option functions. 


\section{Appendix 1C}

Following Acemoglu and Pischke, 1999, consider a frictional labour market where the firm has to decide the investment in training $\tau$. Let $f(\tau), w(\tau)$ and $c(\tau)$ be productivity, the wage and the cost of training, which we assume to be borne by the firm. Let $f(0)=1$, a useful normalization. Each employee in this firm quits with exogenous probability $q$ and receives in the external labour market the wage $v(\tau)$. With this notation, the firm's profits are

$$
P(\tau)=(1-q)[f(\tau)-w(\tau)]-c(\tau)
$$

\section{i. Unions}

Suppose that a union organizes homogenous workers and cares only about its employed members. The representative union member has utility

$$
u(\tau)=(1-q) w(\tau)+q v(\tau)
$$

Let the firm set the optimal level of training in the first step, and let the parties bargain over the wage in the second step. Since training costs are bygones after the investment, profits in the wage bargain are gross of training costs. Let the outside option of the firm be zero and the outside option of the union be $v(\tau)$. Finally, define $B$ as the relative bargaining power of the firm. With Nash bargaining, the bargained wage turns out to be

$$
w(\tau)=\beta v(\tau)+(1-\beta) f(\tau)
$$

Backward induction implies that the (privately) optimal level of training is given by

$$
\left.(1-q) \beta \mid f^{\prime}(\tau)-v^{\prime}(\tau)\right]=c^{\prime}(\tau)
$$

where the prime is for the first derivative. Training is nonzero if the marginal increase of productivity is higher than the marginal increase in the outside option. This condition is called absolute wage compression (Acemoglu and Pischke, 1999b). 
Unions can affect optimal training by influencing turnover and the relative bargaining power of the firm. Stronger unions have higher bargaining power, which reduces $B$ and training. Since they might also reduce turnover via more effective voice mechanism, the overall effect of stronger unions on (employer - provided) training is not clear-cut.

Next suppose that unions are strong enough to bargain over training investment as well. Compared to the previous case, there is contemporaneous bargaining both over wages and over training. It can be shown that the outcome of the Nash bargain is

$$
\left.(1-q) \mid f^{\prime}(\tau)-v^{\prime}(\tau)\right]=c^{\prime}(\tau)
$$

Since $B$ is less than one, training is higher when unions bargain over it.

ii. Average and marginal taxes

Define individual utility as

$$
u(\tau)=[(1-q)[w(\tau)-T(w(\tau))]+q v(\tau)]
$$

where $T(w(\tau))$ is taxes, inclusive of social security contributions, $\mathbf{w}$ is the gross wage rate and the outside option $v$ is not taxed. Then the outcome of the Nash bargain is

$$
w(1-\sigma)=\frac{(1-\beta) f+\beta v}{1-\beta+\beta \lambda}
$$

where $\sigma$ is the average tax rate and $\lambda$ is the index of relative tax progression $\lambda=\frac{1-T^{\prime}}{1-\sigma}$. If training is decided by the firm, the necessary condition to maximize profits is given by

$\left.\varsigma(\sigma, \tau, \lambda)=f^{\prime}\{(1-\beta)+\beta \lambda](1-\sigma)-\beta\right\}-(1-\beta) v^{\prime}-[(1-\beta)+\beta \lambda] c^{\prime}(1-\sigma)=0$

if the second order conditions hold, then $\frac{\partial \tau}{\partial \sigma}<0$ and $\frac{\partial \tau}{\partial \lambda}>0$. 
iii. Product market regulation

The notation used in this part of the Appendix is slightly different and follows Blanchard and Giavazzi, 2003. Consider an economy populated by identical and imperfectly competitive firms. The production function of each firm is simply $y_{i}=n_{i}$, where $\mathrm{i}$ is the index for firms and $\mathrm{n}$ is employment. Profits for each firm are $\left(p_{i}-w_{i}\right) y_{i}(\tau)-c(\tau)$, where $\mathrm{p}$ are prices, output depends on training and $\mathrm{c}$ is the training cost. Let the average price $\mathrm{P}$ be normalized to 1 . The firm sets training to maximize profits; after training has been set, the firm and the worker bargain over wages and prices (or employment). There is no turnover. The Nash maximand in log terms is

$$
\Omega_{i}=(1-\beta) \log \left[\left(w_{i}-v_{i}\right) y_{i}\right]+\beta \log \left(p_{i}-w_{i}\right) y_{i}
$$

and the relationship between output and prices for each firm is

$$
y_{i}=p_{i}^{-\sigma}
$$

where $\sigma$ is elasticity of demand with respect to the price. Deregulation increases $\sigma$.

The maximization of [1C-9] with respect prices and wages yields

$$
\begin{aligned}
& p_{i}=(1+\mu) v_{i} \\
& w_{i}=[1+(1-\beta) \mu] v_{i}
\end{aligned}
$$

where $\mu=\frac{1}{\sigma-1}$. In the symmetric equilibrium prices are equal to the average price. Hence, $v=1 /(1+\mu)$ and $w=[1+(1-\beta) \mu] /(1+\mu)^{28}$. Using these results in the definition of profits before training we obtain

$$
P(\tau)=\left[1-\frac{[1+(1-\beta) \mu]}{1+\mu}\right] y(\tau)-c(\tau)
$$

\footnotetext{
${ }^{28}$ Since the equilibrium is symmetric, we drop the subscript from now on.
} 
Let $y_{\mu \tau}(\tau)$ be the partial derivative of the marginal productivity of training $y^{\prime}(\tau)$ with respect to $\mu$, and assume this partial to be negative. Optimal training requires

$$
\left[1-\frac{[1+(1-\beta) \mu]}{1+\mu}\right] y^{\prime}(\tau)-c^{\prime}(\tau)=\varphi(\tau, \mu)=0
$$

If the second order conditions for a maximum hold, as we assume, then

$$
\operatorname{sign} \frac{\partial \tau}{\partial \mu}=\operatorname{sign} \frac{\partial \varphi}{\partial \mu}>0
$$

Therefore, deregulation ( $a$ decline in $\mu$ ) reduces training. Next assume that $\beta^{\prime}(\mu)>0$, so that the workers' bargaining power increases with regulation. Then

$$
\frac{\partial \varphi}{\partial \mu}=\frac{\beta+\mu(1+\mu) \beta^{\prime}}{(1+\mu)^{2}} y^{\prime}(\tau)+\left[1-\frac{[1+(1-\beta) \mu]}{1+\mu}\right] y_{\mu \tau}(\tau)
$$

can be negative if $\beta^{\prime}$ and $y_{\mu \tau}(\tau)$ are large enough. 


\section{Chapter 2: Stylised facts about workplace training}

The purpose of this chapter is to document stylised facts about the distribution of workplace training in Europe (and, when possible, OECD countries) by looking at the most recent cross-comparable datasets available in the scientific community. When discrepancies emerge, we will also compare the picture that emerges from these datasets with previous literature.

In which country are investments in training greater? How large are regional differences within countries? How do employers and employees share the cost of training? At face value, how much do employers invest in training? How does training vary over the business cycle? What type of individual has a greater propensity to take training and/or be trained by his/her employer? And once we control for individual characteristics, how large are differences across countries? These are the questions we address in this chapter. In order to do so, we will use several large cross-country datasets that are available for OECD countries, such as: i) OECD aggregate training data (OECD, 2004); ii) the Continuing Vocational Training Survey (CVTS); iii) the International Adult Literacy Survey (IALS); and iv) the European Community Household Panel (ECHP). These datasets are briefly described in Appendix 2A.

The datasets we use in this chapter provide information that is essentially complementary. OECD training data cover 30 OECD and European countries, but provide only aggregate figures. The CVTS is an employer survey covering firms with more than 10 employees in 25 European countries. As such, it provides information on training firms and employer-paid training but little information on trainees and no information on employee-paid training. The International Adult Literacy Survey (IALS) is an individual survey covering many OECD countries. Unfortunately, few European countries fall within the IALS country sample. In addition, the IALS has limited information on the labour market status of trainees (labour market status is measured after the training). None of these three so urces, however, has a longitudinal dimension. Whenever necessary, therefore, we will resort to the European Community Household Panel (ECHP), which provides comparable data on training participation for $13 \mathrm{EU}$ countries. ${ }^{29}$ The disadvantage of the ECHP is primarily on the fact that additional training information (financing,

\footnotetext{
29 All the 15 countries that belonged to the EU before enlargement are covered by the ECHP. However, we exclude Germany, since German data exclude short training spells, and Luxembourg, due to sample size.
} 
duration, etc.) is of less good quality (since it is provided only for the last course taken and training refers to a time interval the length of which can vary from country to country and even from one interviewee to another (cf. Appendix 2A). Conversely, its advantage relies in its large set of individual characteristics and its longitudinal dimension.

We start in Section 2.1 by discussing measurement issues. Then, in Section 2.2, we look at cross-country and cross-region training patterns. Next, we focus on training financing, looking particularly at how large is the share of training investments paid for by the firm (Section 2.3), how training varies over the business cycle (Section 2.4), and how it varies across different types of firms (Section 2.5). Finally, in Section 2.6 we will turn the attention more specifically to the employees and look at the impact of individual characteristics on the probability of taking/receiving training. The chapter ends with a summary of the key results.

\subsection{Measurement issues}

Training and, more in general, the stock of human capital is difficult to measure. Initially, studies of training used labour market experience as a proxy for general training and job tenure as a proxy for specific training. In the last two decades datasets containing self-reported measures of training have increasingly become available. ${ }^{30}$ These datasets are typically based on household surveys such as the Current Population Survey (CPS) and the National Longitudinal Survey of Youth (NLSY) in the United States, in which respondents are asked whether they participated in some form of training in a specific reference period. In addition to household surveys, employer based (see Barron et al., 1987) and matched employer-employee surveys (Lynch and Black, 2001, for example) are also slowly becoming available. Finally there are a few studies that use administrative data from a single firm (e.g. Bartel, 1995).

Most surveys collect flow measures of training, namely: the amount of training over a specified calendar period (for example the previous 12 months, or the period since a previous interview). In the CPS the reference period covers the time

\footnotetext{
${ }^{30}$ An early attempt at measuring training more directly is found in the Michigan Panel Study of Income Dynamics (PSID). Respondents were asked: "on a job like yours, how much time would it take the average new person to become fully trained and qualified?" This seems to measure a characteristic of the job instead of the amount of training the respondent participated in.
} 
since the start of the job, which implies that if all reported training is specific this question would measure the stock of training. Logically the amount of training that is reported depends on the period covered by the training questions (e.g. Loewenstein and Spletzer, 1998). The retrospective nature of these self-reported training measures introduces, however, measurement errors because of recollection problems. The measurement error is expected to increase both with the span of time between the training spell and the interview, and with the detail of the training questions. It is for this reason that training questions that measure flows are probably more accurate than training questions that attempt to measure stocks. Surveys often ask about training incidence, but increasingly try to measure the length of training spells in an attempt to more accurately measure training effort.

Training is almost inherently heterogeneous and some aggregation is therefore inevitable. The aggregation implicit in the training questions varies between surveys. The types of training measured by these surveys therefore vary and are typically derived from the institutional setting, and often combine mode of delivery and provider. The NLSY, for example, asks about: training followed at business schools, apprenticeship programs, vocational or technical institutes, but also about correspondence courses, formal company training run by the employer, military training, seminars or training programs run at work by someone other than employer, seminars or training programs outside of work, and training given by vocational rehabilitation centres. It is not immediately clear to what extent this is an economically sensible classification. ${ }^{31}$

Related to these problems regarding the measurement of the time investment in training, is the issue of cost. For example, if respondents are employees, they are unlikely to be fully aware of the full opportunity cost of training (i.e. foregone productivity) and, to the extent that the employer paid for training, they are also unlikely to have information on the direct (monetary) cost of training.

The above illustrates the conceptual and practical complexity of collecting information on training. The heterogeneity in training questions introduces problems of comparability between surveys and even within surveys, particularly across countries. For instance, Campanelli et al. (1994) note, from a study of both

\footnotetext{
${ }^{31}$ Apart from formal training there is a growing interest in measuring informal training (e.g. Barron et al., 1997; Frazis et al., 1996; Loewenstein and Spletzer, 1999).
} 
linguistic and survey data, that the interpretation of the term "training" varies across groups in the population, in particular employers, employees, and training researchers. Yet, little is known about the extent to which these conceptual measurement problems lead to actual measurement error. The only quantitative study to date hinting at this is Barron et al., 1997. These authors use data from a matched employer-employee survey dataset to see to what extent employer and employee responses are consistent. They find that correlations between worker and establishment measures are less than 0.5 and that establishments report 25 percent more hours of training on average than workers do. On average, incidence rates are similar between worker and establishment reports, although 30 percent disagree on whether on-site formal training occurred. This suggests that training is measured with substantial error.

One of the conclusions that emerges from these measurement problems is that one needs being particularly careful when trying to document cross-country variation in training, due to the idiosyncratic definition of the concept of training in each specific survey. Early literature (see for instance OECD, 1993, Lynch, 1994, Blinder and Krueger, 1996, and Acemoglu and Pischke, 1999) often resorted to national surveys and compared aggregate training incidence across surveys to infer the cross-country distribution of training. The above discussion suggests that this approach must be handled with care. The extent of the problem is immediately evident by looking at Chart 2.1, which compares training participation rates obtained from the ECHP with OECD aggregate data. ${ }^{32}$ ECHP training participation rates are about $3 / 4$ on average of the participation rate in the OECD dataset and this figure is significantly different from 1 . In other words, a cross-country comparison of participation rates made by taking some countries from the ECHP and other countries from OECD data, would systematically underestimate the relative training effort of the former countries with respect to the latter.

More on the positive side, however, we can observe that the correlation among the two measures is high and the ranking of countries is approximately the same in both OECD and ECHP data (with France and the Netherlands being the only two countries with major differences across datasets), ${ }^{33}$ showing that certain crosscountry differences are persistent across surveys, and not all the information

\footnotetext{
32 All figures reported in this chapter refer to employed workers aged between 25 and 64 years, except when differently specified.

${ }^{33}$ Similar correlations are found also between ECHP, CVTS and IALS data. This is not surprising since OECD data are constructed from CVTS and IALS data (cf. Appendix 2A).
} 
contained therein is noise. This is reassuring and allows us to meaningfully proceed in our analysis of training patterns using large cross-country datasets.

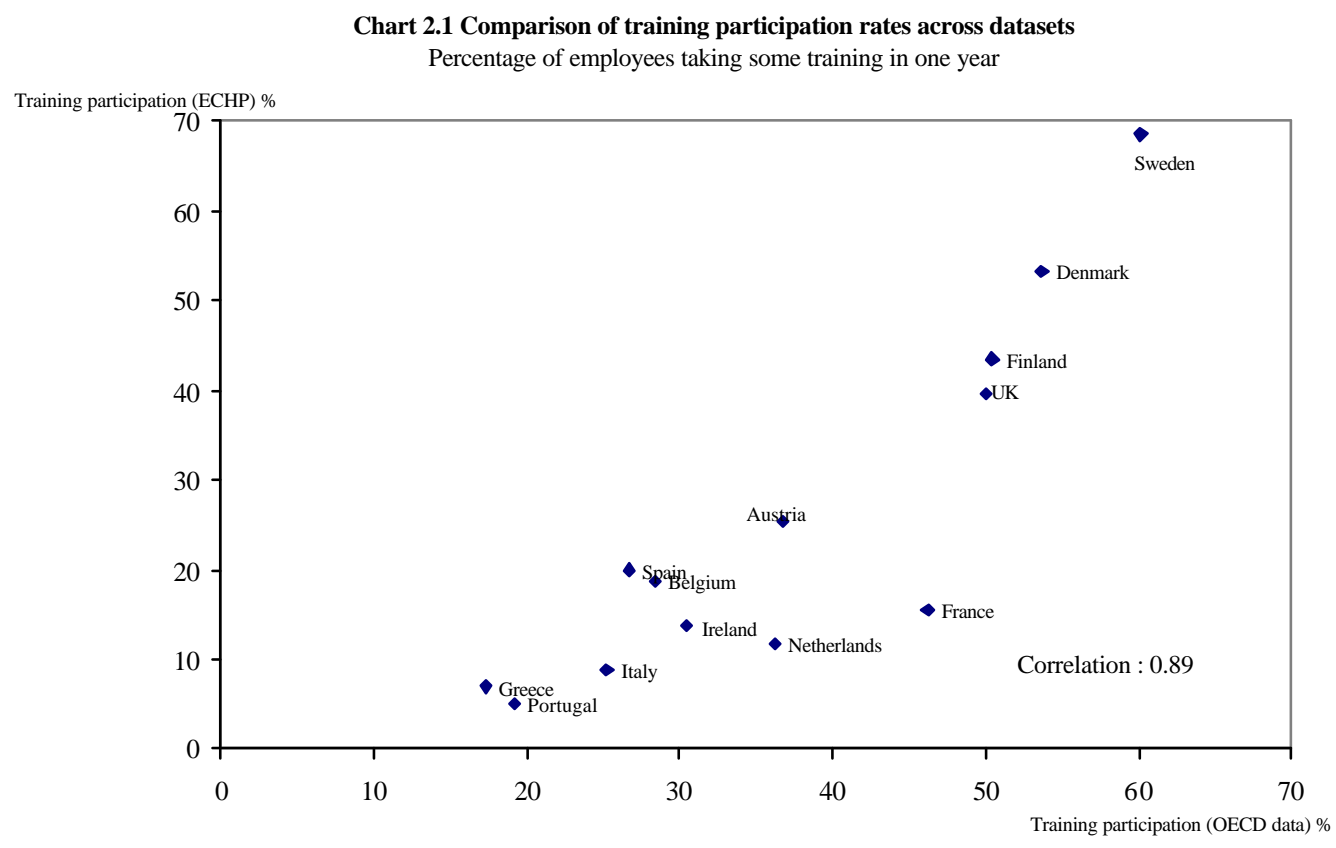

Note: ECHP data refer to 1997, OECD data to the second half of the 1990s

Source: OECD (2004) and ECHP.

\subsection{The distribution of training across countries and regions}

In which country do employees take/receive more training? The most common training measures in the literature are participation rates, that is the share of employees receiving training in a given period, and training hours per employee. On the basis of the OECD datasets, the largest available to us, Chart I.1 in the general introduction shows participation rates and hours per employee for 30 European or Anglo-Saxon countries in the second half of the 1990s. Annual training participation varies between 10.8 per cent in Romania and 60.1 per cent in Sweden while average annual hours per employee vary between 6.7 in Romania and 36.1 in Denmark. The two measures are nonetheless strongly correlated. This is due to the fact that training hours per participants are much more homogenous across countries, varying between a low 43 hours in the United States to a high 80 hours in Ireland (Chart 2.2) with a coefficient of variation of 0.16 against 0.42 for participation rates and 0.45 for hours per employee. Hence, with some notable 
exception, the relative position of countries is the same irrespective to the measure used.

Scandinavian countries as well as France and New Zealand appear to be the most training intensive countries (with participation rates above 45 per cent and more than 30 hours per employee). The United Kingdom could be added to this group as regards participation rate ( 50 per cent); but it falls behind by more than one standard deviation in terms of hours of training (23 per employee). A similar fate occurs to the US, which is about one standard deviation above the mean in terms of participation rates (41.4 per cent) and just below the mean in terms of hours of training per employee (17.9). At the bottom of the distribution we find several Eastern European countries (Romania, Poland, Lithuania, Latvia, Bulgaria and Hungary) and, just above, the group of Southern European EU countries (except Spain).

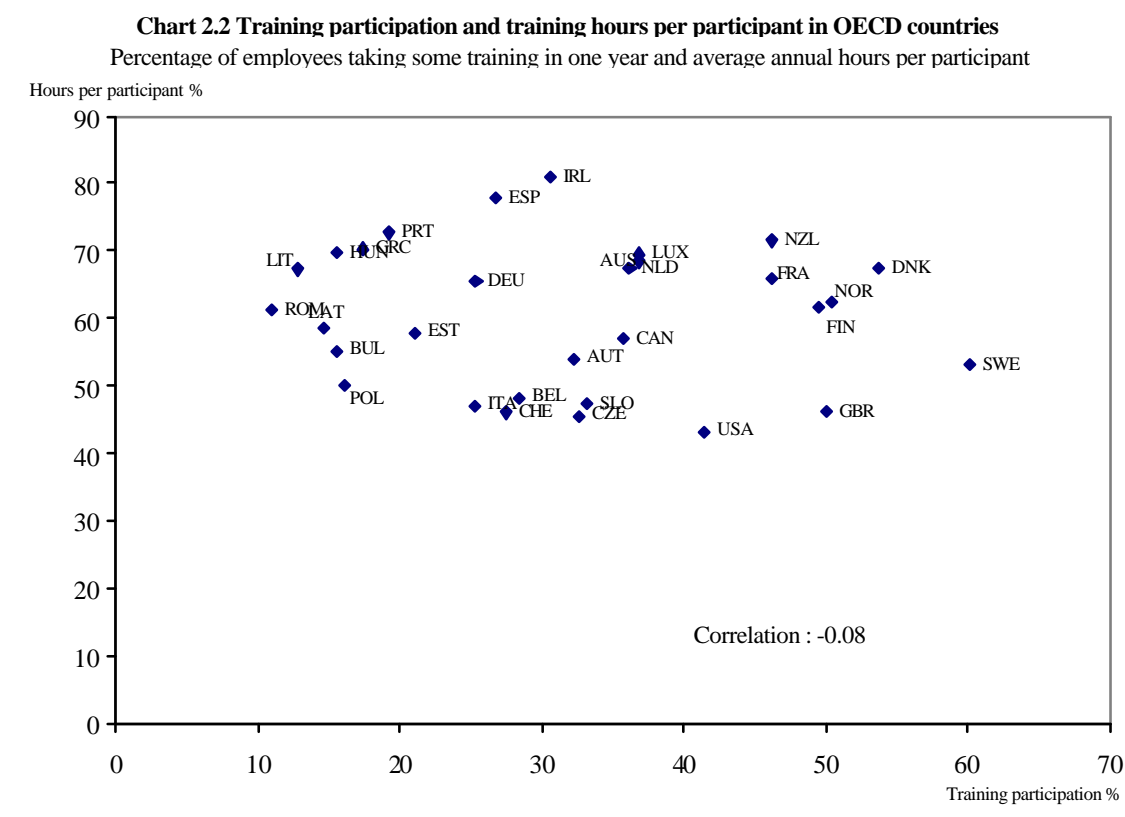

Note: the data refer to the second half of the 1990s

Source: OECD (2004) based on IALS and CVTS, see appendix for the methodology

Overall, we find that, irrespective to the measure considered, training varies by a factor of 6 between the least and the best performing country. This reduces to 33.5, if we focus on the EU before the enlargement (EU 15 hereafter). But does looking at the distribution of training by country suffice to provide an accurate picture of the geographical distribution of training? To answer this question in a very descriptive manner, Chart 2.3 provides the distribution of training by region for selected EU countries using the 1997 wave of the ECHP and the most 
disaggregate available decomposition (NUTS 2 for the UK, Portugal, Sweden and Finland; NUTS 1 for all other countries).

Care must be taken in interpreting these figures, since distributions at NUTS 2 level are obviously more disperse than at NUTS 1 level. Taking this into account, however, one fact strikes: regional dispersion of participation rates is somewhat negatively related to the country average. In Finland and, especially, Sweden there is in practice no regional variation. Conversely, Italy, Greece and Portugal are by far the countries with the greatest disparities. In Italy, the best performing region (Nord Ovest) trains six times more frequently than the least performing one (Abruzzo-Molise). In Portugal, training varies across regions by a factor of 4 (although these statistics are based on a NUTS 2 classification). These figures are remarkable if compared with the cross-country variation in training participation rates shown in Chart 2.1.

The variation in the distribution of training across regions within a country can be explained at least in part as the result of the interaction between the density of local economic activity and the training decisions of firms. In two separate empirical investigations of the UK and Italy, Brunello and Gambarotto, 2004, and Brunello and De Paola, 2004, show that in both countries more agglomerated local areas are characterized by lower training participation. They explain this result as the outcome of the trade-off between turnover and poaching effects and pooling externalities associated to the diffusion of knowledge.
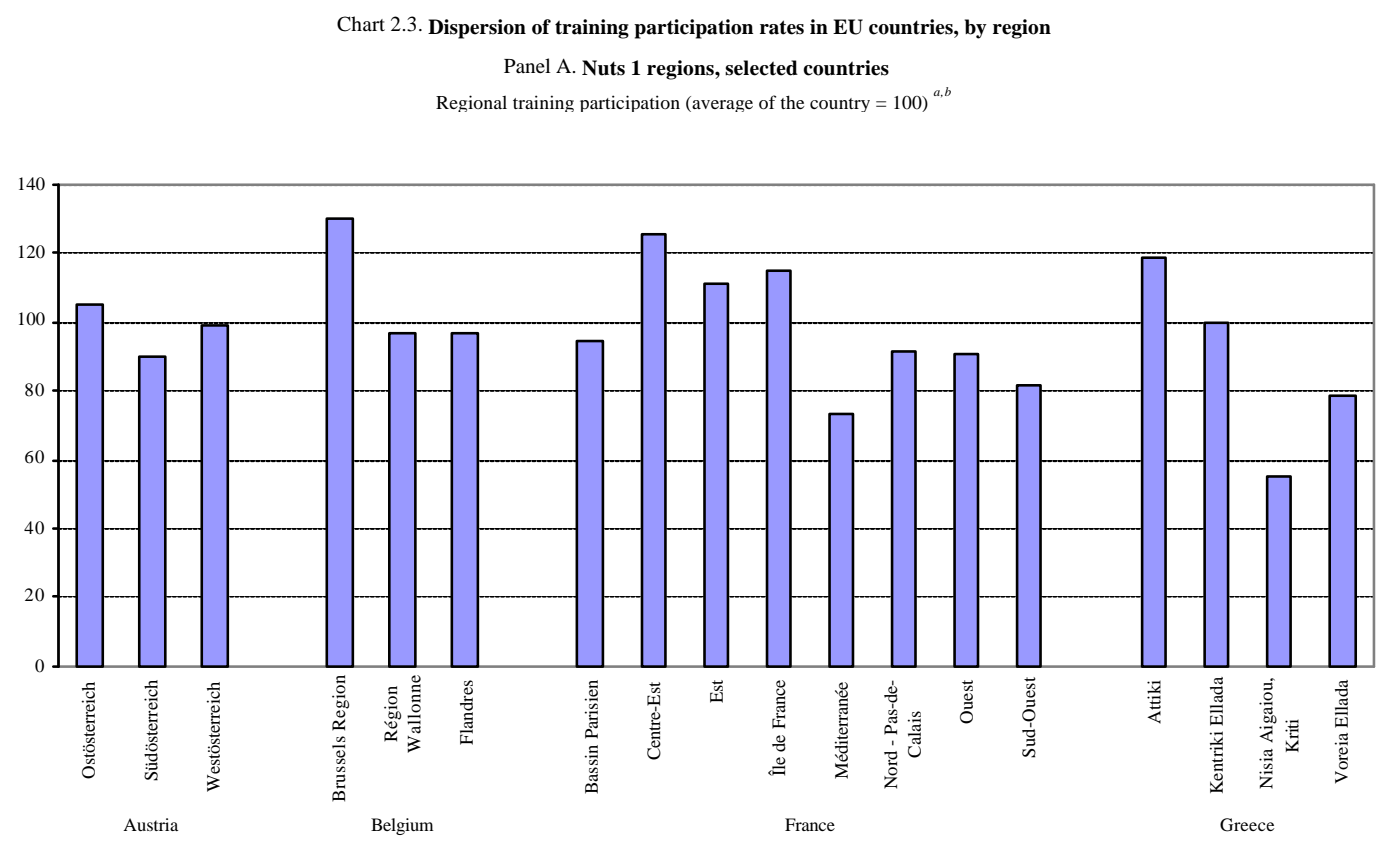
Panel B. Nuts 1 regions, Italy and Spain

Regional training participation (average of the countrv $=100)^{a, b}$

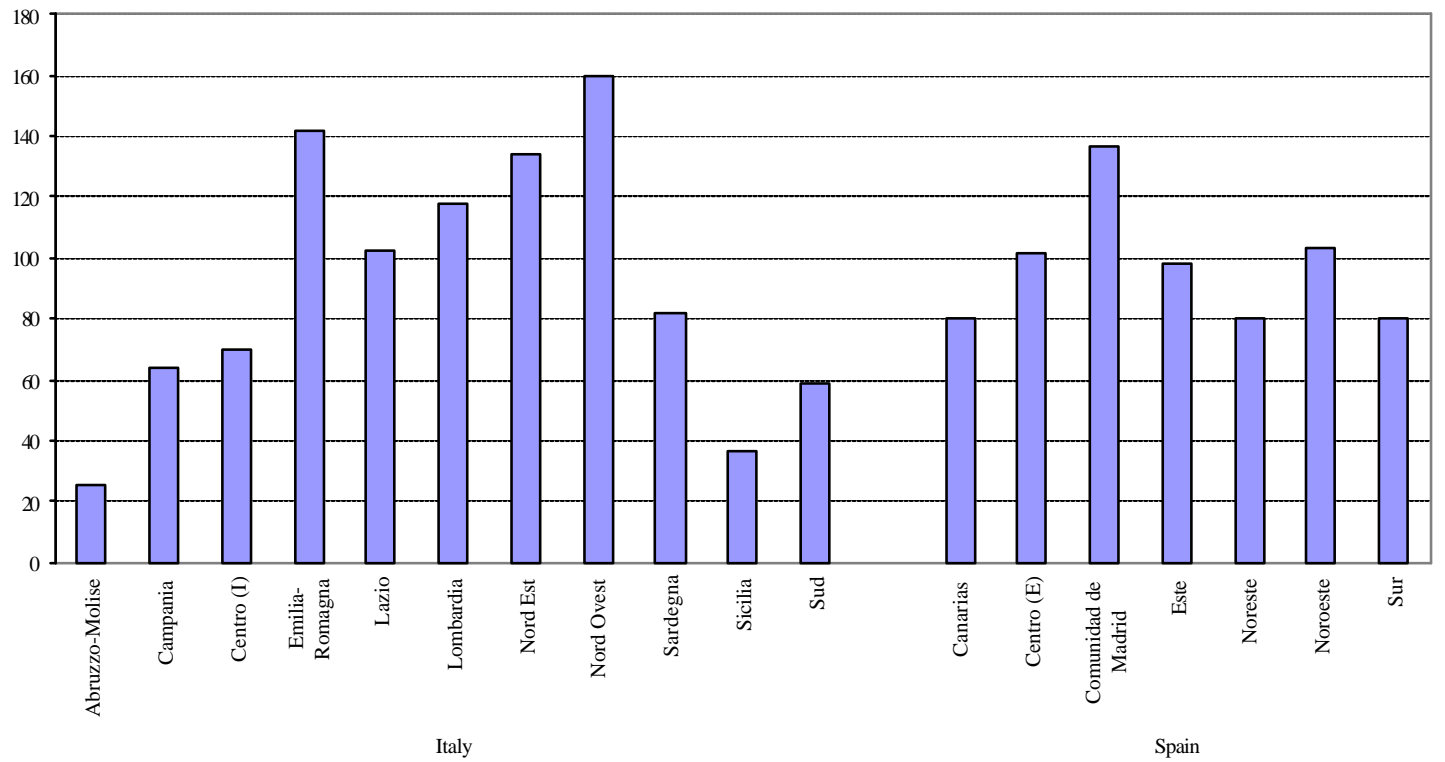

Chart 2.3. Dispersion of training participation rates in EU countries, by region (cont. )

Panel A. Nuts 2 regions, selected countries

Regional training participation (average of the country $=100)^{a, b}$

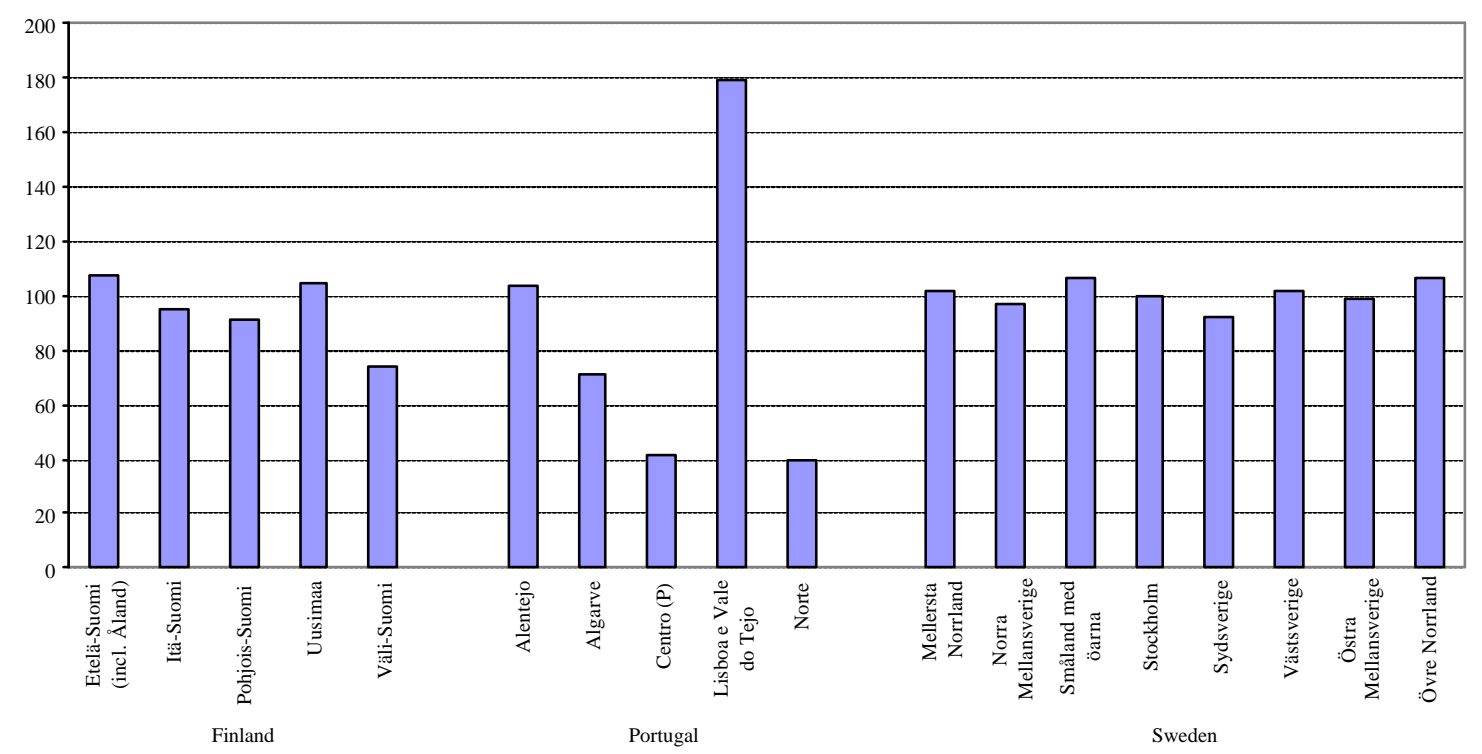


Panel D. Nuts 2 regions, United Kingdom

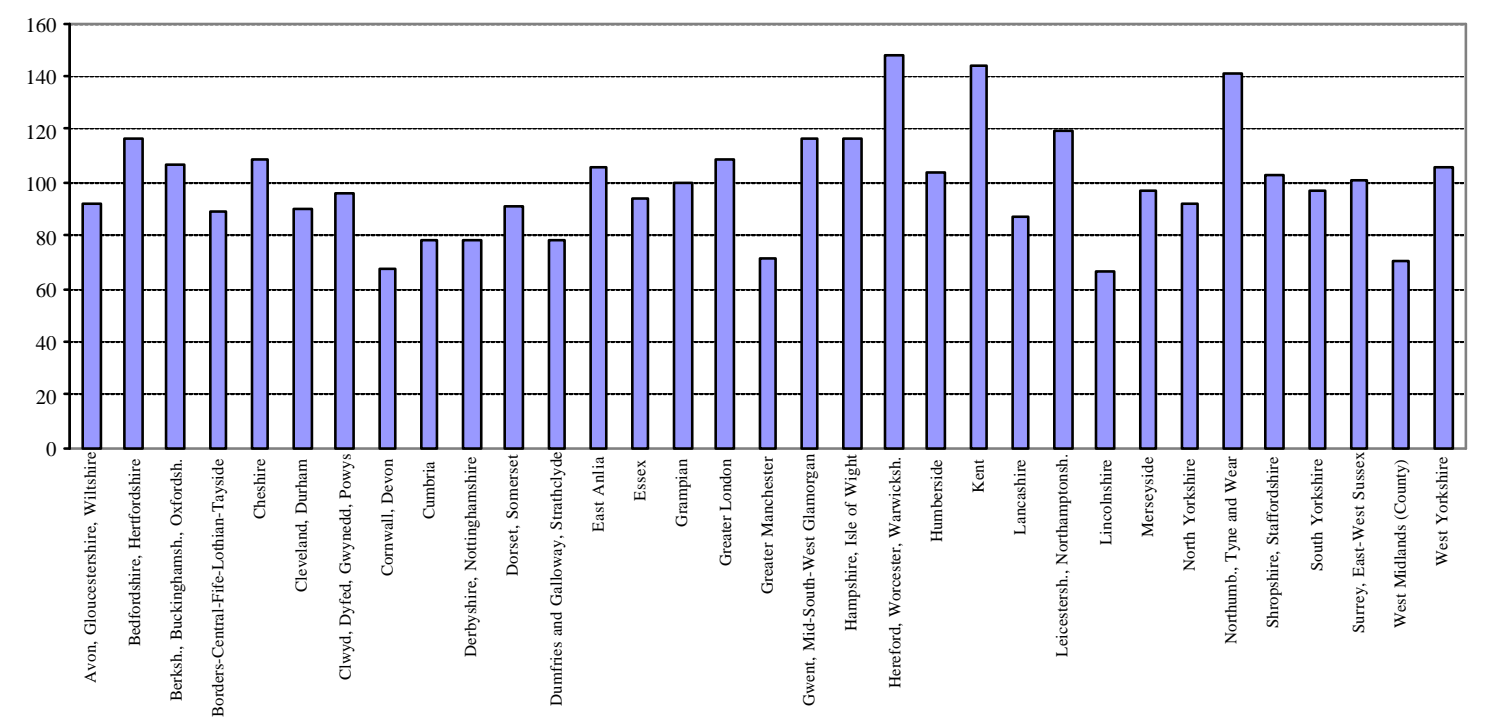

a) Data refer to 1997

b) Few regions are not shown due to insufficient data. For the same reason Etelä-Suomi and Åland are aggregated.
Source: ECHP.

\subsection{Who pays for training?}

As discussed in Chapter 1, in the standard theory of human capital, employers and employees share the cost and benefits of training when training is firm-specific (and/or training is general but there are multiple skills and each firm employs a specific-combination of skills, see Lazear, 2003). When training is perfectly general, employees will pay for the full cost of training if the labour market is competitive, while employers might pay for part or all of it if labour markets are imperfectly competitive.

In Chart 2.4 we decompose the number of training courses according to whether they are (or they are not) partially paid for or provided by the employer (employer-sponsored hereafter) in 16 OECD countries using data from the IALS. Panel A shows that, on average, $80 \%$ of vocational training courses are paid for or provided by employers. Although cross-country variation is large, in all countries at least $50 \%$ of vocational training courses are employer-sponsored. A similar pattern emerge in the ECHP, where on average $72 \%$ of the training courses on which we have information on the source of financing ${ }^{34}$ is employer-sponsored (see Table A2.1 in the Appendix). According to IALS data, a large majority of employer-

\footnotetext{
${ }^{34}$ In the ECHP the information on financing is reported for the last course taken only.
} 
sponsored training courses (93\% on average, with little cross-country variation) is also reported to be entirely financed by employers (see Table A2.2 in the Appendix).

Decomposing the number of courses by source of finance, however, overstates the share of training investment borne by firms. Employer-sponsored courses are in fact shorter than non-sponsored ones. In the same IALS country sample, nonsponsored vocational training courses are about twice as long as employersponsored ones (see Table A2.3 in the Appendix). Even in the country where the two distributions are less different (Switzerland), employer-sponsored courses are, on average, $25 \%$ shorter than non-sponsored one. ${ }^{35}$

When we decompose the volume of training by source of financing (Chart 2.4, Panel B), it appears, however, that the degree of employer's support is still large. On average, 2/3 of employee training is reported to be employer-sponsored. Furthermore in all but three countries (Ireland, Italy and Switzerland) more than half of the training volume is reported to be at least partially financed by the employer.

When employers only are reported to pay for training, do they really bear the cost of it? Or, are firms simple providers of training services and workers indirectly pay for them by accepting a different wage pattern and accepting to be trained outside normal working hours? Indeed, sharing the cost of training through lower wages does not necessarily imply a nominal wage cut, which is relatively rare, particularly in European countries (see Nickell and Quintini, 2002). Employees can trade-off wage increases in exchange of training and newly-hired individuals can be offered a contract with lower than usual pay - although possibly steeper tenure-earnings profile - in exchange of current training or future training.

The existing empirical literature on training and wages during the training period focuses mainly on the United States and, to a lesser extent, the United Kingdom. We can distinguish two strands of research on the basis of the source of data. Studies that used employer surveys are generally confined to cross-sections. Autor (2001), using a cross-section of temporary help firms from the 1994 BLS Occupational Compensation Survey, finds that temporary help agency do provide their workers with nominally free computer skills training, that is inherently general. This notwithstanding, workers share part of the cost of training by not being paid during training: almost without exception, training is given prior to or

\footnotetext{
35 A similar pattern is also consistent across surveys: although the ECHP reports information on duration by intervals, it emerges from Table A2.4 that the degree of employer's support decreases with course duration (certain countries are excluded due to missing data, see the Appendix for the description of the datasets).
} 
between assignments during unpaid hours with all direct costs paid by the temporary help supply firm. Barron, Berger and Black (1999), using data from the Employer Opportunity Pilot Project (EOPP), find that initial pay and training are inversely related. However, the effect they found is small (doubling the proportion of time spent on training leads to only 1.8 per cent of wage reduction) and accounted for by the fact that employers do not have a significant propensity to pay lower wages to newly-hired individuals that require more training than normal but are ready to pay higher wages to those who require less training than normal (because of previously accumulated transferable skills that can be used in the new job). The drawbacks of their analysis are that i) they do not control for employer effects and ii) they do not distinguish between general and specific training in their analysis. By contrast, using the same data, Sicilian (2001) makes this distinction and finds a stronger yet small effect (about 5 per cent in the case of fully general training). The limitation of this study is however that, in order to control for firm selection, the sample is reduced to those firms reporting information on at least two workers and therefore estimates are driven by less than 150 individuals.

Recent empirical studies based on employee data have exploited the longitudinal dimension of several individual datasets. For instance, for the United States, Loewenstein and Spletzer (1998) consider 5 waves of the National Longitudinal Survey of Youth (NLSY) and estimate a wage level equation that allows for a dummy for job changes to control for match-specific effects on wages. They find that uncompleted spells of training have insignificant effects on wages (even in the case of off-site training courses). Booth and Bryan (2002) use the same technique to estimate wage level equations for the United Kingdom on 3 waves of the British Household Panel Survey and find that next year's' training has a positive but insignificant impact on current wage, suggesting that employees do not exchange training against wage moderation before training.

Overall, these studies find little evidence that workers pay for a large share of training costs out of their wages. Obviously, the limit of these analyses is that if workers pay out of their wages only for a small share of training costs, measurement error may suffice to prevent finding a significant effect of current or future training on average hourly wages reported for a given year. Nevertheless, the evidence discussed in this section suggest the following conclusions: i) workers do not pay for most of the cost of employer-sponsored training out of their wages, ii) the evidence that workers accept lower wages to co-finance training is very 
limited and not robust; iii) there is some evidence that they may accept to be trained outside normal working hours, at least under certain circumstances. ${ }^{36}$

This cautiously suggests that the degree of employer's support that is reported in surveys can be considered an imperfect but not thoroughly unreliable proxy of employer's true investment in training. Hence, from the fact that, at face value, most training is employer-sponsored, we can conclude that employers are major players in the training market.

But how large are their investments in economic terms? As shown in Table 2.1, training expenditures of European employers are reported to have been on average 444 Euros per employee (in Purchasing Power Parity, with EU 15 as the base) in 1999, on the basis of CVTS data. ${ }^{37}$ In EU 15 countries, this figure is higher, being on average at 603 Euros, with Danish firms spending up to 1132 Euros per employee. Are these figures significant in economic terms? Most often yes. In fact, they correspond to 1.7, 2.3 and 3 per cent of total labour costs, on average, in EU 15 and in Denmark, respectively.

Chart 2.4. Share of employer-sponsored training

Panel A. Training courses

Decomposition by source of training course financing ${ }^{a, b}$

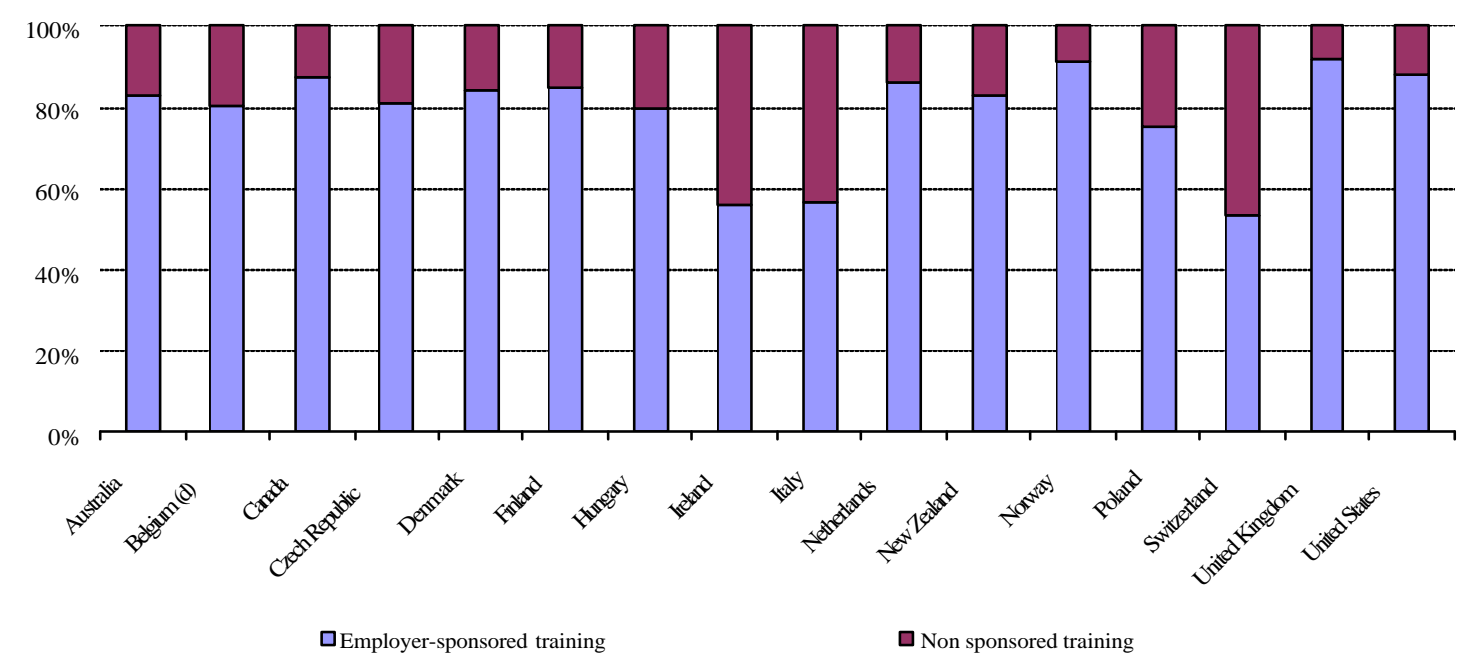

\footnotetext{
${ }^{36}$ Employer-sponsored training outside normal working hours is however more the exception than the rule in many countries. For instance, Pischke (2001) reports that only $27 \%$ of training during leisure hours is at least partially financed by the employer.

${ }^{37}$ Employers are likely to be more precise as regards to firm choices and characteristics than employees. For this reason we resort entirely to the CVTS in this section.
} 


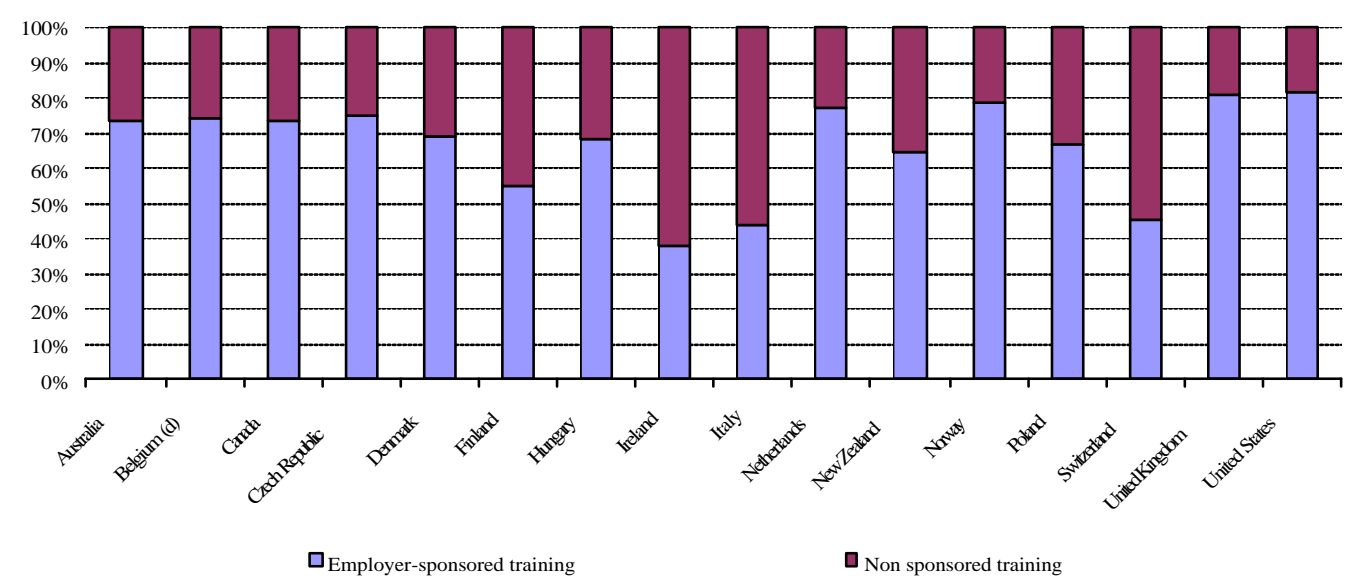

a) Data refer to employed persons aged 26 to 65 years.

b) Data refer to 1994 for Canada, Ireland, the Netherlands, Poland, Switzerland (German and French-speaking regions) and the United States, to 1996 for Australia, Belgium, New Zealand and the United Kingdom, and to 1998 for the Czech Republic, Denmark, Finland, Hungary, Italy, Norway and the Italian-speaking regions of

Switzerland.

c) Annual hours spent in training undertaken for job or career-related purposes.

d) Flanders only.

Source: IALS.

Country rankings by training expenditure follow closely those by participation and hours, except in the case of Italy, which is much closer to the average of EU 15 countries in terms of spending per employee. This might reveal inefficient spending by firms and/or that Italian firms invest in better quality but more expensive training. While available data do not allow us to tell, the Italian experience with apprenticeship training discussed in Chapter 5 suggests that the former explanation goes at least some of the way in accounting for the observed facts.

\subsection{Are training investments pro-cyclical or counter-cyclical?}

According to Hall, 2000, re-organisations take place during slack periods when the cost of foregoing production to re-allocate resources is smaller. The case studied by Hall concerns creation/destruction of job matches and search. However, it can well apply to internal re-organisation, which usually requires long periods of adaptation, learning and training before becoming again fully efficient.

The evidence that the propensity of firms to internally reorganise is countercyclical is tenuous: for instance, Caroli and van Reenen, 2001, find that although British firms tend to re-organise more frequently during periods of changing demand patterns, they tend to do it equally often when demand rises or falls. 
Conversely, French firms do not seem to be significantly sensitive to changes in demand.

Table 2.1. Cross-country distribution of training expenditures by firms, European countries

\begin{tabular}{l|cc}
\hline Country & $\begin{array}{c}\text { As a percentage of total } \\
\text { labour costs (\%) }\end{array}$ & $\begin{array}{c}\text { Annual expenditure per } \\
\text { Employee (Eur, in PPPs) }\end{array}$ \\
\hline Austria & 1.3 & 365 \\
Belgium & 1.6 & 675 \\
Bulgaria & 1.0 & 134 \\
Czech Republic & 1.9 & 250 \\
Denmark & 3.0 & 1132 \\
Estonia & 1.8 & 197 \\
EU 15 & 2.3 & 603 \\
Finland & 2.4 & 698 \\
France & 2.4 & 753 \\
Germany & 1.5 & 506 \\
Greece & 0.9 & 223 \\
Hungary & 1.2 & 144 \\
Ireland & 2.4 & 600 \\
Italy & 1.7 & 563 \\
Latvia & 1.1 & 90 \\
Lithuania & 0.8 & 65 \\
Luxembourg & 1.9 & 592 \\
Netherlands & 2.8 & 875 \\
Norway & 2.3 & 666 \\
Poland & 0.8 & 97 \\
Portugal & 1.2 & 240 \\
Romania & 0.5 & 41 \\
Slovenia & 1.3 & 167 \\
Spain & 1.5 & 385 \\
Sweden & 2.8 & 868 \\
United Kingdom & $n . a$. & 628 \\
\hline
\end{tabular}

Notes: Data refer to training taken in 1999. The reference for the PPPs is the average of the EU15 (the values for EU 15 are expressed in current Euros). Initial training is excluded. Source: CVTS.

In the case of training, however, there might be valid reasons for a pro-cyclical pattern. For instance, unlike investments in physical capital, human capital generated through training investments cannot be used as collateral (Piore, 1968). Accordingly, the firm will have to finance its training expenditures by internal profits, making it easier to do training investments during booms rather than during downturns. In addition, accounting standards and fiscal systems do not allow equal treatment of investments in physical and human capital. In fact expenditures for physical capital formation can be inputed pro-rata in several years as depreciations. This fact implies smaller fluctuations in the firm's reported 
results, since only a proportion of large one-shot investments is reported in the balance sheet in the year the expenditure is made. This is not the case of expenditures in human capital that typically are treated as operating costs. This difference of accounting treatment has two consequences: large training investments might make the position of the firm making losses more fragile with respect to shareholders; and the firm will not be able to make use of tax deductions of training expenditures to the extent that it does not earn positive profits. $^{38}$

Evidence from business surveys in Sweden reveals that large company managers consider that training in their company has been historically affected by their firm's profit record. This piece of evidence is compounded by the fact that no homogeneous opinion exists as regards capacity usage, with about equal fractions of managers arguing that training is affected positively or negatively by capacity usage (Hakanson et al., 2003). Yet, to our knowledge, little quantitative evidence has been provided so far on objective data ${ }^{39}$.

To shed some light on this issue in a very descriptive manner, we aggregate data on training participation from the ECHP for the years 1995-2001. Then we look at the partial correlation of training rates with, alternatively, the output gap the difference between current and potential output - and the unemployment rate, both taken from the OECD database. In order to do so we estimate the following simple log-linear regression model by $\mathrm{OLS}^{40}$ :

$$
\log Y_{c t}=\alpha_{c}+\alpha_{t}+\beta X_{c t}+\gamma_{c} t+\varepsilon_{i t}
$$

where $Y$ is the training participation rate - in percentage points - in country $c$ at time $t, \alpha_{c}$ and $\alpha_{t}$ are country and year effects, $\mathrm{X}$ is, alternatively, the output gap or the unemployment rate - both measured in percentage points $-\gamma_{c} t$ is a countryspecific time trend and e a random error. Country-specific effects and trends as well as common time dummies are included to capture the evolution of training

\footnotetext{
${ }^{38}$ In almost all OECD countries, human resource expenditures can be deduced from turnover before computing the tax base. Few countries have also more generous systems (see OECD, 2003, and Chapter 5).

${ }^{39}$ Sepulveda, 2002, studies US data and finds that training is weakly counter-cyclical.

${ }^{40}$ Using a log-linear specification instead of a thoroughly linear one is equivalent to express changes in training rates in percentages rather than percentage points. A thoroughly linear specification is likely to be inappropriate: training participation varies in the ECHP between 5 and 70 percent (see Chart 2.1), so that the variation estimated to be associated with one percentage point change in unemployment means completely different things in countries as different as Portugal and Sweden. This qualitative argument is confirmed by Breusch-Pagan tests for exponential heteroskedasticity, which turns out always significant in thoroughly linear specifications. As a sensitivity analysis we consider also logit and inverted normal transformations of the training participation rate, estimating them alternatively by OLS and WLS. Results, available from authors upon request, are robust across methods and specifications.
} 
over time for reasons that are unrelated to the business cycle (but that can be correlated with changes in unemployment or output gap within a relatively short sample window). A negative (resp. positive) estimated coefficient for the output gap (resp. unemployment) suggests a countercyclical behaviour of the training rate. The opposite holds for a positive (resp. negative) coefficient.

Results shown in Panel A of Table 2.2 suggest a negative sign for the output gap and a positive one for the unemployment rate, consistent with the countercyclicality hypothesis. A one percentage point increase in the output gap is estimated to be associated with a reduction in training participation by about 3$6 \%$. Similarly, a one point increase in the unemployment rate is estimated to be associated with a 3-5\% growth in training participation.

In Panel A we look at total training. But the theoretical conjectures discussed above focus essentially on the behaviour of firms. It seems natural, therefore, repeating the same experiment on employer-sponsored training only. This is done in Panel B. The coefficients of interest are now always estimated to be significant, at least at the 5 percent level. ${ }^{41}$ The estimated effects are also stronger. A one percentage change in the output gap (resp. the unemployment rate) is estimated to be associated with about a 4-8\% (resp. 6\%) change in training participation.

Since the reference period for training in each wave is longer than 1 year (see the Appendix) and may therefore overlap with the period of the previous wave, we run the risk of double counting training spells. We could try to solve this problem by using the starting dates of any training spell, but this information has a lot of missing values in the data, and is available only for some of the countries in the sample. Rather than losing information or adjusting counts in an ad-hoc way, we ignore double counting in the main regressions. Nevertheless, we perform a robustness check which compares our results with those obtained from a reduced sample which only retains odd years, thus eliminating the possibility that relatively long training spells are counted twice by definition. Results from these experiments are presented in Table A2.5. The pattern found through the main regressions is essentially confirmed. ${ }^{42}$

\footnotetext{
${ }^{41}$ Sweden is eliminated from this sample due to lack of ECHP data on training financing for this country.

${ }^{42} \mathrm{~A}$ second problem that we have in our data is that the routing of the questions on training in the UK questionnaire changed in 1998. We therefore re-run our experiments by eliminating UK after 1998 from the sample. No significant variation of estimated coefficients emerge (results available from authors upon request).
} 
Table 2.2. Variation of training over the business cycle 1995-2001.

Panel A: Total training

\begin{tabular}{|c|c|c|c|c|c|c|}
\hline & (1) & (2) & (3) & (4) & (5) & (6) \\
\hline Output gap & $\begin{array}{l}-0.028 * * \\
(0.013)\end{array}$ & $\begin{array}{l}-0.029 \\
(0.019)\end{array}$ & $\begin{array}{c}-0.061 * * \\
(0.028)\end{array}$ & & & \\
\hline $\begin{array}{l}\text { Unemployment } \\
\text { rate }\end{array}$ & & & & $\begin{array}{c}0.046^{* * * *} \\
(0.010)\end{array}$ & $\begin{array}{l}0.030^{*} \\
(0.015)\end{array}$ & $\begin{array}{l}0.035 * * \\
(0.017)\end{array}$ \\
\hline Country dummies & yes & yes & yes & Yes & yes & yes \\
\hline $\begin{array}{l}\text { Country-specific } \\
\text { trends }\end{array}$ & no & yes & yes & No & yes & yes \\
\hline Time dummies & no & no & yes & No & no & yes \\
\hline $\begin{array}{l}\text { Number of } \\
\text { observations } \\
\text { R-squared }\end{array}$ & $\begin{array}{c}88 \\
0.96\end{array}$ & $\begin{array}{c}88 \\
0.98\end{array}$ & $\begin{array}{c}88 \\
0.98\end{array}$ & $\begin{array}{c}88 \\
0.97\end{array}$ & $\begin{array}{c}88 \\
0.98\end{array}$ & $\begin{array}{c}88 \\
0.98\end{array}$ \\
\hline
\end{tabular}

Panel B: Employer-sponsored training

\begin{tabular}{|c|c|c|c|c|c|c|}
\hline & (7) & $(8)$ & (9) & $(10)$ & $(11)$ & $(12)$ \\
\hline Output gap & $\begin{array}{c}-0.045^{* * *} \\
(0.016)\end{array}$ & $\begin{array}{c}-0.053^{* *} \\
(0.023)\end{array}$ & $\begin{array}{c}-0.077 * * \\
(0.031)\end{array}$ & & & \\
\hline $\begin{array}{l}\text { Unemployment } \\
\text { rate }\end{array}$ & & & & $\begin{array}{c}0.062 * * * \\
(0.012) \\
\end{array}$ & $\begin{array}{c}0.058 * * * \\
(0.018) \\
\end{array}$ & $\begin{array}{c}0.058 * * * \\
(0.021)\end{array}$ \\
\hline Country dummies & yes & Yes & yes & Yes & yes & yes \\
\hline $\begin{array}{l}\text { Country-specific } \\
\text { trends }\end{array}$ & no & Yes & yes & No & yes & yes \\
\hline Time dummies & no & No & yes & No & no & yes \\
\hline $\begin{array}{l}\text { Number of } \\
\text { observations } \\
\text { R-squared }\end{array}$ & $\begin{array}{c}83 \\
0.93\end{array}$ & $\begin{array}{c}83 \\
0.97\end{array}$ & $\begin{array}{c}83 \\
0.98\end{array}$ & $\begin{array}{c}83 \\
0.94\end{array}$ & $\begin{array}{c}83 \\
0.97\end{array}$ & $\begin{array}{c}83 \\
0.98\end{array}$ \\
\hline
\end{tabular}

Note: OLS with log-linear specifications. Robust standard errors in parentheses. ***, **, *: significant at the $1 \%$, $5 \%$ and $10 \%$ level of confidence, respectively.

\subsection{The distribution of training investments across firms}

Are all firms equal in their propensity to train? And if not, which firms do invest more? And how much do they invest? To investigate these issues Chart 2.5 shows the distribution by firm size of participation rates, hours and the two measures of training expenditure considered above.

The first fact that emerges from the Chart is that large firms train more than small ones. This is not surprising for several reasons: i) the collection of information, the definition of a training plan and the establishment of a training facility involve fixed costs and scale economies; ii) small firms might find more difficult to replace a worker who temporarily leaves for training; and iii) small firms 
might have fewer opportunities to fully reap the benefits of training through internal reallocation of workers.

Small firm employees receive on average 6.8 hours of training less than their large firm peers and have a participation rate smaller by 20 percentage points. This is reflected in employers' expenditures. On average, expenditures on total labour costs are 1 percentage point greater in the case of large firms. However, the cross-country variation of training is far smaller in the case of large firms than in the case of small firms: in the latter case the coefficients of variation are .71, $.68, .56$ and .85 for participation, hours, expenditure on labour cost and expenditure per employee, respectively, while in the former they are .38, .42, .39 and .62, respectively. In other words, large firms are relatively similar across countries as regards training, and the difference in training rates across countries is mostly due to the behaviour of small firms as well as to the distribution of firm size within countries. Indeed, countries with the greatest percentage difference between large and small firms (such as Portugal) are concentrated at the bottom end of the cross-country distribution of training, irrespective of the measure of training employed. ${ }^{43}$

The distribution by size in the UK is worth mentioning. In contrast with all other countries, this is essentially flat, especially in terms of hours and spending. As a consequence, the UK ranks below the EU 15 average in the distribution of large firms (except in the case of participation rates) while being at the top in the case of small firms. This is more evident when looking at spending: with an equivalent of 513 Euros per employee, the UK ranks just higher than Portugal and Greece, within EU countries, in terms of spending of large firms.

A similar pattern of cross-country distribution of inter firm differences can be found as regards to innovation and adoption. Chart 2.6 plots training participation rates in firms that introduced (resp. did not introduce) new products or processes in the same period. In fact, although innovative firms have on average participation rates that are 15 percentage points higher, innovative and non innovative firms are not very different in training intensive countries (for instance, in Scandinavian countries, the average difference in participation rates is only 11.8 percentage points). By contrast, these differences are huge in less training intensive countries (up to 33 percentage points in Slovenia, and 22 in both

\footnotetext{
${ }^{43}$ Interestingly, there is a strong negative correlation between this percentage difference and the average level. Correlation coefficients are $-0.90,-0.82,-0.71$ and -0.65 for participation, hours, expenditure on labour cost and expenditure per employee, respectively.
} 
Bulgaria and Portugal). Again, it is mainly the difference across non-innovative firms which is to be blamed for the dispersion of training rates across countries. ${ }^{44}$

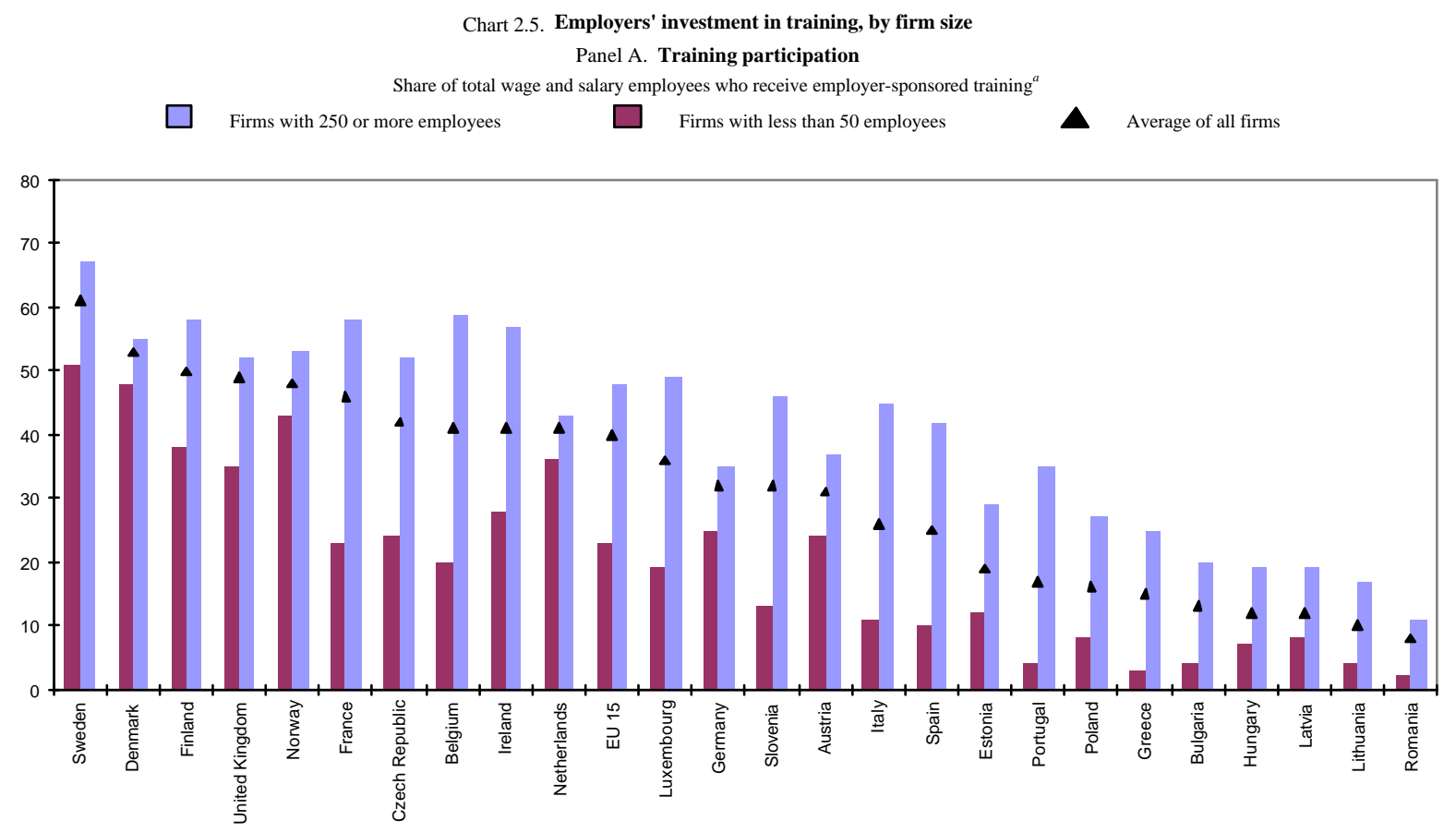

Panel B. Training hours

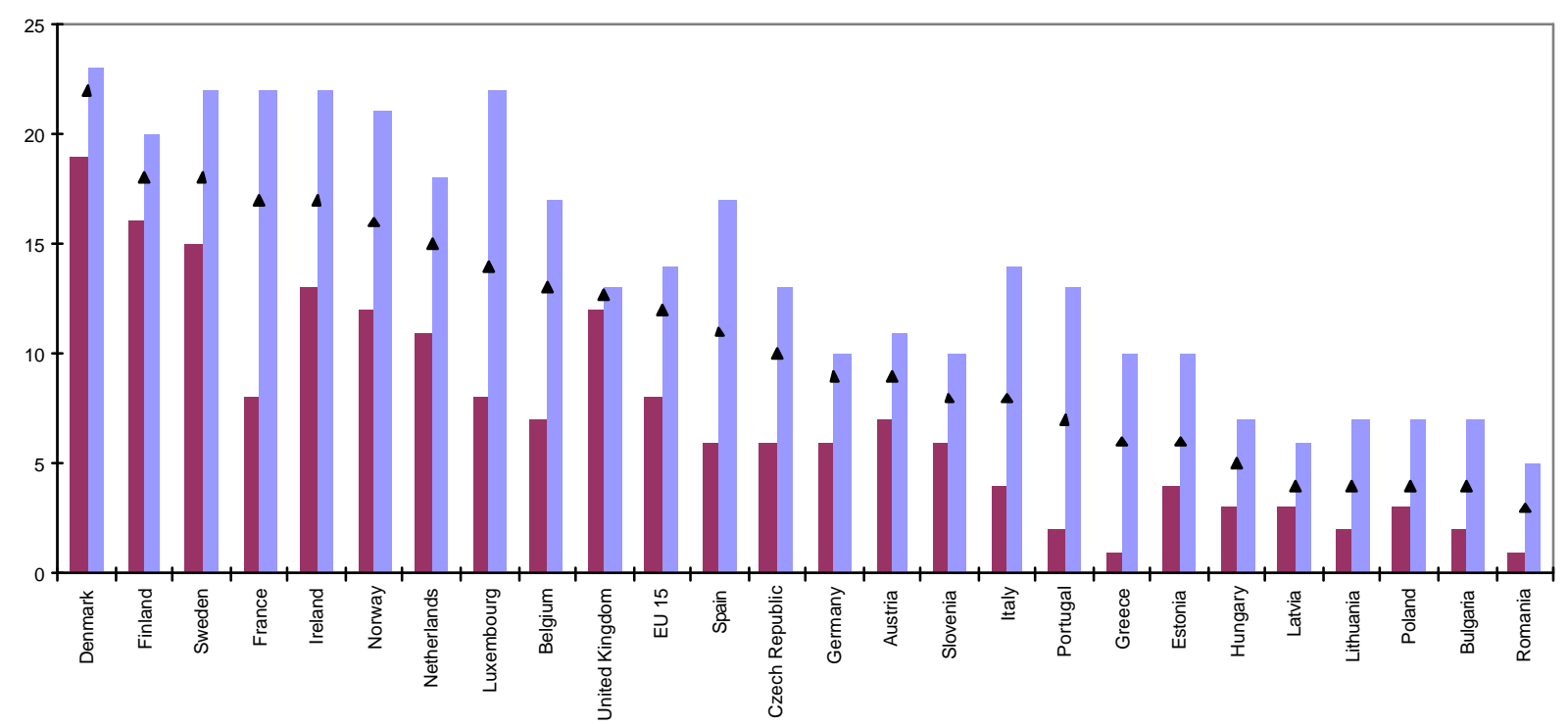

\footnotetext{
${ }^{44}$ This relationship between innovation and training is not only due to the fact that large firms tend to be more innovative than small firms (see Table A2.6 in the Appendix).
} 
Chart 2.5. Employers' investment in training, by firm size (cont.)

Panel C. Training expenditure as a percentage of total labour costs

Employers' expenditure in training as a percentage of total labour costs ${ }^{a}$

$\triangle \quad$ Average of all firms

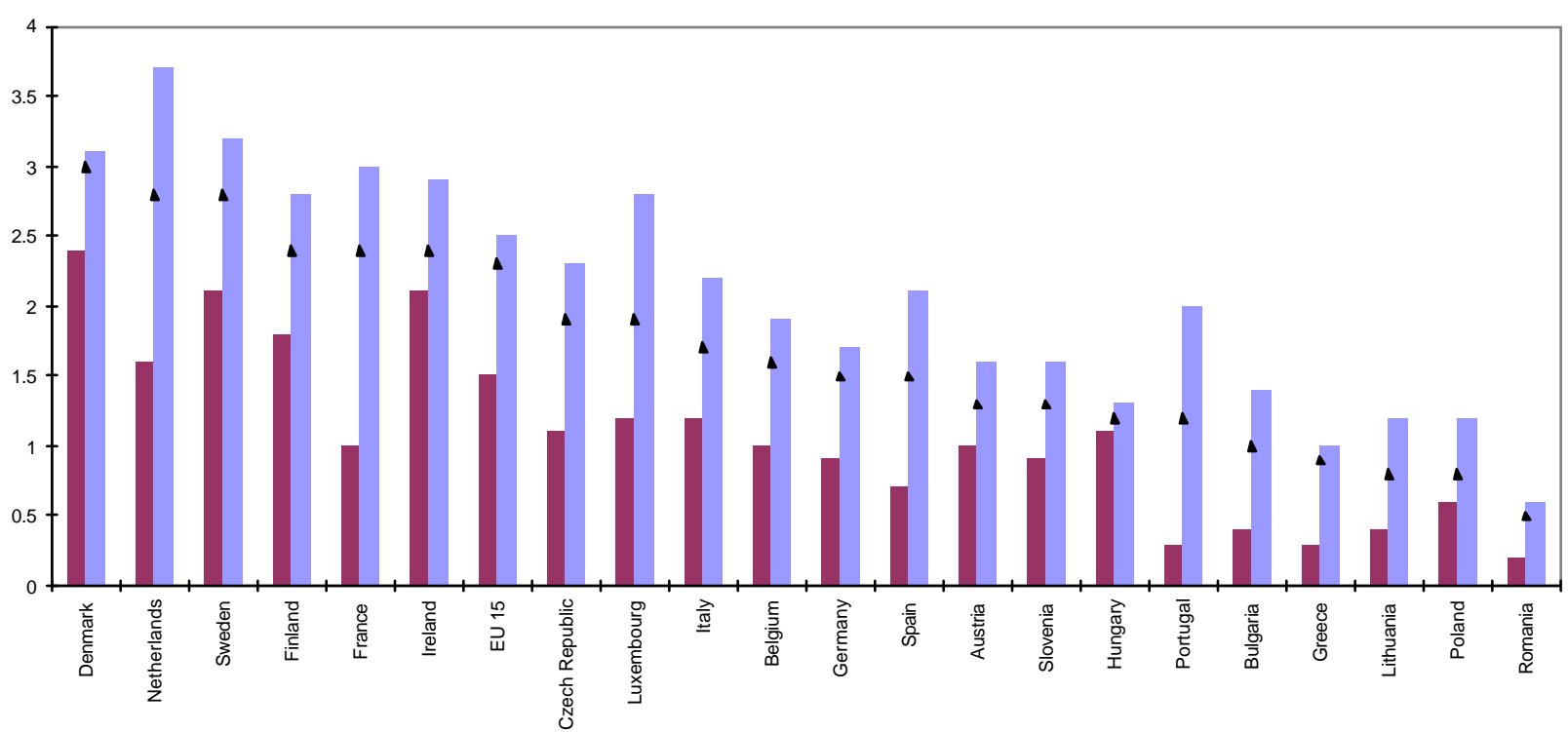

Panel D. Training expenditure per employee

Annual employers' expenditure in training per employee, Euros, in PPPs

Firms with 250 or more employees $\quad \square \quad$ Firms with less than 50 employees

Average of all firms

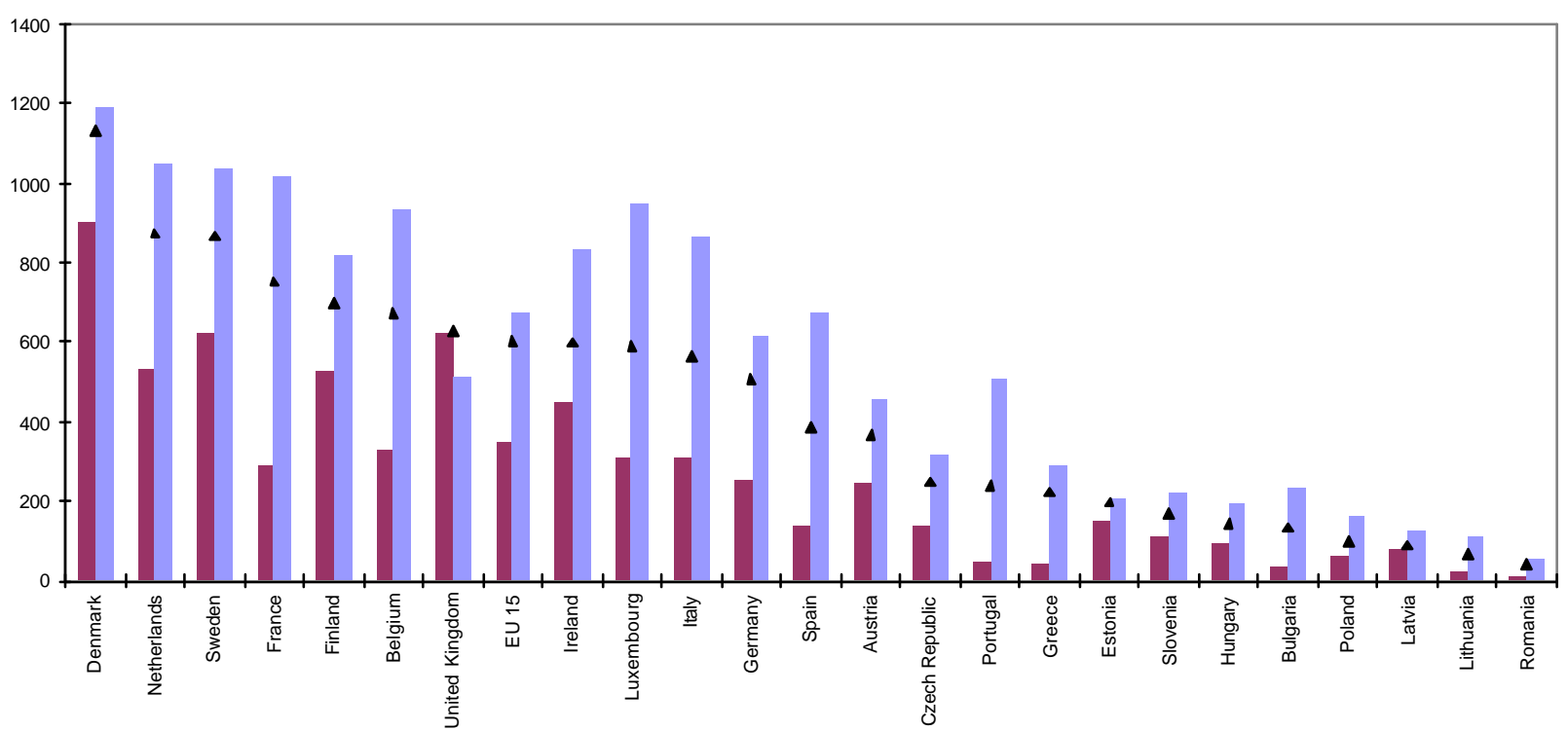


Chart 2.6 Training participation in innovative and non-innovative firms

Share of total wage and salary employees who receive employer-sponsored training ${ }^{a}$

Firms that introduced product or process innovations

Firms that did not introduce either product or process innovations

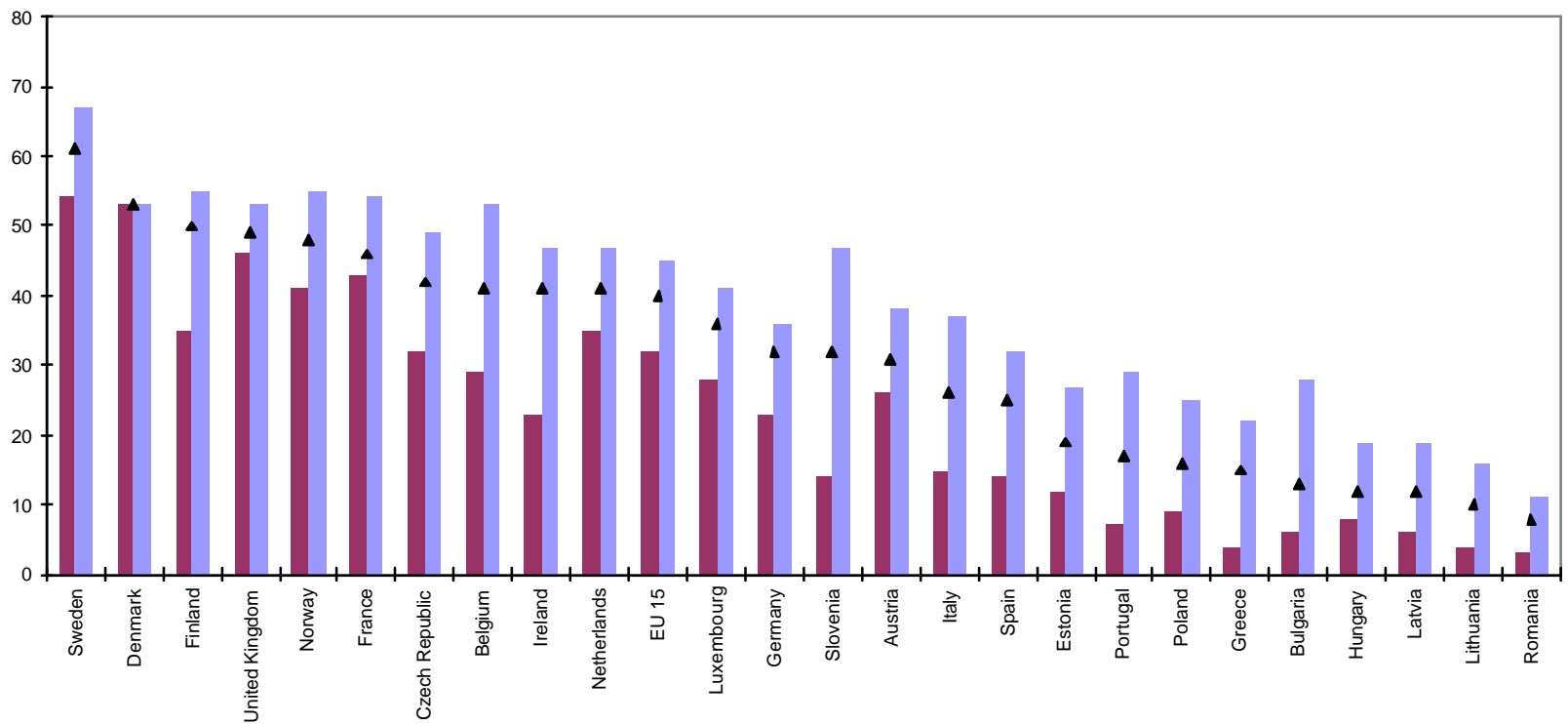

\subsection{Training differences across employees}

In the previous sections we have treated employees as if they had the same probability of receiving training. By contrast, in this section, we look at the distribution of training among employees with different observable characteristics. In order to do so in a synthetic way we estimate a simple reduced form model of the probability of training as a function of different individual, job and firm characteristics on the basis of ECHP data from 1995 to 2001 (see Appendix 2A for details on the selection of the sample).

We characterize the empirical relationship between training and individual characteristics with the following probit specification

$$
\operatorname{Prob}\left\{T_{i t}=1\right\}=\Phi\left(\alpha_{c}+\alpha_{c t}+X_{i t} \beta\right)
$$

where $\mathrm{T}$ is the training event over the reference period, $\alpha_{c}$ and $\alpha_{c t}$ are country and country by year effects (for years other than 1997, which is taken as reference), $X$ is a vector of time varying individual, job and firm characteristics, $i$ is 
the index for individuals, c for the country, $t$ for time, and $F$ is the cumulative normal distribution.

Since we pool all available observations over countries and time, we include country and country by time dummies to capture all time varying and countryspecific factors, such as those due to institutions (see Chapter 3) and nation-wide policies (see Chapter 5), which could affect both co-variates and training. These dummies also pick up differences in the interpretation of the training question, which could vary across countries because of language as well as broad cultural and social reasons. Country by year dummies also capture the variation of training over the business cycle.

A potential drawback of specification [2.2] is that the random error e could include an unobserved individual effect $f$. If this is the case, we can distinguish between two alternatives: (i) the individual effect is both independent of the regressors in [2.2] and normally distributed; (ii) independency or normal distribution or both fail to hold. As a first approximation, which seems suitable to simply describe the main patterns, we assume the former to be the case. ${ }^{45}$ Table $^{2}$ 2.3 presents estimation results for the probability both of taking any training and of receiving employer-sponsored training as a function of educational attainment, gender, tenure, marital status, age (divided in four classes), public/private sector employment, part time/full time status, type of contract (fixed term, casual job and other, with permanent job as the reference), country, industry, firm size and occupation. All time-varying variables are lagged. The table reports average partial effects, that is the deviations in the participation to training from the reference individual (indicated in the table). Percentage point effects can be obtained by multiplying reported figures by 100 .

Results presented in Table 2.3 show that training increases with education and skill-intensity of occupations, while it decreases with age. ${ }^{46}$ All these results are

\footnotetext{
45 Any parametric alternative to the pooled probit model remains somewhat arbitrary. First, there is no strong justification for a specific distributional form. Second, the individual effect might not be time-invariant (due for instance to unobserved firm characteristics that change from match to match - e.g. innovative firms are more training intensive than non-innovative firms). Finally, parameters might be heterogeneous across several dimensions (see for instance below) and a fully-specified model might require several interactions. For these reasons, we prefer to stick with the simplest model in this descriptive exercise. The probit model applied to pooled data does not estimate partial effects but average partial effects, obtained by averaging partial effects across the distribution of the unobserved individual effect in the population (see Wooldridge, 2002). If we are interested in estimating the partial effects of a regressor on the probability of training at $f=0$, then the pooled probit does not do the job. However, if we are happy with the average partial effect with respect to the distribution of $f$, as it is usually the case, the pooled probit does the job.
}

\footnotetext{
${ }^{46}$ As regards tenure, we find a U-shaped curve: training is greater at low tenure and at high tenure, consistent both
} with the view that initial training is often required at hiring to adapt workers' competences to the specificity of 
quite recurrent in the literature (see Asplund, 2004, for a recent survey). Consistent with recent evidence (see e.g. Wooden and van den Heuvel, 1997, and Arulampalam et al., 2004), we find that women have, ceteris paribus, a greater probability of taking training than men, although the differences associated with gender are small (0.6 percentage points). The same occurs for workers in the public sector. However, their advantage with respect to small-firm workers (6.8 percentage points) is no larger than the advantage enjoyed by workers in firms with more than 500 employees (7.7 percentage points). Conversely, as usually found in the literature (see OECD, 2002), part-time and temporary workers typically take training less often.

Even controlling for this relatively large set of characteristics, cross-country variation remains large: a Danish employee has still a 20 percentage point greater probability of taking training than a Portuguese. The estimated range of variation among country effects is far greater than that estimated for educational levels ( 7.6 percentage points), age classes (6.2), firm size classes (7.7), occupations (13) and industries (12.4). Indeed, the analysis of variance reveals that country effects alone explain 45.9 per cent of the fraction of total variance explained by our covariates. ${ }^{47}$ Yet, residual (unexplained) variance remains large. Part of this is due to the persistence of training participation: the analysis of variance reveals that simply including a dummy for training participation in the previous year as an additional regressor raises by up to 28 per cent the fraction of the variance explained by the model.

The comparison of estimates for total and employer-sponsored training is instructive in many respects. When we focus on employer-sponsored training only, the advantage of women disappears. Tenure is a far less important factor. To some extent the same applies to differences by age and education. Conversely, firm size, type of contract and marital status are far more important factors in the case of employer-sponsored training. These patterns suggest that differences across individuals are not homogenous with respect to the source of financing and that certain gaps are concentrated in one form of financing. For instance, it is evident from the estimates reported in Table 2.3 that women are ready to pay for their own training more often than men but firms are not ready to train them more often.

\footnotetext{
their new job (see e.g. Barron et al. 1999) and with the observation that further training is usually delayed (Loewenstein and Spletzer, 1997). However, tenure is likely to be endogenous and we must be cautious in interpreting these results.

${ }^{47}$ The analysis of variance has been performed on a linear-probability version of model [2.2]. Complete results are available from the authors upon request.
} 
In other words, women's demand in the downstream training market ${ }^{48}$ looks greater than that for men but this is not the case for the employers' supply they face. By contrast, this is not the case for older and low educated workers, whose poor training rates seem at least equally due to demand and supply factors. Similar patterns are found by Oosterbeek (1998), Leuven and Oosterbeek (1999) and OECD (2003) in IALS data.

To explore this issue further, we estimate several tentative models ${ }^{49}$ of the probability of taking non-sponsored training. Results are reported in the Appendix. To start, we replicate the probit model [2.2] by substituting non-sponsored for total or employer-sponsored training (Table A2.8, Panel A, first column). However, given that those receiving employer-sponsored training are not a negligible subset of the sample, selection problems are likely to be important for the non-sponsored training equation. For this reason, we estimate also two alternative models that simultaneously consider the probability of employer-sponsored and non-sponsored training. In one of them, we take explicitly into account that employer-sponsored and non-sponsored training are mutually exclusive categories by design ${ }^{50}$ and estimate a trinomial logit model, with no training as base category (Table A2.8, Panel B). Next, we assume that decisions about training financing are taken sequentially: first, the employer decides whether or not to pay for training and then, in the case he does not, the employee chooses whether or not to pay for her training.

Under this hypothesis, non-sponsored training can obviously be observed only for those individuals for whom their employer have decided not to pay. With the same distributional assumptions as in [2.2], we can estimate this model as a bivariate probit with censoring (Table A2.8, Panel A, second and third column). ${ }^{51}$

\footnotetext{
48 The market for training can be broken into two sub-markets (see Stevens, 1994, 1999): upstream, employers buy training services from a training provider; downstream employers re-sell these training services to their employees, with the price for training hidden in wages. The price of the latter transaction might be even zero when the employer bears all the cost. In the case of internal training, training provider and employer are the same institution; in such a case the price of the upstream transaction is not observable and even ill-defined. Conversely, in the downstream market, one can in principle distinguish between a well-defined supply (by the employer) and demand (by its employees). Training outcomes then can be considered as the result of the reaction of supply and demand to market and institutional incentives.

${ }^{49}$ Care must be taken in interpreting the estimates: due to the small incidence of non-sponsored training (see Table A2.2), they are likely to be very imprecise.

${ }^{50}$ The source of financing is reported only for the last course taken in the ECHP, cf. the Appendix.

${ }^{51}$ The log likelihood of this model for the couple $T_{i}=\left(E_{i}, N_{i}\right)$, where $E$ and $N$ stands for employer-sponsored and non-sponsored training, respectively, can be written as follows:

$l=\sum_{E_{i}=1} \log \Phi\left(Z_{i t} \beta_{E}\right)+\sum_{T_{i}=(0,1)} \log \Phi_{2}\left(-Z_{i t} \beta_{E}, Z_{i t} \beta_{N}, \rho\right)+\sum_{T_{i}=(0,0)} \log \Phi_{2}\left(-Z_{i t} \beta_{E},-Z_{i t} \beta_{N},-\rho\right)$

where $\mathrm{Z}$ stands for the vector of covariates (including countryXtime dummies), $\Phi_{2}$ stands for the cumulative distribution of the bivariate normal and $\mathrm{E}$ and $\mathrm{N}$ are indexes whose interpretation is trivial.
} 
The importance of the selection issue can be seen by looking at the estimated coefficients for firm size. In the probit model without selection, non-sponsored training is estimated to decrease with firm size, pointing to the fact that, on average, employees of small firms tend to pay for their own training more often than what employees in large firms do. In the logit model, this pattern is already more ambiguous, while in the bivariate probit model it disappears completely. These results suggest that workers in small firms do not have a greater propensity to pay for their training. They pay more often only to compensate for the lack of employer support. In other words, they have the same demand for training as workers in large firms but they are in short supply. Results from Table A2.8 do confirm that women have a greater demand for training, perhaps due to training needs at re-entry points in the labour market after career interruptions.

Not surprisingly, part time and temporary workers have the same demand as full time and permanent workers, since these workers might regard their status as temporary and seek to acquire new competences to qualify for better jobs. By contrast, married workers, despite receiving more employer-sponsored training, appear to have a smaller demand than their unmarried peers, possibly because of liquidity constraints due to family responsibilities.

Finally, even taking selectivity into account, the estimated probability of taking non-sponsored training decreases with age and educational attainment as steeply as the estimated probability of receiving employer-sponsored training does, confirming that employers' discrimination is not, or at least not only, at the origin of downward sloped training-age profiles and upward sloped training-education profiles.

But do women, the educated and younger workers take also longer courses? Do training duration gaps look like training participation gaps? By and large yes, as shown by the results presented in Table A2.9 in the Appendix, obtained by estimating Gaussian interval regression models of training duration. ${ }^{52}$ The main exceptions are the following: i) older workers tend to take much shorter courses, when they participate, than their younger peers (workers aged more than 54 years take courses that are on average two weeks shorter than prime-age workers); and

\footnotetext{
52 The ECHP reports information on duration only by intervals (0-2 weeks, 2-9 weeks, and more than 9 weeks). Since cut-off points between classes are known, the Gaussian interval regression model becomes the natural generalisation to our data of the probit [2]. Its log likelihood can be written as follows:

$l=\sum_{T_{i}=0} \log \left(1-\Phi\left(Z_{i t} \beta / \sigma\right)\right)+\sum_{\substack{A<T_{i} \leq B \\(A, B] \in\{(0,2],(2,9)\}}} \log \left(\Phi\left(\left(B-Z_{i t} \beta\right) / \sigma\right)-\Phi\left(\left(A-Z_{i t} \beta\right) / \sigma\right)\right)+\sum_{T_{i}>9} \log \Phi\left(\left(Z_{i t} \beta-9\right) / \sigma\right)$

where $\mathrm{Z}$ stands for the vector of covariates (including countryXtime dummies) and $\sigma$ for the variance of the random disturbance.
} 
Table 2.4. Individual characteristics and training incidence. ECHP 1995-2001. Average partial effects

\begin{tabular}{|c|c|c|c|c|c|c|}
\hline \multirow[b]{2}{*}{ Upper secondary education } & \multicolumn{3}{|c|}{ All training } & \multicolumn{3}{|c|}{ Emp. spon. training } \\
\hline & -.021 & 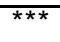 & $(.003)$ & -.011 & *** & $(.002)$ \\
\hline Less than upper secondary education & -.076 & $* * *$ & $(.003)$ & -.053 & *** & $(.003)$ \\
\hline Female & .006 & ** & $(.002)$ & .002 & & $(.002)$ \\
\hline Tenure & -.003 & $* \star \star$ & $(.001)$ & -.001 & ** & $(.001)$ \\
\hline Tenure squared & .000 & $* * *$ & $(.000)$ & .000 & ** & $(.000)$ \\
\hline Married & .004 & & $(.002)$ & .011 & *** & $(.002)$ \\
\hline Age 25-34 & .008 & $* * *$ & $(.003)$ & .007 & *** & $(.002)$ \\
\hline Age $45-54$ & -.022 & $* \star *$ & $(.002)$ & -.016 & $* \star *$ & $(.002)$ \\
\hline Age $55-64$ & -.054 & $* \star *$ & $(.003)$ & -.041 & *** & $(.002)$ \\
\hline Public sector & .068 & $* \star *$ & $(.004)$ & .068 & $* \star *$ & $(.004)$ \\
\hline Part time & -.025 & $* * *$ & $(.004)$ & -.027 & $* \star *$ & $(.003)$ \\
\hline Fixed term contract & -.024 & $* * *$ & $(.005)$ & -.034 & $* * *$ & $(.004)$ \\
\hline Casual job & -.057 & $* * *$ & $(.008)$ & -.063 & $* * *$ & $(.005)$ \\
\hline Other type of contract & -.026 & $* * *$ & $(.008)$ & -.021 & $* \star *$ & $(.007)$ \\
\hline Denmark & .064 & $* \star *$ & $(.012)$ & .031 & *** & $(.010)$ \\
\hline Netherlands & -.141 & $* \star *$ & $(.003)$ & -.119 & $* \star *$ & $(.002)$ \\
\hline Belgium & -.107 & $* * *$ & $(.004)$ & -.089 & *** & $(.003)$ \\
\hline France & -.118 & $* * *$ & $(.004)$ & -.095 & *** & $(.003)$ \\
\hline Ireland & -.119 & $* * *$ & $(.004)$ & -.096 & $* * *$ & $(.003)$ \\
\hline Italy & -.144 & $* * *$ & $(.004)$ & -.118 & *** & $(.003)$ \\
\hline Greece & -.146 & $* * *$ & (.003) & -.113 & $* * *$ & (.002) \\
\hline Spain & -.092 & $* * *$ & $(.006)$ & -.089 & $* * *$ & $(.004)$ \\
\hline Portugal & -.156 & $* * *$ & $(.004)$ & -.125 & $* * *$ & $(.003)$ \\
\hline Austria & -.074 & $* * *$ & $(.006)$ & -.072 & $* * *$ & $(.004)$ \\
\hline Finland & .010 & & $(.009)$ & -.003 & & $(.007)$ \\
\hline ISIC C+E & .024 & $* * *$ & (.009) & .036 & *** & $(.008)$ \\
\hline ISIC DA & -.028 & $* * *$ & $(.006)$ & -.014 & $* *$ & $(.006)$ \\
\hline ISIC DB+DC & -.069 & $* * *$ & $(.006)$ & -.054 & $* * *$ & $(.005)$ \\
\hline ISIC DD+DE & -.028 & $* \star \star$ & $(.006)$ & -.016 & $* * *$ & $(.006)$ \\
\hline ISIC DF-DI & -.005 & & $(.007)$ & .010 & & $(.006)$ \\
\hline ISIC DJ+DK & -.018 & $* \star *$ & $(.006)$ & -.007 & & $(.005)$ \\
\hline ISIC DL-DN & -.015 & $* * *$ & $(.006)$ & -.001 & & $(.005)$ \\
\hline ISIC F & -.050 & $* * *$ & $(.005)$ & -.031 & $* * *$ & $(.005)$ \\
\hline ISIC G & -.018 & $* * *$ & $(.005)$ & -.004 & & $(.004)$ \\
\hline ISIC H & -.049 & $* \star *$ & $(.006)$ & -.040 & $* * *$ & $(.005)$ \\
\hline ISIC I & -.015 & $* * *$ & $(.005)$ & -.002 & & $(.004)$ \\
\hline ISIC J & .055 & $* * *$ & $(.007)$ & .069 & $* * *$ & $(.007)$ \\
\hline ISIC K & .000 & & $(.005)$ & .011 & ** & $(.005)$ \\
\hline ISIC L & .004 & & $(.004)$ & .014 & *** & $(.004)$ \\
\hline ISIC M & .003 & & $(.004)$ & .007 & * & $(.004)$ \\
\hline ISIC O-Q & -.015 & *** & $(.005)$ & -.008 & & $(.005)$ \\
\hline Firm size: 50-99 employees & .033 & $* * *$ & $(.005)$ & .041 & *** & $(.005)$ \\
\hline Firm size: $100-499$ employees & .054 & $* \star *$ & $(.004)$ & .057 & *** & $(.004)$ \\
\hline Firm size: 500 or more employees & .077 & *** & $(.005)$ & .083 & *** & $(.005)$ \\
\hline Legislators, senior officials and managers & .063 & $* \star \star$ & $(.006)$ & .057 & *** & $(.006)$ \\
\hline Professionals & .056 & $* \star \star$ & $(.006)$ & .047 & *** & $(.005)$ \\
\hline Technicians and associate professionals & .057 & $* * *$ & $(.005)$ & .050 & $* * *$ & $(.004)$ \\
\hline Clerks & .016 & $* * *$ & $(.004)$ & .011 & *** & $(.004)$ \\
\hline Skilled agricultural and fishery workers & -.049 & *** & $(.014)$ & -.049 & *** & $(.012)$ \\
\hline Craft and related trades workers & -.033 & *** & $(.004)$ & -.026 & *** & $(.004)$ \\
\hline Plant and machine operators and assemble & -.038 & $* \star \star$ & $(.004)$ & -.032 & $* * *$ & $(.004)$ \\
\hline Elementary occupations & -.067 & $* \star *$ & $(.004)$ & -.056 & $* * *$ & $(.003)$ \\
\hline Pseudo R-squared & 0.2014 & & & 0.2133 & & \\
\hline Observations & 165188 & & & 163386 & & \\
\hline
\end{tabular}

Notes: Each regression includes a constant and countryXyear dummies. Country dummies shown above refer to 1997. Observations are weighted by ECHP longitudinal weights. The reference individual is a male full time single British employee aged 35-44 years with tertiary education, average tenure, tenure, working in 1997 under a permanent contract as a service workers or shop and market sales workers for a private firm with less than 50 employees in the health and social work industry. One, two and three stars for the coefficients statistically significant at the 10,5 and 1 percent level of confidence respectively. Heteroskedasticity consistent standard errors in parentheses. See Table A2.7 for the list of industries and industry codes. 
ii) parameter differences between the equation for total and employer-sponsored training are often larger. In particular, the correlation between country-effects for total and employer-sponsored training is extremely low (their Fisher and Spearman rank correlation coefficients are only 0.29 and 0.12 , respectively). Total training durations are longer in Denmark and Finland and shorter in Greece and Portugal. But the latter two countries move up to the third and fourth position, respectively, in the ranking of durations of employer-sponsored training, just after Denmark and Austria, while bottom performers are, in this case, Italy and Spain.

The models considered above assume that the effect of characteristics is invariant across gender, skill groups and age. The discussion of demand and supply patterns made above suggests that this might not be the case. For instance, if greater training participation for women is due to their demand at reentry points in the labour market, we can posit that this effect should show up especially among the elders. We look for differential effects by estimating separate regressions by gender, skill and age group (results are reported in Table A2.10 in the Appendix).

We define as high skilled labour those employees who in the year before the survey were classified as professionals, technicians and craft workers, and as low skilled labour the rest, except skilled agricultural and fishery workers that are difficult to classify and therefore excluded. Furthermore, we define as young individuals those aged between 25 and 40 and as old the rest. Only few estimated coefficients are heterogeneous across groups. Tenure effects are less important for men, for whom, by contrast, age plays a major role. Consistent with previous literature (e.g. Nestler and Kailis, 2002), women receive comparatively less training in certain medium/low-tech manufacturing industries (agro-food, textile, metal products, and machinery and equipment not elsewhere classified, such as household appliances and machine tools). Differences across occupations are larger in the case of women and older workers. Finally, consistent with our conjecture, women's advantage emerges only among the skilled and older workers. By contrast, young women - that is, women at ages when career interruptions are more frequent - get training comparatively less frequently than men. Interestingly, the latter pattern is essentially due to employer-sponsored training: ${ }^{53}$ on average, the probability of receiving employer-sponsored training is 1.5 percentage points smaller for young women than for their male peers.

\footnotetext{
${ }^{53}$ Not shown in the table but available from authors upon request.
} 
As done before as regards firm size, we are interested in seeing how training profiles by gender, age, education and type of contract vary across countries. We therefore re-estimate model [2.2] by country and find the following (cf. Table A2.11 in the Appendix):

- Training-education profiles are always downward-sloped, except in the Netherlands and Portugal.

- The penalty for standard fixed-term contracts that we observed in Table 2.3, seems to be driven by only four countries (Denmark, the United Kingdom, Austria and Finland), where the training gap between permanent and temporary workers is estimated to be above 4 percentage points. ${ }^{54}$ In all other countries the penalty, if any, is contained within 1 percentage point. ${ }^{55}$

- The relative position of women varies markedly across countries. In Anglo-Saxon countries, women take training, ceteris paribus, more frequently than men by 2.5 percentage points. In Greece, the opposite is true: being a woman in Greece reduce the probability of training by 0.8 percentage points. Large negative coefficients (below - 1 percentage points), although not significant, are also estimated in Austria and Belgium.

- Age-training profiles are downward sloped in all countries. However, the estimated training gap between younger and older workers is smaller than 3 percentage points in Italy, Greece and Portugal, while it is greater than 7 percentage points in Denmark, the UK, and Finland. One would be tempted to conclude that in the least training intensive countries age discrimination in the access to training is smaller. However, this conclusion would be unwarranted. If we rescale estimated gaps by the average training participation rate of each country (cf. Chart 2.7), we see that countries such as Italy and Greece appear to be far more unequal.

- The cross-country distribution of "re-scaled" age-training gaps correlates quite well with that of the employment rate of older workers (cf. Chart 2.7).$^{56}$ Of course a bivariate correlation is not a causal relationship and indeed this pattern can be explained in two opposite ways: i) training is a crucial determinant of the

\footnotetext{
${ }^{54}$ Estimates are however very imprecise, pointing to a great heterogeneity.

${ }^{55}$ However, the penalty for atypical contracts is often large.

${ }^{56}$ Employment rates are from the OECD Database on Labour Force Statistics.
} 
employability of older workers, that are therefore more prematurely expelled from employment in countries where they are trained comparatively less frequently; and ii) the expected age of retirement negatively affects the incentives of older workers to upgrade or maintain their skills through training. Our finding above that trainingage profiles are equally downward sloped in the case of both employer-sponsored and non-sponsored training, suggests that the second explanation might be valid, at least partially: we can make the conjecture that the greater the incentives to retire early the larger the age-training gap. Chapter 3 will look at this issue in a more systematic way.

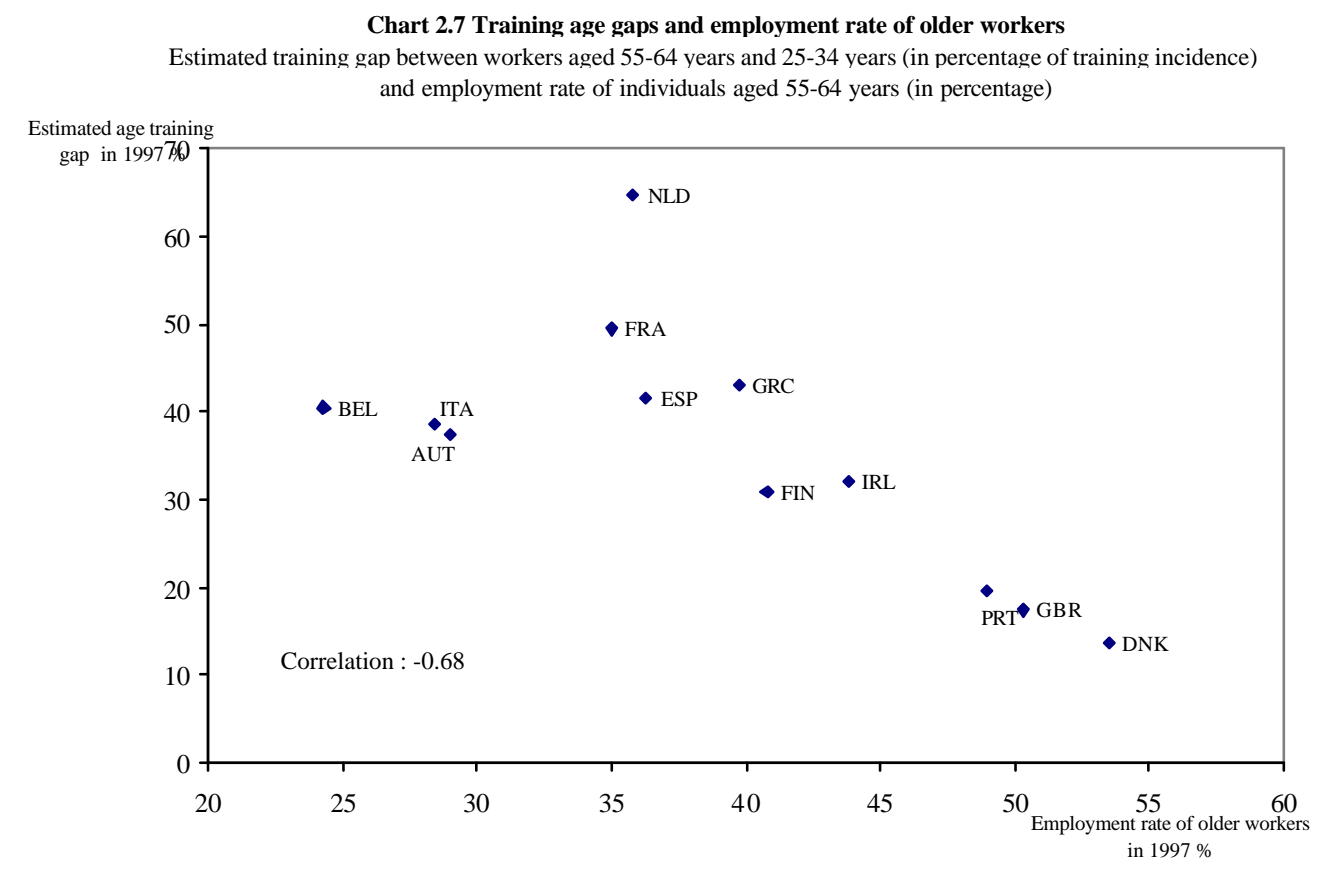

Source: $O E C D$ and own calculations on ECHP data.

Finally, as done before in the business cycle regressions, we check the robustness of our main estimates to using only odd years and eliminating the last three waves for the UK. In addition, in a separate exercise, we only retain individuals who are present in consecutive years, independently of whether these years are two - the minimum - or seven - the maximum. Overall coefficient estimates appear quite robust to these variations. ${ }^{57}$

\footnotetext{
${ }^{57}$ Results are available from authors upon request.
} 


\subsection{Summary}

We summarize the results of this descriptive analysis with the following points:

- Cross-country variation of training incidence and intensity in Europe is large, with Scandinavian countries training up to six times more than Eastern countries. Within-country regional variation is also large in countries that are not training intensive, and can be as large as the cross-country variation (in the case of Italy).

- At face value, employers appear to be the main actors in the training market. On average, the entire cost of $3 / 4$ of the training courses is directly paid by employers, and there is little evidence that employees indirectly pay through lower wages. Employers' training investments are not negligible and can be as high as $3 \%$ of total labour costs (in Denmark).

- Employers' investments in training exhibit a clear countercyclical pattern. A one percentage point change in the output gap is estimated to be associated with about a $4-8 \%$ change in participation in employer-sponsored training.

- Large and innovative firms train more than small and non-innovative firms, with the UK being the only European country where this does not hold. Cross-country variation among large and innovative firms is, however, small. Therefore, aggregate cross-country differences are essentially due to variation among small and non-innovative firms.

- Training in Europe increases with education and skill-intensity of occupations, while it decreases with age. The age-training gap is negatively correlated with the employment rate of older workers, reflecting either the impact of training on older workers' employability or the incentive of the expected retirement age.

- Women take more training than men, but essentially because they pay for their own training more often, while firms do not appear to accommodate their greater demand for training. Quite the contrary, women tend to receive less employer-sponsored training than men when they are young.

- Even when controlling for observable individual characteristics, country effects account for almost $1 / 2$ of the explained variation in training participation. In fact, differences associated with country of 
residence remain, ceteris paribus, larger than differences associated with industry, occupation, education, age and firm size. Other factors, thus, concur in explaining the difference across countries. In the next chapter, we will turn our attention to the role of labour and product market institutions. 


\section{Appendix 2.A}

\section{Description of the datasets}

\section{i) IALS}

The International Adult Literacy Survey (IALS) is an individual survey that was carried out by the OECD and Statistics Canada in the 1990s (see e.g. OECD and Statistics Canada, 2000). The survey asks whether the workers have received any training or education during the 12 months prior to the survey, but it includes details only about the three most recent courses (purpose, financing, training institution, duration, etc.). Data refer to 1994 for Canada, Ireland, the Netherlands, Poland, Switzerland (German and French-speaking regions), and the United States, to 1996 for Australia, Belgium (Flanders only), New Zealand and the United Kingdom and to 1998 for the Czech Republic, Denmark, Finland, Hungary, Italy, Norway and the Italian-speaking regions of Switzerland.

In the IALS, there is a distinction between job- or career-related training and training for other purposes. Furthermore, education and training courses are divided into seven mutually exclusive categories: i) leading to a university degree/diploma/certificate; ii) leading to a college diploma/certificate; iii) leading to a trade-vocational diploma/certificate; iv) leading to an apprenticeship certificate; v) leading to an elementary or secondary school diploma; vi) leading to professional or career upgrading; and vii) other. In this chapter, only job- or career-related training is considered. Moreover, in order to thoroughly exclude formal education courses, only items iv, vi, and vii are retained in the definition of vocational training courses, while items $\mathrm{i}$, ii, iii and $\mathrm{v}$ are subsumed into the category of formal education (used only in Table A2.4 below).

A limited set of demographic, job and firm characteristics is available in the IALS. However, most of these characteristics have been recorded at the date of the survey, thereby at or after the end of the reported training courses.

\section{ii) CVTS}

The second Continuing Vocational Training Survey (CVTS), is an enterprise survey covering establishments with at least ten employees. It was carried out by Eurostat in 2000 in EU Member states, Norway and nine EU candidate countries (Eurostat, 2000). It provides information on employer-sponsored training, which is taken during the year prior to the survey, for employed persons, excluding 
apprentices and trainees (this makes figures for countries with a dual education system - such as Austria and Germany - difficult to compare to other countries).

Training is defined as "courses which take place away from the place of work, i.e. in a classroom or training centre, at which a group of people receive instruction from teachers/tutors/lecturers for a period of time specified in advance by those organising the course."

The survey provides a large set of characteristics for the enterprises, but only gender, training participation and total training hours for the employee.

iii) OECD Aggregate data

OECD aggregate data are obtained by aggregating and merging CVTS and IALS data on both training participation rates and the log of training hours per employee (OECD, 2004). The merging methodology is as follows. First, the aggregate crosscountry distributions stemming from surveys were standardised to have zero mean and unit variance. Second, a cross-survey training index was constructed by taking, for each country, the cross-distribution unweighted average of the available standardised values. Third, final measures were reconstructed by multiplying the cross-survey index by the average of the standard errors of the original distributions and adding the average of their means.

Cross-country correlation rates of OECD aggregate data and the original CVTS or IALS measures are very high (greater than 0.95 in all cases). Moreover, regressing IALS or CVTS participation rates on OECD data without including a constant, the hypothesis that the coefficient of OECD data is not significantly different from 1 cannot be rejected at the 5\% level. This holds only at the $10 \%$ level in the case of hours.

iv) ECHP

All the regression analyses are based on the European Community Household Panel (ECHP), waves 2 to 8 (1995 to 2001). As discussed in detail by Bassanini and Brunello, 2003, and Arulampalam, Booth and Bryan, 2004, the ECHP is an attractive source of information because it covers a significant number of European countries with a commonly designed questionnaire.

The key question on training in the survey is: "Have you at any time since J anuary in the previous year been in vocational education or training, including any part-time or short-courses?". While this question is informative on training incidence, it is silent on the duration of training spells as well as their source of financing. 
The duration of the last training spell is reported in classes (less than 2 weeks, 2-9 weeks, more than 9 weeks). Unfortunately, the information on the duration of training in the ECHP is completely missing for the Netherlands and Sweden, and largely missing for the UK. Therefore, we exclude these countries in the whole analysis of duration.

In a separate question, the respondent is asked whether the last training spell was paid or provided by the employer. This information is, however, not available for Sweden. For comparability with the previous empirical literature, we select our sample as in Arulampalam, Booth and Bryan, 2004. In particular, we only consider individuals (i) aged between 25 and 64 years and working at least 15 hours per week; (ii) not employed in agriculture; (iii) present in at least two consecutive waves; (iv) not in apprenticeships or in special employment training schemes.

Since the reference period of each wave may overlap with the period of the previous wave, we run the risk of double counting training spells. We could try to solve this problem by using the starting dates of any training spell, but this information has a lot of missing values in the data, and is available only for some of the countries in the sample. Rather than losing information or adjusting counts in an ad-hoc way, we prefer to ignore double counting in the main regressions and to perform a robustness check which compares our results with those obtained from a reduced sample which only retains odd years, and therefore avoids double counting by definition.

There is also the problem of omitted spells, which appears to be particularly serious in Germany. German data in the ECHP are derived from GSOEP and exclude many shorter training spells. We follow, therefore, Arulampalam, Booth and Bryan, 2004, and drop this country from the whole analysis. Finally, in the case of Sweden, no longitudinal information is available for Sweden, which will be therefore omitted in all analyses requiring lagged variables at the individual level. 


\section{Additional Tables}

Table A2.1. Training participation rates by source of financing in the ECHP

\begin{tabular}{l|lll}
\hline Country & Total training & $\begin{array}{l}\text { Employer-sponsored } \\
\text { Training }\end{array}$ & Ratio \\
\hline Austria & 25.33 & 20.78 & 82.05 \\
Belgium & 18.76 & 15.23 & 81.14 \\
Denmark & 53.21 & 48.55 & 91.25 \\
Finland & 43.50 & 39.20 & 90.12 \\
France & 15.56 & 14.20 & 91.30 \\
Greece & 6.96 & 6.14 & 88.14 \\
Ireland & 13.72 & 11.30 & 82.35 \\
Italy & 8.79 & 7.31 & 83.13 \\
Netherlands & 11.75 & 7.63 & 64.93 \\
Portugal & 5.11 & 4.10 & 80.34 \\
Spain & 19.98 & 14.09 & 70.53 \\
UK & 39.67 & 39.40 & 99.33 \\
\hline Average & 23.97 & 17.25 & 71.97 \\
\hline Notes: All figures are in percentages and refer to 1997. Ratio $=$ Emp.-sponsored training/Total training. Source: ECHP
\end{tabular}

Table A2.2. Percentage of employers-sponsored training courses that are entirely paid by employers, selected OECD countries (IALS sample)

\begin{tabular}{l|l}
\hline Country & Emp-sponsored voc. training \\
\hline Australia & 96.3 \\
Belgium (Flanders) & 93.2 \\
Canada & 89.4 \\
Czech Republic & 96.0 \\
Denmark & 97.8 \\
Finland & 85.4 \\
Hungary & 98.3 \\
Ireland & 93.5 \\
Italy & 91.8 \\
Netherlands & n.a. \\
New Zealand & 92.2 \\
Norway & 89.8 \\
Poland & 96.5 \\
Switzerland & 86.9 \\
United Kingdom & 99.0 \\
United States & 94.3 \\
\hline Notes: See Chart 2.4 for the year. n.a. = not available. Source: IALS.
\end{tabular}


Table A2.3. Hours of training per participant and source of financing, selected OECD countries (IALS sample)

\begin{tabular}{|c|c|c|c|c|}
\hline Country & $\begin{array}{l}\text { Emp.-sponsored } \\
\text { training }\end{array}$ & $\begin{array}{l}\text { Emp-sponsored } \\
\text { education }\end{array}$ & $\begin{array}{l}\text { Non sponsored } \\
\text { training }\end{array}$ & $\begin{array}{l}\text { Non sponsored } \\
\text { education }\end{array}$ \\
\hline Australia & 63.2 & 134.1 & 110.8 & 245.5 \\
\hline Belgium (Flanders) & 73.5 & 23.2 & 102.0 & 289.3 \\
\hline Canada & 61.4 & 125.8 & 153.4 & 411.8 \\
\hline Czech Republic & 83.8 & 92.9 & 115.8 & 206.2 \\
\hline Denmark & 81.3 & 273.6 & 192.2 & 487.1 \\
\hline Finland & 54.2 & 120.8 & 246.4 & 546.6 \\
\hline Hungary & 95.2 & 118.9 & 177.7 & 271.7 \\
\hline Ireland & 85.1 & 298.3 & 179.0 & 420.8 \\
\hline Italy & 55.3 & 29.7 & 94.4 & 356.2 \\
\hline Netherlands & 88.9 & 249.6 & 166.2 & 258.8 \\
\hline New Zealand & 68.8 & 180.8 & 183.2 & 381.3 \\
\hline Norway & 77.9 & 229.4 & 226.8 & 655.2 \\
\hline Poland & 75.0 & 121.1 & 115.8 & 304.7 \\
\hline Switzerland & 60.9 & 116.1 & 83.6 & 256.1 \\
\hline United Kingdom & 50.0 & 223.4 & 131.4 & 288.8 \\
\hline United States & 56.0 & 104.7 & 92.2 & 299.3 \\
\hline
\end{tabular}

Notes: See Chart 2.4. Source: IALS.

Table A2.4. Ratio of employer-sponsored training to total training in the ECHP, by course duration

\begin{tabular}{l|lll}
\hline Country & $0-2$ weeeks & $2-9$ weeks & $>9$ weeks \\
\hline Austria & 94.40 & 83.44 & 59.34 \\
Belgium & 94.69 & 82.52 & 51.08 \\
Denmark & 93.93 & 92.00 & 78.88 \\
Finland & 97.15 & 93.29 & 60.74 \\
France & 94.87 & 92.35 & 77.55 \\
Greece & 94.63 & 96.05 & 64.90 \\
Ireland & 95.78 & 88.38 & 72.21 \\
Italy & 91.52 & 82.99 & 62.74 \\
Portugal & 94.87 & 76.76 & 66.38 \\
Spain & 88.27 & 88.06 & 48.96 \\
\hline
\end{tabular}

Notes: Data refer to 1997. Source: ECHP. 
Table A2.5. Variation of training over the business cycle, odd years only.

Panel A: Total training

\begin{tabular}{|c|c|c|c|c|c|c|}
\hline & (1) & (2) & (3) & (4) & (5) & (6) \\
\hline Output gap & $\begin{array}{l}-0.036 \\
(0.024)\end{array}$ & $\begin{array}{l}-0.055 \\
(0.050)\end{array}$ & $\begin{array}{r}-0.095^{*} \\
(0.046)\end{array}$ & & & \\
\hline $\begin{array}{l}\text { Unemployment } \\
\text { rate }\end{array}$ & & & & $\begin{array}{c}0.051 * * * \\
(0.012) \\
\end{array}$ & $\begin{array}{c}0.062 * * \\
(0.025) \\
\end{array}$ & $\begin{array}{l}0.069 * * \\
(0.027) \\
\end{array}$ \\
\hline Country dummies & yes & yes & yes & yes & yes & yes \\
\hline $\begin{array}{l}\text { Country-specific } \\
\text { trends }\end{array}$ & no & yes & yes & no & yes & yes \\
\hline Time dummies & no & no & yes & no & no & yes \\
\hline $\begin{array}{l}\text { Number of } \\
\text { observations } \\
\text { R-squared }\end{array}$ & $\begin{array}{c}50 \\
0.96\end{array}$ & $\begin{array}{c}50 \\
0.98\end{array}$ & $\begin{array}{c}50 \\
0.99\end{array}$ & $\begin{array}{c}50 \\
0.97\end{array}$ & $\begin{array}{c}50 \\
0.98\end{array}$ & $\begin{array}{c}50 \\
0.99\end{array}$ \\
\hline
\end{tabular}

Panel B: Employer-sponsored training

\begin{tabular}{|c|c|c|c|c|c|c|}
\hline & (7) & (8) & (9) & (10) & (11) & (12) \\
\hline Output gap & $\begin{array}{l}-0.056^{*} \\
(0.030)\end{array}$ & $\begin{array}{l}-0.087 \\
(0.060)\end{array}$ & $\begin{array}{l}-0.107 * \\
(0.056)\end{array}$ & & & \\
\hline $\begin{array}{l}\text { Unemployment } \\
\text { rate }\end{array}$ & & & & $\begin{array}{c}0.063 * * * \\
(0.016)\end{array}$ & $\begin{array}{c}0.082 * * * \\
(0.030)\end{array}$ & $\begin{array}{l}0.086 * * \\
(0.036)\end{array}$ \\
\hline Country dummies & yes & yes & yes & yes & yes & yes \\
\hline $\begin{array}{l}\text { Country-specific } \\
\text { trends }\end{array}$ & no & yes & yes & no & yes & yes \\
\hline Time dummies & no & no & yes & no & no & yes \\
\hline $\begin{array}{l}\text { Number } \\
\text { observations } \\
\text { R-squared }\end{array}$ & $\begin{array}{c}47 \\
0.93\end{array}$ & $\begin{array}{c}47 \\
0.97\end{array}$ & $\begin{array}{c}47 \\
0.98\end{array}$ & $\begin{array}{c}47 \\
0.93\end{array}$ & $\begin{array}{c}47 \\
0.97\end{array}$ & $\begin{array}{c}47 \\
0.98\end{array}$ \\
\hline
\end{tabular}

Note: OLS with log-linear specifications. Robust standard errors in parentheses. ***,**, *: significant at the $1 \%, 5 \%$ and $10 \%$ level of confidence, respectively. 
Table A2.6. Share of total wage and salary employees who receive employer-sponsored training in innovative and non-innovative firms, by firm size. European countries

\begin{tabular}{|c|c|c|c|c|}
\hline \multirow[b]{2}{*}{ Country } & \multicolumn{2}{|l|}{ 10-49 employees } & \multicolumn{2}{|c|}{250 and more employees } \\
\hline & Non-innovative firr & Innovative firms & Non-innovative firr & Innovative firms \\
\hline Austria & 25 & 40 & 29 & 40 \\
\hline Belgium & 16 & 32 & 49 & 63 \\
\hline Bulgaria & 2 & 18 & 10 & 33 \\
\hline Czech Republic & 20 & 32 & 45 & 55 \\
\hline Germany & 18 & 36 & 30 & 36 \\
\hline Denmark & 48 & 46 & 56 & 54 \\
\hline Estonia & 9 & 19 & 13 & 34 \\
\hline Spain & 6 & 14 & 31 & 45 \\
\hline Finland & 32 & 47 & 46 & 58 \\
\hline France & 22 & 29 & 57 & 62 \\
\hline Greece & 1 & 7 & 5 & 29 \\
\hline Hungary & 5 & 12 & 13 & 23 \\
\hline Ireland & 18 & 33 & 50 & 58 \\
\hline Italy & 7 & 18 & 33 & 49 \\
\hline Lithuania & 3 & 9 & 8 & 20 \\
\hline Luxembourg & 15 & 28 & 52 & 48 \\
\hline Latvia & 5 & 15 & 10 & 22 \\
\hline Netherlands & 34 & 43 & 33 & 47 \\
\hline Norway & 39 & 52 & 45 & 56 \\
\hline Poland & 5 & 17 & 16 & 32 \\
\hline Portugal & 2 & 10 & 20 & 40 \\
\hline Romania & 1 & 3 & 5 & 14 \\
\hline Sweden & 46 & 60 & 61 & 71 \\
\hline Slovenia & 9 & 23 & 24 & 56 \\
\hline United Kingdom & 41 & 48 & 47 & 53 \\
\hline
\end{tabular}

Notes: Data refer to training taken and innovation introduced in 1999. Innovative firms are defined as those

that introduced new products or processes. Initial training is excluded. Source: CVTS.

Table A2.7 List of industries used in the regressions

\begin{tabular}{ll}
\hline ISIC Rev.3 Codes & Industry definition \\
\hline C+E & Mining and quarrying + Electricity, gas and water supply \\
DA & Manufacture of food products, beverages and tobacco \\
DB+DC & Manufacture of textiles, clothing and leather products \\
DD+DE & Manufacture off wood and paper products; publishing and printing \\
DF-DI & Manufacture of coke, refined petroleum/chemicals/rubber \& plastic products \\
DJ+DK & Manufacture of metal products, machinery and equipment n.e.c. \\
DL-DN & Other manufacturing \\
F & Construction \\
$\mathrm{G}$ & Wholesale and retail trade; repair of motor vehicles, motorcycles \\
$\mathrm{H}$ & personal/household goods \\
$\mathrm{I}$ & Hotels and restaurants \\
$\mathrm{J}$ & Transport, storage and communication \\
$\mathrm{K}$ & Financial intermediation \\
$\mathrm{L}$ & Real estate, renting and business activities \\
$\mathrm{M}$ & Public administration and defense; compulsory social security \\
$\mathrm{N}$ & Education \\
$\mathrm{O}-\mathrm{Q}$ & Health and social work \\
& Other community, social and personal service activities; private households \\
\hline
\end{tabular}


Table A2.8 Individual characteristics and training. Alternative models for sponsored and nonsponsored training.

Panel A: Probits for non-sponsored training with and without selection

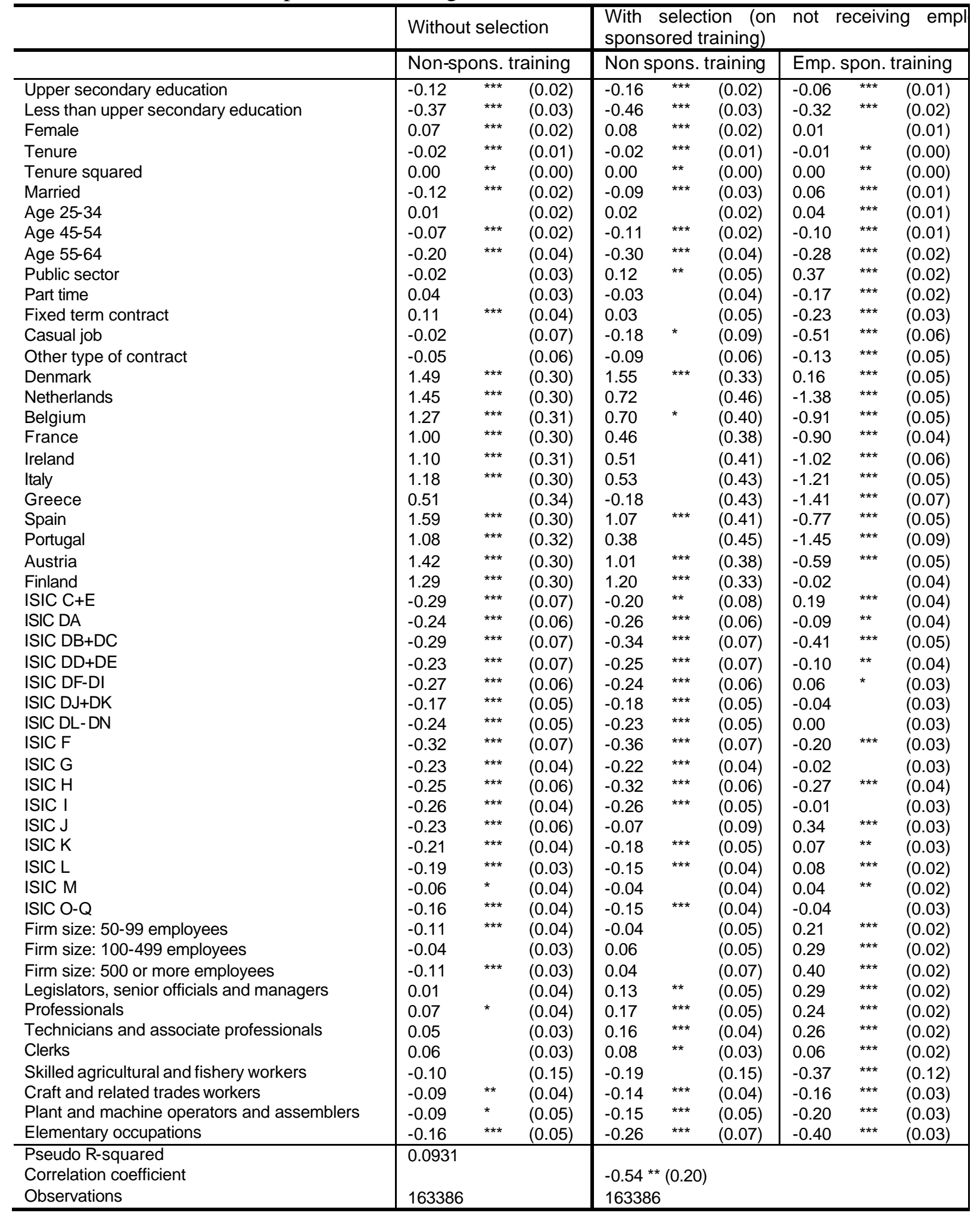


Table A2.8 Individual characteristics and training. Alternative models for sponsored and nonsponsored training (cont.)

Panel B: Multinomial logit

\begin{tabular}{|c|c|c|c|c|c|c|}
\hline \multirow{2}{*}{ Upper secondary education } & \multicolumn{3}{|c|}{ Non-spons. training } & \multicolumn{3}{|c|}{ Emp. spon. training } \\
\hline & -0.31 & $* * *$ & $(0.06)$ & -0.11 & 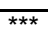 & $(0.03)$ \\
\hline Less than upper secondary education & -0.93 & *** & $(0.07)$ & -0.63 & *** & $(0.03)$ \\
\hline Female & 0.17 & *** & $(0.05)$ & 0.04 & & $(0.02)$ \\
\hline Tenure & -0.05 & $* * *$ & $(0.01)$ & -0.02 & *** & $(0.01)$ \\
\hline Tenure squared & 0.00 & ** & $(0.00)$ & 0.00 & 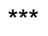 & $(0.00)$ \\
\hline Married & -0.26 & $\star \star \star *$ & $(0.04)$ & 0.10 & *** & $(0.02)$ \\
\hline Age $25-34$ & 0.01 & & $(0.05)$ & 0.06 & ** & $(0.03)$ \\
\hline Age $45-54$ & -0.19 & $* * *$ & $(0.05)$ & -0.18 & *** & $(0.02)$ \\
\hline Age 55-64 & -0.56 & *** & $(0.09)$ & -0.50 & *** & $(0.04)$ \\
\hline Public sector & 0.09 & & $(0.07)$ & 0.68 & *** & $(0.04)$ \\
\hline Part time & 0.03 & & $(0.07)$ & -0.31 & 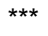 & $(0.04)$ \\
\hline Fixed term contract & 0.18 & ** & $(0.08)$ & -0.41 & *** & $(0.05)$ \\
\hline Casual job & -0.18 & & $(0.18)$ & -0.97 & 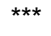 & $(0.13)$ \\
\hline Other type of contract & -0.15 & & $(0.14)$ & -0.29 & $\star \star \star *$ & $(0.09)$ \\
\hline Denmark & 4.30 & $* * *$ & (1.01) & 0.36 & $* * *$ & $(0.08)$ \\
\hline Netherlands & 3.43 & *** & $(1.01)$ & -2.46 & *** & $(0.10)$ \\
\hline Belgium & 3.16 & $\star \star \star *$ & (1.02) & -1.54 & $* * *$ & $(0.10)$ \\
\hline France & 2.49 & ** & $(1.02)$ & -1.55 & 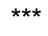 & $(0.08)$ \\
\hline Ireland & 2.71 & $\star * *$ & $(1.03)$ & -1.78 & $\star * \star *$ & $(0.11)$ \\
\hline Italy & 2.87 & *** & (1.02) & -2.10 & $* \star *$ & $(0.09)$ \\
\hline Greece & 1.10 & & (1.11) & -2.52 & $* * *$ & $(0.13)$ \\
\hline Spain & 3.94 & $\star \star * *$ & $(1.01)$ & -1.24 & 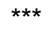 & $(0.09)$ \\
\hline Portugal & 2.58 & ** & $(1.05)$ & -2.60 & $* * *$ & $(0.18)$ \\
\hline Austria & 3.64 & 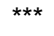 & (1.01) & -0.92 & *** & $(0.08)$ \\
\hline Finland & 3.66 & *** & (1.01) & 0.01 & & $(0.07)$ \\
\hline ISIC C+E & -0.61 & $* * *$ & $(0.18)$ & 0.34 & $* * *$ & $(0.07)$ \\
\hline ISIC DA & -0.55 & *** & $(0.15)$ & -0.18 & ** & $(0.07)$ \\
\hline ISIC DB+DC & -0.68 & *** & $(0.18)$ & -0.86 & *** & $(0.11)$ \\
\hline ISIC DD+DE & -0.54 & $\star \star \star *$ & $(0.17)$ & -0.18 & $\star \star \star *$ & $(0.07)$ \\
\hline ISIC DF-DI & -0.58 & $* * *$ & $(0.14)$ & 0.08 & & $(0.06)$ \\
\hline ISIC DJ+DK & -0.40 & $* * *$ & $(0.12)$ & -0.11 & * & $(0.06)$ \\
\hline ISIC DL-DN & -0.55 & $\star \star \star *$ & $(0.12)$ & -0.04 & & $(0.06)$ \\
\hline ISIC F & -0.77 & $* * *$ & $(0.16)$ & -0.42 & $* * *$ & $(0.07)$ \\
\hline ISIC G & -0.51 & *** & $(0.09)$ & -0.07 & & $(0.05)$ \\
\hline ISIC H & -0.61 & $\star \star \star *$ & $(0.14)$ & -0.57 & *** & $(0.09)$ \\
\hline ISIC I & -0.60 & $* * *$ & $(0.10)$ & -0.05 & & $(0.05)$ \\
\hline ISIC J & -0.36 & ** & $(0.15)$ & 0.57 & *** & $(0.05)$ \\
\hline ISIC K & -0.44 & $* * *$ & $(0.10)$ & 0.09 & * & $(0.05)$ \\
\hline ISIC L & -0.41 & $\star * \star$ & $(0.08)$ & 0.12 & *** & $(0.04)$ \\
\hline ISIC M & -0.13 & & $(0.08)$ & 0.06 & * & $(0.04)$ \\
\hline ISIC O-Q & -0.34 & *** & $(0.10)$ & -0.10 & * & $(0.05)$ \\
\hline Firm size: $50-99$ employees & -0.22 & ** & $(0.09)$ & 0.37 & *** & $(0.04)$ \\
\hline Firm size: $100-499$ employees & -0.01 & & $(0.08)$ & 0.53 & $* * *$ & $(0.03)$ \\
\hline Firm size: 500 or more employees & -0.14 & * & $(0.08)$ & 0.72 & 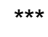 & $(0.03)$ \\
\hline Legislators, senior officials and managers & 0.11 & & $(0.10)$ & 0.52 & $* * *$ & $(0.05)$ \\
\hline Professionals & 0.23 & $* * *$ & $(0.09)$ & 0.46 & *** & $(0.04)$ \\
\hline Technicians and associate professionals & 0.21 & $* * *$ & $(0.08)$ & 0.48 & *** & $(0.04)$ \\
\hline Clerks & 0.14 & * & $(0.08)$ & 0.12 & $\star \star * \star$ & $(0.04)$ \\
\hline Skilled agricultural and fishery workers & -0.30 & & $(0.39)$ & -0.68 & *** & $(0.23)$ \\
\hline Craft and related trades workers & -0.28 & *** & $(0.10)$ & -0.32 & *** & $(0.05)$ \\
\hline Plant and machine operators and assemblers & -0.29 & *** & $(0.11)$ & -0.40 & *** & $(0.05)$ \\
\hline Elementary occupations & -0.47 & *** & $(0.12)$ & -0.78 & $* * *$ & $(0.06)$ \\
\hline $\begin{array}{l}\text { Pseudo R-squared } \\
\text { Observations }\end{array}$ & $\begin{array}{l}0.193 \\
16338\end{array}$ & & & & & \\
\hline
\end{tabular}

Notes: In the probit model with selection (bivariate probit with censoring), individuals are assumed to be observed paying for training only if they do not receive employer-sponsored training). Each regression includes a constant and countryXyear dummies. Country dummies shown above refer to 1997. Observations are weighted by ECHP longitudinal weights. The reference individual is a male full time unmarried British employee aged 35-44 years with tertiary education, average tenure, tenure, working in 1997 under a permanent contract as a service workers or shop and market sales workers for a private firm with less than 50 employees in the health and social work industry. One, two and three stars for the coefficients statistically significant at the 10, 5 and 1 percent level of confidence respectively. Heteroskedasticity consistent standard errors in parentheses. See Table A2.6 for the list of industries 
Table A2.9. Individual characteristics and training duration. ECHP 1995-2001. Interval regression models

\begin{tabular}{|c|c|c|c|c|c|c|}
\hline \multirow[b]{2}{*}{ Upper secondary education } & \multicolumn{3}{|c|}{ All training } & \multicolumn{3}{|c|}{ Emp. spon. training } \\
\hline & -0.37 & *** & $(0.11)$ & -0.20 & ** & $\overline{(0.09)}$ \\
\hline Less than upper secondary education & -2.43 & *** & $(0.15)$ & -1.70 & *** & $(0.12)$ \\
\hline Female & 0.27 & *** & $(0.09)$ & 0.11 & & $(0.08)$ \\
\hline Tenure & -0.08 & *** & $(0.03)$ & -0.01 & & $(0.02)$ \\
\hline Tenure squared & 0.00 & *** & $(0.00)$ & 0.00 & & $(0.00)$ \\
\hline Married & -0.04 & & $(0.09)$ & 0.32 & $\star * \star *$ & $(0.08)$ \\
\hline Age $25-34$ & 0.29 & *** & $(0.11)$ & 0.22 & $\star \star *$ & $(0.09)$ \\
\hline Age $45-54$ & -0.74 & *** & $(0.09)$ & -0.58 & *** & $(0.08)$ \\
\hline Age $55-64$ & -2.14 & *** & $(0.14)$ & -1.73 & $* * *$ & $(0.13)$ \\
\hline Public sector & 1.85 & *** & $(0.13)$ & 2.09 & $* * *$ & $(0.12)$ \\
\hline Part time & -0.50 & *** & $(0.16)$ & -0.72 & $* * *$ & $(0.15)$ \\
\hline Fixed term contract & -0.43 & ** & $(0.19)$ & -1.18 & $\star \star \star *$ & $(0.18)$ \\
\hline Casual job & -1.57 & *** & $(0.41)$ & -2.62 & *** & $(0.41)$ \\
\hline Other type of contract & -0.81 & $\star \star$ & $(0.34)$ & -0.77 & ** & $(0.32)$ \\
\hline Denmark & 0.99 & *** & $(0.25)$ & 5.20 & *** & $(0.31)$ \\
\hline Belgium & -4.43 & *** & $(0.34)$ & 0.16 & & $(0.31)$ \\
\hline France & -4.87 & *** & $(0.26)$ & -0.23 & & $(0.41)$ \\
\hline Ireland & -4.93 & *** & $(0.40)$ & -1.50 & $\star \star \star *$ & $(0.36)$ \\
\hline Italy & -6.34 & *** & $(0.33)$ & -2.67 & *** & $(0.44)$ \\
\hline Greece & -8.42 & *** & $(0.45)$ & 1.45 & $* * *$ & $(0.34)$ \\
\hline Spain & -2.16 & *** & $(0.30)$ & -2.83 & $* * *$ & $(0.56)$ \\
\hline Portugal & -7.73 & *** & $(0.56)$ & 1.55 & $* * *$ & $(0.33)$ \\
\hline Austria & -2.79 & $\star \star \star *$ & $(0.29)$ & 4.36 & $\star * \star *$ & $(0.30)$ \\
\hline ISIC C+E & 0.60 & $\star \star$ & $(0.27)$ & 0.89 & $* * *$ & $(0.24)$ \\
\hline ISIC DA & -0.84 & $* * *$ & $(0.28)$ & -0.41 & & $(0.26)$ \\
\hline ISIC DB+DC & -2.15 & *** & $(0.35)$ & -2.12 & $* \star *$ & $(0.34)$ \\
\hline ISIC DD+DE & -0.55 & * & $(0.30)$ & -0.30 & & $(0.26)$ \\
\hline ISIC DF-DI & 0.17 & & $(0.25)$ & 0.63 & $* * *$ & $(0.23)$ \\
\hline ISIC DJ+DK & 0.18 & & $(0.23)$ & 0.30 & & $(0.20)$ \\
\hline ISIC DL-DN & -0.01 & & $(0.22)$ & 0.26 & & $(0.20)$ \\
\hline ISIC F & -1.86 & $* \star *$ & $(0.30)$ & -1.39 & $* * *$ & $(0.24)$ \\
\hline ISIC G & -0.55 & *** & $(0.19)$ & -0.02 & & $(0.17)$ \\
\hline ISIC H & -1.80 & *** & $(0.32)$ & -1.63 & $\star \star \star *$ & $(0.30)$ \\
\hline ISIC I & -0.33 & * & $(0.18)$ & 0.09 & & $(0.16)$ \\
\hline ISIC J & 1.79 & $* * *$ & $(0.23)$ & 2.05 & $* * *$ & $(0.19)$ \\
\hline ISIC K & 0.17 & & $(0.20)$ & 0.33 & * & $(0.18)$ \\
\hline ISIC L & 0.27 & * & $(0.15)$ & 0.51 & $* * *$ & $(0.14)$ \\
\hline ISIC M & 0.47 & $\star \star \star *$ & $(0.16)$ & 0.61 & $* * *$ & $(0.14)$ \\
\hline ISIC O-Q & -0.12 & & $(0.21)$ & -0.01 & & $(0.19)$ \\
\hline Firm size: 50-99 employees & 0.93 & *** & $(0.17)$ & 1.31 & *** & $(0.16)$ \\
\hline Firm size: $100-499$ employees & 1.40 & *** & $(0.14)$ & 1.67 & *** & $(0.12)$ \\
\hline Firm size: 500 or more employees & 1.82 & *** & $(0.15)$ & 2.23 & $\star \star \star *$ & $(0.13)$ \\
\hline Legislators, senior officials and managers & 2.10 & *** & $(0.19)$ & 1.92 & *** & $(0.17)$ \\
\hline Professionals & 2.04 & *** & $(0.18)$ & 1.69 & $\star \star \star *$ & $(0.16)$ \\
\hline Technicians and associate professionals & 1.66 & *** & $(0.15)$ & 1.43 & $\star \star \star *$ & $(0.14)$ \\
\hline Clerks & 0.78 & *** & $(0.16)$ & 0.54 & *** & $(0.14)$ \\
\hline Skilled agricultural and fishery workers & -1.23 & * & $(0.72)$ & -1.83 & $* \star *$ & $(0.70)$ \\
\hline Craft and related trades workers & -1.14 & *** & $(0.19)$ & -0.97 & *** & $(0.17)$ \\
\hline Plant and machine operators and assemblers & -1.15 & *** & $(0.20)$ & -1.09 & *** & $(0.18)$ \\
\hline Elementary occupations & -2.27 & *** & $(0.23)$ & -2.19 & *** & $(0.20)$ \\
\hline Left-censored observations & 107734 & & & 11057 & & \\
\hline Right-censored observations & 4166 & & & 2690 & & \\
\hline Observations & 130565 & & & 13030 & & \\
\hline
\end{tabular}

Notes: The dependent variable is the number of weeks of training (or fraction of weeks). Each regression includes a constant and countryXyear dummies. Country dummies shown above refer to 1997. Observations are weighted by ECHP longitudinal weights. The reference individual is a male full time unmarried Finnish employee aged 35 44 years with tertiary education, average tenure, tenure, working in 1997 under a permanent contract as a service workers or shop and market sales workers for a private firm with less than 50 employees in the health and social work industry. One, two and three stars for the coefficients statistically significant at the 10, 5 and 1 percent level of confidence respectively. Heteroskedasticity consistent standard errors in parentheses. See Table A2.6 for the list of industries 
Table A2.10. Individual characteristics and training incidence. ECHP 1995-2001. Average partial effects, by gender, skill group and age.

\begin{tabular}{|c|c|c|c|c|c|c|c|c|c|c|c|c|c|c|c|c|c|c|}
\hline \multirow[b]{2}{*}{ Upper secondary education } & \multicolumn{3}{|c|}{ Males } & \multicolumn{3}{|c|}{ Females } & \multicolumn{3}{|c|}{ Skilled } & \multicolumn{3}{|c|}{ Unskilled } & \multicolumn{3}{|c|}{ Young } & \multicolumn{3}{|c|}{ Old } \\
\hline & -.023 & $* * \star$ & $(.004)$ & -.024 & $* * *$ & $(.004)$ & -.022 & 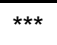 & $(.004)$ & -.023 & $* * *$ & $(.004)$ & -.029 & $* * *$ & $(.004)$ & -.014 & *** & $(.004)$ \\
\hline Less than upper secondary education & -.071 & *** & $(.004)$ & -.084 & *** & $(.005)$ & -.083 & *** & $(.005)$ & -.069 & *** & $(.004)$ & -.086 & 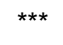 & $(.004)$ & -.065 & $\star \star \star *$ & $(.004)$ \\
\hline Female & & & & & & & .015 & 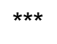 & $(.004)$ & -.002 & & $(.003)$ & -.012 & $\star \star \star *$ & $(.004)$ & .025 & $\star \star \star *$ & $(.003)$ \\
\hline Tenure & -.001 & & $(.001)$ & -.007 & *** & $(.001)$ & -.004 & $* * *$ & $(.001)$ & -.003 & $* \star *$ & $(.001)$ & -.004 & $\star \star \star *$ & $(.001)$ & -.002 & * & $(.001)$ \\
\hline Tenure squared & .000 & & $(.000)$ & .000 & $* * *$ & $(.000)$ & .000 & 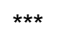 & $(.000)$ & .000 & $* *$ & $(.000)$ & .000 & $* * *$ & $(.000)$ & .000 & * & $(.000)$ \\
\hline Married & .014 & $* \star \star$ & $(.003)$ & -.004 & & $(.004)$ & -.001 & & $(.004)$ & .007 & $* *$ & $(.003)$ & .003 & & $(.003)$ & .011 & $\star \star \star$ & $(.003)$ \\
\hline Age $25-34$ & .023 & $* * *$ & $(.004)$ & -.008 & * & $(.004)$ & .010 & $* *$ & $(.005)$ & .006 & * & $(.003)$ & .003 & & $(.003)$ & & & \\
\hline Age $45-54$ & -.028 & $\star \star \star *$ & $(.003)$ & -.011 & $\star * *$ & $(.004)$ & -.019 & $\star \star \star *$ & $(.004)$ & -.023 & $* * *$ & $(.003)$ & & & & -.019 & $\star \star \star$ & $(.003)$ \\
\hline Age $55-64$ & -.058 & $* * *$ & $(.003)$ & -.044 & $* * *$ & $(.006)$ & -.058 & $* \star *$ & $(.005)$ & -.048 & $* * *$ & $(.003)$ & & & & -.052 & 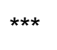 & (.003) \\
\hline Public sector & .070 & $* * *$ & $(.006)$ & .062 & $* * *$ & $(.006)$ & .074 & $* \star *$ & $(.006)$ & .060 & $* * *$ & $(.005)$ & .064 & $* \star *$ & $(.006)$ & .067 & $\star * *$ & (.005) \\
\hline Part time & -.008 & & $(.012)$ & -.029 & $* \star *$ & $(.005)$ & -.036 & $\star \star \star *$ & $(.006)$ & -.017 & $* \star \star$ & $(.004)$ & -.025 & $* \star \star$ & $(.006)$ & -.024 & $\star \star \star ~$ & $(.005)$ \\
\hline Fixed term contract & -.025 & $* * *$ & $(.006)$ & -.019 & ** & $(.007)$ & -.030 & $* * *$ & $(.007)$ & -.017 & $* * *$ & $(.005)$ & -.017 & $* * *$ & $(.006)$ & -.033 & $* * *$ & $(.007)$ \\
\hline Casual job & -.056 & $* * *$ & $(.009)$ & -.060 & $* * *$ & $(.013)$ & -.098 & $* \star \star$ & $(.013)$ & -.028 & $* * *$ & $(.008)$ & -.034 & $* *$ & $(.012)$ & -.079 & $\star \star *$ & $(.009)$ \\
\hline Other type of contract & -.018 & * & $(.010)$ & -.038 & $* * *$ & $(.012)$ & -.041 & $* \star *$ & $(.013)$ & -.013 & & $(.009)$ & -.033 & 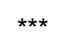 & $(.010)$ & -.027 & $* *$ & $(.012)$ \\
\hline Denmark & .087 & 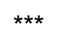 & $(.017)$ & .038 & $\star *$ & $(.019)$ & .102 & 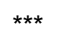 & $(.020)$ & .029 & $* *$ & $(.015)$ & .065 & $* \star \star$ & $(.019)$ & .059 & $\star \star \star$ & $(.016)$ \\
\hline Netherlands & -.127 & $* * *$ & $(.004)$ & -.158 & $* * *$ & $(.005)$ & -.198 & $* * *$ & $(.005)$ & -.086 & $* * *$ & $(.005)$ & -.128 & $* * *$ & $(.006)$ & -.149 & $* * *$ & $(.003)$ \\
\hline Belgium & -.087 & $* * *$ & $(.006)$ & -.133 & $* * *$ & $(.006)$ & -.143 & $* * *$ & $(.007)$ & -.074 & $* * *$ & $(.005)$ & -.105 & $* * *$ & $(.007)$ & -.105 & $* * *$ & $(.005)$ \\
\hline France & -.102 & $* * \star$ & $(.004)$ & -.140 & $* * *$ & $(.006)$ & -.154 & 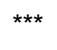 & $(.006)$ & -.084 & $* * *$ & $(.004)$ & -.115 & $* * *$ & $(.006)$ & -.118 & $\star \star \star *$ & $(.004)$ \\
\hline Ireland & -.109 & $* \star \star$ & $(.004)$ & -.129 & $* * *$ & $(.007)$ & -.154 & 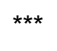 & $(.006)$ & -.085 & $* \star \star$ & $(.005)$ & -.116 & 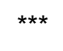 & $(.007)$ & -.116 & 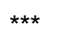 & $(.004)$ \\
\hline Italy & -.131 & $* * *$ & $(.004)$ & -.158 & $* \star *$ & $(.006)$ & -.167 & $* * *$ & $(.006)$ & -.116 & $* \star *$ & $(.004)$ & -.146 & $\star \star \star *$ & $(.006)$ & -.137 & $* * *$ & $(.005)$ \\
\hline Greece & -.128 & $* * *$ & $(.004)$ & -.169 & $* * *$ & $(.004)$ & -.185 & $* * *$ & $(.005)$ & -.108 & $* * *$ & $(.003)$ & -.150 & $* * *$ & $(.004)$ & -.138 & $* * *$ & $(.003)$ \\
\hline Spain & -.081 & $* * *$ & $(.007)$ & -.108 & $* * *$ & $(.009)$ & -.111 & $* \star \star$ & $(.010)$ & -.073 & $* * *$ & $(.006)$ & -.090 & $* * *$ & $(.009)$ & -.091 & $\star \star \star *$ & $(.007)$ \\
\hline Portugal & -.140 & $\star \star \star *$ & $(.005)$ & -.177 & $\star \star * *$ & $(.008)$ & -.191 & $\star \star \star *$ & $(.007)$ & -.119 & $* * *$ & $(.005)$ & -.166 & 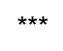 & $(.007)$ & -.140 & $\star \star *$ & $(.006)$ \\
\hline Austria & -.061 & 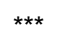 & $(.008)$ & -.090 & $\star \star \star *$ & $(.010)$ & -.073 & $\star \star \star *$ & $(.011)$ & -.066 & $* * *$ & $(.006)$ & -.062 & 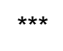 & $(.010)$ & -.079 & $\star \star \star ~$ & $(.007)$ \\
\hline Finland & .015 & & $(.012)$ & .002 & & $(.015)$ & .013 & & $(.014)$ & .008 & & $(.012)$ & .006 & & $(.014)$ & .009 & & $(.012)$ \\
\hline Firm size: $50-99$ employees & .033 & 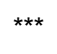 & $(.006)$ & .030 & *** & $(.009)$ & .042 & *** & $(.008)$ & .021 & *** & $(.006)$ & .037 & $* \star *$ & $(.007)$ & .026 & 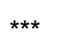 & $(.007)$ \\
\hline Firm size: 100-499 employees & .053 & 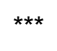 & $(.005)$ & .054 & *** & $(.008)$ & .063 & $\star \star \star *$ & $(.007)$ & .042 & *** & $(.006)$ & .056 & $\star \star \star \star ~$ & $(.006)$ & .050 & $\star \star \star ~$ & $(.006)$ \\
\hline Firm size: 500 or more employees & .081 & *** & $(.006)$ & .065 & 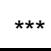 & $(.008)$ & .087 & *** & $(.007)$ & .063 & *** & $(.006)$ & .073 & $\star \star \star \star ~$ & $(.007)$ & .082 & $\star \star \star *$ & $(.007)$ \\
\hline
\end{tabular}


Table A2.10. Individual characteristics and training incidence. ECHP 1995-2001. Average partial effects, by gender, skill group and age (cont.)

\begin{tabular}{|c|c|c|c|c|c|c|c|c|c|c|c|c|c|c|c|c|c|c|}
\hline \multirow[b]{2}{*}{ ISIC C+E } & \multicolumn{3}{|c|}{ Males } & \multicolumn{3}{|c|}{ Females } & \multicolumn{3}{|c|}{ Skilled } & \multicolumn{3}{|c|}{ Unskilled } & \multicolumn{3}{|c|}{ Young } & \multicolumn{3}{|c|}{ Old } \\
\hline & .027 & 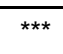 & $(.011)$ & .031 & & $(.021)$ & .034 & $* \star \star$ & $(.014)$ & .016 & & $(.010)$ & .029 & ** & $(.013)$ & .019 & * & $(.011)$ \\
\hline ISIC DA & -.010 & & $(.009)$ & -.052 & $* * *$ & $(.011)$ & .000 & & $(.012)$ & -.039 & $\star * *$ & $(.006)$ & -.038 & 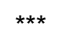 & $(.009)$ & -.020 & ** & (.009) \\
\hline ISIC DB+DC & -.039 & $\star \star \star *$ & $(.010)$ & -.080 & $\star \star \star *$ & $(.009)$ & -.087 & $* \star \star$ & $(.010)$ & -.051 & 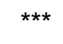 & $(.006)$ & -.070 & 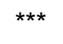 & $(.008)$ & -.064 & $* \star \star$ & $(.008)$ \\
\hline ISIC DD+DE & -.023 & $\star \star$ & $(.009)$ & -.017 & & $(.012)$ & -.035 & $* * *$ & $(.010)$ & -.021 & $* *$ & $(.008)$ & -.020 & * & $(.010)$ & -.040 & $* * *$ & $(.008)$ \\
\hline ISIC DF-DI & .008 & & $(.009)$ & -.019 & & $(.012)$ & -.004 & & $(.010)$ & -.005 & & $(.008)$ & .001 & & $(.010)$ & -.014 & & $(.008)$ \\
\hline ISIC DJ+DK & -.005 & & $(.008)$ & -.046 & $\star * *$ & $(.011)$ & -.031 & $* * *$ & $(.008)$ & .002 & & $(.008)$ & -.019 & $\star \star$ & $(.009)$ & -.020 & ** & $(.007)$ \\
\hline ISIC DL-DN & -.005 & & $(.008)$ & -.017 & & $(.011)$ & -.017 & $* *$ & $(.008)$ & -.011 & & $(.007)$ & -.011 & & $(.008)$ & -.021 & $* * *$ & $(.007)$ \\
\hline ISIC F & -.048 & $* * *$ & $(.006)$ & .011 & & $(.027)$ & -.065 & $* * *$ & $(.008)$ & -.028 & $* * *$ & $(.009)$ & -.056 & $* \star *$ & $(.008)$ & -.046 & $* * *$ & $(.007)$ \\
\hline ISIC G & .002 & & $(.008)$ & -.040 & $* * *$ & $(.006)$ & .012 & & $(.009)$ & -.030 & $* * *$ & $(.005)$ & -.020 & 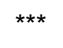 & $(.007)$ & -.020 & $\star \star \star *$ & $(.006)$ \\
\hline ISIC H & -.043 & $* * *$ & $(.009)$ & -.057 & $* * *$ & $(.009)$ & -.096 & $* * *$ & $(.014)$ & -.035 & $* * *$ & $(.005)$ & -.051 & $* \star \star$ & $(.008)$ & -.047 & $* \star *$ & (.009) \\
\hline ISIC I & -.008 & & $(.007)$ & -.016 & * & $(.009)$ & .017 & * & $(.010)$ & -.026 & $\star * *$ & $(.005)$ & -.021 & $* * *$ & $(.007)$ & -.010 & & $(.006)$ \\
\hline ISIC J & .078 & $* * *$ & $(.011)$ & .038 & *** & $(.010)$ & .071 & $* \star \star$ & $(.011)$ & .043 & $* \star \star$ & $(.009)$ & .046 & $* \star \star$ & $(.010)$ & .062 & $* * *$ & $(.010)$ \\
\hline ISIC K & .022 & ** & $(.009)$ & -.024 & $* * *$ & $(.007)$ & .000 & & $(.008)$ & .005 & & $(.008)$ & -.007 & & $(.008)$ & .005 & & $(.007)$ \\
\hline ISIC L & .008 & & $(.007)$ & .005 & & $(.006)$ & .009 & & $(.007)$ & .000 & & $(.005)$ & .013 & * & $(.007)$ & -.002 & & $(.005)$ \\
\hline ISIC M & -.008 & & $(.007)$ & .008 & & $(.006)$ & .002 & & $(.006)$ & .010 & & $(.008)$ & -.003 & & $(.007)$ & .004 & & $(.005)$ \\
\hline ISIC O-Q & -.012 & & $(.009)$ & -.017 & $* *$ & $(.008)$ & -.019 & $* *$ & $(.009)$ & -.011 & * & $(.006)$ & -.008 & & $(.008)$ & -.021 & $* * *$ & $(.007)$ \\
\hline Legislators, s & .052 & *** & $(.008)$ & .080 & $* * *$ & $(.011)$ & & & & & & & .058 & $\star \star \star \star ~$ & $(.009)$ & .074 & $\star \star \star *$ & $(.009)$ \\
\hline Professionals & .043 & 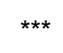 & $(.008)$ & .069 & *** & $(.008)$ & .004 & & $(.006)$ & .013 & $* \star *$ & $(.004)$ & .047 & 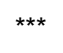 & $(.008)$ & .068 & $* * *$ & $(.008)$ \\
\hline Technicians and associate professionals & .052 & *** & $(.007)$ & .059 & *** & $(.007)$ & -.003 & & $(.005)$ & & & & .050 & $* \star \star$ & $(.007)$ & .065 & $* * *$ & $(.007)$ \\
\hline Clerks & .008 & & $(.006)$ & .025 & $\star * *$ & $(.006)$ & & & & & & & .022 & $* \star \star$ & $(.006)$ & .012 & * & $(.006)$ \\
\hline Skilled agricultural and fishery workers & -.045 & *** & $(.014)$ & -.026 & & $(.050)$ & & & & & & & -.038 & & $(.023)$ & -.055 & ** & $(.018)$ \\
\hline Craft and related trades workers & -.029 & $* * *$ & $(.005)$ & -.072 & *** & $(.010)$ & -.100 & $* \star *$ & $(.005)$ & & & & -.036 & $* \star \star$ & $(.006)$ & -.026 & $* * \star$ & $(.006)$ \\
\hline $\begin{array}{l}\text { Plant and machine operators and } \\
\text { assemblers }\end{array}$ & -.033 & *** & $(.005)$ & -.070 & *** & $(.009)$ & & & & -.032 & *** & $(.004)$ & -.035 & $* \star \star$ & $(.006)$ & -.039 & $* * *$ & $(.006)$ \\
\hline Elementary occupations & & $* * *$ & $(.005)$ & -.079 & $\star \star \star *$ & $(.007)$ & & & & -.056 & *** & $(.003)$ & -.059 & $* * *$ & $(.007)$ & -.073 & $* * *$ & $(.005)$ \\
\hline $\begin{array}{l}\text { Pseudo R-squared } \\
\text { Observations }\end{array}$ & & 9.197 & & & $\begin{array}{l}0.21 \\
6872\end{array}$ & & & $\begin{array}{l}0.200 \\
8708\end{array}$ & & & $\begin{array}{ll}0.18 \\
7751\end{array}$ & & & 0.184 & & & $\begin{array}{ll}0.227 \\
8692\end{array}$ & \\
\hline
\end{tabular}

Notes: Each regression includes a constant and countryXyear dummies. Country dummies shown above refer to 1997. Observations are weighted by ECHP longitudinal weights. The reference individual is a male full time unmarried British employee aged 35-44 years with tertiary education, average tenure, tenure, working in 1997 under a permanent contract as a service workers or shop and market sales workers for a private firm with less than 50 employees in the health and social work industry, except that in the second column the reference individual is female and in the third one works as legislator, senior official or manager. One, two and three stars for the coefficients statistically significant at the 10, 5 and 1 percent level of confidence respectively. Heteroskedasticity consistent standard errors in parentheses. See Table A2.6 for the list of industries. 
Table A2.11. Individual characteristics and training incidence. ECHP 1995-2001. Average partial effects, by country

\begin{tabular}{|c|c|c|c|c|c|c|c|c|c|c|c|c|c|c|c|c|c|c|}
\hline & \multicolumn{3}{|c|}{ Denmark } & \multicolumn{3}{|c|}{ The Netherlands } & \multicolumn{3}{|c|}{ Belgium } & \multicolumn{3}{|c|}{ France } & \multicolumn{3}{|c|}{ United Kingdom } & \multicolumn{3}{|c|}{ Ireland } \\
\hline Upper secondary education & -.031 & * & $(.016)$ & .007 & & $(.008)$ & -.055 & 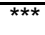 & $(.012)$ & -.027 & ${ }^{* \star *}$ & $(.007)$ & -.090 & $\overline{* \star \star \star}$ & $(.013)$ & -.011 & & $(.010)$ \\
\hline Less than upper secondary education & -.145 & *** & $(.022)$ & -.008 & & $(.009)$ & -.080 & *** & $(.014)$ & -.051 & *** & $(.008)$ & -.160 & *** & $(.011)$ & -.061 & *** & $(.012)$ \\
\hline Female & .012 & & $(.016)$ & -.006 & & $(.006)$ & -.013 & & $(.011)$ & .002 & & $(.006)$ & .030 & *** & $(.011)$ & .026 & *** & $(.010)$ \\
\hline Tenure & -.010 & ** & $(.004)$ & -.004 & $\star \star \star *$ & $(.002)$ & .002 & & $(.004)$ & -.002 & & $(.06$ & -.015 & *** & $(.003)$ & -.004 & * & $(.002)$ \\
\hline Tenure squared & .000 & ** & $(.000)$ & .000 & & $(.000)$ & .000 & & $(.000)$ & .000 & & $(.000)$ & .001 & *** & $(.000)$ & .000 & & $(.000)$ \\
\hline Married & -.001 & & $(.014)$ & -.017 & $* * *$ & $(.006)$ & .005 & & $(.011)$ & -.006 & & $(.006)$ & .026 & *** & $(.010)$ & .023 & ** & $(.009)$ \\
\hline Age $25-34$ & -.004 & & $(.019)$ & .015 & ** & $(.006)$ & .016 & & (.013) & .003 & & $(.008)$ & .016 & & (.012) & .015 & & $(.010)$ \\
\hline Age $45-54$ & -.014 & & $(.016)$ & -.038 & $* * *$ & $(.005)$ & -.047 & 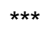 & $(.012)$ & -.027 & 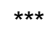 & $(.0$ & -.021 & * & $(.011)$ & -.010 & & $(.009)$ \\
\hline Age 55-64 & -.077 & $\star * *$ & $(.021)$ & -.061 & $* * *$ & $(.006)$ & -.060 & 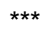 & $(.018)$ & -.074 & 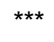 & $(.007)$ & -.053 & *** & $(.015)$ & -.029 & ** & $(.011)$ \\
\hline Public sector & .137 & *** & $(.021)$ & .024 & ** & $(.010)$ & .061 & *** & $(.018)$ & .076 & *** & $(.010)$ & .103 & *** & (.018) & .026 & * & $(.014)$ \\
\hline Part time & -.063 & 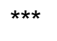 & $(.023)$ & -.014 & ** & $(.007)$ & -.036 & ** & $(.015)$ & -.017 & & $(.010)$ & -.145 & *** & $(.024)$ & -.022 & * & $(.012)$ \\
\hline Fixed term contract & -.051 & & $(.043)$ & .000 & & $(.016)$ & -.008 & & $(.023)$ & .008 & & $(.016)$ & -.059 & * & $(.033)$ & -.007 & & $(.021)$ \\
\hline Casual job & -.192 & $* * *$ & (.039) & .049 & & (.052) & -.128 & & $(.049)$ & -.113 & $* * *$ & $(.028)$ & -.137 & *** & $(.044)$ & -.034 & * & $(.017)$ \\
\hline Other type of contract & .022 & & $(.073)$ & -.015 & & $(.011)$ & .005 & & $(.031)$ & .050 & ${ }^{\star *}$ & $(.024)$ & -.211 & *** & $(.044)$ & -.016 & & $(.023)$ \\
\hline ISIC C+E & .148 & $* * *$ & $(.050)$ & .068 & ** & $(.033)$ & .099 & ** & $(.047)$ & .004 & & $(.023)$ & -.064 & * & $(.033)$ & -.023 & & $(.024)$ \\
\hline ISIC D/ & -.077 & * & $(.044)$ & .006 & & $(.018)$ & -.026 & & $(.035)$ & -.042 & & $(.023)$ & -.154 & *** & $(.027)$ & -.023 & & $(.019)$ \\
\hline ISIC DB+DC & -.056 & & $(.081)$ & .010 & & $(.043)$ & -.033 & & (.033) & -.012 & & $(.027)$ & -.267 & *** & $(.025)$ & -.062 & ** & $(.017)$ \\
\hline ISIC DD+DE & -.054 & & $(.048)$ & -.004 & & $(.016)$ & .022 & & $(.048)$ & .039 & ** & $(.020)$ & -.178 & *** & $(.024)$ & -.046 & ** & $(.019)$ \\
\hline ISIC DF-DI & -.021 & & $(.046)$ & .011 & & $(.017)$ & .073 & ** & $(.034)$ & 011 & & $(.018)$ & -.156 & *** & $(.022)$ & .046 & * & $(.030)$ \\
\hline ISIC DJ+DK & -.041 & & $(.037)$ & -.011 & & 6) & .028 & & $(.032)$ & .024 & & $(.017)$ & -.213 & *** & $(.020)$ & -.038 & & $(.022)$ \\
\hline ISIC DL-DN & -.027 & & $(.040)$ & .011 & & 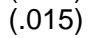 & .051 & * & $(.0$ & -.040 & ** & $(.0$ & -.182 & *** & $(.0$ & .011 & & $(.023)$ \\
\hline ISIC F & -.103 & 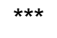 & $(.037)$ & -.029 & ** & $(.011)$ & .027 & & $(.037)$ & .038 & $\star \star \star *$ & $(.015)$ & -.082 & *** & $(.029)$ & -.062 & $\star \star \star *$ & $(.016)$ \\
\hline ISIC G & -.016 & & $(.032)$ & .000 & & $(.011)$ & -.023 & & $(.026)$ & -.054 & ** & $(.021)$ & -.160 & *** & $(.019)$ & -.056 & $\star \star * *$ & $(.013)$ \\
\hline ISIC H & -.151 & ** & $(.063)$ & -.005 & & $(.021)$ & -.053 & & $(.044)$ & .019 & & $(.014)$ & -.158 & *** & $(.027)$ & -.046 & ** & $(.017)$ \\
\hline ISIC I & -.012 & & $(.034)$ & -.017 & & (1) & 101 & *** & $(.031)$ & .030 & * & $(.019)$ & -.165 & *** & (.020) & -.010 & & $(.017)$ \\
\hline ISIC J & .138 & $* \star \star$ & $(.036)$ & .083 & *** & $(.018)$ & .117 & $* * *$ & $(.029)$ & -.002 & & $(.013)$ & -.119 & *** & $(.022)$ & -.050 & $* * *$ & $(.014)$ \\
\hline ISIC K & .060 & * & $(.032)$ & .013 & & 011) & .095 & $\star \star * *$ & $(.03$ & .010 & & $(.011)$ & -.144 & 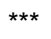 & $(.020)$ & .001 & & $(.020)$ \\
\hline ISIC L & . 096 & 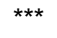 & $(.026)$ & .007 & & & 131 & $\star \star \star *$ & & -.044 & $\star \star \star *$ & & -.070 & *** & $(.0$ & .061 & $\star \star \star *$ & $(.021)$ \\
\hline ISIC M & .088 & 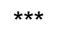 & (.028) & .013 & & 12) & -.009 & & $(.0$ & .043 & ** & $(.0$ & -.061 & *** & ) & -.012 & & $(.015)$ \\
\hline ISIC O-Q & .055 & * & $(.030)$ & -.018 & & 014) & .061 & ** & $(.027)$ & .019 & & $(.015)$ & -.153 & *** & $(.024)$ & -.043 & $\star \star *$ & $(.017)$ \\
\hline Firm size: & .075 & 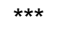 & $(.025)$ & .013 & & & .073 & $\star \star \star *$ & $(.027)$ & .081 & $\star \star \star *$ & $(.014)$ & .030 & * & $(.0$ & .001 & & $(.016)$ \\
\hline Firm siz & .121 & 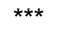 & $(.021)$ & . 023 & 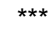 & 009) & .049 & ** & $(.020)$ & .067 & $\star \star \star *$ & $(.014)$ & .065 & *** & $(.018)$ & .028 & $\star \star$ & $(.014)$ \\
\hline Firm siz & .109 & 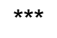 & $(.023)$ & .038 & *** & & .102 & $\star \star \star *$ & $(.020$ & .060 & $\star \star \star *$ & $(.021)$ & .134 & 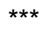 & $(.0$ & .065 & $\star \star \star *$ & $(.021)$ \\
\hline enior officials and managers & .131 & *** & $(.028)$ & -.008 & & $(.011)$ & .116 & *** & $(.037)$ & .049 & $* * *$ & $(.017)$ & .054 & *** & $(.019)$ & .068 & $* * *$ & $(.022)$ \\
\hline Profess & 166 & $\star \star \star *$ & $(.026)$ & -.022 & ** & & .057 & ** & & .083 & $\star \star \star *$ & $(.014)$ & .048 & ** & & 079 & $\star \star \star *$ & $(.022)$ \\
\hline ind associate professionals & .143 & $* * *$ & $(.023)$ & .005 & & ) & .037 & & $(.02-2$ & .054 & $* * *$ & $(.014)$ & .038 & ** & & .042 & ** & $(.018)$ \\
\hline Clerks & .040 & & $(.026)$ & -.014 & & $(.010)$ & .015 & & $(.024)$ & -.075 & & $(.030)$ & -.031 & * & $(.018)$ & .002 & & $(.015)$ \\
\hline Skilled as & -.128 & & $(.142)$ & -.072 & ** & $(.015)$ & -.048 & * & $(.026)$ & .025 & * & $(.0$ & -.147 & $* *$ & $(.0$ & .074 & & $(.079)$ \\
\hline Craft and related trades workers & -.038 & & $(.032)$ & -.036 & ** & $(.010)$ & -.050 & * & $(.024)$ & -.011 & & $(.014)$ & -.036 & * & $(.021)$ & -.027 & * & $(.015)$ \\
\hline $\begin{array}{l}\text { Plant and machine operators and } \\
\text { assemblers }\end{array}$ & -.028 & & $(.032)$ & -.020 & & $(.012)$ & -.074 & *** & $(.022)$ & -.043 & *** & $(.013)$ & -.086 & $\star * \star *$ & $(.021)$ & -.024 & & $(.015)$ \\
\hline Elementary occupations & -.107 & $\star \star \star *$ & $(.031)$ & -.054 & $* \star \star *$ & $(.009)$ & -.055 & $\star * *$ & $(.012)$ & -.027 & $\star \star \star *$ & $(.007)$ & -.137 & *** & $(.022)$ & -.052 & *** & $(.014)$ \\
\hline $\begin{array}{l}\text { Pseudo R-squared } \\
\text { Observations }\end{array}$ & & $\begin{array}{l}.100 \\
004\end{array}$ & & & $\begin{array}{l}0.06 \\
193\end{array}$ & & & $\begin{array}{r}0.07 \\
829\end{array}$ & & & $\begin{array}{l}0.068 \\
1568\end{array}$ & & & $\begin{array}{l}0.101 \\
1499\end{array}$ & & & $\begin{array}{l}0.09 \\
946\end{array}$ & \\
\hline
\end{tabular}


Table A2.11. Individual characteristics and training. ECHP 1995-2001. Average partial effects, by country (cont.)

\begin{tabular}{|c|c|c|c|c|c|c|c|c|c|c|c|c|c|c|c|c|c|c|}
\hline & \multicolumn{3}{|c|}{ Italy } & \multicolumn{3}{|c|}{ Greece } & \multicolumn{3}{|c|}{ Spain } & \multicolumn{3}{|c|}{ Portugal } & \multicolumn{3}{|c|}{ Austria } & \multicolumn{3}{|c|}{ Finland } \\
\hline Upper secondary education & -.001 & & $(.006)$ & -.017 & $* * * *$ & $(.004)$ & -.022 & $\star \star$ & $(.009)$ & .007 & & $(.006)$ & -.026 & & $(.017)$ & -.079 & 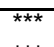 & $(.020)$ \\
\hline Less than upper secondary education & -.038 & $\star * \star$ & $(.007)$ & -.048 & $* * *$ & $(.005)$ & -.103 & *** & $(.009)$ & -.005 & & $(.006)$ & -.098 & $* * *$ & $(.017)$ & -.180 & $* * *$ & $(.023)$ \\
\hline Female & -.001 & & $(.004)$ & -.008 & ** & $(.004)$ & .001 & & $(.008)$ & .006 & ** & $(.003)$ & -.017 & & $(.011)$ & .016 & & $(.017)$ \\
\hline Tenure & .002 & & $(.002)$ & -.002 & * & $(.001)$ & .003 & & $(.002)$ & .002 & * & $(.001)$ & -.011 & $* \star *$ & $(.003)$ & -.005 & & $(.005)$ \\
\hline Tenure squared & .000 & & $(.000)$ & .000 & ** & $(.000)$ & .000 & & $(.000)$ & .000 & * & $(.000)$ & .001 & $* * *$ & $(.000)$ & .001 & ** & $(.000)$ \\
\hline Married & -.002 & & $(.005)$ & -.001 & & $(.004)$ & -.007 & & $(.008)$ & -.007 & ** & $(.004)$ & .011 & & $(.010)$ & .066 & $* * *$ & $(.015)$ \\
\hline Age $25-34$ & -.009 & & $(.006)$ & .007 & & $(.005)$ & .011 & & $(.009)$ & -.005 & & $(.003)$ & .031 & ** & $(.013)$ & .056 & *** & (.020) \\
\hline Age $45-54$ & -.018 & *** & $(.005)$ & -.011 & ** & $(.0$ & -.016 & ** & $(.008)$ & -.003 & & $(.0$ & -.032 & $* \star *$ & $(.011)$ & -.027 & & (.018) \\
\hline Age 55-64 & -.043 & $* * *$ & $(.005)$ & -.023 & $* * *$ & $(.004)$ & -.072 & *** & $(.009)$ & -.015 & *** & $(.002)$ & -.064 & $* * *$ & $(.015)$ & -.078 & $* * *$ & (.026) \\
\hline Public sector & .023 & *** & (.008) & .018 & $* \star *$ & $(.006)$ & .079 & *** & $(.016)$ & .023 & $* * *$ & $(.006)$ & .034 & ** & $(.017)$ & .162 & $\star \star *$ & (.022) \\
\hline Part time & -.001 & & $(.008)$ & -.010 & & $(.006)$ & .012 & & $(.022)$ & -.008 & & $(.004)$ & -.013 & & $(.016)$ & -.079 & $\star *$ & $(.036)$ \\
\hline Fixed term contract & .005 & & $(.013)$ & -.004 & & $(.008)$ & -.006 & & $(.012)$ & -.005 & & $(.005)$ & -.044 & ** & $(.020)$ & -.064 & ** & $(.026)$ \\
\hline Casual job & -.048 & * & $(.015)$ & -.012 & & $(.008)$ & -.051 & * & $(.025)$ & -.004 & & $(.013)$ & -.084 & & (.069) & -.070 & & $(.071)$ \\
\hline Other type of contract & -.012 & & $(.013)$ & .001 & & (.019) & -.056 & ** & $(.021)$ & -.002 & & $(.006)$ & -.050 & & (.032) & -.119 & & (.098) \\
\hline ISIC C+E & .007 & & $(.016)$ & .008 & & $(.013)$ & .031 & & $(.033)$ & -.007 & & $(.005)$ & -.007 & & $\begin{array}{l}(.032) \\
\text { (. }\end{array}$ & .060 & & $(.064)$ \\
\hline ISIC DA & -.020 & & $(.013)$ & .021 & & $\begin{array}{l}(.021) \\
(.021)\end{array}$ & -.003 & & $(.022)$ & -.009 & & $(.006)$ & -.125 & $* * *$ & $(.0$ & .001 & & $(.054)$ \\
\hline ISIC DB+DC & $\begin{array}{l}-.046 \\
-.04\end{array}$ & *** & (.008) & .010 & & (.018) & $\begin{array}{l}-.022 \\
-.022\end{array}$ & & $(.024)$ & -.017 & $* * *$ & $(.003)$ & $\begin{array}{l}-.122 \\
-\end{array}$ & $* \star *$ & $(.024)$ & -.209 & $\star \star * *$ & $(.064)$ \\
\hline ISIC DD+DE & -.021 & & $(.012)$ & -.013 & & $(.011)$ & -.009 & & (.028) & -.011 & & (.005) & -.103 & *** & $(.021)$ & .060 & & $(.039)$ \\
\hline ISIC DF-DI & -.017 & & $(.012)$ & .019 & & $(.018)$ & -.005 & & $(.023)$ & .001 & & $(.009)$ & -.035 & & $(.030)$ & -.080 & * & (.047) \\
\hline ISIC DJ+DK & -.016 & & $(.010)$ & .174 & $* * *$ & $(.042)$ & .025 & & $(.023)$ & .001 & & $(.011)$ & -.080 & $* * *$ & $(.020)$ & -.003 & & $(.041)$ \\
\hline ISIC DL-DN & -.022 & ** & $(.010)$ & .005 & & $(.017)$ & .033 & & $(.023)$ & -.008 & & $(.0$ & -.074 & $* * *$ & $(.0$ & -.054 & & $(.041)$ \\
\hline ISIC F & -.046 & $* * *$ & $(.007)$ & -.021 & * & $(.008)$ & -.060 & *** & $(.017)$ & -.003 & & (.009) & -.148 & $* * *$ & $(.015)$ & .026 & & (.043) \\
\hline ISIC G & -.005 & & $(.011)$ & .015 & & $(.012)$ & -.014 & & $(.016)$ & -.009 & * & $(.004)$ & -.085 & $* * *$ & $(.017)$ & .034 & & $(.034)$ \\
\hline ISIC H & -.018 & & $(.014)$ & .004 & & $(.016)$ & -.036 & * & $(.01$ & -.016 & $* * *$ & $(.002)$ & -.107 & $* * *$ & $(.021)$ & -.144 & $* * *$ & (.047) \\
\hline ISIC I & -.001 & & $(.0$ & .021 & ** & $(.012)$ & -.024 & & $(.01$ & .001 & & $(.0$ & -.040 & * & $(.0$ & -.012 & & (.035) \\
\hline ISIC J & .024 & * & $(.014)$ & .123 & *** & $(.027)$ & .127 & *** & $(.034)$ & .014 & * & $(.010)$ & .015 & & $(.027)$ & .146 & $* * *$ & $(.044)$ \\
\hline ISIC K & -.007 & & $(.011)$ & .008 & & $(.013)$ & .003 & & $(.021)$ & -.005 & & $(.005)$ & -.041 & & $(.023)$ & .048 & & (.034) \\
\hline ISIC L & -.013 & & $(.007)$ & -.002 & & $(.007)$ & .003 & & $(.014)$ & .010 & * & $(.007)$ & -.042 & ** & $(.018)$ & .057 & & (.036) \\
\hline ISIC M & .045 & $* * *$ & $(.011)$ & -.006 & & $(.007)$ & .026 & * & $(.015)$ & .001 & & $(.005)$ & .001 & & (.023) & -.049 & * & (.029) \\
\hline ISIC O-Q & -.004 & & $(.010)$ & -.001 & & $(.012)$ & -.017 & & $(.020)$ & -.010 & & $(.005)$ & -.038 & & $(.022)$ & -.072 & * & $(.039)$ \\
\hline Firm size: $50-9$ & .013 & & $(.0$ & .008 & & $(.0$ & .056 & *** & $(.01$ & .010 & & $(.0$ & .072 & $* * *$ & $(.0$ & .047 & & $(.031)$ \\
\hline Firm si & .018 & ** & $(.0$ & .022 & ** & $(.0$ & .069 & *** & $(.0$ & .006 & & & .080 & $* * *$ & $(.0$ & .108 & $* * *$ & $(.025)$ \\
\hline Firm size: 500 or & .046 & *** & $(.01$ & .036 & ** & 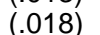 & .057 & *** & $(.01$ & .038 & *** & $(.0$ & .118 & *** & $(.021)$ & .150 & $* \star *$ & (.032) \\
\hline Legislators, senior officials and managers & .090 & $\star \star \star *$ & $(.025)$ & .018 & & $(.015)$ & .073 & *** & $(.02$ & .020 & * & $(.0$ & .186 & *** & $(.027)$ & .057 & & (.037) \\
\hline Professionals & .095 & $\star \star \star *$ & $(.019)$ & .031 & *** & $(.013)$ & .051 & 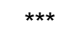 & $(.017)$ & .023 & $\star \star \star *$ & & .170 & *** & $(.033)$ & .040 & & $(.030)$ \\
\hline Technicians and associate professionals & .071 & $\star \star \star *$ & $(.015)$ & .012 & & $(.010)$ & .054 & 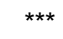 & $(.015)$ & .016 & ** & $(.008)$ & .104 & *** & $(.020)$ & .030 & & $(.028)$ \\
\hline Clerks & .025 & ** & $(.011)$ & .000 & & $(.0$ & .034 & ** & $(.015)$ & .008 & & $(.007)$ & .075 & *** & $(.0$ & -.048 & & $(.031)$ \\
\hline Skilled agricultur & -.049 & ** & $(.013)$ & .030 & & 5) & .030 & & $(.054)$ & -.015 & * & $(.003)$ & .145 & & $(.115)$ & -.338 & ** & (.090) \\
\hline Craft and related trades workers & -.012 & & $(.0$ & -.003 & & & -.016 & & 10 & -.0 & *** & 1 & -.059 & *** & ) & -.148 & *** & $(.031)$ \\
\hline Plant and machine operators and & -.011 & & $(.011)$ & -.003 & & $(.008)$ & -.033 & ** & $(.014)$ & -.009 & * & $(.004)$ & -.087 & *** & $(.018)$ & -.217 & $* \star *$ & $(.033)$ \\
\hline Elementary occupations & -.034 & *** & $(.008)$ & -.020 & & $(.007)$ & -.046 & *** & $(.013)$ & -.011 & $\star *$ & $(.004)$ & -.140 & $* * *$ & $(.014)$ & -.195 & $\star \star *$ & $(.036)$ \\
\hline $\begin{array}{l}\text { Pseudo R-squared } \\
\text { Observations }\end{array}$ & \multicolumn{3}{|c|}{$\begin{array}{l}0.1272 \\
21452\end{array}$} & \multicolumn{3}{|c|}{$\begin{array}{l}0.1596 \\
11571\end{array}$} & \multicolumn{3}{|c|}{$\begin{array}{l}0.1203 \\
18546\end{array}$} & \multicolumn{3}{|c|}{$\begin{array}{l}0.1921 \\
17215\end{array}$} & \multicolumn{3}{|c|}{$\begin{array}{c}0.126 \\
11001\end{array}$} & \multicolumn{3}{|c|}{$\begin{array}{c}0.1018 \\
7541\end{array}$} \\
\hline
\end{tabular}

Notes: Same as Table 2.4, except for the country of residence of the reference individual. 


\section{Chapter 3: Training and labour market institutions}

Institutional factors affecting the labour and the product market differ significantly among European countries. Product market competition, for instance, is recognized to be stronger in Anglo-Saxon countries, and employment protection to be highest in Southern European countries. There is an extensive literature which investigates how these institutional differences affect unemployment dynamics (see for instance Blanchard and Wolfers, 2000; Nickell, Nunziata and Ochel, 2005, and the references therein). The bottom line of this research is that the interaction of institutions with economic shocks does a good job in explaining unemployment differences across OECD countries.

Do labour and product market institutions affect training incidence and can they account for part of the variation in training outcomes observed across European countries? The theoretical aspects of this important question are reviewed in detail in Chapter 1 of this report. The next section reviews the empirical literature. Most of the existing evidence is not comparative but country - specific, with a strong emphasis on the US and to a lesser extent on the UK.

In this chapter we take a European perspective by matching data from the European Community Household Panel - a large dataset covering 15 EU countries which we have used extensively in the previous chapter - with information on time varying institutions - mainly from the OECD database - and provide an empirical investigation of the relationship between training incidence and labour and product market institutions.

We focus on cross - country and time series variations in institutions, because cross - country variations per se cannot be easily disentangled from the host of country specific effects that characterize European labour markets. By so choosing we hope to be able to answer the first part of the question above - whether changes in institutions affect training incidence - but acknowledge that it is difficult to answer with these data the second part - how important are institutions in the cross - country variation of training outcomes.

The chapter is organized as follows. We start in Section 3.1 by briefly reviewing the relevant empirical literature. Next, we present the data (Section 3.2), setup the empirical exercise (Section 3.3), and discuss the key empirical findings (Section 3.4). The chapter ends with a summary of the main results. 


\subsection{Previous empirical literature}

We find it convenient to organize this brief review of the empirical literature on institutions and training by discussing in sequence the following institutions: unions, minimum wages, employment protection, product market regulation and school design.

\subsubsection{Unions and training}

Table 1.2 summarizes the testable predictions on the relationship between unions and training and suggests that this relationship is complex. The empirical papers investigating the different aspects of this relationship provide mixed results. Among the first studies in the US, Duncan and Stafford, 1980, and Mincer, 1983, find evidence of a negative union effect on training. Similarly, Barron and coauthors, 1987, use data from a survey of US employers and find that the proportion of non-supervisory workers covered by collective bargaining has a significant negative effect on total training. On the contrary, Lynch, 1992, finds evidence of a positive effect of unions on training in the US National Longitudinal Survey of Youth (NLSY). Similarly, Kennedy et al., 1994, find that Australian firms where unions are actively involved in bargaining have significantly higher training incidence, in spite of the fact that union density does not have statistically significant effects. Green, 1993, shows that unions in Britain have significant positive effects on training in small firms but virtually no effect in large firms.

Beside the Lynch's study, additional evidence of a positive union effect is provided by Veum, 1995, Booth 1991, Greenhalgh and Mavrotas 1992, Arulampalam and Booth, 1998, Green, Machin and Wilkinson 1999, and Booth, Francesconi and Zoega, 2003. The latter study investigates the impact of union coverage on work-related training and finds that union - covered British men are more likely to receive training and also receive more days of training than workers with no coverage. A positive union effect is also the key result of a recent investigation of unions and training in German data, by Dustmann and Schonberg, 2004. On the other hand, Lynch and Black, 1998, find no link between unions and training, as do Green and Lemieux, 2001 using Canadian data. These authors find that, everything else equal, unions have little effect on the provision of training. 


\subsubsection{Minimum wages and training}

The available empirical evidence on the effects of the minimum wages on training is also rather inconclusive, with recent studies in the United States and the United Kingdom reporting contradictory findings. Recall that in perfectly competitive labour markets, the introduction of a minimum wage reduces training, because some workers are not be capable of financing training by accepting lower wages. Conversely, when labour markets are characterized by monopsonistic power, minimum wages may increase employer - provided training of low paid workers.

Early research by Leighton and Mincer, 1981, and Hashimoto, 1982, finds that age-earnings profiles are significantly flatter among workers whose wages are bound by the minimum wage, which is interpreted as suggesting that an increase in the minimum wage significantly reduces on-the-job training. Sharply in contrast, Lazear and Miller, 1981, find no statistically significant relationship between the slope of age-earnings profiles and an indicator of whether the minimum wage is binding or not. However, more recent research by Grossberg and Sicilian, 1999, shows that the effect of minimum wages on wage growth could be unrelated to the effect produced on training. As suggested by Acemoglu and Pischke, 2003, minimum wages eliminate the lower tail of the wage distribution and by so doing flatten the slope of the age-earning profile. This effect is independent of the impact of minimum wages on training. Leighton and Mincer, 1981, and Neumark and Wascher, 2001, using data on individual workers, consider the relationship between the variation of minimum wages across US states and the investment in training and find that the more binding is the minimum wage, the less likely is a worker to receive on-the-job training. Since the minimum wage variable used by Neumark and Wascher is at a higher level of aggregation than training, the estimated standard errors may understate the inaccuracy of the estimates. This problem is taken into account by Acemoglu and Pischke, 2003, who, by focusing on workers affected by minimum wages changes, find no evidence that minimum wages reduce training.

Schiller, 1994, and Grossberg and Sicilian, 1999, are two relatively recent studies that find opposite results: while Schiller produces evidence that minimum wages reduce training, Grossberg and Sicilian do not. Their approach, however, may be biased because the omitted determinants of training can also be correlated with their indicator of whether minimum wages are binding. Arulampalam, Booth and 
Bryan, 2004, use two different treatment groups, workers stating that they were affected by minimum wages and workers with a wage in 1998 below the minimum. Their study of British Household Panel Survey data finds no evidence that the introduction of the minimum wage in Britain in 1999 has reduced the training of treated workers. If anything, there is evidence that training has increased.

\subsubsection{Flexible labour contracts and training}

A widespread concern with the recent diffusion of flexible employment practices, such as temporary labour contracts, is that these contracts may be detrimental to economic performance because temporary workers are less likely to be trained. Arulampalam and Booth, 1998, investigate the relationship between employment flexibility and training using UK data, and find that workers on temporary contracts are less likely to receive work - related training. Quite in contrast, recent work by Autor, 2004, on temporary help firms in the US shows that almost one quarter of temporary help supply firms have received skills training as temporaries. Training in this context not only provides skills but also operates as a screening and a selfsorting device.

\subsubsection{Product market competition, employment protection and training}

The relationship between product market competition and training is significantly less studied in the literature, both theoretical and empirical. In the only empirical investigation we are aware of, Autor, 2004, presents evidence of a negative and statistically significant correlation between the Herfindahl index, a measure of product market concentration, and the training provided by temporary help firms in the US. The evidence on the relationship between firing costs, employment protection and training is also rather limited. Bishop, 1991, is one study in the area, which reports that the likelihood and amount of formal training are higher at firms where firing a worker is more difficult. Acemoglu and Pischke, 2000, argue that there are complementarities between regulation regimes and training systems, and that reducing firing costs and increasing employment flexibility could reduce the incentives to train. Their evidence, however, is impressionistic and focuses mainly on Germany. Clearly, a broader comparison would be more problematic. Take for instance Italy and Japan. The former country has one of the strictest systems of 
employment protection and very little training, and the latter country is often mentioned as a leading example of a high training equilibrium - see Lynch, 1994 in spite of its having a much lower index of employment protection than Italy.

\subsubsection{Schooling and training}

There is substantial evidence that the quantity of education and training are complements (See Leuven, 2003, for a review), and there is also evidence that the strength of this complementarity depends on whether training is provided on - the job or off - the - job (see Ariga and Brunello, 2002). To our knowledge, no empirical research has been done so far on the relationship between the quality of education and training. Since quality depends on the design of schooling institutions, an important empirical question is which institutions are more conducive to work-related training.

\subsubsection{Training and pensions}

The traditional way of looking at the relationship between pension benefits and training is that deferred payments - such as pensions - reduce turnover, increase incentives, and therefore allow firms to recoup the costs of their investments in training (see Lazear, 1979). This view suggests that there is a positive relationship between employer - provided training and the generosity of the pension plans designed by firms.

If we focus on workers approaching retirement age, however, we notice that these employees face the choice of retiring versus continuing work and investing in further training. The incentive to stay and train is likely to be higher in countries were the implicit tax on continuing work is lower. This tax is defined as minus the change in pension wealth from remaining in the labour market during a given period of time (see Duval, 2004). Many European countries have recently changed or are considering reforming the pension system, with the view of increasing its sustainability in the face of persistent ageing. One concern raised by these policies is that a postponement of retirement age might increase the unemployment rate of older workers, who are unlikely to receive the training needed to stay longer in the labour market. To cope with this, some countries in Europe have in place early retirement schemes, which facilitate the transition of older dismissed workers from 
work to retirement. These systems are expensive for the taxpayer, and do not contribute to increase the participation rate of older workers. In principle, however, less generous expected benefits from retirement should positively affect the training of senior workers - both employer and employee provided - by increasing the expected length of working life after the investment, and the time available to recoup the costs of the investment.

As in the case of the relationship between school design and training, we are not aware of any empirical research which has investigated whether the generosity of mainly public - pension schemes has a significant effect on the training incidence of senior workers.

\subsection{The Data}

Our data on individual training events are drawn from the European Community Household Panel (ECHP) ${ }^{58}$, waves 1995 to 2001. As discussed in the Appendix to Chapter 2, the ECHP is an attractive source of information because it covers a significant number of European countries with a commonly designed questionnaire. For comparability with the previous empirical literature, we select our sample as in Arulampalam, Booth and Bryan, 2004. In particular, we only consider individuals (i) aged between 25 and 60 years and working at least 15 hours per week; (ii) not employed in agriculture; (iii) present in at least two consecutive waves; (iv) not in apprenticeships or in special - employment training schemes.

Since the reference period of each wave may overlap with the period of the previous wave, we run the risk of double counting training spells. Rather than losing information or adjusting counts in an ad-hoc way, we prefer to ignore double counting in the main regressions and to perform a robustness check which compares our results with those obtained from a reduced sample which only retains odd years, and therefore avoids double counting by definition. There is also the problem of omitted spells, which appears to be particularly serious for Germany. Since the data for Germany also miss important information on employer provided training, as well as on industry affiliation, we follow Arulampalam, Booth and Bryan, 2004, and drop this country from the sample ${ }^{59}$. A comparison between

\footnotetext{
${ }^{58}$ The December 2003 release of these data is available at the Department of Economics, University of Padova, under contract n. 14/99.

59 The German data in the ECHP are derived from GSOEP and exclude many shorter training spells.
} 
these training data and those drawn from other sources can be found in the Appendix to Chapter 2.

We consider all training, independently of whether it is defined as general or as firm - specific, or as paid by the employer or by the employee. As documented in the introduction to Chapter 2, average training incidence is higher in countries with a higher percentage of the population having at least a high school diploma. Not only the quantity but also the quality of education matters. As discussed above, one important area where European secondary schools differ is the degree of stratification or tracking. Compared to the US, where tracking consists of ability grouping within the same comprehensive schooling system ${ }^{60}$, stratification in Europe occurs mainly by separating students into vocational and general tracks, with different degrees of osmosis between tracks. Hannah, Raffe and Smyth, 1996, and OECD, 2004, classify countries into three groups, depending on the degree of stratification of school curricula: a high stratification group, which includes Germany, Austria, Belgium and the Netherlands; a low stratification group, with the UK, Spain and Scandinavian countries (Sweden, Denmark and Finland); an intermediate group, with the rest of Europe, including France and Italy, which lies between these two extremes. In systems with high stratification, students are divided relatively early into separate tracks, and develop specific and relatively narrow skills in the vocational track. In systems with low stratification, tracking takes place later if ever, and students receive a broader and more versatile education.

We define a dummy equal to 0 for low, 1 for intermediate and 2 for high stratification. Figure 3.1 plots average training incidence in 1997 - obtained by the weighted aggregation of the residuals of a linear probability model, where the dependent variable is the individual training event, and the controls are education, gender, age, lagged industry and country by year dummies - separately for the three groups of countries. Since training participation depends also on the quantity of education, we divide it by the share of individuals with at least upper secondary education. The figure shows a negative relationship between stratification and incidence. One reading is that more comprehensive education can increase versatility in the presence of unexpected shocks, but requires additional training to transform the general skills it produces into more operational competencies.

\footnotetext{
${ }^{60}$ See Epple, Newlon and Romano, 2002 for a brief description of tracking in US secondary schools.
} 


\section{Figure 3.1. Training incidence and tracking in secondary schools}

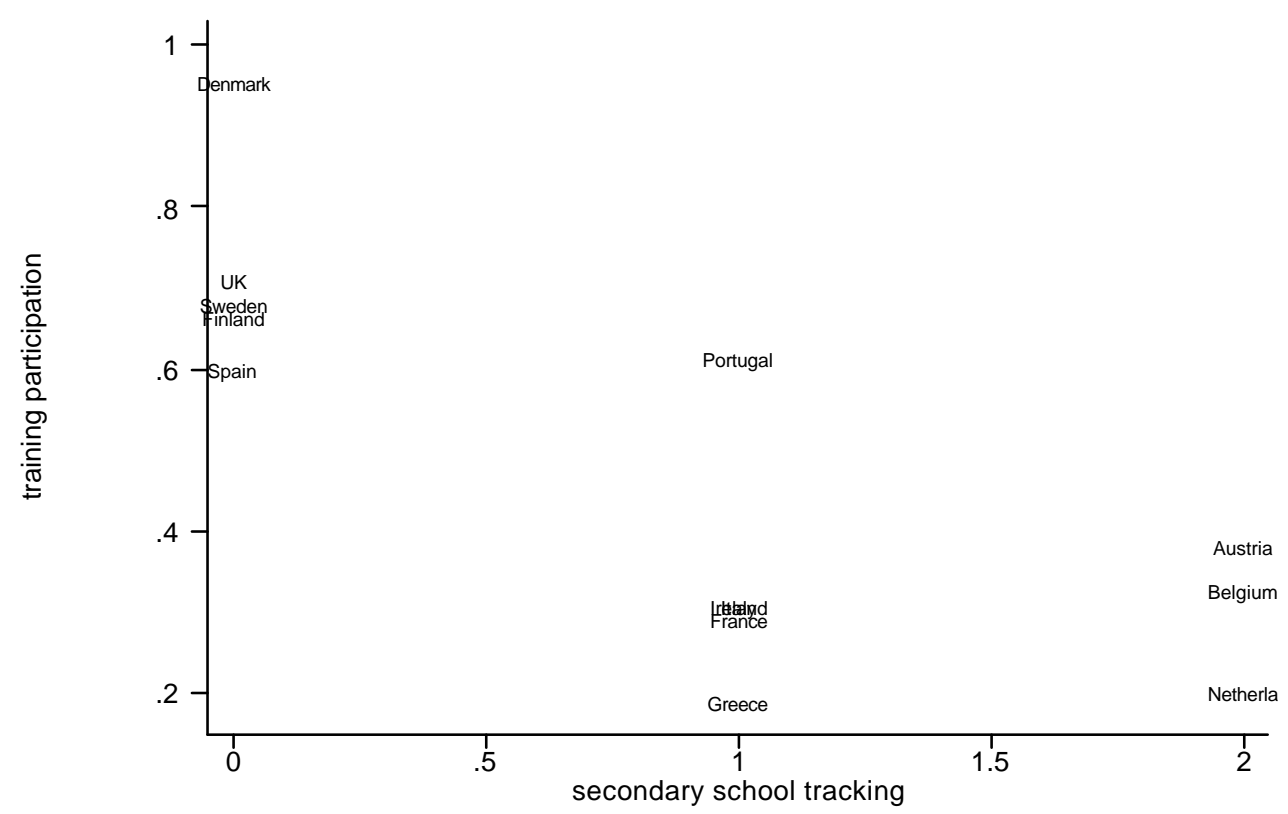

Note: 1998 for Sweden. Training density is obtained by weighted aggregation of the residuals of a linear probability model, where the dependent variable is the individual training event, and the controls are education, gender, age, lagged industry and country by year dummies.

The data on labour and product market institutions come from a variety of sources. Time varying union density is from the OECD database. This variable has been used in the literature as a proxy of union influence, mainly because of the availability of time varying data. An important drawback, however, is that the variable of interest in the empirical analysis is union coverage, which might be poorly related to union density. Only in half a dozen OECD economies with predominantly company bargaining do the two go closely together. The case of France, where coverage is high but density low, is a clear example of poor correlation. It follows that, when the extension of union agreements is high, changes in union density are not as informative of union influence on wages, employment and training decisions as when extension is low.

The OECD has developed a measure of the legal or administrative extension of union agreements. Extension makes a collective agreement generally binding within an industrial sector, covering all employees who are not members of its signatory parties. This measure is a dummy equal to one for countries where extension is low (Denmark, the UK and Sweden), two for countries with medium extension (Netherlands, Ireland, Italy, Greece, Finland) and three for countries with high 
extension (Belgium, France, Spain, Portugal and Austria) ${ }^{61}$. Since variations of union density are a good measure of union influence and coverage when extension is low, we define a new variable - the interaction of density with a dummy equal to one for the countries with low extension. This is equivalent to restricting the analysis of the relationship between training and union density to these countries. Since the ECHP measure of training for each year covers the previous year as well, we use the second lag of union density. By so doing, we try to attenuate potential endogeneity problems originated by reverse causality running from training incidence to unionisation rates.

We characterize the flexibility of the employment relationship in Europe with three variables - the index of stringency of employment protection legislation for regular and temporary workers and the share of temporary workers in the labour force $^{62}$. The data for these variables are also from the OECD database. As in the case of union density, we use the second lag of each variable to reduce potential endogeneity problems. Figures 3.2 and 3.3 illustrate the relationship between the employment protection index for regular and temporary workers in 1995 and training participation in 1997.

Figure 3.2. Training in 1997 and the employment protection of regulars in $\mathbf{1 9 9 5}$

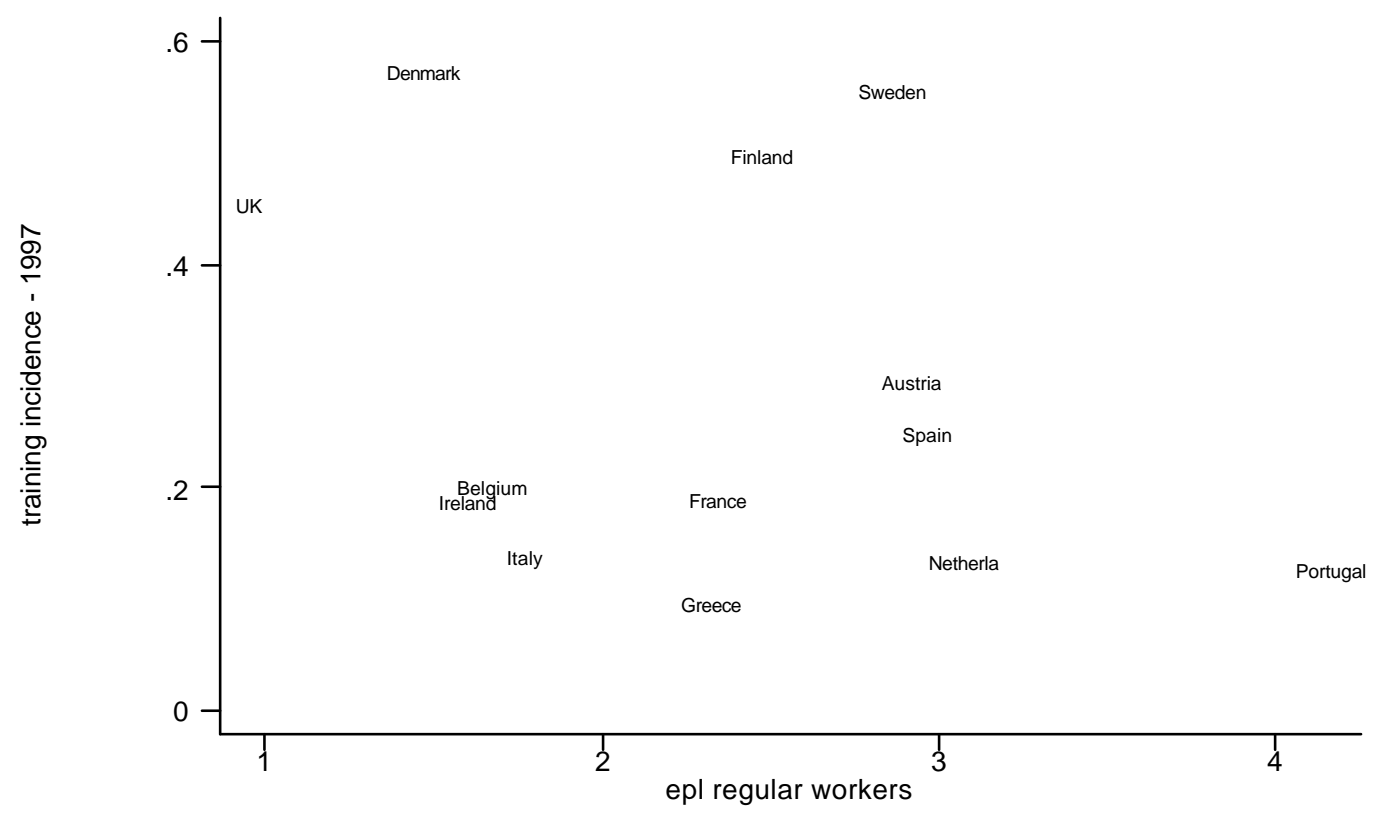

Note: see Figure 3.1

\footnotetext{
${ }^{61}$ See OECD, 2004.

${ }^{62}$ While the index of employment protection for regular workers focuses mainly on firing restrictions, the index for temporary workers considers mainly hiring restrictions.
} 
Figure 3.2 suggests the presence of a negative correlation between the employment protection of regulars and training incidence, which turns out, however, to be not statistically significant (coefficient: -0.055 , standard error: $0.043)$. The negative correlation is even more pronounced in the case of the index of employment protection for temporary workers. In this case, the estimated coefficient in a linear regression of training on EPL is statistically different from zero $(-0.060$, standard error: 0.025). The negative correlation between training incidence and either measure of employment protection presumably reflect the fact that the latter is a tax, and that a higher tax reduces profits and the incentive to train.

Figure 3.3. Training in 1997 and the employment protection for temporary workers in 1995

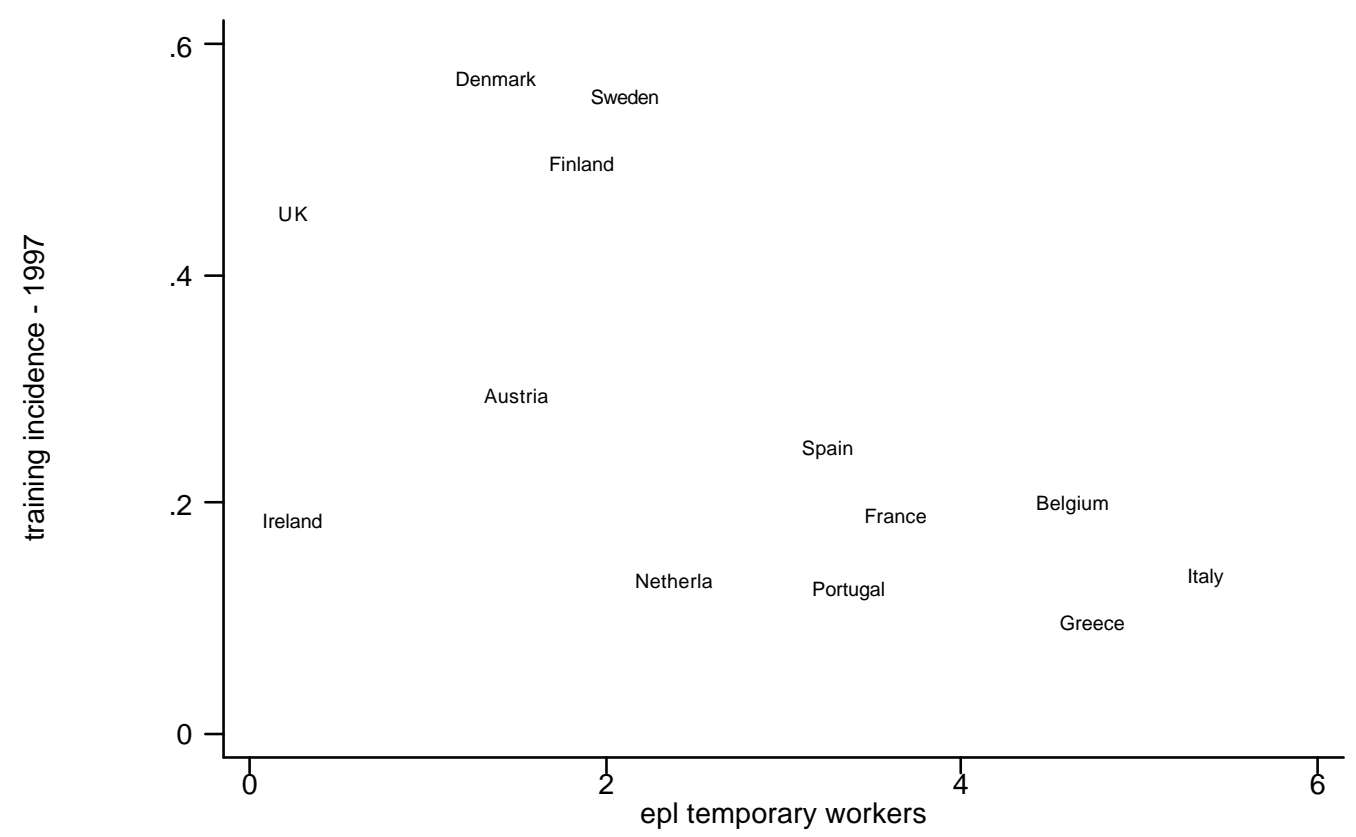

The relationship between training participation, the share of temporary workers and the index of product market regulation has already been described in the general introduction of this report. We use the index of product market regulation developed by Nicoletti and Scarpetta, 2003, which measures the stringency of anticompetitive product market regulation - varying between 0 and 6 from the least to the most stringent. Since the indicator covers the period from the late eighties to 
$1998^{63}$, we minimize the loss of information by associating to training between year $\mathrm{t}-1$ and year $\mathrm{t}$ product market regulation in year $\mathrm{t}-3$.

Next, we plot in Figure 3.4 the relationship between training participation for workers aged between 50 and 59 - relative to participation for the younger age group aged 25 to 49 - and the implicit tax rate on continued work. This indicator measures the change in pension or social wealth from remaining in the labour market during the 5 years from age 60 to age 64 and is defined as minus this change divided by length of the interval. Unfortunately, it has been estimated by the OECD only for the year 2003 and does not include Greece (see Duval, 2004). For the purposes of this study, we shall assume hereafter that the indicator proxies in a satisfactory way expected pension benefits during the second part of the 1990 . With the noteworthy exceptions of I taly and Sweden, a higher value of the implicit tax is associated to a lower relative training participation for workers aged 50 to 59.

Figure 3.4. Training of older workers and the implicit tax on continuing work

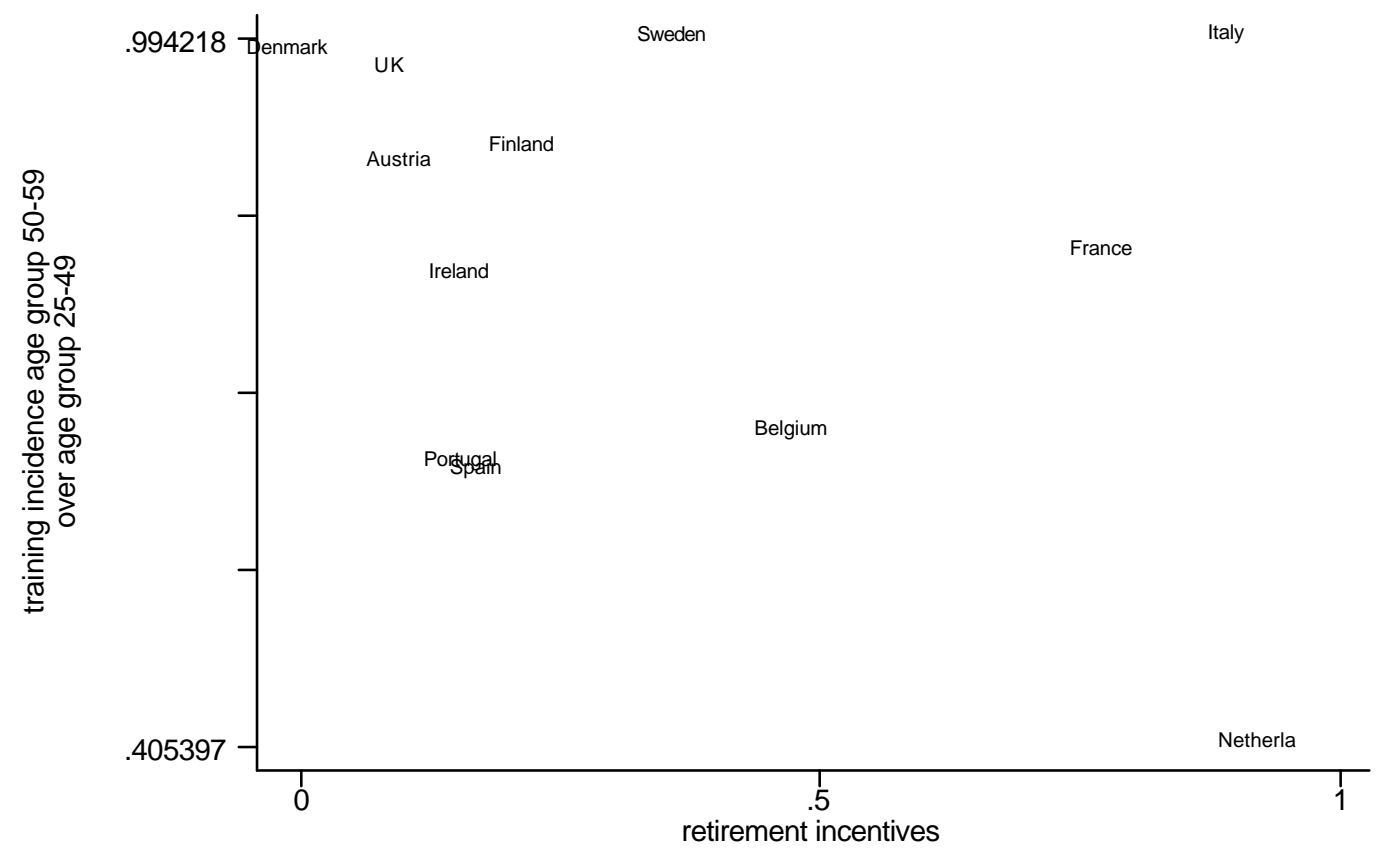

Note: see Figure 3.1

${ }^{63}$ A recent update to include the year 2003 has been produced by the OECD. 
Table 3.1. Changes of institutional and other indicators between 1995 and 2001, by country

\begin{tabular}{|c|c|c|c|}
\hline & Decreased & Constant & Increased \\
\hline Union density & DK, UK, SW & - & - \\
\hline Employment protection of regulars & DK, SP, FL & $\begin{array}{c}A U, B E, F R, I R, I T, \\
U K, S W, N L\end{array}$ & PT \\
\hline Employment protection of temporary & $\begin{array}{c}\text { DK, BE, IT, SP, } \\
\text { PT, SW }\end{array}$ & $\begin{array}{c}\mathrm{NL}, \mathrm{FR}, \mathrm{UK}, \mathrm{IR} \\
\mathrm{GR}, \mathrm{AU}, \mathrm{FL}\end{array}$ & \\
\hline Share of temporary workers & $\mathrm{DK}, \mathrm{IR}, \mathrm{FL}$ & - & $\begin{array}{l}\mathrm{BE}, \mathrm{NL}, \mathrm{FR}, \mathrm{UK}, \mathrm{GR}, \\
\mathrm{IT}, \mathrm{SP}, \mathrm{PT}, \mathrm{AU}, \mathrm{SW}\end{array}$ \\
\hline Product market regulation & All countries & - & - \\
\hline$R \& D$ expenditure on GDP & FR, UK, IT & & $\begin{array}{l}\mathrm{DK}, \mathrm{NL}, \mathrm{BE}, \mathrm{IR}, \mathrm{GR}, \\
\mathrm{SP}, \mathrm{PT}, \mathrm{FL}, \mathrm{SW}, \mathrm{AU}\end{array}$ \\
\hline
\end{tabular}


Table 3.1 summarizes our data on time varying institutions by classifying countries according to whether the relevant variable has increased, remained constant or increased between 1993 and 1999. Union density has declined in all the countries with low extension of union contracts; the share of temporary workers has increased in all countries, with the notable exceptions of Denmark, Ireland and Finland, where it has declined.

The index of employment protection of regular employees has remained constant in the large majority of countries, increased in Portugal and declined in Denmark, Spain and Finland; the same index for temporary workers has declined in half of the sample and remained constant in the rest; product market regulation has declined across the board; finally, the expenditure on R\&D as a share of GDP has increased in most countries but declined in France, Italy and the UK.

\subsection{The Empirical Setup}

We characterize the empirical relationship between training and institutions with the following probit specification

$$
\operatorname{Pr} o b\left\{T_{i t}=1\right\}=\Phi\left(\alpha_{c}+\alpha_{t}+\beta X_{i t}+\gamma I_{c t}+\delta Y_{c t}\right)
$$

where $T$ is the training event over the reference period, $\alpha_{c}$ and $\alpha_{t}$ are country and year effects, $X$ is a vector of individual characteristics, I a vector of time varying institutional variables, $Y$ a vector of confounding country - specific time varying effects, $i$ is the index for individuals, $c$ for the country, $t$ for time and $F$ is the cumulative normal distribution.

As already remarked in Chapter 2, the probit model applied to pooled data does not estimate partial effects but average partial effects, obtained by averaging partial effects across the distribution of the unobserved individual effect in the population (see Wooldridge, 2002). Since we pool all available observations over countries and time, we include country dummies to capture all time invariant and country - specific institutional differences, which could affect both labour market outcomes and training. These dummies also pick up differences in the interpretation 
of the training question, which could vary across countries because of broad cultural and social reasons.

We also include year dummies to capture all common macroeconomic shocks hitting the countries in the sample. The introduction of country and time dummies in [3.1] implies that we can estimate the relationship between training and labour market institutions only if the latter vary both across countries and over the available time span. However, the variation of training across countries and over time can also be due to confounding factors, which operate at the same level of aggregation of the selected institutional variables, and failure to control for these factors could seriously bias our results. To illustrate, suppose that training incidence is affected by country - specific technical progress, and let this variable change over time. By excluding measures of technical progress from the regression, we run the risk of attributing its effects to time varying institutions.

An alternative route is to use grouped data by country, year and relevant subgroups - education (college versus less than college) and age (24 to 49 and 50 to 59) - and to estimate by weighted least squares a logistic transformation of the dependent variable, the proportion of trained employees in each subgroup. Compared to the probit specification which uses individual data, aggregation has the advantage of reducing individual heterogeneity and measurement error in the dependent variable.

One important feature both of specification [3.1] and of the estimate based on grouped data is that the institutional variables are at a higher level of aggregation than the dependent variable. Because of this, we need to adjust the estimated standard errors for the clustering effects induced by different levels of aggregation.

\subsection{The Empirical Results}

We estimate equation [3.1] on ECHP data for 13 countries $^{64}$ and the period 1995$2001^{65}$, using as controls age, gender, education, country, industry and year dummies $^{66}$. In these estimates we take into account the fact that training covers

\footnotetext{
64 These countries are: Austria, Belgium, Denmark, Finland, France, Ireland, Italy, Greece, the Netherlands, Portugal, Spain, Sweden and the UK.

${ }^{65}$ We exclude 1994, the first wave, because it does not contain data on Austria, Finland and Sweden and is slightly different from the other waves in the availability of data on training.

${ }^{66}$ This specification contains fewer controls than the one in Chapter 2, because we want o maximize the number of countries available for the study of the effects of institutions.
} 
both the year of the survey and the previous year by using the latter as reference for the selected controls.

The vector of institutions I includes union density interacted with a dummy equal to 1 if the extension of union contracts is low, the index of employment protection for regular and temporary employees, the index of product market regulation ${ }^{67}$, the interaction between age in the range 50 to 59 and the implicit tax on continued work and the interactions between the share of $R \& D$ expenditure on GDP, no college education - a dummy equal to 1 for individuals with less than college education - and no tracking - a dummy equal to zero for countries with a comprehensive secondary school system. These two dummies are interacted both separately and jointly with $R \& D$ expenditure.

The first interaction is expected to capture the disincentive effects on training of higher expected returns from retirement. The second set of interactions investigates whether the effects of technical innovations - captured by the share of $R \& D$ expenditure on GDP - vary with the level of educational attainment and with the degree of tracking in secondary schools. Technical change is likely to make narrowly specialized skills obsolete, and it might be necessary as a consequence to re-train more individuals with a less versatile and narrower education than individuals with general skills. If this is the case, we expect the relationship between technical progress and training to be positive and stronger in countries where schooling is more stratified.

In so doing, we also need to take into account the fact that the degree of secondary school stratification has changed over time in some countries, most notably Italy and the UK. In the UK, stratification was fairly radical before 1965, when individuals were tracked into grammar and secondary schools ${ }^{68}$. In Italy, a sweeping reform unified lower secondary school in a single comprehensive track in 1963. We take this into account by assigning to the high tracking group the individuals born before 1995 in the UK and before 1952 in Italy.

\footnotetext{
67 This index ranges from 0 to 6 and measures the intensity of regulation with respect to: economic and administrative regulation, tariff and other barriers, state control and public ownership, barriers to entrepreneurship, impediments to trade and investment. See Nicoletti and Scarpetta, 2002.

${ }^{68}$ See Galindo-Rueda and Vignoles, 2004.
} 
Table 3.2. Summary statistics

\begin{tabular}{|c|c|c|c|c|}
\hline & Mean & $\begin{array}{c}\text { Standarı } \\
\text { Dev. }\end{array}$ & Minimum & Maximum \\
\hline Training & .207 & .405 & & \\
\hline Less than upper secondary education & .367 & .482 & & \\
\hline Upper secondary education & .346 & .475 & & \\
\hline Gender & .566 & .495 & & \\
\hline Union density $*$ low extension dummy & .116 & .251 & 0 & .822 \\
\hline Share of temporary workers & .126 & .768 & .049 & .350 \\
\hline Employment protection index for regular workers & 2.394 & .896 & .950 & 4.330 \\
\hline Employment protection index for temporary workers & 2.608 & 1.532 & .250 & 5.380 \\
\hline Product market regulation & 3.907 & 1.127 & 1.024 & 5.665 \\
\hline Implicit tax on continued work & .421 & .344 & -.014 & .920 \\
\hline$R \& D$ expenditure as share of GDP & 1.606 & .763 & .470 & 3.800 \\
\hline Unemployment rate & .096 & .042 & .002 & .18 \\
\hline
\end{tabular}


There is a substantial literature on skill biased technical change (see Katz and Autor, 1999 for a review), showing that new technological developments and higher education are complements. Complementarities between innovations and educational attainment imply that new innovations increase the relative demand for college graduates. If training and education are also complements, an implication is that the effect of technical progress, captured by $R \& D$ expenditure, is likely to be stronger for individuals with higher education.

The vector $Y$ of confounding factors consists of the country and time specific unemployment rate, of the share of temporary workers in the labour force and of the share of $R \& D$ expenditure on GDP. The first two variables are expected to capture cyclical effects and changes in the composition of labour contracts, and the latter variable to proxy technical progress.

I deally, we would also like to include indicators which capture changes in training policy, but the only closely related indicator - the share of expenditure on active labour market policies on GDP - includes almost entirely training subsidies paid out to the unemployed.

Table 3.2 presents the summary statistics of the key variables used in the regressions, and Table 3.3 reports our results from estimating model [3.1]. About 20 percent of the close to 30 thousand workers aged 25 to 60 get trained at least once during the sample period. Close to 70 percent of sampled individuals have less than college education, and about 56 percent are males.

Table 3.3 consists of three columns: in the first column we present a parsimonious specification which excludes all institutional variables; in the second column we include all institutional variables except the interaction of age with the implicit tax on continuing work, which is not available for Greece; in the last column we add the latter variable and restrict our sample to 12 countries.

We find that training incidence increases with the unemployment rate - albeit not with a statistically significant coefficient - which supports the results in Chapter 2 and the view that firms and individuals engage more frequently in training activities when the opportunity cost of training - in terms of foregone production - is lower (Hall, 2000).

Training participation also increases with total expenditure on $R \& D$ - measured as share of GDP - and this effect is significantly lower for college graduates, which suggests that the latter require less training when innovations occur. The effect of union density on training - limited to the countries with low extension of union 
contracts - is positive but imprecisely estimated. Since one of the countries with limited coverage is the UK, our results are not in contrast with the findings by Booth, Francesconi and Zoega, 2003, who report that training incidence is significantly higher among union - covered British employees.

Table 3.3. All training and time varying institutions. ECHP 1995-2001. Probit estimates. Average partial effects.

\begin{tabular}{l|ccc}
\hline & Full sample & Full sample & Full sample \\
\hline Unemployment rate & 0.202 & 0.080 & 0.050 \\
& $(.142)$ & $(.174)$ & $(.199)$ \\
Total R\&D expenditure on GDP & $0.135^{* * *}$ & $0.108^{* * *}$ & $0.116^{* * *}$ \\
& $(.025)$ & $(.031)$ & $(.033)$ \\
Share of temporary workers in & $-0.256^{*}$ & $-0.326^{* *}$ & $-0.307^{* *}$ \\
total employment & $(.157)$ & $(.146)$ & $(.150)$ \\
Union density * low extension dummy & & 0.465 & 0.516 \\
& & $(.376)$ & $(.385)$ \\
Product market regulation & & $-0.064 *$ & $-0.068^{* *}$ \\
& & $(.027)$ & $(.032)$ \\
Employment protection index for & & $-0.031 *$ & $-0.034^{*}$ \\
regular workers & & $(.017)$ & $(.019)$ \\
Employment protection index for & & -0.004 & -0.004 \\
temporary workers & & $(.006)$ & $(.006)$ \\
[Aged between 50 and 59 /100] $*$ & & - & $-0.106 * * *$ \\
implicit tax rate on continued work & & & $(.019)$ \\
at age 60-64 & & $0.039 * * *$ & $0.041^{* * *}$ \\
Total R\&D expenditure on GDP * & & $(.006)$ & $(.006)$ \\
less than college dummy & & -0.001 & 0.003 \\
Total R\&D expenditure on GDP * & & $(.003)$ & $(.003)$ \\
no tracking dummy & & -0.012 & -0.014 \\
Total R\&D expenditure on GDP * & & $(.009)$ & $(.010)$ \\
no tracking * less than college & & .004 & .006 \\
No tracking * less than college & & $(.015)$ & $(.018)$ \\
R Squared & & .192 & .187 \\
\hline Nobs & & 191491 & 178941 \\
\hline Nos & .191 & & \\
\hline
\end{tabular}

Notes: The coefficients of the probit estimates are average partial effects. Each regression includes a constant, country, age, education, gender, industry and year dummies. One, two and three stars for the coefficients statistically significant at the 10,5 and 1 percent level of confidence respectively. Heteroskedasticity consistent and cluster adjusted standard errors.

Training turns out to be lower when the share of temporary workers in total employment increases. Therefore, an increase in the flexibility of the employment relationship associated to the introduction and diffusion of temporary labour contracts reduces the incentives of both parties to train.

At the same time, however, training incidence is lower when the degree of employment protection of both regular workers and temporary workers increases, although this effect is statistically different from zero only for the former. How do we explain this? It is well known that employment protection is associated to firing 
costs, and that these costs have both a transfer and a tax component. While the transfer part could be undone by properly designed labour contracts, the tax component is difficult to undo (see Garibaldi and Violante, 2002). A common view in this literature is that firing costs increase wages (see Mortensen and Pissarides, 1999). According to Lindbeck and Snower, 1988, these costs increase the bargaining power of insiders by sheltering them from the competition of outsiders. How could this affect training? Using the simple illustrative model in Appendix 1.C, suppose that wages of regular workers - the insiders - are the results of Nash bargaining and let

$$
w(\tau)=\beta(\theta) v(\tau)+[1-\beta(\theta)] f(\tau)
$$

where the notation is $w$ for wages, $\beta$ for the bargaining power of the firm, $f$ for productivity, $v$ for the outside option, $\theta$ for the firing tax and $\tau$ for training. If training is employer - provided and the firm bears its costs, optimal provision satisfies the following condition

$$
(1-q) \beta(\theta)\left[f^{\prime}(\tau)-v^{\prime}(\tau)\right]-c^{\prime}(\tau)=0
$$

where $\mathrm{q}$ is the exogenous rate of turnover. If a higher firing tax reduces the bargaining power of the firm, and the second order conditions for a local maximum hold, then it follows that

$$
\frac{\partial \tau}{\partial \theta}<0 \quad \text { if } \quad(1-q) \frac{\partial \beta}{\partial \theta}\left[f^{\prime}(\tau)-v^{\prime}(\tau)\right]<0
$$

which holds when there is wage compression and the bargaining power of insiders increase in the firing tax.

An alternative explanation is selection. When firing costs are high, employers cannot easily dismiss less able or less suitable regular employees and therefore end up with a more heterogeneous regular labour force than employers who can more easily dismiss unsuitable employees. If training and ability are complements, or if labour force heterogeneity imposes a negative firm-specific externality on individual 
productivity, employers with a more homogeneous regular labour force should train more $^{69}$.

Conditional on employment protection, training incidence is lower when product market regulation is higher. Therefore, liberalizing product markets do not damage training incentives, quite the contrary. This evidence does not support the view expressed by Gersbach and Schmutzler, 2004, that training should be higher when industrial concentration is high and /or competitive intensity is comparatively low, but is in line with the finding by Autor, 2004, that temporary help firms operating in more concentrated markets train more.

Overall, these results provide an interesting picture. On the one hand, product market liberalization does not reduce training. On the other hand, more flexible labour markets have contrasting effects on the incentive to train. If higher flexibility is obtained by reducing the employment protection of regular workers, training increases. If this flexibility is the consequence of the diffusion of temporary work in two - tier systems, training incentives are reduced.

We find that the interaction of age and the implicit tax on continued work is negative and statistically significant. Therefore, the age - training profile of workers in the 50-59 age group is reduced by the expectation of better retirement benefits. An implication of this finding is that pension reforms which reduce the implicit tax on continuing work during age 60 to 64 are likely to increase the training of senior employees. Thus, the concerns about the labour market prospects of senior workers which often accompany these reforms might be exaggerated to the extent that these workers receive further training. As shown by Bassanini, 2005, additional training of senior workers increases their employability.

Finally, the interaction between productivity growth and lack of secondary school tracking yields a negative - albeit not statistically significant - coefficient for individuals with less than college education, suggesting that technical progress has a positive effect on training where schooling is stratified and a negative effect where schooling is comprehensive. This result points to the possibility that the vocational skills developed in stratified schools require more training and updating in the face of technical innovations. Therefore, countries with less stratified schooling systems have endowed workers with more versatile skills and need less

\footnotetext{
${ }^{69}$ One could object that employers facing higher employment protection select their employees more carefully, and therefore reduce heterogeneity. If labour quality can only be learned over time, however, hiring policies cannot fully undo heterogeneity.
} 
training to match newly developed techniques than countries with more stratified education systems.

How big are the effects discussed above? Using the results in the last column of the table, a one unit increase in the share of $R \& D$ expenditure raises the probability of training for college graduates by 0.116 . The Lisbon strategy sets at 3 percent the target share of R\&D expenditure on GDP, to be attained by 2010. According to our estimates, this would require an increase from the current European average of 1.4 percentage points. If such an increase could be attained, we expect training participation to increase by 0.162 , a substantial amount. The expected increase in the probability of training is even higher for individuals without a college degree, and depends on the nature of the secondary school. When evaluated at the sample mean values of employment protection, a similar increase in the degree of product market regulation reduces the probability of training by 0.068 . Conversely, a unit increase in employment protection reduces training incidence by 0.034 in the case of regular workers and by 0.004 in the case of temporary workers. Given that average training incidence in the sample is close to 0.2 , these effects are not negligible.

As shown in Table 3.3A in the Appendix, our results do not vary significantly when we restrict our sample only to odd years, in order to remove the risk of double counting training events. Furthermore, Table 3.4 reports the weighted least squares estimates of the logistic model fitted on grouped data. The qualitative results discussed above are confirmed. Interestingly, we can compare the goodness of fit of the less parsimonious model in the second column, which include time varying institutions, with the fit of the parsimonious model in the first column, which exclude them. Since the decline in the adjusted $\mathrm{R}$ Squared turns out to be quite small, from 0.952 to 0.937 , we conclude the contribution of time varying institutions to explaining the time series and cross section variation of training outcomes is rather limited.

Clearly, cross country differences in the level of institutions are likely to be important, as suggested by Figures 3.1 - 3.7, but cannot be identified in these data because of the impossibility to control for the full set of confounding country specific effects. 
Table 3.4. Employer provided training and time varying institutions. ECHP 1995-2001. Logistic transformation. Weighted least squares.

\begin{tabular}{|c|c|c|c|}
\hline & Full sample & Full sample & Full sample \\
\hline Unemployment rate & $\begin{array}{r}2.819 * * \\
(1.199)\end{array}$ & $\begin{array}{l}2.115^{*} \\
(1.273)\end{array}$ & $\begin{array}{c}1.296 \\
(1.252)\end{array}$ \\
\hline Total R\&D expenditure on GDP & $\begin{array}{l}0.821 * * * \\
(.219)\end{array}$ & $\begin{array}{l}0.576 * \\
(.317)\end{array}$ & $\begin{array}{l}0.694 * * \\
(.317)\end{array}$ \\
\hline $\begin{array}{l}\text { Share of temporary workers in } \\
\text { total employment }\end{array}$ & $\begin{array}{c}-0.174 * \\
(.099)\end{array}$ & $\begin{array}{l}-0.173 \\
(.119)\end{array}$ & $\begin{array}{l}-0.171 \\
(.109)\end{array}$ \\
\hline Union density $*$ low extension dummy & & $\begin{array}{l}0.004 \\
(.029)\end{array}$ & $\begin{array}{l}0.007 \\
(.028)\end{array}$ \\
\hline Product market regulation & & $\begin{aligned}-.434 * * * \\
(.157)\end{aligned}$ & $\begin{array}{l}-0.460 * * \\
(.175)\end{array}$ \\
\hline $\begin{array}{l}\text { Employment protection index for } \\
\text { regular workers }\end{array}$ & & $\begin{array}{c}-0.254 * * \\
(.101)\end{array}$ & $\begin{array}{c}-0.284 * * * \\
(.101)\end{array}$ \\
\hline $\begin{array}{l}\text { Employment protection index for } \\
\text { temporary workers }\end{array}$ & & $\begin{array}{c}-0.085^{* *} \\
(.036)\end{array}$ & $\begin{array}{c}-0.072 * \\
(.037)\end{array}$ \\
\hline $\begin{array}{l}\text { [Aged between } 50 \text { and } 59 / 100]^{*} \\
\text { implicit tax rate on continued work } \\
\text { at age } 60-64\end{array}$ & & - & $\begin{array}{c}-0.500 * * * \\
(.131)\end{array}$ \\
\hline Total R\&D expenditure on GDP * & & $0.471 * * *$ & $0.536 * * *$ \\
\hline no college dummy & & $(.077)$ & $(.091)$ \\
\hline $\begin{array}{l}\text { Total R\&D expenditure on GDP * } \\
\text { no tracking dummy }\end{array}$ & & $\begin{array}{l}-0.035 \\
(.377)\end{array}$ & $\begin{array}{l}-0.121 \\
(.378)\end{array}$ \\
\hline $\begin{array}{l}\text { Total R\&D expenditure on GDP * } \\
\text { no tracking } * \text { no college }\end{array}$ & & $\begin{array}{c}-0.223^{* *} \\
(.103)\end{array}$ & $\begin{array}{c}-0.274 * * * \\
(.112)\end{array}$ \\
\hline Year dummies & Yes & Yes & Yes \\
\hline Country dummies & Yes & Yes & Yes \\
\hline R Squared & .937 & .952 & .957 \\
\hline Nobs & 319 & 319 & 292 \\
\hline
\end{tabular}

Notes: Each regression includes a constant, the percentage of females, college and age group dummies. One, two and three stars for the coefficients statistically significant at the 10,5 and 1 percent level of confidence respectively. Heteroskedasticity consistent and cluster adjusted standard errors.

\subsection{Extensions}

Before concluding this chapter we briefly report about two extensions. In the former extension, we add to the list of time varying institutional variables the average and marginal tax rate, gross of social security contributions paid by the employee and the employer. In the second extension, we restrict our attention to employer - provided training rather than to total training.

Average and marginal affect training because they influence the bargained wage. As shown in the Appendix to this chapter, an increase in the average and marginal tax rates is expected to reduce employer provided training, which covers the large part of total training in Europe. We measure average and marginal taxes using the OECD database. These data are classified by type of household and report tax rates 
for the typical individual with 100 percent, 66 percent and 167 percent of the income of an average production worker. We select single earners with no children and use as average rate the rate for the individuals with 100 percent of average income and the marginal tax rate as the difference between the rate at 167 percent and at 66 percent of average income, divided by the rate at 100 percent.

Not reported here but available from the authors upon request are the replications of Tables 3.3 and 3.4 with the addition of average and marginal tax rates. As expected, these variables attract the expected negative sign but are not statistically significant. We also do not report the estimates for employer - provided training. It suffices to say for the purposes of this chapter that by focusing explicitly on the training provided by the employer we capture a large part of all training events. Not surprisingly, the relationship between time varying institutions and training remains qualitatively unchanged.

\section{Summary}

We summarize the results of this empirical investigation with the following points:

- product market regulation affects training negatively and significantly. Therefore, more competition in the product market is conducive to higher investment in training;

- labour market flexibility affects training in a less straightforward manner: on the one hand, the diffusion of temporary contracts reduce the investment in training; on the other hand, the reduction in the degree of employment protection for regular workers increases the provision of training. Therefore, labour market reforms that accelerate the diffusion of temporary contracts and at the same time increase the protection of a limited core of permanent employees produce negative effects on the accumulation of human capital taking place mainly in firms;

- training incidence declines with age and is lower than average for workers who have reached age fifty. The decline is higher, ceteris paribus, in countries with a more generous pension system, because the higher implicit tax on continuing work at age 60 to 64 reduces the expected time horizon required to recoup the 
costs of the investment. Therefore, pension reforms which reduce the implicit tax are likely to have as a by-product an increase in the training of senior workers;

- there is little evidence that union density matters significantly for training. One reason could be that our measure of unionism does not allow us to fully capture the complexity of this relationship. We have restricted union density to affect training only in those countries where the extension of union contracts is low, and cannot say much on the effects of unions on training in the remaining countries;

- training and investment in research and development are complements, but the degree of complementarity is lower for college graduates, possibly because the latter have sufficient skills and do not need to be trained or re-trained to be able to cope with innovations;

- secondary school design matters in the relationship between innovative activity and training: when schooling is more comprehensive, high school graduates require less training to adapt to technical progress. 


\section{Chapter 4 - The Costs and Benefits of Workplace Training}

In our review of the basic theory of workplace training in Chapter 1, we have remarked that efficient provision requires that the marginal private and social benefits or training be equal to marginal private and social costs. We have also argued that employers in imperfectly competitive labour markets are willing to bear the costs of general training if the increase in productivity after training is higher than the increase in wages. Since the costs and returns to training play an important role in both statements, the natural question to ask is what do we know about the effects of training on wages and productivity, and about training costs.

This chapter documents that the answer to this question is: not enough. While there is an extensive literature on the social returns to schooling - see De la Fuente and Ciccone, 2002, little is known on the size of externalities associated to training. The large literature that has documented the relation between human capital and income, both at the individual and at the national level, leaves little doubt that investments in human capital are crucial for economic well-being. Many of these investments take place both in the household and in the educational system but, as documented in Chapter 2, substantial investment in human capital takes place after entry into the labour market. However, most of the existing literature that considers returns to human capital has focused on schooling.

To the extent that the determinants of individual wage growth over the life-cycle (i.e. after entry into the labour market) have been considered, the literature has estimated returns to experience and tenure. Although experience and tenure are considered to be proxies for human capital, it is well-known that other economic mechanisms than human capital alone can generate upward sloping wage profiles. One mechanism that generates wage growth is job search and matching (Jovanovic, 1979a, Mortensen, 1978), a second mechanism is contract based: upward sloping wage profiles that by postponing rewards can provide an incentive for workers to exert effort early on. Distinguishing between these alternative explanations of life-cycle wage patterns has proven to be a daunting task. That there is a direct relation between these returns and training investment is suggested by the analysis of Brown, 1989, who finds that firm-specific wage growth occurs mainly during periods of on-the-job training. This illustrates the importance of studying the incidence and effects of more direct measures of training. 
In the last two decades an increasing number of studies has attempted to estimate returns to training using more direct measures. In this chapter we discuss the fundamental problems that arise in the context of such estimations, including measurement and identification problems, and show that the interpretation and comparison of return estimates is not always straightforward.

\subsection{Estimating the Private Returns to Training}

Let wages $\mathrm{w}$ and productivity $\mathrm{y}$ be a functions of training $\tau$. Most of the empirical literature estimates parametric specifications of $w(\tau)$ that in turn give estimates of $\partial w / \partial \tau$, the marginal impact of training on earnings. If labour markets are perfectly competitive, wages are equal to (the value of) marginal product, $w(\tau)=y(\tau)^{70}$. As discussed in Chapter 1, labour market imperfections can drive a wedge $\Delta(\tau)$ between wages and productivity, so that $w(\tau)=y(\tau)-\Delta(\tau)$. If $\Delta(\tau) \neq \Delta$, the partial $\partial w / \partial \tau$ traces the impact of training not on productivity alone, but on productivity net of the marginal return to the employer, $\partial \Delta / \partial \tau$. With absolute wage compression, $\Delta^{\prime}(\tau)>0$ and the marginal effect of training on productivity is higher than the effect on earnings.

\subsubsection{I dentification}

The fundamental problem that one encounters when estimating returns to training (either $\partial w / \partial \tau$ or $\partial y / \partial \tau$ ) is treated extensively in the evaluation literature (see Heckman et al., 1999, for an overview). It is an omitted variables/selectivity problem and can be conveniently illustrated by considering the prototypical wage equation that is estimated in the literature: ${ }^{71}$

$$
\ln w_{i t}=x_{i t}^{\prime} \beta+\gamma \tau_{i t}+\varepsilon_{i t}
$$

\footnotetext{
${ }^{70}$ Except when workers finance training by taking a wage cut. Costs then drive a wedge between wages and productivity: $w(\tau)=y(\tau)-c(\tau)$.

${ }^{71}$ We will discuss the main estimation issues in the context of the estimation of $w(\tau)$, but the same problems arise in analyses based on firm level data that relate training to output instead of wages.
} 
where $w_{i t}$ is the wage of individual $\mathrm{i}$ at time $\mathrm{t}, x_{i t}$ is a vector of control variables and $\varepsilon_{i t}$ the residual/error term. The first studies estimated (4.1) by ordinary least squares (OLS). Without covariates $x_{i t}$ and with $\tau_{i t}$ defined as mere participation, the OLS estimate of the effect of training is simply the difference in mean earnings between those who participated in training and those who did not. Participation in training must therefore be random and the important shortcoming of OLS is that $\gamma$ is unbiased only if training is uncorrelated with the error term: $E\left[\tau_{i t} \varepsilon_{i t} \mid x_{i t}\right]=0$. Ordinary least squares therefore ignores the possibility that there are unobserved individual characteristics, such as ability, that affect wages and correlate with training.

The current state-of-the-art in this literature is to estimate fixed effect versions of (4.1), where it is assumed that $\varepsilon_{i t}=c_{i}+u_{i t}$, so that the estimation equation now becomes

$$
\ln w_{i t}=x_{i t}^{\prime} \beta+\gamma \tau_{i t}+c_{i}+u_{i t}
$$

This method effectively estimates (4.2) using deviations from individual means and is comparable to estimating (4.1) in first differences. ${ }^{72}$ The fixed effects estimator takes into account any confounding influence of unobserved individual characteristics that correlate both with wages and training, as long as these are fixed over time (they are picked up by $c_{i}$ ). Thus, the crucial identifying assumption here is that participants would have experienced the same wage growth as nonparticipants in the absence of training.

Some studies (f.e. OECD, 2004; Lowenstein and Spletzer, 1998, 1999) have estimated equations that control for match-specific effects. These fixed effects estimates are within-job estimates and therefore do not capture returns to training in the form of mobility to better jobs. Return estimates from these types of studies are therefore expected to be lower than returns estimates from standard fixed effects models.

\footnotetext{
${ }^{72}$ With $T=2$ first differencing and fixed estimation are equivalent. With $T>2$ they are not. Which of the two is more efficient depends on the properties of $u_{i t}$. If $u_{i t}$ is i.i.d. FE is more efficient and if $u_{i t}$ follows a random walk first differencing is more efficient.
} 
A few studies (Pischke, 2001; Frazis and Lowenstein, 1999) have recognized that training participants may experience higher wage growth in the absence of training than non-participants. If this is the case, then standard fixed effect estimates are biased. To take this into account Pischke, 2001, estimated fixed effect growth equations by adding individual specific growth rates of earnings $\delta_{i} t$ to equation (4.2).

As an alternative to fixed effect based approaches a number of papers have estimated $\gamma$ using selection models or instrumental variables (IV). The outcome equation (4.1) is now augmented with a participation equation

$$
\tau_{i t}^{*}=w_{i t}^{\prime} \eta+v_{i t}
$$

Selection models specify a joint parametric distribution for $(\varepsilon, v)$ and can be estimated using maximum likelihood. An alternative is a 2-step method where in the first step a control function $\hat{\lambda}_{i t}=\lambda\left(w_{i i}^{\prime} \hat{\eta}\right)$ is estimated such that $E\left[d_{i t}\left(\rho \hat{\lambda}_{i t}+\varepsilon_{i t}\right)\right]=0$. Equation (4.1) is then augmented in a second step with the control function, and OLS gives a consistent estimate of the effect of training on wages $\gamma$.

It has been pointed out that selection models and control function methods can be very sensitive to misspecification of the joint distribution of $(\varepsilon, v)$ and are identified exclusively on functional form and distributional assumptions unless $w_{i t}$ includes variables that are not included in $x_{i t}$. Unfortunately not any variable will do. What is needed is a variable $z_{i t}$ that affects participation but is orthogonal to the error term in (4.1): $E\left[z_{i t} \varepsilon_{i t}\right]=0$. This is commonly referred to as an exclusion restriction, and to $z_{i t}$ as an instrumental variable. In addition $z_{i t}$ will need to have a significant effect on participation. With an instrument a common approach is to estimate $\gamma$ using two-stage least squares (2SLS). The obvious challenge is to find variables that arguably affect training participation but are independent of wages or productivity. 


\subsubsection{Rates of Return}

To estimate rates of return we need information on costs: $r=b / c$, with $\mathrm{b}$ for benefits and $\mathrm{c}$ for costs. The benefits for the employee equal $b=h \cdot w(\tau+\Delta \tau)-h \cdot w(\tau) \equiv h \cdot \Delta w$, where $h$ is hours worked. To see how wage return estimates relate to rates of return, assume that training is measured in hours and that there are no direct costs. In this case the cost of training equals $c=\Delta \tau \cdot w$ and the rate of return is

$$
r=\frac{b}{c}=\frac{\Delta w / w}{\Delta \tau / h}
$$

Equation (4.2) estimates $\gamma=\Delta \ln w / \Delta \tau \approx(\Delta w / w) / \Delta \tau=r / h$. If training is measured as incidence, then it estimates $\gamma=\Delta \ln w \approx(\Delta w / w)=r \cdot \Delta \tau / h$.

This discussion assumes that there are no direct costs. Almeida and Carneiro, 2004, find for Portugal that it is in fact direct costs which represent the bulk of training costs, as opposed to opportunity costs. With direct costs, total training costs now become $c=\Delta \tau \cdot w+f$, and returns $r^{\prime}=(\Delta w / w) /(\Delta \tau / h+f /(w h))>r$.

\subsection{Returns to Employees}

As mentioned in the introduction, the initial literature that estimated wage returns to training was based on indirect training measures. These studies regress wages on labour market experience and job tenure (seniority). The coefficient on labour market experience is then interpreted as the return to general training, whereas the coefficient of job tenure is interpreted as the return to specific human capital. Abraham and Farber, 1987, Altonji and Shakotko, 1987, and Topel, 1986, are early attempts to estimate the return to seniority up and above the return to experience. They find only small effects of seniority on wage growth. Topel, 1991, re-examined the data and concluded that the findings in these studies are biased because of measurement error and selectivity issues. He finds that 10 years of current job seniority raises the wage of a typical male worker in the U.S. by 25 percent.

Human capital theory predicts upward sloping productivity profiles, and wage profiles are assumed to proxy these productivity profiles. There are several other theories (e.g. deferred compensation, self-selection, and matching theories) besides human capital theory that predict upward sloping wage profiles, and as such it is hard to argue that this is a definitive test. One would like to know to what 
extent wage growth correlates with productivity growth. Medoff and Abraham, 1981, and Medoff and Abraham, 1980, use performance ratings among professional and managerial employees in three U.S. corporations, but do not find any statistically significant correlation between these ratings and wage growth. They conclude that the on-the-job training model explains only a small part of the observed return to labour market experience. This result rests on the assumption that these ordinal performance ratings are unbiased measures of productivity.

\subsubsection{The US evidence}

Table 4.1 contains a summary of the main empirical studies on the wage returns to training. For the US training returns have been estimated using a number of datasets. Some of these, such as the Panel Study of Income Dynamics (PSID) or the Current Population Survey (CPS), have very limited information on training. The most widely used datasets are the Employment Opportunity Pilot Project Survey (EOPP) and especially the National Longitudinal Survey of Youth Cohort (NLSY) which has arguably the most precise and comprehensive information on training.

Lynch, 1992, is one of the first studies that uses the early waves of the NLSY (1981 and 1983) to estimate wage returns. The sub-sample she considers includes those who did not graduate from college and finished schooling by the 1980 interview date. She presents return estimates using both Heckman two-step selectivity corrections and fixed effects regressions. In the estimations she controls for tenure, experience and personal and job characteristics. The two-step estimates show that a week of company training (completed or uncompleted) is associated with a 0.2 per cent higher wage. This estimate is significant for uncompleted training. The fixed effect estimates do not show a significant impact on wages. One drawback of these early NLSY data is that training is only reported if it lasted longer than one month. It seems likely that many training spells are left unreported. Of the 12,686 individuals in the NLSY only 3,064 are used in the analysis. Of these 128 report on-the-job training, which is 4.2 per cent of the sample.

Veum, 1995, uses the NLSY for the years 1986 to 1990. After 1986 the training questions changed and also covered training lasting less than a month. Respondents could report information for up to 4 training programs. Veum considers those who had completed formal schooling by the 1986 interview. 
Table 4.1 Wage returns studies

\begin{tabular}{|c|c|c|c|c|c|c|c|}
\hline country & study & dataset & period & traindef & method & b & se \\
\hline \multirow[t]{7}{*}{ United States } & Lynch (1992) & NLSY & $1980-1983$ & Weeks of OJT & $\mathrm{OLS}+\mathrm{SC}$ & 0.0020 & \\
\hline & & & & & FE & -0.0002 & -0.0012 \\
\hline & Veum (1995) & NLSY & $1986-1990$ & Hours of OJT & OLS & 0.0073 & -0.0399 \\
\hline & & & & & FE & 0.0090 & -0.0392 \\
\hline & Parent (1999) & NLSY & $1979-1991$ & Years of OJT & OLS & 0.1692 & -0.0255 \\
\hline & & & & & $\mathrm{HT}$ & 0.1216 & -0.0372 \\
\hline & Loewenstein and Spletzer (1998) & NLSY & 1988-1991 & Formal Company Training & FE & 0.0346 & -0.0193 \\
\hline \multirow{2}{*}{ Canada } & Daniel Parent (2003) & FSLS, Men & 1995 & Career of job-related training & FE & 0.1034 & -0.0311 \\
\hline & & FSLS, Women & & & FE & 0.0168 & -0.0292 \\
\hline \multirow{17}{*}{ United Kingdom } & Booth (1991) & BSAS, Men & 1987 & incidence, formal job-related & OLS & 0.1060 & -0.0380 \\
\hline & & BSAS, Women & & & OLS & 0.1660 & -0.0400 \\
\hline & Booth (1993) & BNSG, Men & $1986 / 87$ & weeks in 1st year, employer provided & $\mathrm{OLS}+\mathrm{SC}$ & 0.0100 & -0.0020 \\
\hline & & BNSG, Women & & & $\mathrm{OLS}+\mathrm{SC}$ & 0.0100 & -0.0030 \\
\hline & & BNSG, Men & & & FE & -0.0020 & -0.0030 \\
\hline & & BNSG, Women & & & FE & 0.0100 & -0.0040 \\
\hline & Blundell et al. (1996) & NCDS, Men & 1981-1991 & incidence, on-the-job empl provided & quasi-difference & 0.0360 & -0.0180 \\
\hline & & NCDS, Men & & & & 0.0660 & -0.0170 \\
\hline & & NCDS, Women & & & quasi-difference & 0.0030 & -0.0320 \\
\hline & & NCDS, Women & & & & 0.0460 & -0.0320 \\
\hline & Blundell et al. (1999) & NCDS, Men & 1981-1991 & empl prov course without qual & OLS & 0.0830 & -0.0170 \\
\hline & & NCDS, Men & & & FE & 0.0500 & -0.0190 \\
\hline & & NCDS, Men & & & IV & 0.0650 & -0.0440 \\
\hline & & NCDS, Women & & & OLS & 0.1420 & -0.0220 \\
\hline & & NCDS, Women & & & FE & 0.1100 & -0.0260 \\
\hline & & NCDS, Women & & & IV & 0.0270 & -0.0560 \\
\hline & Arulampalam and Booth (2001) & NCDS & 1981-1991 & incidence, work related & Selection model & 0.3420 & -0.1740 \\
\hline \multirow{4}{*}{ France } & Goux and Maurin (2000) & $\mathrm{FQP}$ & 1988-93 & participation, firm provided & $\mathrm{OLS}+\mathrm{SC}$ & -0.0570 & -0.0680 \\
\hline & & $\mathrm{FQP}$ & & & OLS & 0.0710 & -0.0200 \\
\hline & Denis Fougère et al. (2001) & FQP, Job switchers & 1993 & participation, firm provided & Switching Regr. & 0.2930 & -0.1210 \\
\hline & & FQP, Non switchers & & & Switching Regr. & 0.1280 & -0.0910 \\
\hline \multirow[t]{3}{*}{ Germany } & Pischke (2001) & GSOEP & $1986-89$ & years, work related & FE, growth & 0.0380 & -0.0270 \\
\hline & & & & & FE & 0.0260 & -0.0190 \\
\hline & Kuckulenz and Zwick (2003) & $\mathrm{BIBB} / \mathrm{AAB}$ & 1998/99 & incidence, work-related & Selection Model & 0.1500 & -0.0400 \\
\hline \multirow[t]{2}{*}{ Norway } & Pal Schoene $(2002)$ & NSOE & $1989 / 1993$ & incidence, employer provided & OLS & 0.0530 & -0.0070 \\
\hline & & & & & FE & 0.0110 & -0.0060 \\
\hline \multirow[t]{2}{*}{ Netherlands } & Leuven and Oosterbeek (2002) & EPIO & 2000 & incidence, work related & OLS & 0.0980 & -0.0290 \\
\hline & & & & & $\mathrm{SC}$ & -0.0050 & -0.0560 \\
\hline Switzerland & Gerfin (2003) & SLFS & $1998-2000$ & incidence, work-related & Matching & 0.0200 & \\
\hline
\end{tabular}


About $18 \%$ report having participated in company training, while the average time spent on this training was 135 hours. This does indeed suggest that many company training programs are of short duration. Veum finds that one hour of company training increases wages by 0.7 to 0.9 per cent.

Parent, 1999, uses the NLSY for the longer period of 1979 to 1991 . About 16 per cent of the individuals report having participated in on-the-job training. He estimates both simple OLS regressions and IV regressions with Hausman - Taylor type instruments that are orthogonal to the individual fixed effects. ${ }^{73}$ The OLS estimate of the return to one full-time year of training is 18 percent. This estimate drops slightly in his partial fixed effect estimation to 12 percent.

Frazis and Lowenstein, 2003, estimate various specifications using the NLSY data for the years 1979 to 2000 . They focus on rates of return - instead of wage returns, and find that at median training of 60 hours the rate of return is in the 150-175 percent range, while their preferred estimate that takes into account heterogeneity in wage growth (fixed effects wage growth regressions) is a rate of return in the region of 40 to 50 percent for one full-time week of training.

Finally, Parent, 2003, uses data for Canada from a Follow-Up to the School Leavers Survey (FSLS). He estimates fixed effects models for men and women separately. For men participation in employer-supported training increases hourly wages by more than 10 percent. For women the effects is much more modest, about 2 percent, and not statistically significant. Parent also reports returns to weekly earnings. These returns are higher, both for men (0.1364) and for women (0.0564), suggesting that there might be employment effects.

With the exception of Lynch, 1992, (and to some extent of Parent, 1999), return estimates for the US are high. There are various possible explanations for Lynch's results. First, her sample is made up of less educated individuals. Second the data are for the early 1980s, while it is widely documented that returns to skill increased substantially over the 1980s. A more likely explanation for her relatively low return estimates is the fact that training spells that lasted less than a month are not reported in her data (the same holds for most of the data used in Parent, 1999).

\footnotetext{
73 Hausman and Taylor, 1981, observed that for time-varying variables the deviation from their time mean can be used as instruments. They also showed that the time means of the exogenous time-invariant variables can be used as instruments for the time-invariant endogenous variables. This requires that there are at least as many exogenous time-invariant variables as endogenous time-invariant variables.
} 
This not only suggests that there are quickly decreasing returns to train ing, but is also suggestive that the high returns that subsequent studies found are largely due to relatively short training spells.

\subsubsection{The European evidence}

There are numerous studies that estimate wage returns for the United Kingdom. An early study is Greenhalgh and Stewart, 1987, that uses 1975 data from the British National Training Survey. The outcome variable they consider is occupational status. It is found that training, defined as anything that may have helped an individual to learn/do his work, has a significant effect on occupational status, but the marginal benefit is zero after four weeks. Booth, 1991, uses data from the 1987 British Social Attitudes Survey (BSAS). The outcome variable that Booth considers is annual earnings. She finds high returns, 11.2 per cent for men and 18.1 percent for women. Potential selectivity into training is not taken into account. Booth, 1993, improves on this using the 1980 British National Survey of Graduates and Diplomats (BNSG). This study reports estimates using both selectivity corrected OLS and fixed effect estimates. She finds that one week of training in the first year on the job increases earnings by one per cent both for men and women. Unfortunately, her exclusion restriction in the training probit lack explanatory power so that her Heckman two-step procedure is basically identified on functional form only. Turning to fixed effect estimates, there are no longer nonzero returns for men, while the point estimate for women remains the same.

A number of studies have used the National Child Development Survey (NCDS) to estimate the wage returns to training. These studies look at training incidence and wage growth over the period 1981 to 1991. Blundell et al, 1996, use a quasidifferencing approach that allows unobserved heterogeneity to affect wages differentially over time. In addition, the remaining transitory shocks are instrumented using individual first job characteristics and wages, observed ability, family background, pre-1981 training and post school qualification variables other than a degree. They find that participation in employer provided on-the-job training increases wages by 3.6 per cent for men. For women there is no significant effect on wages. Participation in off-the-job training has higher returns, about 7 percent for men and 5 per cent for women. 
Blundell et al, 1999, report OLS, fixed effect and instrumental variable estimates using the same data but for a somewhat larger sample, and consider employer provided training courses. For men, OLS gives a wage return of 8.3 per cent, the fixed effect estimate is lower at 5 per cent while the IV estimate is 6.5 per cent. Returns to training courses that do lead to a qualification are of similar magnitude. For women the returns are somewhat less clear cut, but still considerable. The OLS estimate of the return to an employer - provided training course that does not lead to a qualification is about 15 per cent, the estimated return from the fixed effect specification is about 12 percent, and the IV estimate drops to about 3 percent. Returns are higher for training courses that do lead to a qualification. Here the fixed effect estimate is over 17 per cent and the IV estimate about 8 per cent.

Finally, Arulampalam and Booth, 2001, estimate a hurdle model on the NCDS data, where the number of training occurrences is instrumented with the local unemployment rate in 1981, marital status, the presence of children, early ability measures and pre-1981 training courses. It is found that participation is associated with a 41\% higher wage growth between 1981 and 1991 . This study only finds significant returns to incidence, but not to the number of training courses.

For countries other than the US or the UK, evidence on training returns is more scant. Goux and Maurin, 2000, estimate wage returns to employer - provided training for France. While their OLS estimate is 7.1 per cent and significant, it drops to -5.7 with a large standard error after correcting for selectivity. This finding is somewhat at odds with the results of Fougere et al, 2001, who find returns to training participation for job-switchers close to 30 percent. For non-switchers the point estimate is still a sizable 13 percent, but no longer statistically significant. Pischke, 2001, is a careful study using the German Socio Economic Panel (GSOEP). He present both fixed effect estimates and is the first to estimate fixed effect wage growth regressions. He finds that one year of full-time work-related training increases wages by 2.6 to 3.8 percent. These estimates are however not significant. Kuckulenz and Zwick, 2003, have access to the 1999 "Qualification and Career Survey" (BIBB/IAB), a 0.1 per cent sample of all employed Germans. They find that participation in work-related training is associated with more than 15 per cent higher wages after correcting for the endogeneity of training. Their exclusion restriction includes self perceived training needs and dummy variables indicating whether the employer went through a period of downsizing or workplace restructuring. Schone, 2002, finds that training participation is associated with 1 
per cent higher wages in Norway. Gerfin, 2003, finds effects twice that size for Switzerland using matching methods, where it is worthwhile to note that the average training course lasted 17 hours (median 8). Finally, Leuven and Oosterbeek, 2002, find cross sectional returns to training in the Netherlands of about 10 per cent, but this return drops to almost zero after narrowing down the comparison group of non-participants.

\subsubsection{Evidence from the ECHP}

Cross - country comparisons of private returns to training are difficult because of the different definitions of training, different empirical specifications and econometric methods. Some comparative perspective can be gained for European countries if we estimate the same specification - model [4.2] - using the European Community Household Panel, a dataset explicitly conceived for international comparisons, and focusing on the effects of training incidence. Since we are interested in the stock rather than in the flow of training, we cumulate this variable from the initial year of the sample, which we choose to be 1995, to the final year, 2001. Because of the problems associated with the definition of the reference period - discussed in some detail in Chapter 2 - we only use odd years. We select the sub-sample of workers aged 25 to 59 who are employed full-time in the private sector and work between 15 and 70 hours per week. Table 4.2 presents the results by country, using both ordinary least squares and fixed effects.

Table 4.2 Private returns to training. ECHP 1995-97-99-01.

\begin{tabular}{l|cc}
\hline & OLS & FE \\
\hline Denmark & $.042 * * *(.005)$ & $.020 * * *(.007)$ \\
Netherlands & $.037^{*} *(.019)$ & $-.030(.031)$ \\
Belgium & $.055^{*} *(.011)$ & $.026 *(.016)$ \\
France & $.072 * * *(.007)$ & $.000(.013)$ \\
UK & $.079 * * *(.005)$ & $.019 *(.010)$ \\
I reland & $.081 * * *(.010)$ & $.005(.022)$ \\
Italy & $.097 * * *(.013)$ & $.038^{* * *}(.014)$ \\
Greece & $.216 * * *(.027)$ & $.060 *(.032)$ \\
Spain & $.072 * * *(.007)$ & $.017(.012)$ \\
Portugal & $.180 * * *(.013)$ & $.105 * * *(.025)$ \\
Austria & $.103 * * *(.006)$ & $.004(.012)$ \\
Finland & $.055^{*} * *(.008)$ & $.038 * *(.018)$ \\
& & \\
\hline
\end{tabular}

Note: each regression include age, age squared, country, year, education, gender, marital status and industry dummies. 
Ordinary least square estimates of the impact of training incidence on log hourly earnings range between 3.7 and 21.6 percent, and are higher in the countries with lower incidence, especially Greece and Portugal. Since we have defined training incidence as a stock variable ranging between 0 and 4 , this impact is the expected return to receiving at least one training course in one year of the sample.

When we turn to fixed effects, however, estimated returns are considerably lower and often not statistically different from zero, with the noteworthy exception of Denmark, the UK, Italy, Greece, Finland, Portugal and Belgium. Figure 4.2 plots these estimated returns against training incidence, and shows some evidence of a negative relationship.

\section{Figure 4.2 Returns to training and training incidence, by country}

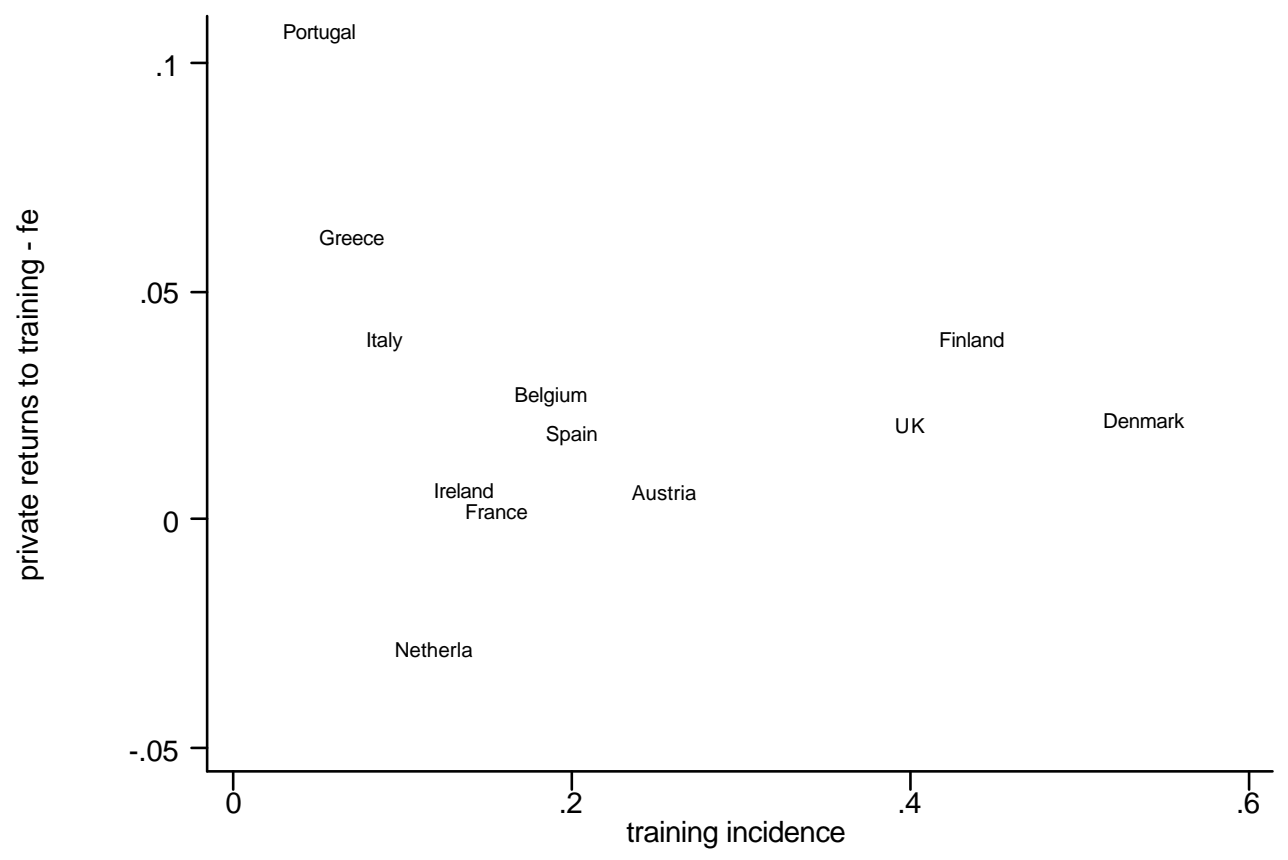

Overall, the returns to private-sector training are high compared to the returns to schooling. Since over 65 percent of the training courses in the ECHP data are shorter than 2 weeks, our estimates suggest that a relatively short training spell administered to a worker during a year could increase log hourly earnings by close to 2 percent in Denmark and the UK, 4 percent in Italy and Finland, and an hefty 10 percent in Portugal. For these countries, one additional year of education yields for men - 6.4 percent in Denmark, 6.2 percent in Italy, 9.7 percent in Portugal, 8.6 percent in Finland and 9.4 percent in the UK (see Harmon, Walker and Westergaard Nielsen, 2000). 


\subsubsection{Are the wage returns to training really high?}

These high returns raise the question whether the estimates reviewed above are indeed causal effects. To illustrate this point, consider the recent work by Leuven and Oosterbeek, 2004, who exploit a provision in the Dutch tax system that allows employers to deduct an extra 40 percent of the training cost of employees that are 40 years or older from their taxable profits. The structure of the age-dependent tax deduction is therefore discontinuous at age 40. All workers younger than 40 are excluded from this additional deduction, while all workers aged 40 or older are included. This structure constitutes a perfect example of a so-called regression discontinuity (RD) data design. While the IV point estimates do not provide evidence of substantial returns to employer provided training, they are too imprecise to warrant firm conclusions.

Although IV seems promising, and a few studies discussed above have followed this approach, it is very difficult to come up with variables that affect wages only through training. An alternative approach is followed by Leuven and Oosterbeek, 2002. The idea is to narrow down the comparison group to those non-participants who did not participate due to some random event. This is achieved by using the information obtained through two especially designed survey questions in the Netherlands. The first is whether there was any training related to work or career that the respondent wanted to follow but did not do so. The second asks whether this non-participation was due to some random event such as family circumstances, excess demand for training places, transient illness, or sudden absence of a colleague. Respondents who give an affirmative answer to both questions are arguably a more appropriate comparison group.

It turns out that OLS estimates based on these data are similar in magnitude to those found for the studies cited above, and equal to 12.5 percent for those participating in one training course (with median duration of 40 hours) during the past 12 months. Restricting the comparison group to workers who wanted to participate in training but did not do so reduces the estimated return to 8.7 percent. When the comparison group is further restricted to those workers who wanted to participate in training but did not do so due to some random event, the point estimate of the return to training is 0.6 percent. Although the sample size does not allow precise estimation of the latter effect, the credibility of the proposed strategy is supported by the fact that on each subsequent narrowing down of the 
comparison group, the participants and comparison individuals are increasingly similar on observed characteristics. In line with this increased similarity of trainees and non-trainees, the point estimate of the return to training consistently drops.

While instructive, these results are based on a small sample. The question is whether they can be generalized to the relevant population. Under some homogeneity assumptions, they measure the average treatment effect on the treated. However, if these assumptions do not hold, they capture a local average treatment effect. It is the former which has policy relevance, not the latter (see Angrist, 2004). Furthermore, in all the studies reviewed here, the effect of training on wages is estimated by restricting the sample to employed workers; therefore, estimated returns might also be biased downward, due to exclusion from the control group of those that are expelled from employment between two observations (or during the time period covered by the survey). For instance, consistent with the IV estimates of Leuven and Oosterbeek (2004), OECD (2004) and Bassanini (2005) find non-significant wage returns for workers aged 35 years or more, using ECHP data; training, however, is found to enhance job security of this category of workers, so that once foregone income due to unemployment spells is taken into account, training appears to increase earnings at any age.

\section{Summary}

The bottom line of the discussion in this section can be summarized as follows:

1. estimated private returns to training are high, especially in the countries where training incidence in rather low - Portugal and Greece are good examples;

2. these estimates could be over-stated by the failure to control in an adequate way for the spurious correlation of training with confounding factors that affect wages;

3. recent research based on the identification of credible instruments for training participation finds much lower returns. It is still an open question, however, whether these results can be generalized.

\subsection{Returns to employers}

Returns to employers depend on the effects of training investment on productivity and wages, as well as on training costs. Due to measurement problems, there are relatively few studies on the productivity effects of training. 
These studies are usually based on firm level data, because of the issues surrounding the measurement of individual productivity. The papers in this line of research typically regress some measure of output on a vector of inputs which includes training. As with the wage return studies, the comparison of results between studies is hampered by the differences in training definitions. In addition, there is a large variety of functional form specifications and output measures, which further complicates comparison.

There are basically two types of quantitative studies: survey based studies, and case studies - sometimes company-sponsored. Survey based studies have the potential advantage that the results are representative for a particular population of firms, and that the findings can be generalized. The disadvantage is that they usually lack information on the cost of training, and it is therefore in general not possible to estimate rates of return using survey data. Case studies have the advantage that they more often have information on cost.

Dearden et al, 2000, combine British data from various sources and construct a panel of industries covering the period 1983-1996. Training information comes from the Labour Force Survey. They find that increasing the proportion of trained workers in an industry by 5 percentage points leads to a 4 percent increase in value added per hour, and a 1.6 percent increase in hourly wages. Barrett and O'Connell, 2001, analyze a sample of Irish firms and find that training which provided "broad skills and knowledge" has a positive impact on sales growth between 1993 and 1995. In particular, increasing the number of training days per employee by 1 percent increased productivity by 3 percent. On the other hand, they find that training "directly related to the operation of the company" did not have an impact on productivity.

Zwick, 2004, uses German IAB data to study the impact of participative work practices on firm productivity and finds that training positively affects training. Brunello, 2004, uses survey data for 97 Italian large enterprises and estimates by fixed effects the relationship between value added per head and alternative measures of training. He finds that a 10 percent increase in the average number of hours of training per head increase productivity in his sample by 1.32 percent.

Most studies that consider the productivity effects of training are however for the United States. Bartel, 1994, uses a survey dataset consisting of 495 business lines, and compares businesses that implemented formal training programs (in 1983) with those that did not. She finds that the former experienced a 6 percent higher 
annual productivity. Holtzer et al., 1993, use data on firms that applied for training grants between 1988 and 1989 in Michigan. They estimate fixed effect regressions of hours of training on the scrap rate and found that doubling training reduced the scrap rate by 7 percent (worth about $\$ 15,000$ ). This effect, however, halved in the next year, and it seems likely that this dissipation would have continued in subsequent years.

Black and Lynch, 2001, use a nationally representative sample of businesses to estimate a production function with sales as the dependent variable. They are able to estimate fixed effects regressions, but do not find any effect of training on productivity. Bartel, 2000, provides a comprehensive review of the literature measuring the employer's rate of return, including case studies. As discussed above, cost data are necessary to calculate rates of return. She concludes that large scale survey studies are uninformative on rates of return because of missing cost data, and that econometric studies more in general fail to solve endogeneity issues. She also reviews 16 company case studies (published between 1987 and 1997) that measure rates of return on training investments. With the exception of two studies, Bartel argues that this research is plagued by serious methodological flaws, including inappropriate evaluation design, lack of attention to selection bias, a focus on short term outcomes, and using self-reports from trainees as information on productivity gains from training. The two studies that were well conceived found high rates of return on investment, ranging from 100 to 200 percent. Although these studies get rid of within - company selectivity, they do not solve between company selectivity issues and it is unclear to what extent the results from these two companies can be generalized to the population of enterprises as a whole.

The limited information on productivity hampers the possibility of developing a direct test of the absolute wage compression hypothesis advocated by Stevens, 1994, and Acemoglu and Pischke, 1999b, and discussed at length in Chapter 1. In a recent attempt to probe the standard Beckerian view of general training against this hypothesis, Bassanini and Brunello, 2003, develop an upper bound estimator of the relationship between wage compression and training, which does not require measures of productivity. Under the maintained hypothesis that wages and productivity are positively correlated, they estimate for a sub-sample of European country the relationship between training incidence and training wage premia. Their evidence is that this relationship is negative. Since most of the training is general in 
nature, they conclude that only the wage compression view is consistent with their results.

The combined findings on the productivity and wage effects of training begs the question whether training has a positive effect on the profitability of training firms. Blundell and co-authors, 1999, review this literature and conclude that "...not all the productivity gains resulting from training are compensated through a corresponding increase in individual remuneration, so that the investment in training remains profitable for firms.." (p.13). Importantly, the profitability of the investment appears to extend to future employers, who hire already trained employees. This evidence confirms that poaching externalities may be an important component of the training decision ${ }^{74}$.

\subsection{Training and growth}

As mentioned in the introduction to this chapter, most of the empirical literature on the relationship between human capital and growth finds that human capital matters. Unfortunately, human capital is typically measured with the average number of years of schooling, and no attempt has been made, so far, to investigate the importance of training, mainly because of lack of suitable data. In a recent review of the empirical literature, de la Fuente and Ciccone, 2002, find that the contribution of years of schooling to productivity growth in the OECD between 1960 and 1990 has been equal to 15.36 percent. Our evidence in Chapter 2, as well as most of the empirical literature, shows that education and training are complements in the production of human capital. We infer from this that schooling affects growth both directly and indirectly, by accelerating the accumulation of human capital.

\section{Summary}

We summarize the discussion in this chapter as follows:

1. Traditional wage return studies, that depend on differencing (fixed effect) methods where non-participants are used as a comparison group, often find high wage returns. Studies that exploit arguably exogenous variation in training participation are in their infancy. They find much lower wage effects of training. These estimates, however, are imprecise, and rely on small and somewhat specific samples.

\footnotetext{
${ }^{74}$ Collier, Green, Peirson and Wilkinson, 2003, show that training increases company survival.
} 
2. Compared to the numerous studies on wage effects of training, there are relatively few studies on the impact of training on productivity. This is mainly explained by the lack of data on productivity. If such information is available then it is either at the industry or, in the best case, at the firm level. These studies do not give a consistent picture of the impact of training on output.

3. Rates of return estimates are even scarcer than productivity studies. This is because data on cost are even more difficult to find than data on output. When such data are available (in company case studies) it is unclear to what extent we can generalize the results. 


\section{Chapter 5: Is there scope for policy?}

In the European Employment strategy designed in Lisbon, more and better education and training are considered as key factors to increase the competitiveness of European countries or to avoid social exclusion. The view is that training and lifelong learning are especially valuable for those workers - the old and low skilled - who face the highest risk of being negatively affected by the ongoing economic changes.

Public training policies can be justified either on efficiency or on equity grounds. Both of them are crucial. Perhaps surprisingly, even if there is a large consensus in the economic literature on the importance of training, there is less agreement on whether the observed levels of investment in training are inefficiently low and, consequently, on the necessity of policy interventions. In spite of the many theoretical reasons for under-investment, discussed in Chapter 1 , it is difficult to come up with convincing empirical evidence that workplace training is underprovided, and even more difficult to know how far the private optimum deviates from the first best. The key reason, we have argued in Chapter 4, is that training costs and returns - on which efficiency evaluations are based - are not well measured.

A part from efficiency arguments, equity considerations can be relevant to justify training for groups of workers in disadvantaged economic conditions. If equity is interpreted as equality of opportunities - as in Roemer, 1998, low participation in training activities by some disadvantaged categories of workers may be not socially desirable, even if efficient. A key issue here is whether economic policy should try to correct outcomes - differences in training - or to modify initial conditions - for instance differences in educational attainment. In addition, since it is often very costly to increase the human capital of low skilled and older workers, costeffectiveness considerations have to be taken into account.

We start this final chapter with a brief discussion of how the design of training policies is strictly related to the type of potential market failures conducive to under-provision. Next we turn to consider the empirical evidence on the relevance of efficiency and equity issues. We then propose a political economy view of training subsidies. The last two sections of the chapter are devoted to examining the key features of the training policies in place and the implications for training of 
labour and product market reforms. A long Appendix describing existing policies in some detail concludes.

\subsection{Policy Responses to Market Failures in Training Provision}

Since market failures in the provision of training can originate both in the labour and in the capital market, the appropriate policy intervention depends on the nature of the problem at hand, as illustrated in Table 5.1. With perfectly competitive capital and labour markets, there is little role for policies pursuing efficiency. If capital and labour markets are characterized by imperfections, however, training investment may be lower than the efficient level and a natural policy approach is to try to eliminate the sources of inefficiency. Credit constraints may be relaxed both by interventions which make credit markets more competitive and by subsidies paid out to constrained individuals. When labour markets are imperfect and there is absolute wage compression, firms are involved in general training and bear the costs. In the case of under-provision, training subsidies should be targeted at individuals and firms. An additional role for policy is to reduce asymmetric information in the market for training and improve contractibility by removing the problems which emerge when the worker and the firm have different information on the contents of training.

Since the identification of market failures and unequal circumstances are prerequisites to sensible public intervention, we turn to examine the empirical case for the under-provision of workplace training and for inequality of opportunity in the investment.

\subsection{Under-provision: what is the evidence?}

As shown in Chapter 2, the empirical literature on training shows that there is substantial variation across countries and across socio-economic groups in training participation rates, with Nordic European countries showing higher participation than Southern European countries and low-educated and older workers generally participating less than other groups in training activities. 
Table 5.1. Different types of market failures and policy interventions aimed at restoring efficiency

\begin{tabular}{|c|c|c|c|c|}
\hline & $\begin{array}{c}\text { Perfectly } \\
\text { competitive } \\
\text { capital markets }\end{array}$ & Policy interventions & $\begin{array}{l}\text { Capital market } \\
\text { imperfections }\end{array}$ & Policy interventions \\
\hline \multirow{2}{*}{$\begin{array}{l}\text { Perfectly } \\
\text { competitive } \\
\text { labour markets }\end{array}$} & Efficient investment & & $\begin{array}{l}\text { Training investment can } \\
\text { be inefficient }\end{array}$ & Subsidies to individuals \\
\hline & & & $\begin{array}{l}\text { Workers are not able to } \\
\text { accept a sufficiently low } \\
\text { wage or are unable to } \\
\text { insure against uncertain } \\
\text { training returns }\end{array}$ & \\
\hline \multirow[t]{2}{*}{$\begin{array}{l}\text { Labour market } \\
\text { imperfections }\end{array}$} & $\begin{array}{l}\text { Training investment } \\
\text { can be inefficient }\end{array}$ & $\begin{array}{l}\text { Policies that reduce } \\
\text { contractibility problems }\end{array}$ & $\begin{array}{l}\text { Training investment can be } \\
\text { inefficient }\end{array}$ & $\begin{array}{l}\text { Policies that reduce } \\
\text { contractibility problems }\end{array}$ \\
\hline & $\begin{array}{l}\text { Contractibility problems } \\
\text { are less relevant since } \\
\text { part of the training is } \\
\text { financed by the firm }\end{array}$ & Subsidies to firms & $\begin{array}{l}\text { Investment higher than } \\
\text { with perfectly competitive } \\
\text { labour markets accompanied } \\
\text { by capital market imperfections }\end{array}$ & $\begin{array}{l}\text { Subsidies to firms and } \\
\text { individuals }\end{array}$ \\
\hline
\end{tabular}


These differences reflect individual incentives to train, which are affected by labour and product market institutions - as discussed in Chapter 3 - and by training and education policies already in place.

When considering workplace training policy, one would like to know first of all whether training outcomes produced by economic agents in the absence of policy would have attained the first best allocation. If yes, there would obviously be no role for policy on efficiency grounds. To do that, however, we would need to observe training outcomes in the absence of policy, obviously a difficult task given that such policies are quite widespread. Nor can we infer nefficiency by observing how ubiquitous training policies are, since many of these policies may be ineffective and not altering private outcomes.

Another difficulty with assessing the presence of under-investment is that such an evaluation would require that we compare social and private benefits with social and private costs. Again, the discussion in Chapter 4 has shown that we know very little about costs. Some have claimed that evidence of under-investment is the combination of high private rates of return to training and low training incidence, and have quoted in support several studies suggesting that private rates of return to training are considerably higher than the real rate of return of other investments with similar risk. Even if we take such evidence at face value, we question whether one can infer from high returns to training and low investments the existence of under-provision. Assuming that the marginal returns to training decrease with the stock invested, high observed returns are consistent both with the presence of liquidity constraints, which prevent some individuals from investing, and with high marginal costs of training. While the former explanation supports under-provision, the latter explanation is perfectly in line with efficient provision.

A reason for under - provision is that private and social returns to workplace training do not coincide, because of the positive externalities generated by the complementarity of training on innovation (see Acemoglu, 1997) and of the positive spillovers on the productivity of unskilled employees (see J ohnson, 1984). As briefly reviewed in Chapter 4, however, we have little empirical evidence of the positive external effects of human capital, and what we have refers exclusively to the impact of schooling.

As discussed in Chapter 1, models of workplace training in imperfectly competitive labour markets do not suggest that private outcomes in the absence of 
policy are necessarily inefficient. The observation that employers who invest in general training are forced to share some of the revenues with employees - the hold up problem - or the fact that some of the returns to training are captured by future employers - the poaching externality problem - can both be causes of under - provision but do not necessarily produce it, as Bishop, 1997, concludes. The Appendix 1.B to Chapter 1 shows that, when turnover is endogenous, a negative relationship between training and turnover can undo the negative effects of hold up and poaching externalities and even produce over - investment.

In the next two sub-sections, we examine the evidence on the effect of training on turnover, and review the limited evidence on the importance of credit constraints. To anticipate our conclusion, the evidence at hand is not sufficient to claim the existence of under-provision, or, even more difficult, to measure the gap between the socially optimal allocation and the outcomes produced by private agents. We conclude that one needs to be prudent when designing public policies aimed at raising the provision of workplace training.

\subsubsection{Training and turnover}

We investigate the empirical relationship between training and turnover using ECHP data and focusing on voluntary quits. The ECHP dataset includes two interesting questions on turnover behaviour, which can be used to study whether (voluntary) turnover is affected by employer-provided training: first, workers are asked to indicate the year when they stopped working in their previous job. Second, they are asked to indicate the reason of separation. If we focus on individuals who were trained by the employer between year $t-1$ and year $t$ and compute the percentage of those who quitted between year $t+1$ and year $t+2-$ conditional on staying in the job in year $\mathrm{t}$ - we find that the percentage of workers who leave for a better job is on average 6.94 percent in the sample of 11 European countries with available data ${ }^{75}$. This percentage increases to 9.88 percent when we add voluntary turnover due to non economic reasons - such as childbearing, moving, marriage and else. Therefore, a European employer who is considering training a worker can expect - based on this data, that 7 to 10 trained workers out of 100 quit between one and two years after training.

\footnotetext{
75 These countries are Denmark, Belgium, France, the UK, Ireland, Italy, Greece, Spain, Portugal, Austria and Finland.
} 
Does turnover decline among trained employees? We investigate this question by selecting the individuals who had received employer provided training from J anuary in the year $t-2$ to $t$, the time of the survey, and by asking whether they have quitted their last job in the year $t+1$, conditional of no turnover in year $t$. We choose to focus on turnover one year after the survey rather than in the same year to avoid the risk of having separations taking place before the training event, and to reduce endogeneity issues. The empirical model is

$$
q_{i t}=\alpha+\beta X_{i t}+\gamma \tau_{i, t-1}+f_{i}+\varepsilon_{i t}
$$

where $\mathrm{q}$ is turnover - a dummy equal to 1 in the event of turnover and to 0 otherwise; $X$ is a vector of time varying controls, $\tau$ is the training dummy, $\mathrm{c}$ is an individual fixed effect and $\mathrm{e}$ is a random error orthogonal to training. If more able individuals are less likely to quit and more likely to receive training, failure to account for unmeasured individual fixed effects could seriously bias downwards our estimates. To take this into account, we estimate a linear probability model using fixed effects. The vector $X$ includes age, age squared, year dummies and five dummies representing the time varying degree of job satisfaction. Table 5.2 reports the estimates separately for turnover to a better job - column 1 in the table - and for any voluntary turnover - column 2.

In these estimates, we consider the period 1996-2000 and restrict our attention to individuals aged 25 to 54 . As expected, our estimates show that turnover declines with age and with the index of job satisfaction.

Conditional on these factors, the relationship between training and turnover is negative, small and not statistically different from zero. Therefore, our results lack sufficient precision to reach any firm conclusion. Ambiguous results emerge also from the few papers in the literature which address this issue. Lynch, 1991, using US data on young workers (National Longitudinal Survey of Youth), finds that while on-the-job training (more firm specific) reduces the probability of job separations, workers participating in off-the-job training (more general) are more likely to leave their current employer. Veum, 1997, using the some source of data, concludes that trainees are equally likely to quit than non-trainees. Similar results are obtained by Krueger and Rouse, 1998, by focusing on personnel files from two large U.S. companies. On the other hand, Parent, 1999, using data from the NLSY, shows that on the job training reduces the probability of job separations. 
Table 5.2. Estimates of the probability of separation in year $t+1$ as a function of employer provided training in years t- 2 to $t$. Linear probability model. Fixed effects. 1996-2000

\begin{tabular}{|c|c|c|}
\hline & $\begin{array}{l}\text { Quitted because } \\
\text { of a better job }\end{array}$ & $\begin{array}{l}\text { Quitted for } \\
\text { different reasons }\end{array}$ \\
\hline $\begin{array}{l}\text { Trained by employer between } \\
\text { vear t- } 2 \text { and } t\end{array}$ & $\begin{array}{l}-.002 \\
(.004)\end{array}$ & $\begin{array}{l}-.004 \\
(.003)\end{array}$ \\
\hline Age & $\begin{array}{c}-.029 * * * \\
(.005)\end{array}$ & $\begin{array}{c}-.020 * * * \\
(.004)\end{array}$ \\
\hline Age squared & $.0003 * * *$ & $.0002 * * *$ \\
\hline & $(.000)$ & $(.000)$ \\
\hline J ob satisfaction at time t: level 2 & -.012 & -.009 \\
\hline & $(.012)$ & $(.007)$ \\
\hline J ob satisfaction at time t: level 3 & $-.017 *$ & -.014 \\
\hline J ob satisfaction at time t: level 4 & $-.027 * * *$ & $-.026 * * *$ \\
\hline J ob satisfaction at time t: level 5 & $\begin{array}{c}-.049 * * * \\
(.010)\end{array}$ & $\begin{array}{c}-.043 * * * \\
(.008)\end{array}$ \\
\hline J ob satisfaction at time t: level 6 & $\begin{array}{c}-.057 * * * \\
(.010)\end{array}$ & $\begin{array}{c}-.046 * * * \\
(.009)\end{array}$ \\
\hline Nobs & 55154 & 55154 \\
\hline
\end{tabular}

\subsubsection{Credit constraints}

Even when the labour market is perfectly competitive, there could be under provision if workers investing in general training are credit constrained. The importance of these constraints is a very investigated topic in the economics of education literature. According to Kane and Rouse, 1999, for instance, the presence of these constraints is confirmed both by the fact that pupils from poor households invest less in education in spite of the higher returns from the investment, and by the higher impact that an increase in tuition costs produce on their choices. On the contrary, Carneiro and Heckman, 2004, and Cameron and Taber, 2000, argue that there is no relationship between family income and educational outcomes and that, after controlling for ability, differences in returns among groups of individuals vanish. Some attempts to study the effect of credit constraints on training are Greenhalgh and Mavrotas, 1994, and Chapman, 2002, who show that the training 
decisions of low income workers may be negatively influenced by financial restrictions. ${ }^{76}$

\subsection{Is there an Equity I ssue?}

With scant evidence on market failures and efficiency, we can justify widespread policy intervention in the market for training because of equity reasons. As discussed in Chapter 1, policies aimed at equal opportunities need to be grounded in the distinction between differences arising from variations in the individual expenditure of effort and differences arising from circumstances for which society believe individuals should not be held accountable - such as race, gender, and family background.

In this section, we replicate the empirical study by Carneiro and Heckman, 2004, on the relationship between family background and training provision using data for Europe drawn from the European Community Household Panel. Unfortunately, this dataset has not been designed to collect information on family background, which precludes a straightforward investigation of the role played by parental variables in educational choice. As a gross approximation, however, we focus on individuals aged between 18 and 30, and link up these individuals with the households of their parents to recover as much as possible the necessary information on parental background. Since the ECHP includes both a personal and a household file, this is clearly possible as long as the young individual is still living with his/her parents. When this is not the case, one can still retrieve to an extent the relevant parental background information by tracking young individuals as they leave their parents to form their own households.

Clearly, our ability to connect household information to young individuals is higher for the "olive belt" countries of Southern Europe, because young individuals in these countries tend to live in their parents' household much longer than in Northern and Continental Europe. Since individuals in these countries are overrepresented in the final sample, we need to be careful in interpreting our results as suggestive rather as representative of the European situation.

\footnotetext{
76 In his study Chapman considers job losers. After controlling for a large number of characteristics, he shows that having liquid assets at the time of the job loss is very important in determining investment in self-financed training.
} 
We select individuals working at least 15 hours per week. To connect these individuals with the households of their parents, we start by selecting a sub-sample of households with one of the following characteristics: i) one person household aged less than 30; ii) single parent with at least one child aged 16 or more; iii) couple with at least one child aged 16 or more; iv) couple without children, with both members aged less than 65 .

The household types ii) and iii) clearly include our target group of young individuals, and for these individuals it is easy to construct the relevant parental background variables. Conversely, the household types i) and iv) include those youngsters who have recently moved out of their parents' household to start their own families. For this sub-group of individuals, we use longitudinal information. To illustrate the idea, consider a young individual aged 24 in 2001 who moved out of his parents' household at 20 to live on her own or with a partner. The ECHP associates a time invariant personal identification number to each individual, but updates the household identification number when the individual moves out. Therefore, in our example we should find that the household identification number in 1997 is different and typically lower than the newly assigned household number ${ }^{77}$. In such case, we assign to the individual her old household number and the attached parental background variables. By so doing, we are able to retain in the final sample many - but not all - young individuals who are living on their own.

Parental background information includes the attained education of parents at the time of the survey. Information on the education of each parent is categorized as a dummy equal to 1 for upper secondary or college education and to 0 otherwise. Since we pool all available observations over countries and time, we include time and country dummies to capture time effects and all time invariant and country - specific institutional differences, which could affect both labour market outcomes and training. Country dummies also pick up differences in the interpretation of the training question, which could vary across countries because of broad cultural and social reasons.

Table 5.3 focuses on workplace training and presents the estimates of two alternative specifications: in column (1) and (2) we include two dummies for educational attainment - high school and less than high school, a gender dummy, age, household size and two dummies for parental background, the education of

77 We are grateful to Simona Comi for a clarifying discussion on this point. 
the father and the mother. In the remaining two columns we add interactions of these two dummies with a dummy for the countries belonging to the "olive belt". For each specification, we report the average marginal effect of parental background on participation in workplace training, both conditional and unconditional on attained individual education.

Inspection of the table shows that parental background has a statistically significant positive effect on workplace training, independently of whether we control for individual education or not. As expected, this effect, and particularly the father's education, is more relevant for young individuals in the countries of Southern Europe. We conclude that employer - provided training in Europe is not neutral to family background, contrary to the evidence for the US presented by Carneiro and Heckman. Table 5.4 confirms these results when we restrict attention to employer - provided training. With the caution required by the quality of the data at hand, our results suggest that workplace provided training in Europe, rather than offsetting the differences associated to initial circumstances, increase such differences. A tentative explanation of the uncovered difference is that family and social networks are more pervasive and more important in the Europe than in the US, and that these networks extend beyond the schooling stage - especially in Southern Europe - to influence the likelihood of finding a good job and therefore receiving company provided training.

Table 5.3. Enrolment in education. 1996-2001. Average partial effects. Weighted estimates. Dependent variable: workplace training.

\begin{tabular}{l|llll}
\hline & $(1)$ & $(2)$ & $(3)$ & $(4)$ \\
\hline High school education & $-.029 * * *$ & - & $-.028^{* * *}$ & \\
& $(.006)$ & & $(.006)$ & \\
Less than high school & $-.110^{* * *}$ & - & $-.108^{* * *}$ & \\
& $(.005)$ & & $(.006)$ & \\
Father with high school or college & $.011^{* *}$ & $.025^{* * *}$ & -.000 & .008 \\
& $(.005)$ & $(.005)$ & $(.006)$ & $(.006)$ \\
Mother with high school or college & $.021^{* * *}$ & $.034 * * *$ & $.022^{* * *}$ & $.033^{* * *}$ \\
& $(.006)$ & $(.006)$ & $(.006)$ & $(.006)$ \\
Father with high school or college $*$ & - & - & $.038^{* * *}$ & $.051^{* * *}$ \\
Olive belt dummy & & & $(.013)$ & $(.014)$ \\
Mother with high school or college $*$ & - & - & -.002 & .003 \\
Olive belt dummy & & & $(.012)$ & $(.013)$ \\
Nobs & 37492 & 37492 & 37492 & 37492 \\
\hline R Squared & .146 & .131 & .147 & .132 \\
\hline
\end{tabular}

Note: each regression includes a constant, age, gender, year and country dummies. Robust standard errors within parentheses. One, two and three stars for statistical significance at the 10, 5 and 1 percent level of confidence. 
How big is the estimated impact of family background? A switch of father's education from less than high school to higher education is estimated to increase on average - participation to workplace training by 0.011 when controlling for education and by 0.025 without controls. This effect increases to 0.038 and 0.059 when we consider Southern European countries. Since the average participation rate in the sample at hand is 0.180 , this increase is between 10 and 30 percent of mean participation - a significant effect.

Table 5.4. Enrolment in education. 1996-2001. Average partial effects. Weighted estimates. Dependent variable: employer provided training.

\begin{tabular}{|c|c|c|c|c|}
\hline & (1) & $(2)$ & (3) & $(4)$ \\
\hline High school education & $\begin{array}{l}-.024 * * * \\
(.004)\end{array}$ & - & $\begin{array}{l}-.023 * * * \\
(.004)\end{array}$ & \\
\hline Less than high school & $\begin{array}{l}-.050 * * * \\
(.004)\end{array}$ & - & $\begin{array}{l}-.048 * * * \\
(.004)\end{array}$ & \\
\hline Father with high school or college & $\begin{array}{l}.010 * * \\
(.004)\end{array}$ & $\begin{array}{l}.017 * * * \\
(.004)\end{array}$ & $\begin{array}{l}.000 \\
(.004)\end{array}$ & $\begin{array}{l}.004 \\
(.004)\end{array}$ \\
\hline Mother with high school or college & $\begin{array}{l}.010 * * \\
(.003)\end{array}$ & $\begin{array}{l}.016 * * * \\
(.004)\end{array}$ & $\begin{array}{l}.010 * * \\
(.004)\end{array}$ & $\begin{array}{l}.014 * * * \\
(.004)\end{array}$ \\
\hline $\begin{array}{l}\text { Father with high school or college * } \\
\text { Olive belt dummy }\end{array}$ & - & - & $\begin{array}{l}.038 * * * \\
(.012)\end{array}$ & $\begin{array}{l}.046 * * * \\
(.013)\end{array}$ \\
\hline Mother with high school or college * & - & - & -.001 & .001 \\
\hline $\begin{array}{l}\text { Olive belt dummy } \\
\text { Nobs }\end{array}$ & 35826 & 35826 & $\begin{array}{l}(.009) \\
35826\end{array}$ & $\begin{array}{l}(.004) \\
36075\end{array}$ \\
\hline R Squared & .127 & .119 & .129 & .121 \\
\hline
\end{tabular}

Note: each regression includes a constant, age, gender, year and country dummies. Robust standard errors within parentheses. One, two and three stars for statistical significance at the 10,5 and 1 percent level of confidence.

We conclude that there is some evidence of an equity issue in the distribution of training outcomes in the European young population, especially the one residing in the Southern part of the Continent. The uncovered differences in training outcomes by parental background partly reflect the within - country differences remarked in Chapter 2. A good example here is Italy: average parental education is much lower in the South than in the North of the country, with consequences both on educational attainment (see Brunello and Checchi, 2005), and on the distribution of training within the country.

\subsection{What do we learn from the empirical evidence?}

The discussion in the previous two sections suggests that it is difficult to make a strong case for under-provision of workplace training: measurement problems and estimation issues concur to the conclusion that more needs to be done in order to 
provide a satisfactory answer to this crucial question. We need more research on externalities, more information on costs, and to verify whether the existing estimates, especially those on the private returns to training, are robust to more adequate estimation techniques.

We are more optimistic when it comes to the distributional implications of training. We have presented evidence which clearly suggests that differences in training outcomes may be due to a significant extent to differences in circumstances which are partially out of control of individuals. If more training means better earnings and higher job security, there is ground for training policies which reduce social exclusion.

Given the status of our knowledge to date, which training policy should be recommended? And which kind of intervention is more likely to produce satisfactory results? What are the expected effects on training investment of policies and reforms which affect the rules and institutions of European labour markets? Before attempting to answer these questions, we suggest an alternative justification of training policies, which does not rely on efficiency, but is based on a political economy approach.

\subsection{A Political Economy Approach}

The scant empirical evidence that market failures exist and are important is in striking contrast with the great attention lavished by many policy-makers on lifelong learning policies. In the absence of efficiency issues, one can claim the need to redistribute and provide equal opportunity as a firm ground for public training policy. There are two problems with this view, however. First, as we shall argue below, training is not a very good redistributive instrument, since its returns to disadvantaged workers are not particularly high. Second, firms are concerned with profitability and may pay little attention to the need of compensating disadvantaged individuals, even in the presence of subsidies.

We posit that a consensus on training policies could emerge even in the absence of efficiency or equity considerations when firms and employed workers, which are generally better organized than the average individual in the population, succeed in influencing political decisions in favour of redistribution to their advantage.

In the very simple model illustrated in Appendix 5.A, we consider a majority voting equilibrium involving firms, trained and untrained employees. In the absence 
of training subsidies and taxes, there is a socially optimal provision of training. Suppose now that firms receive a training subsidy funded by a proportional payroll tax on all workers, and that workers receive wages that are proportional to productivity. Because of the subsidy, there is over-provision of training. We show that firms generally favour the policy and argue that skilled workers may also support it if firms redistribute part of the subsidy. If these two groups have sufficient political power, they can promote this policy independently of efficiency or equity considerations. Notice that such a policy could even be supported by unskilled labour if there are strong complementarities between skills and unskilled labour, as discussed by Johnson, 1984, with reference to education subsidies.

\subsection{Policies offering Financial Support to Workplace Training}

European policies offering financial support to individuals and firms usually consist of government sponsored co-financed schemes. In the last years the policy approach has shifted from direct subsidisation of external (public or private) providers of training services to co-financing schemes. The emphasis on the increase of the contribution of firms and trainees to financing training schemes responds both to shrinking government budgets and to the need of providing adequate incentives for training quality.

Co-financing schemes in Europe are oriented both to firms (levy/grant schemes, train or pay and tax deduction systems) and to individuals (subsides, vouchers, individual learning accounts, grants from specific funds, etc.). In spite of the diffusion of these systems, rigorous empirical evaluations of their effectiveness are uncommon, and many investigations provide only descriptive statistics with no counterfactual for the assessment of the policy impact. As a consequence, it is not possible at this stage to tell whether these policies have determined sufficiently high gains to compensate for their costs.

The main characteristics of each scheme are described and discussed in some detail in Appendix 5.B. Here we focus on the key aspects that are relevant for the design of effective policies. First, it is important to avoid subsidizing training investments that would have been realized in any case by the parties involved. To do this, the subsidy component of a policy package should compensate only the gap between marginal costs and marginal private benefits that may arise at the socially desirable investment level, leaving to firms or workers the responsibility of 
financing the rest. As discussed in the appendix, while some of the implemented policies respect these principles, others do not and tend to generate large deadweight losses ${ }^{78}$. Since little is known on the relevance of informal training processes, these policies may also produce inefficient substitution between informal learning processes and formal training. This risk is especially relevant for policies directed to firms, since informal training is usually aimed at imparting specific competencies and is generally paid by the employer.

It is important to stress that co-financing schemes directed at firms do not address the low training participation of particular groups of workers. As shown in Chapter 2, firms generally prefer to involve in their training programmes better educated workers who are involved in more complex jobs, and the targeting of public support in favour of particular groups of workers is likely to produce relevant substitution effects. As a consequence, when training policy is aimed at reducing perceived inequalities, it is necessary to adopt co-financing schemes focused directly on individuals (such as loan and individual subsidy schemes). These policies should be accompanied by complementary measures which favour the diffusion of information on training opportunities, the quality of the training schemes on supply and the portability of the acquired skills.

In markets that are rapidly changing, the access to training opportunities might be improved by government policies which establish information systems with data on "the availability, cost, subsidies and markets for trained personnel in a variety of occupations as well as individual data on providers" (Levin 1998). A number of countries has experimented with models for forecasting employment by occupation (in the Netherlands, Canada, USA and Australia this work has been enhanced by estimates of labour demand for newcomers or re-entrants in the workforce). However, governments often do not have any advantage over the private sector in anticipating training needs and their contribution is therefore that of collecting information and creating systems incorporating data about training providers.

An additional role for governments is that of increasing the individual benefits of training via qualification systems that make potential employers aware of the skills and competences acquired by learning experiences. Such systems are being developed on a European scale by the European Union under the Lisbon strategy and in several countries - including Australia, Austria, Denmark, Hungary, Italy,

\footnotetext{
${ }^{78}$ According to the survey of large Italian firms by Isfol, 2004, close to 53 percent of the 185 surveyed firms declared that they would have invested in training even in the of the training subsidies.
} 
Netherlands, New Zealand, Norway and UK. The goal of a transparent system of reliable vocational qualification is, however, difficult to achieve, since the definition of "skill standards" poses many measurement problems (Greenhalgh, 1999; OECD, 2003a; Colardyn, 2002).

Some countries (for example the UK) rely on locally administrated vocational qualification systems, which use different methods of assessment, with greater risk for employers and consequently lower wages for trained workers (Conlon, 2000). More satisfactory results are obtained in countries such as Finland, France and Germany, where social partners contribute in deciding the content of training and in supervising its provision. This suggests that unions may play an important role both in solving hold-up problems and in helping workers to obtain a share of training benefits, and by so doing in avoiding poaching problems. A role for the government can also be that of creating framework and legal condition that ensure that private parties are willing and able to finance training. Contracts, such as pay-back clauses, apprenticeships and working-time accounts, go in this direction and are reviewed in the appendix of this chapter.

There is little agreement on the effectiveness of training policies in addressing equity issues, and one matter of debate is whether these issues have to be posed in terms of income redistribution or in terms of better access to training opportunities. One view if that while public assistance might undermine self-reliance, training helps individuals in finding jobs that assure a decent standard of life.

Table 5.5 Private returns to training by education

\begin{tabular}{l|cc}
\hline & Average return to training & $\begin{array}{c}\text { Deviation from average } \\
\text { for the poorly educated }\end{array}$ \\
\hline Denmark & $.023 * * *$ & $-.034^{* *}$ \\
Netherlands & -.015 & -.017 \\
Belgium & $.029 *$ & -.025 \\
France & -.002 & .031 \\
UK & $.028 * *$ & $-.053^{* * *}$ \\
Ireland & .010 & -.030 \\
Italy & $.041 * * *$ & -.026 \\
Greece & $.066 * *$ & -.114 \\
Spain & $.020 *$ & -.032 \\
Portugal & $.143 * * *$ & $-.080 * *$ \\
Austria & .010 & $-.121 * *$ \\
Finland & $.040 * *$ & -.016 \\
\hline
\end{tabular}


An alternative view casts doubts on the fact that providing more human capital will enable disadvantaged workers to get jobs that meet their expectations or that such efforts can be cost-effective.

Training may not be an effective way to redistribute income when disadvantaged workers obtain relatively low returns from it. To better illustrate this point, we have replicated the fixed effects estimates in Table 4.2 by adding an interaction term between the stock of training and low education, which is expected to pick up the differential in the return to training for the poorly educated. Our results are presented in Table 5.5.

As expected, we find that the wage returns to workplace training are lower for those with less than secondary education, a result which confirm existing evidence from the US. The gap is particularly significant in the UK, Portugal and Austria. These findings suggest that a more effective strategy for improving the income of the poor could be to invest more in the highly skilled, tax them and redistribute to the poor. A relevant problem with this approach, however, is that it would breed a culture of poverty and helplessness - see Heckman, 1999.

More agreement exists on the role that can be played by policies targeted at increasing the educational attainment of disadvantaged groups. As shown in Chapter 2, there is broad support of the fact that education and training are complements, and that learning begets learning. By increasing the basic skills of the work force, in terms of literacy, numeracy and cognitive and communication abilities, policy can contribute both to directly raise the standard of life of disadvantaged individuals and to increase the private incentive to train. We illustrate the potential relationship between cognitive abilities and training by plotting in Figure 5.1 average training participation in 2001 for the age group 25-30 and the average score in the math tests taken by 15 years old children at school in PISA 2003. The picture is only meant to be suggestive, but the message is clear: countries where children at school perform better in their maths are also the countries with the higher workplace training incidence.

\subsection{Labour Market Policies and Training}

Labour and product market policies that aim at reducing regulation and increasing competitiveness have implications for training. A recurrent theme in policy debates is, for instance, the potentially negative effects that reforms which 
increase labour market flexibility may have on training incentives. Clearly, these reforms affect many economic variables and a general equilibrium approach would be necessary to fully investigate the issue. According to many, the success of market reforms is strictly related to a different type of flexibility, which refers to the individual ability of performing multiple tasks and operations and to continuously acquire the skills required to move from old to new jobs. Clearly, understanding whether higher product and labour market flexibility increases or reduces the incentives for workers and firms to invest in skill acquisition is a key issue.

\section{Figure 5.1 Training and PI SA scores}

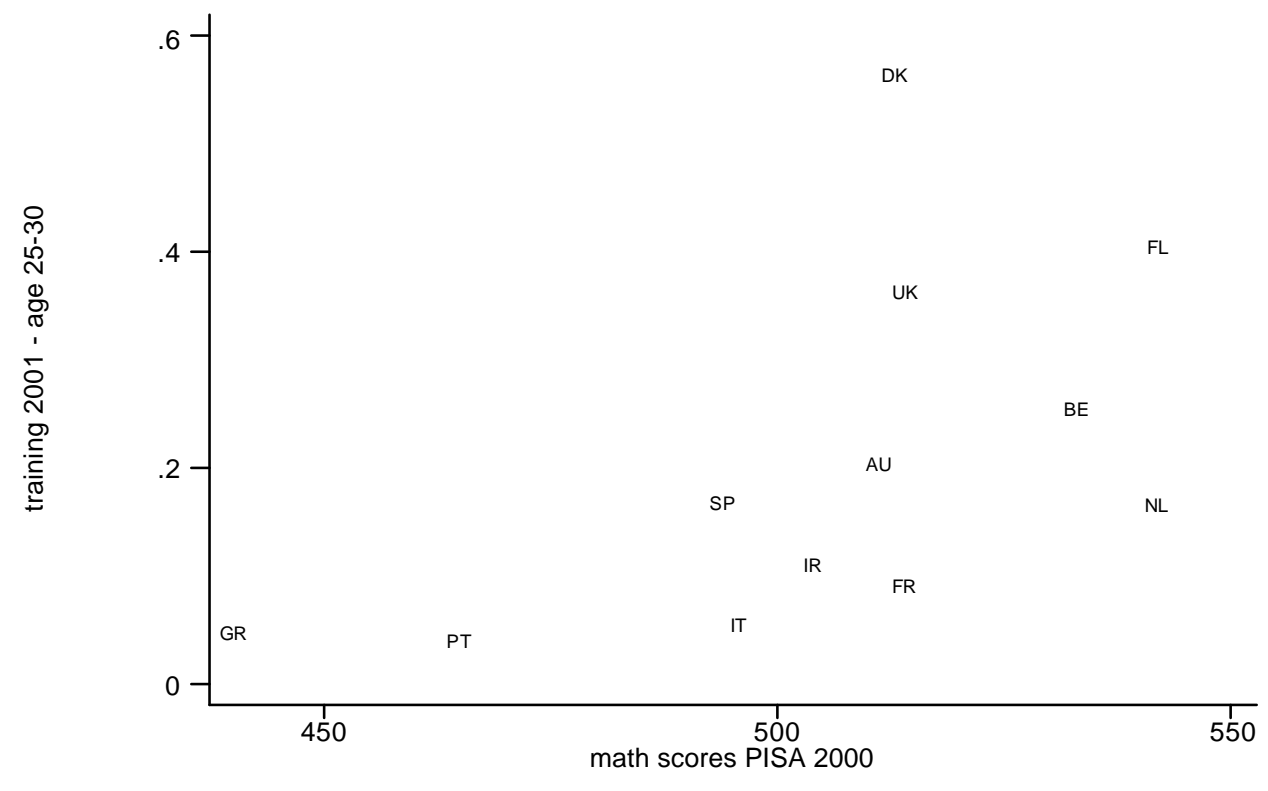

As shown in Chapter 3 of this report, there is evidence that European policies which increase product market competition are positively correlated with the incidence of workplace training. Less straightforward, however, is the relationship between increased labour market competition and workplace training. Reforms which increase labour market flexibility tend to produce several effects both on employers and employees' incentives to invest in training. For example, measures which favour the reduction of a compressed wage structure by affecting minimum wages and the rules of collective bargaining are expected to have opposite effects on employees and employers ${ }^{79}$.

\footnotetext{
${ }^{79}$ A compressed wage structure should not be confounded with the concept of absolute wage compression.
} 
A less compressed wage structure, on the one hand, increases the returns to training reaped by workers but reduce the gains obtained by firms: training increases if the higher incentives to invest for workers compensates the lower incentive for firms. As discussed by Stevens, 1998, this is unlikely to happen when workers are liquidity constrained, or in presence of contractibility problems and poor information on training opportunities and returns.

The common strategy followed by European countries of liberalising atypical/temporary/part-time employment contracts for new entrants in the labour market (Golden and Appelbaum, 1992; OECD, 1993; OECD, 1996) has also implications for training. The higher flexibility in the adjustment of the labour force - on the one hand - helps firms in dealing with the risk of negative shocks; on the other hand, it reduces the incentive to provide skills and knowledge to workers. As shown in Chapter 3, the empirical evidence suggests that training incidence in Europe declines with the increase in the relative importance of temporary contracts. In many European countries higher labour market flexibility has also extended to reducing the employment protection of regular workers. Again, the evidence in Chapter 3 suggests a negative correlation between the degree of protection of regulars and training. It follows that the combined reduction of employment protection for regulars with the diffusion of temporary contracts have an overall ambiguous effect on average training incidence.

Finally, the common European concern on the ageing society, and the need to reform pension policies - widely perceived by European citizens (see Boeri, BoeschSupan and Tabellini, 2002) - raises worries that a reduction of expected benefits and / or an increase in retirement age could reduce the training incentives of senior employees. Our evidence in Chapter 3 suggests the opposite, and shows that senior employees are more likely to train where the implicit tax on continuing work is lower.

\section{Summary}

We summarize the key points of this chapter as follows:

- The design of public policies for workplace training should vary with the type of problem that needs to be tackled, be it a particular market failure or inequality of opportunity; 
- There is no clear-cut evidence that the level of workplace training produced by firms and employees is significantly lower than the socially efficient level;

- Compared to the US, the distribution of training opportunities is significantly affected by circumstances which are usually considered as beyond the individual control, such as parental education;

- Policies addressing perceived market failures should affect marginal benefits and costs in order to minimize deadweight losses;

- Since firms care about profits rather than social inclusion, training policies addressing equality of opportunity should be targeted at individuals rather than at firms;

- Since the returns to training to the disadvantaged are low, one should consider complementary policies, such as those which improve access to good quality education; these policies clearly work on the long run;

- Governments have an important role to play in improving information about training opportunities, setting appropriate legal frameworks and ensuring portability of skills. The European Employment Strategy, especially after the Copenhagen declaration, is rightly investing efforts in developing a European - wide system of recognition of skills;

- Product and labour market reforms do affect training participation. While less regulation in the product market encourages skill formation at work, less clear-cut is the impact of deregulation in the labour market. Pension reforms which reduce the implicit tax on continuing work may increase the willingness to invest in skills by senior workers, who have a longer time horizon to reap the associated benefits. 


\section{Appendix 5.A. A Simple Political Economy Model of Training Subsidies}

Consider a simple economy populated by a given number of workers and firms. Let the measure of each be equal to 1. Each firm can hire at most one worker. Workers differ in their ability $A$, which is uniformly distributed in the support $A \in[0,1]$. Let output without and with training be $A y$ and $A(y+\sigma)$. Wages are set after the training decision taken by each firm and are equal to a share $1-\beta$ of output. Training costs $c$ are borne by the firm.

After training workers can quit and exit the labour force. Let the quit rate of trained and untrained workers be $q_{1}$ and $q_{0}$, with $q_{1}<q_{0}$. Therefore, training reduces turnover by increasing the attachment of each worker to the firm. We normalize ex-post profits and earnings in the event of quits to zero.

If there are no subsidies, training firms are those for whom

$$
\left(1-q_{1}\right) A(y+\sigma) \beta-c \geq\left(1-q_{0}\right) A y \beta
$$

which yields

$$
A \geq \frac{c}{\left[\left(q_{1}-q_{0}\right) y+\left(1-q_{1}\right) \sigma\right] \beta}=A^{*}
$$

Efficiency requires that training occurs if

$$
A^{b} \geq \frac{c}{\sigma}
$$

Since we want to start from a situation where subsidies are not required because of efficiency reasons, we assume that

$$
\left[\left(q_{1}-q_{0}\right) y+\left(1-q_{1}\right) \sigma\right]=\frac{\sigma}{\beta}
$$

which yields the first best allocation. 
Next assume that the government pays to training firms a subsidy $s$ as a percentage of training costs. Let this subsidy be funded with a payroll tax on all workers. The percentage of training firms and workers becomes

$$
A \geq \frac{c(1-s)}{\sigma}=A^{\wedge}
$$

and the budget constraint is

$$
s c\left(1-F\left(A^{\wedge}\right)\right)=\delta(1-\beta) \sigma \underset{A^{\wedge}}{ } A d A+\frac{\delta \beta y}{2}
$$

Since $A$ has a uniform distribution, we have $1-F\left(A^{\wedge}\right)=1-A^{\wedge}$ and $\int_{A^{\wedge}} A d A=\frac{\left(1-A^{\wedge}\right)^{2}}{2}$ , so that

$$
\delta=\frac{2 s c[\sigma-c(1-s)]}{(1-\beta)\left\{\sigma y+[\sigma-c(1-s)]^{2}\right\}}
$$

Suppose that each firm and worker votes on the introduction of the training subsidy. There are three groups of workers: the always untrained, the always trained and those who are trained because of the subsidy. We examine them in turn. The always untrained are against the subsidy because they need to pay payroll taxes without any change in gross income; the always trained are also against the subsidy, because they would be trained anyway, even without paying the payroll tax. Finally, the workers in the ability range $\left\lfloor A^{b}, A^{\wedge}\right\rfloor$ are trained only with the subsidy. They are better off if

$$
(1-\delta)\left(1-q_{1}\right)(1-\beta) A(y+\sigma)>\left(1-q_{0}\right)(1-\beta) A y
$$

that is, if the increase of productivity and the reduction of turnover are sufficient to compensate the payroll taxes needed to fund the subsidy. Suppose this is the case. Then the percentage of workers supporting the subsidy is $A^{*}-A^{\wedge}$. Next consider firms. The firms which were training before the subsidy are better off because they receive the subsidy. On the other hand, the firms that do not train independently of the subsidy - are as well off, since the burden on the measure is 
on workers and they receive no subsidy. Finally, the firms which train because of the subsidy are gaining because of (5.A.2). It follows that the percentage of firms voting in favour of the subsidy is $F\left(A^{*}\right)-F\left(A^{\wedge}\right)+1-F\left(A^{*}\right)=1-A^{\wedge}$. If each worker and firm have one vote and vote independently, majority voting in favour of the subsidy requires

$$
1+A^{*}-2 A^{\wedge}>1
$$

or

$$
A^{*}>2 A^{\wedge}
$$

which holds if the subsidy is higher than $\frac{1}{2}$. In this case, there might be a political equilibrium in favour of a positive training subsidy even if the private training outcome is by construction equivalent to the social optimum. Notice that in our illustrative simple model most workers vote against the subsidy. It is clear, however, that this is mt necessarily the case. In his discussion of educational subsidies, Johnson,1984, shows that unskilled workers may support such subsidies - or training subsidies - if there are complementarities between skilled and unskilled labour. In this case, an increase in skilled labour would increase the productivity of unskilled workers, who would be better off and might vote for the subsidy if the payroll tax is not too high.

In our simple model training firms which receive the subsidy have a windfall profit gain, which they can share with trained employees by offering them higher wages. Such redistribution from profits to wages could induce trained employees to favour the subsidy. Yet another variation is that training subsidies are financed by a tax on payroll and on profits. This would imply that some firms would not favour the subsidy anymore. 


\section{Appendix 5.B. Training Policies in Europe}

In this appendix we review the main training policies adopted in the OECD countries, and discuss their advantages and drawbacks. First, we review the institutional arrangements that create adequate incentives for employers and individuals to invest in skill development. Second, we turn to policies which provide financial support to firms and individuals investing in training.

\section{B.1 Regulation: pay-back clauses, time working accounts and apprenticeship contracts}

Firms may not invest efficiently in training because of the risk of turnover, and workers may not be able to finance the investment because of liquidity constraints. If contracts were fully enforceable these problems could be solved by agreements that force workers to stay with the current firm after training a period of time sufficient to recoup training costs. Pay-back clauses, working-time accounts for employees and apprenticeship contracts operate in this direction. Since these systems are widespread in OECD countries, in this section we shall discuss the main advantages and problems encountered in their application, which are summarized in table 5A1.

Payback clauses are essentially devices that encourage firms to undertake the costs associated to training programs by imposing a penalty on workers who quit within a certain period. These schemes help in reducing the risk of poaching, since workers are induced to stay with the firm providing training. Legal frameworks, which establish and permit pay-back clauses in individual contracts or collective agreements, are present in many European countries (see OECD, 2003a). Their practical diffusion, however, is limited, because it is difficult to contract upon the contents of training ${ }^{80}$. The reason is that the worker's promise to pay may not be credible if he is liquidity constrained and the contract does not require the poaching firm to pay.

\footnotetext{
80 Moreover, the penalty imposed on the trainee in the event of exit needs to be neither too low, otherwise quits cannot be discouraged, nor too high, otherwise workers will not accept the training contract.
} 
Table 5A1. Regulation: pay-back clauses, time working accounts and apprenticeship contracts

\begin{tabular}{|c|l|l|l|}
\hline & Diffusion & Main advantages & Main problems \\
\hline Pay-back clauses & $\begin{array}{l}\text { Legally admitted in many OECD countries } \\
\text { (for example Luxembourg, Germany, Italy). } \\
\text { Limited practical diffusion. }\end{array}$ & $\begin{array}{l}\text { Reduce the risk of poaching and help } \\
\text { credit constrained workers }\end{array}$ & Difficulties due to training contractibility \\
\hline Apprenticeship contracts & $\begin{array}{l}\text { Several OECD countries (for example } \\
\text { Germany, Italy, UK, Spain, France) }\end{array}$ & $\begin{array}{l}\text { Facilitate the sharing of training costs } \\
\text { and the school-to-work transition }\end{array}$ & $\begin{array}{l}\text { When publicly financed likely to produce } \\
\text { deadweight losses and substitution effects } \\
\text { Low training quality - it requires an } \\
\text { adequate length and certification system }\end{array}$ \\
\hline Time working accounts & $\begin{array}{l}\text { Several OECD countries (for example } \\
\text { Denmark, the Netherlands, France). }\end{array}$ & Overcome time related constraints & Difficulties due to training contractibility \\
\hline
\end{tabular}


On the other hand, since training is hardly verifiable, firms may require workers to pay even if the training provided was of poor quality and scarcely valuable in the labour market. These problems imply that pay back clauses are adequate for training programs with contents and quality that can be easily assessed and certified, but less useful for other types of training (OECD, 2003a). ${ }^{81}$

The sharing of training costs among firms and workers is facilitated by working times accounts, diffused in many OECD countries (for example in Denmark, the Netherlands, France, see OECD 2003a for details). These systems allow workers to accumulate working time credits, for example through overtime hours, which can be used for undertaking training activities. Clearly, as for other sharing costs systems, a crucial issue is represented by training contractibility: the worker will anticipate the cost of training, working additional time before the training programme, only if he can trust the firm in providing general and high quality training $^{82}$.

Another contractual form having an important role in the training system of many European countries is apprenticeship, which combines training and employment in a way which enables people to enter an occupation and develop skills valuable in many firms. With perfectly competitive labour markets, the firm cannot reap the benefits deriving from general training and the cost of the investment is shifted on the apprentices, who accept a sufficiently low wage in the expectation of earning a higher wage once they have qualified. This expectation depends on the value that acquired skills have in the labour market. In the case of large markets where information is not easily available, the worker is interested in investing in skills only if there is a system that certifies her competences, making them recognizable in the market. As a consequence, as already noticed, the state may have a role in defining an adequate certification system even in case of training financed completely by workers.

The importance of state regulation increases when firms lend part of the training cost to workers or when they share with workers the investment. Since it is often the case that the worker's contribution to production net to training costs during

\footnotetext{
81 Enforcing such kind of legal devices may result difficult also for certified training. Story and Redman, 1997, do not find many cases of enforced payments, suggesting that firms use this instrument more as a deterrent than that a cost recovery practice.

${ }^{82}$ In many countries statutory or contractual training leave schemes guarantee employees the right to return to their jobs after training periods. In some of them are available training leave subsidies allowing workers to cover living expenses or partially replace foregone income (see Bassanini, 2004).
} 
the apprenticeship period is very low, paying a wage equal to the net productivity of the worker may prevent liquidity constrained individuals from investing. This problem can be solved with a contractual arrangement such that the trainee is required to stay with the employer providing training for a defined spell of time. Agreements of this type can be based either on explicit rules, such as pay-back clauses, or on systems that implicitly make early quits not convenient for workers, such as apprenticeship contracts. Under the latter the worker is overpaid during the first period of the training and underpaid during the final part of the training spell (allowing in this way the firm to recover training costs). The length of the contract is a key element to give adequate incentives to both parties: on the one hand, the incentives for the worker to invest in training decrease with the length of the apprenticeship, as she is paid a lower wage for a longer period; on the other hand, incentives for the firm increase, as the return of its investment amplifies with the length of the apprenticeship contract.

Nevertheless, the definition of an optimal contract length is not an easy task, since public authorities do not have full information on training costs and of their sharing between the parties. Information provided by firms and employees may result distorted by their interest in respectively increasing and reducing the contract length (Brunello and De Paola 2004b).

In order to discourage workers from leaving before expected, the design of the contract usually implies that the (certified) qualification is awarded only at the end of the apprenticeship spell. Clearly, the cost of leaving is higher when the qualification awarded at the end of the apprenticeship is highly valued in the labour market, which is strictly related to the effectiveness of the certification system.

However, in case of firms not only lending to trainees the cost of the training, but also contributing to finance the investment, the certification system may produce some problematic effects. While on the one hand, this system generates adequate incentives for workers, on the other hand it reduces asymmetric information, increases turnover and discourages firms from investing. As a consequence, training should be financed mainly by workers.

This prediction does not find support in the experience of some countries, notably Germany, where, in spite of a well structured certification system, which increase the portability of acquired skills, firms contribute in a substantial way to training expenses (Pischke, 2000). As argued by Acemoglu and Pischke, 2000, this can be explained by taking into account that the effectiveness of training is strictly 
influenced by the active participation of recipients. Certification, by guaranteeing workers a higher wage, induces them to provide a high level of effort in the skill acquisition process, making training convenient also for firms.

Apprenticeship contracts are diffuse in many OECD countries even if the regulation system varies considerably. Table 5.A.2 summarizes the main features in terms of overall governance, educational and training content, duration, and finance. Some important differences emerge in relation to the length of the apprenticeship period and the level of the youth wage. While in Germany, France and the Netherlands, the contract length is defined by law and the average duration is of 2-3 years, in Britain and Spain the contract duration is defined by the firm and the average duration is of less than a year. In Italy the apprenticeship period lasts three years but can be completed in different firms (Brunello and Topo, 2004). As far as the apprentices' wage is concerned, Marsden and Ryan, 1990, report that the youth manual workers wages in Germany were $46 \%$ of adult level, compared to $62 \%$ and $85 \%$ in the UK and Italy, respectively.

The availability of German young workers to accept a low wage during the apprenticeship period is probably due to the good career prospects ensured by a certification systems that makes their competences recognizable also outside the training firm. In Germany apprenticeships end with an examination conducted by a committee including representatives of local Chambers of Commerce, trade unions, sectoral employers' organisations and vocational teachers. Formal tests, conducted by organizations external to the firm, are used also in Austria and Denmark, while Britain, Spain and Italy rely on the evaluations of employers. In Spain, it is the company that provides the training certificate, which lacks any professional value, as it does not have the recognition of either the Employment neither the Education Authorities (Steedman, 2001a, 2001b).

In many European countries apprenticeship is treated as part of upper secondary education and apprentices are required to attend part-time formal education. For example, in France the apprentice attends the "Centres de formation d'apprentis" for 400 hours a year and a fourth of this time is devoted to general training, with the remaining three fourths dedicated to technological specific training. In Germany, off-the job training is provided in public educational institutions. Formal training is required also in Austria, Ireland, Netherlands and Denmark. On the contrary, in Spain, UK and Italy there is less attention to the educational side. In Spain, as argued by Marhuenda Fluixà, 2000, even if formal training should account 
for at least $15 \%$ of the agreed working hours, there is not, up to now, any control over the educational content and apprenticeship contracts may be signed without covering any educational requirement, as far as the company pays the Minimum Inter-professional Wage to the apprentice. In the UK, as argued by Ryan, 2000, offthe-job training attended in a company training centre often suffices to satisfy legal requirements.

These differences in the legislation framework translate in different training quality. In Italy and Spain apprenticeship contracts are mainly a low cost labour contract. Problems related to training quality seems relevant also in the UK where according to Gospel, 1995, 1997 - there are few companies offering good quality apprenticeship slots. The low quality of training provided through apprenticeship in some countries, a part from being related to regulation systems that do not provide adequate incentives to parties, may depend also on particular institutional settings. As argued by Gospel, 1997, poaching problems that hinder firms from offering high quality training require in order to be solved the definition of arrangements that support the system and help to share the training costs. For example, in countries such as Germany, Austria and Switzerland, a crucial role is played by intra-firm organizations and industry-wide arrangements (Pischke, 2000). These systems facilitate implicit agreements among firms aimed at restraining poaching behaviour. On the contrary, the influence of intra-firm training arrangements is low in countries where the apprenticeship system is not strong, as in Britain and Italy.

In many countries public intervention in the apprenticeship system is not limited to designing formal rules, but also provides financial support. In Germany, Denmark, Austria, Netherlands the state pays for formal education while the firms and apprentices pay for the training on-the-job. The role of firms as financing subjects is very important in these countries. According to Berger and Walden, 2002 , employers in Germany provide over $75 \%$ of funding for the operation of the apprenticeship system.

In France firms pay an apprenticeship tax that dates back to 1925 and is mainly used by enterprises for financing - together with the state, local communities and professional organizations - the cost of apprentice training in the Apprenticeship Training Centres. In other countries, for example Italy, the state contribution is considerable and firms which offer these contracts are exempted from paying nearly $100 \%$ of payroll taxes. On the other hand, training content and quality is subject to low monitoring (Croce, 2005). 
Table 5A2 Apprenticeship contacts in selected OECD countries

\begin{tabular}{|c|c|c|c|c|c|c|}
\hline & Germany & Austria & Denmark & Netherlands & Ireland & UK \\
\hline $\begin{array}{l}\text { Principal National } \\
\text { Statutes }\end{array}$ & $\begin{array}{l}\text { Vocational training } \\
196919811984\end{array}$ & $\begin{array}{l}\text { Vocational training } \\
\text { Act } 19691993 \\
1997\end{array}$ & $\begin{array}{l}\text { Apprenticeship } \\
\text { Act 1937, 1956, } \\
1989\end{array}$ & $\begin{array}{l}\text { Apprenticeship } \\
\text { Act 1966, 1992, } \\
1995\end{array}$ & $\begin{array}{l}\text { Apprenticeship } \\
\text { Act } 1993\end{array}$ & $\begin{array}{l}\text { Industrial Act } \\
1937\end{array}$ \\
\hline Target group & No upper limit & $\begin{array}{l}\text { No upper age } \\
\text { limit. Advantages } \\
\text { for older people. }\end{array}$ & $\begin{array}{l}\text { Age } 15 \text { or } 16 . \\
\text { Special shorter } \\
\text { programme for older } \\
\text { than } 25 .\end{array}$ & $\begin{array}{l}\text { At least 16, no upper } \\
\text { limit }\end{array}$ & $\begin{array}{l}\text { At least } 16, \text { no upper } \\
\text { limit }\end{array}$ & $16-25$ \\
\hline $\begin{array}{l}\text { Social parties involved } \\
\text { Employers } \\
\text { Trade unions } \\
\text { Teachers }\end{array}$ & $\begin{array}{l}\text { Yes } \\
\text { Yes } \\
\text { Yes }\end{array}$ & $\begin{array}{l}\text { Yes } \\
\text { Yes } \\
\text { Yes }\end{array}$ & $\begin{array}{l}\text { Yes } \\
\text { Yes } \\
\text { Yes }\end{array}$ & $\begin{array}{l}\text { Yes } \\
\text { Yes } \\
\text { Yes }\end{array}$ & $\begin{array}{l}\text { Yes } \\
\text { Yes } \\
\text { Yes }\end{array}$ & $\begin{array}{l}\text { Yes } \\
\text { No } \\
\text { No }\end{array}$ \\
\hline Training duration & $2-4$ & $2-4$ & $3-5$ & 2 & 4 & Unspecified \\
\hline $\begin{array}{l}\text { Mand. educational } \\
\text { Content. } \\
\text { Share of: } \\
\text { Off-job Ed. } \\
\text { General Ed. }\end{array}$ & $\begin{array}{l}20-25 \\
33\end{array}$ & $\begin{array}{l}4 / 5 \text { of the training } \\
\text { time is spent in the } \\
\text { firm } \\
16 \\
25\end{array}$ & $\begin{array}{l}40 \\
33\end{array}$ & $\begin{array}{l}20-40 \\
33\end{array}$ & $\begin{array}{l}21 \\
2\end{array}$ & $\begin{array}{l}0 \\
0\end{array}$ \\
\hline $\begin{array}{l}\text { Train. Certification } \\
\text { Employers } \\
\text { Vocat. Teach. }\end{array}$ & $\begin{array}{l}\text { Yes } \\
\text { Yes }\end{array}$ & $\begin{array}{l}\text { Yes } \\
\text { n.a }\end{array}$ & $\begin{array}{l}\text { Yes } \\
\text { No }\end{array}$ & $\begin{array}{l}\text { Yes } \\
\text { Yes }\end{array}$ & $\begin{array}{l}\text { Yes } \\
\text { No }\end{array}$ & $\begin{array}{l}\text { Yes } \\
\text { No }\end{array}$ \\
\hline $\begin{array}{l}\text { Public Subsides } \\
\text { Train. outside } \\
\text { workplace }\end{array}$ & Full & Full & Full & Partial & Full & Partial \\
\hline Workplace train. & None & $\begin{array}{l}\text { Some groups of } \\
\text { workers. Tax } \\
\text { reductions for } \\
\text { training companies } \\
\text { and reductions of } \\
\text { social security } \\
\text { contributions for } \\
\text { apprentices. }\end{array}$ & Intermittent & Tax relief & None & Grants \\
\hline Relative pay & $20-45 \%$ & $40-60 \%$ & $51-54 \%$ & n.a. & n.a. & $60 \%$ \\
\hline
\end{tabular}


Table 5A2. Apprenticeship contacts in selected OECD countries. Continued

\begin{tabular}{|c|c|c|c|c|c|c|}
\hline & Finland & $\begin{array}{l}\text { Belgium } \\
\text { Flemish }\end{array}$ & Belgium Frenc & Spain & France & Italy \\
\hline $\begin{array}{l}\text { Principal National } \\
\text { statutes }\end{array}$ & & & $\begin{array}{l}\text { Decree dated 3/7/91, } \\
\text { decree dated 4/5/95 }\end{array}$ & $\begin{array}{l}\text { Decree } 52811977 \\
\text { Royal decree law } \\
\text { 18/1993 }\end{array}$ & $\begin{array}{l}\text { Law on } \\
\text { apprenticeship } \\
1971,1992 \\
1993\end{array}$ & $\begin{array}{l}\text { Law N. } 25 / 1955 \\
\text { and N. 6/1987, } \\
\text { Decree n.276, } 2003\end{array}$ \\
\hline Target Group & $\begin{array}{l}\text { At least } 15, \text { no } \\
\text { upper limit }\end{array}$ & $15-18$ & $\begin{array}{l}\text { At least } 15, \text { no upper } \\
\text { limit }\end{array}$ & $\begin{array}{l}16-21 \\
\text { In some cases } 16-24\end{array}$ & $16-25$ & $15-24$ \\
\hline $\begin{array}{l}\text { Social parties invol } \\
\text { Employers } \\
\text { Trade unions } \\
\text { Vocati. Teach. }\end{array}$ & $\begin{array}{l}\text { Yes } \\
\text { Yes } \\
\text { Yes }\end{array}$ & $\begin{array}{l}\text { Yes } \\
\text { No } \\
\text { Yes }\end{array}$ & $\begin{array}{l}\text { Yes } \\
\text { No } \\
\text { No }\end{array}$ & $\begin{array}{l}\text { No } \\
\text { No } \\
\text { No }\end{array}$ & $\begin{array}{l}\text { Yes } \\
\text { Yes } \\
\text { No }\end{array}$ & $\begin{array}{l}\text { Yes } \\
\text { Yes } \\
\text { No }\end{array}$ \\
\hline Training duration & $2-3$ years & $1-3$ years & 3 years & $\begin{array}{l}6 \text { months } \\
3 \text { years }\end{array}$ & $2-3$ years & $2-6$ years \\
\hline $\begin{array}{l}\text { Mand. educational } \\
\text { content } \\
\text { Share of: } \\
\text { Off-job Ed. } \\
\text { General Ed. }\end{array}$ & $\begin{array}{l}70-80 \\
20\end{array}$ & 1 or 2 days a week & $\begin{array}{l}12 \text { hours/week } \\
\text { in the first year } \\
\text { and } 8 \text { hours / week } \\
\text { in the second and the } \\
\text { third years. }\end{array}$ & $\begin{array}{l}0-15 \% \\
0\end{array}$ & $\begin{array}{l}400 \text { hour for year } \\
1 / 4 \\
3 / 4\end{array}$ & $\begin{array}{l}120 \text { hours of } \\
\text { formal training both } \\
\text { inside and outside the } \\
\text { firm }\end{array}$ \\
\hline $\begin{array}{l}\text { Train. Certification } \\
\text { Employers } \\
\text { Vocati. Teach. }\end{array}$ & $\begin{array}{l}\text { Yes } \\
\text { Yes }\end{array}$ & $\begin{array}{l}\text { Yes } \\
\text { Yes }\end{array}$ & $\begin{array}{l}\text { Yes } \\
\text { Yes }\end{array}$ & $\begin{array}{l}\text { No } \\
\text { No }\end{array}$ & $\begin{array}{l}\text { Yes } \\
\text { Yes }\end{array}$ & To be defined \\
\hline $\begin{array}{l}\text { Public Subsides } \\
\text { Train. Outside } \\
\text { workplace } \\
\text { Workplace train. }\end{array}$ & $\begin{array}{l}\text { Full } \\
\text { partial } \\
\end{array}$ & $\begin{array}{l}\text { Full } \\
\text { none }\end{array}$ & $\begin{array}{l}\text { Partial } \\
\text { none }\end{array}$ & Partial & Partial & $\begin{array}{l}\text { Tax relief } \\
\text { Tax relief } \\
\end{array}$ \\
\hline Relative pay & $80 \%$ & & & $60-80 \%$ & $\mathrm{Na}$ & \\
\hline
\end{tabular}

Sources: Ryan , 2000; Linderholm and Parker, 2000; Marhuenda Fluirà, 2000, Brunello and Topo, 2004 
The evaluation of the effects of the public financial support to apprenticeship systems needs to consider the deadweight losses and substitution effects. The point is that these policies might fail to substantially increase the number of apprentices, due to the fact that part of the financial support goes to investments that would have been realized in any case, or might reduce the supply of other types of job opportunities. In the case of deadweight losses, both the efficiency and the equity arguments usually employed to back up the policy result undermined, since the final beneficiary of the subsidy is not the worker, but the employer, who would have delivered the training even without the public policy.

\section{B.2. Co-financed schemes directed at firms}

Co-financing systems directed at firms can be based on a compulsory or on a voluntary approach. The poaching problem motivates the former approach: with all firms contributing to training through the payment of a levy, the free-riding problem becomes less relevant. The levy schemes take different forms: traditional schemes tax all firms and finance training provided by the public sector or by sectoral training funds ${ }^{83}$; other schemes that reduce training costs through tax arrangements or grants ${ }^{84}$. In this sub-section we review these systems and discuss their main advantages and drawbacks, which are as summarized in Table 5A3.

The most widespread compulsory schemes aimed at increasing employers' investments in training are levy schemes which require firms to pay a tax and obtain resources to award grants to support training (levy-grant schemes), or which impose on firms to pay a tax if they do not meet a pre-determined level of training (train-or-pay schemes).

Levy/grant schemes, which combine a tax levied on all firms - normally on payroll - with grants awarded to training projects presented by some firms, are fairly widespread within the European Union. Some countries, in particular Belgium, Spain and Italy, have defined compulsory financing schemes at a national level and others, such as the Netherlands and United Kingdom, have opted for contributions at a sectoral level (see Ok and Tergeist, 2003, Croce, 2004).

\footnotetext{
${ }^{83}$ Revenue generating schemes that tax firms to finance training provided by the public sector, while still used in many developing countries, are present in industrialized countries only in the form of employment insurance funds to finance training of the unemployed.

${ }^{84}$ In countries where governments do not regulate firms' training expenditure, an important instrument for financing training is represented by collective labour agreements, establishing training clauses and the creation of training funds. Besides, governments offer tax-related incentives for training through different types of tax arrangements.
} 
Table 5A3. Co-financed schemes directed at firms

\begin{tabular}{|c|c|c|c|}
\hline & Diffusion & Main Advantages & Main problems \\
\hline Train-or-pay schemes & France and Canada & $\begin{array}{l}\text { Low cost of administration } \\
\text { Effective in increasing training investments }\end{array}$ & $\begin{array}{l}\text { Low training quality } \\
\text { High expected deadweight losses }\end{array}$ \\
\hline Levy-grant schemes & Belgium, Spain, Italy & $\begin{array}{l}\text { Training quality controlled to some extent } \\
\text { Opportunity for the development of national or sectoral } \\
\text { training policies }\end{array}$ & $\begin{array}{l}\text { Employers may perceive it as an additional tax reducing competitiveness } \\
\text { Demanding in administrative terms and likely to generate abuses }\end{array}$ \\
\hline Tax deductions & $\begin{array}{l}\text { Austria, Italy, } \\
\text { Luxembourg }\end{array}$ & $\begin{array}{l}\text { Low expected deadweight losses } \\
\text { Low costs of administration }\end{array}$ & $\begin{array}{l}\text { Work only as long as there are positive profits. When financed through } \\
\text { general tax revenues, taxpayers are required to pay for the training } \\
\text { obtained by a small portion of the workforce }\end{array}$ \\
\hline
\end{tabular}


In these systems grants can be allocated to priority training programs, and some levy-paying firms may not obtain training grants if their training activity is not in line with national standards and objectives. Since a set of conditions has to be respected by training projects eligible for financing by levy-based funds, it is possible to control, to some extent, the content and the quality of training provided by firms. Employers have to be consulted and involved to avoid that the system be perceived as an additional tax which further reduces competitiveness ${ }^{85}$.

The management of this scheme requires the definition of administrative bodies which decide priority training programs and grants. In some countries a crucial role is played by the government, while in others, for example Spain and Italy, grants are decided by social parties. In the second case the active role of unions can help monitoring training quality and the design of training curricula with an eye to the portability of skills (see Ok and Tergeist, 2003).

This system involves many case - by - case decisions and management competences, is demanding in administrative terms and likely to generate abuses. An alternative to the combination of levies and grants is "train or pay" schemes, with levies payable only if the training investment falls below a legal minimum. Train or pay schemes (or levy-exemption mechanisms), used in France and Canada $^{86}$, allow firms to reduce their levy obligations by the amount of training they provide or purchase. Since these systems operate through the individual actions of employers, they do not require special and costly organizations to be established and, as a consequence, imply low cost of administration. Where bureaucratic costs are high and public procedures slow, this could be an important advantage. On the other hand, in contrast to levy-grant schemes, levy exemption schemes, leaving full autonomy to employers in training decisions, provide less opportunity for the development of national or sectoral training policies. Besides, firms could use training as a perquisite with cosmetic rather than substantial effects on skill development (Brocher and Meiaux, 1997).

Other countries, such as Austria (in 2000), Italy (in 2001), Luxembourg (in 1999) and the Netherlands (introduced in 1998 and abolished in 2004), have opted for tax deductions from revenues, which allow firms to deduct some or all training

\footnotetext{
${ }^{85}$ In the UK the abandonment of the levy/grant systems is partly attributed to the bad perception of employers (Gasskov, 2001).

86 In the Province of Quebec, Canada, a training levy of the French type has been introduced by the law, known as the Loi favorisant le developpement de la formation de la main-d'oeuvre, required firms to devote one percent of their payrolls to training or submit an equivalent amount to the Quebec Minister of Revenue.
} 
costs and thereby to reduce corporate taxes. Tax deductions are generally higher than 100 percent of total expenses, implying a training subside (extra-deductions amounts to $10 \%$ of training expenditures in Luxembourg, $20 \%$ in Austria and the Netherlands and up to $50 \%$ in Italy). Since deductions work only as long as there are positive profits, some countries allow firms to carry forward these expenses to fiscal years where profits are positive (see OECD, 2003a, 2004) ${ }^{87}$.

In spite of the diffusion of tax arrangements and levy-grant schemes, rigorous evaluations of their effectiveness are uncommon. In particular, the substitution between formal and informal training has not been evaluated. An open issue is related to the most appropriate source of funding. Schemes diffused in OECD countries in some cases are based on general tax revenues, such as tax arrangement schemes, while in other cases are financed with funds collected through levies imposed on firms, such as train or pay and levy-grant schemes. In the first case, taxpayers are required to pay for the training obtained by a small portion of the workforce, which can be considered fair only if training is expected to produce large externalities or when training is offered to disadvantaged workers. On the contrary, if externalities take place mainly among firms and workers obtaining training are not in need, systems based on levies imposed on firms seem more adequate. Nevertheless, redistributive considerations are important also in this case. With levies on payroll, even if taxes to finance training are paid by the enterprise, the real burden may be passed onto workers in form of lower wages. If the burden of the tax is entirely on employees, net wages fall to compensate for the tax. On the other hand, the subsidy received by firms reduces in the same proportion the share of the training costs borne by trainees. As suggested by Stevens, 1996, this policy has no impact on employers, but affect the training

\footnotetext{
87 In many countries governments participate in funding training programmes. In European countries are also available resources from the European Community training policies, operating both through the concession of funds into national programs (European Social Funds) and through separate training initiatives. An important community policy instrument is represented by the subsidization of member state programes. These interventions have the aim to increase training to a level higher to that chosen by national governments, under the assumption that training produces public benefit that have not been considered by national government. Clearly a first relevant issue is whether a supra-national institution can decide a level of training that is better than that decided by each state. Another problem is represented by the displacement effect of existing national expenditure by community subsidies. This effect may be avoided following a principle of additionality establishing that the member state has to maintain his public assistance at least at the some level as it was before the obtainment of the Community subsides. However, as argued by Addison and Siebert,1994, since in practice there are problems in enforcing even minimal principles of additionality, displacement effects are very likely to occur. Moreover, it is also to be considered that whether an additionality form was enforced there would be the risk of devoting to many resources to training (Addison and Siebert, 1994).

${ }^{87}$ See also Whalley and Ziderman (1990), who discuss these schemes referring to developing countries.
} 
decisions of employees, with some redistribution from employees not receiving training to employees receiving it. Since most training is obtained by skilled workers, this poses an equity issue because even if all workers may be contributing to the scheme, only workers in better positions benefit from training.

The conclusion that levies on payroll do not influence the supply side of the training market change if employers are not able to shift the burden of the tax entirely on employees and if employees are not able to entirely appropriate the advantages of the subsidy in terms of a lower training price. The incidence of the levy depends on the relative market power of firms and workers. The share of tax borne by the worker increases as the elasticity of labour demand becomes higher and the share of the tax borne by the employer is larger when the elasticity of labour supply is high. On the other hand, workers will respond to the price reduction of training depending on their preferences. As a consequence, evaluating the impact of these schemes requires information on the responsiveness of wages and training prices to changes in payroll taxes and training grants. The impact of taxes levied on profits are more straightforward, since they directly influence the marginal decision between training and poaching by reducing the profits from poaching. Tax deductions financed through corporate taxes may attain a similar objective.

Another open issue is whether kvy or tax deduction rates should be uniform or vary across sectors and whether firms of different dimension should be treated in a different way. Training under-investment - if it exists - may vary among industries and small firms generally require less training since they adopt less sophisticated technologies. Whether levy and tax deduction rates should reflect these differences is a matter of debate. Even if they should, it is questionable whether a differentiated policy can be implemented when some of the costs are not verifiable. If efficiency were the issue, a sector specific policy would require that the government has information on the sector - specific efficient level of training.

A related problem is represented by the definition of training expenses eligible for tax deduction and of training programmes suitable for grants. On the one hand, expenditures and programmes have to be defined in a clear and transparent way in order to avoid abuses and, on the other hand, it is necessary to avoid substitution between different forms of training. Allowing for the deduction of any training expense, either internal or external, or financing any training program, avoids the second problem but imposes a risk, as firms may implement low quality training 
programmes. On the contrary, when only external expenses are deducible firms may substitute informal training programs with more formalized ones. Similarly, since levy - grant and train-or-pay schemes are generally directed to formal training, it is likely that firms react substituting informal training with formal courses.

Finally, an important question, already discussed in this chapter, is that fiscal policy to encourage training may end up subsidizing programmes that would have been provided by firms in any case. For the employer's decision to invest in training, the difference between marginal expected benefits and marginal training costs is relevant. As a consequence, in order to avoid large dead-weight losses the subsidy component of a policy package must seek to compensate only the gap between marginal costs and marginal private benefits that may arise at the socially desirable investment level, leaving to employers the responsibility of financing the rest. Any subsidy that does not change the employer marginal costs and benefits will not modify his investment decisions, but end up in financing the training that would have been done anyway.

Tax deduction and grant schemes respecting this principle are likely to produce efficient results. However, some of the schemes discussed above are not based on these principles and tend to generate large deadweight losses. A typical example is represented by train or pay schemes used in France and Canada, which combine a payroll tax of a given percentage, independent of training expenditures, a $100 \%$ automatic subsidy of training expenditures up to that percentage of payroll and an additional grant funded by the resources collected through the levy and awarded through case-by-case analysis of training projects. By covering total costs up to a pre-determined ceiling, and then leading the marginal cost to zero, train-or-pay schemes do not provide a matched contribution to firms that would have spent less than the legal minimum in the absence of the scheme and, therefore, "overpay" any increase in training investment they induce. Conversely, firms that would have spent up to the legal minimum anyway enjoy a windfall, which does not increase their incentives to invest in training (see Bassanini, 2004).

Finally, these systems, even if they increase training participation, do not address the low participation of particular groups of workers. As a result, participation of unskilled workers, women and minority groups in co-financed training programmes is low (Veeken, 1999). On the other hand, targeting public support in favour of particular groups of workers is likely to produce relevant 
substitution effects. As shown by Leveun and Oosterbeek, 2004, the $40 \%$ extradeduction to train workers aged 40 years or older, introduced in the Netherlands in 1998 and recently abolished, induced significant substitution effects. As a consequence, when training policy is aimed at reducing inequalities, it is necessary to adopt co-financing schemes focused directly on individuals (such as loan and individual subsidy schemes), As we discuss below, their effectiveness depends on the availability of sufficient and reliable information by workers.

\section{A.3. Co-financing schemes directed to individuals}

In OECD countries the upgrading of skills of disadvantaged categories of workers is pursed by funding the supply of training by public and private institutions, and by financing demand with subsidies, tax deductions and loan schemes.

Traditional systems targeted at supply are widespread in those countries where public sponsored training, directly provided by public agencies, is offered to disadvantaged categories of workers. These policies are part of wider active labour market measures aimed at encouraging individual self-support through programmes which facilitate job search and human capital accumulation. ${ }^{88}$ While in the US the main objective of these programmes is to increase the earnings of the working poors, in European countries, characterised by high rates of unemployment, these programmes are mainly aimed at increasing working opportunities of the unemployed or other groups facing a high risk of job loss. As our report does not consider training programmes directed to unemployed subjects, we will not discuss these schemes. We concentrate instead our attention on schemes opened to employed workers, which finance their demand for training with tax deductions, loan schemes and subsides to individuals. The diffusion of these schemes in OECD countries and their main characteristics are discussed below and summarized in Table 5A4.

\footnotetext{
${ }^{88}$ The European Union and the OECD-countries have in recent years emphasized these programs as an important means to reduce long-term unemployment and promote growth. Nevertheless, public expenditure on training programs varies considerably among OECD countries, with countries such as Czech Republic, Japan, Luxembourg, Poland and the USA spending less than $0.05 \%$ of GDP and Scandinavian countries (Denmark, Finland and Sweden) with an expenditure of around $0.5 \%$ of GDP (OECD, 2000).
} 
Table 5A4. Co-financing schemes directed to individuals

Diffusion

Main advantages

Main problems

Tax deductions Austria

Loan schemes

UK, US

Vouchers

Austria, Italy, Switzerland, US

Individual Learning Canada, the Netherlands,

Accounts

UK, US, Spain

Leave Schemes
Encourage training investments

reducing their

convenient also in

case of low and uncertain rates of

Help in solving individual

difficulties in financing training

through borrowing

Increase competition on the supply side with positive expected effects on training quality

The available empirical evidence suggest that they are widespread among disadvantaged categories of workers

Help at overcoming time constraints. Low participation rates.

Since individuals can only make use of these deductions if they nough in a fiscal year to be liable to pay taxes, they are more

investments realized by high-wage employee

They may generate high levels of debt and workers, in face of uncertain returns to training, may not be able to repay the Adults

tend to be reluctant to finance learning processes through loans Large dead-weight losses in case of vouchers that cover training

costs or consisting in a fixed contribution

To be effective require sufficient information about the variets the

quality of training programmes offered by providers

The available evidence suggest that they are mainly used by hig skilled workers

Risk of abuses and frauds.

Austria, Belgium, Finland, France,

Italy, Japan, Korea, Norway, Spain

Sweden. 
While loans financing tertiary education are diffuse among OECD countries, loans financing adult learning have been introduced only in few countries (UK and US) ${ }^{89}$. Similarly, even if in several countries the expenditure for formal education can be deducted from personal income taxes, training expenses usually cannot be deducted. Only recently some countries have launched initiatives aimed at allowing individuals to deduct training expenses (for example, Austria). However, these systems are more likely to be effective for high wage employees, because low-wage workers are scarcely responsive to tax deductions and reluctant to finance learning through loans (Bassanini, 2004).

An alternative system to promote training investments, experimented by a growing number of countries, is represented by different types of subsides (such as vouchers and individuals training accounts), which directly offer financial support to individuals belonging to a target group who undertake training activities. Training vouchers are used in certain regions of Austria, Italy and Switzerland, while individual learning accounts, consisting in saving accounts that can be opened by individuals to fund training activities, with contribution from third parties (government and employer), are experimented in Canada, the Netherlands, the Basque region of Spain, the United Kingdom and the United States (for a review see OECD 2003c).

In Italy training vouchers have been introduced in 1993 (Law n. 236). During the period 1999 to 2001, regions which introduced this system have received about 15 thousand requests and granted 9 thousand vouchers (Croce, 2003). A first look at this data shows that workers participating in the system are mainly those with high skills and high education, while the demand by disadvantaged categories of workers is low (ISFOL, 2001).$^{90}$ A similar result emerges from the training voucher system experimented by the Swiss canton of Geneva, where only 16 percent of total applicants were persons with only compulsory schooling.

To avoid these problems, some countries offer subsidies targeted at particular categories of workers. For example, in Germany the government subsidises the training expenditures of workers aged over 59, with no qualification or employed in semi-skilled or unskilled occupations for more than four years. According to the

\footnotetext{
${ }^{89}$ Career Development Loans, allowing adults to borrow from GBP 300 to GBP 8000 to pay for training at special conditions, were launched in the United Kingdom in 1988. However, the number of borrowers was much lower than expected.

${ }_{90}$ Moreover, due to the lack of a well-defined certification system (there is only a certification of attendance), it may be difficult to make aware potential employers of the acquired skill.
} 
available evidence, a large diffusion among disadvantaged categories of workers has been attained also by systems combining tax arrangements or loans with subsidies, such as individual learning accounts. Different types of such schemes have been introduced in Canada, the Netherlands, the Basque region of Spain, the United Kingdom and the United State (for a review see OECD, 2003b). In many of these countries the aim of these schemes has been that of establishing accounts for the payment of direct training and education costs, while only in few cases their objective has been that of replacing the income of individuals undertaking full-time learning activities. The risk of abuses and frauds is very high in case of direct contribution from third parties.

Usually, to preserve accountability, the co-financing partner matches individual contributions at the time of the transaction to purchase education or training services, but also in this case it is not always possible to prevent that funds are spent for different purposes than those allowed. As for the financial incentives to firms, in the absence of rigorous evaluations it is difficult to compare the different types of schemes discussed above. However, as argued in section 5.5, subsidy schemes are more likely to be efficient when they are matched contributions that reduce marginal costs of training for any subsidy recipient.

In many countries leave schemes guarantee workers the right to return to their jobs after training spells (for a discussion see OECD, 2003a). As foregone income may depress employees' incentives to participate in training programmes, these schemes are more effective when accompanied by subsides covering living expenses and replacing foregone income (such as those offered by the Germany government).

Independently on their specific form, systems financing demand are expected to generate a larger competition among providers with gains in terms of efficiency and innovation. Nevertheless, the use of subsidies directed at individuals does not necessarily stimulate competition. Without sufficient information about the variety and the quality of training programmes offered by providers, consumers are not in the condition to stimulate a high quality and cost-effective supply. Individuals need information that identifies job vacancies and the skills necessary for in-demand jobs, information on local, regional and national employment trends, and on the performance of training providers in preparing people for jobs. Only if sufficient information is available to the demand side it would be possible to enhance a high quality system. On the contrary, in a context of asymmetric information, adverse 
selection problems may lead to a low quality market. In fact, on the one hand, providers may not be able to prove the quality of their services and, on the other hand, consumers may not be able to make adequate cost-benefit evaluations.

Generally, since this information system is very costly and difficult to implement, subsidy schemes do not allow total freedom of choice to individuals, but leave them free to choose within courses offered by accredited training providers with training programmes meeting a minimum standard of performance. If the supply side does not expand, subsidies which increasing the demand for training may lead to higher prices and produce a small increase in training participation. 


\section{References}

Abraham, K. G. and Farber, H. S. (1987), Job duration, seniority, and earnings, American Economic Review, 77(3), pp. 278-297.

Acemoglu, D. (1996), Microfoundation For Social Increasing Returns in Human Capital Accumulation, Quarterly J ournal of Economics, 111, pp. 779-804.

Acemoglu, D. (1997), Training and Innovation in an Imperfect Labor Market, Review of Economic Studies, 64, pp. 445-464.

Acemoglu, D. and Pischke, J. (1998), Why do Firms Train? Theory and evidence, Quarterly J ournal of Economics, 113, pp. 79-119.

Acemoglu, D. and Pischke, J. (1999a), Beyond Becker: Training in Imperfect Labor Market, Economic Journal, 109 (February), F112-F142.

Acemoglu, D. and Pischke, J. (1999b), The Structure of Wages and Investment in General Training, J ournal of Political Economy, pp. 539-72.

Acemoglu, D. and Pischke, J. (2000), Certification of Training and Training Outcomes, European Economic Review, 44, pp. 917-927.

Acemoglu, D. and Pischke, J. (2003), Minimum Wage and On-the-Job Training, Research in Labor Economics, forthcoming.

Addison, J. and Siebert, W. (1994), Vocational Training and the European Community, Oxford Economic Papers, Oxford University Press, vol. 46(4), pp. 696-724.

Agell, J. and Lommerud, K. (1997), Minimum wages and the incentives for skill formation, Journal of Public Economics, Elsevier, vol. 64(1), pp. 25-40.

Alba-Ramirez, A. (1994), Formal Training, Temporary Contracts, Productivity and Wages in Spain, Oxford Bulletin of Economics and Statistics, Blackwell Publishing, vol. 56(2), pp. 151-70.

Almeida, R. and Carneiro, P. (2004), On-the-job training: Estimating costs and returns using firm level data. Working Paper, UCL.

Almeida-Santos, F. and Mumford, K. (2004), Employee Training and Wage Compression in Britain, IZA Discussion Papers, 1197,

Altonji, J. G. and Shakotko, R. (1987), Do wages rise with job seniority? Review of Economic Studies, 54, pp. 437459.

Andrén, T. and Gustafsson B. (2004), Income Effects from Labor Market Training Programs in Sweden during the 80's and 90's, International Journal of Manpower, Vol. 25, Issue no. 8.

Angrist, J. (2004), Treatment and heterogeneity in Theory and Practice, The Economic Journal, C52-C83.

Ariga, K. and Brunello, G. (2002), Do the Better Educated Receive More Training? Evidence from Thailand, IZA Discussion Paper 571

Arulampalam, W, Booth A., and Bryan M. (2004), Training and the New Minimum Wage, Economic Journal, March, C87-C94.

Arulampalam, W. and Booth A. (1998), Labour Market Flexibility and Skills Acquisition: Is There a Trade-off?, British Journal of Industrial Relations, 36, 4, pp. 521-536.

Arulampalam, W. and Booth, A. (2001), Learning and earning: Do multiple training events pay? A decade of evidence from a cohort of young British men, Economica, 68, pp. 379-400.

Arulampalam, W., Booth, A. and Bryan, M. (2004), Training in Europe, Journal of the European Economic Association, 2 (2-3), pp. 346-360.

Asplund, R. (2004), The Provision and Effects of Company Training: A brief review of the literature, ETLA Discussion Paper no. 907. 
Autor, D. (2004), Why Do Temporary Help Firms Provide Free General Skills?, Quarterly J ournal of Economics, MIT Press, vol. 116(4), pp. 1409-1448

Barrett A. and O'Connell P. (2001), Does Training Generally Work? The Returns to In-Company Training, Industrial and Labor Relations Review, 54 (3), pp. 647662.

Barron, J. M., Berger M. and Black D. (1997), On-the-Job Training, W.E Upjohn Institute for Employment Research.

Barron, J. M., Berger, M. and Black, D. (1999), Do Workers Pay for On-the-Job Training?, J ournal of Human Resources 34, 2 , pp. 236-252.

Barron, J. M., Berger, M. C., and Black, D. A. (1997), How well do we measuretraining?, Journal of Labor Economics, 15(3), pp. 507-528.

Barron, J. M., Black, D. A., and Loewenstein, M. A. (1987), Employer size: The implications for search, training, capital investment, starting wages, and wage growth. Journal of Labor Economics, 5(1), pp. 76-89.

Barron, J. Fuess, S., and Loewenstein, M. (1987), Further Analysis of the Effect of Unions on Training [Union Wages, Temporary Layoffs, and Seniority, J ournal of Political Economy, University of Chicago Press, vol. 95(3), pp. 632-40.Bartel, A. (1994), Productivity gains from the implementation of employee training Programs, Industrial Relations, 33(4), pp. 411425.

Bartel, A. (1995), Training, wage growth, and job performance: Evidence from a company database, Journal of Labor Economics, 13, pp. 401-425.

Bartel, A. (2000), Measuring the Employer's Return on Investments in Training: evidence from the Literature, Industrial Relations, 39(3), pp 502-524.

Bhaskar, V. and To, Ted, (2003), Oligopsony and the distribution of wages, European Economic Review, Elsevier, vol. 47(2), pp. 371-399.

Bhaskar V., Manning A. and To T. (2002), "Oligopsony and Monopsonistic Competition in Labour Markets," The Journal of Economic Perspectives, 16(2), pp. 155- 174.

Bassanini A. (2004), Improving Skills for More and Better Jobs? The Quest for Efficient Policies to Promote Adult Education and Training, presented at the Conference on Quality and Efficiency in Education, Brussels, May.

Bassanini A. (2005), Training, Wages, and Employment Security: an Empirical Analysis on European Data, EPEE Working Paper, 05/04, Université d’Evry-Val d'Essonne.

Bassanini, A. and Brunello G. (2003), Is Training More Frequent when Wage Compression is Higher? Evidence from the European Community Household Panel, IZA discussion papers, n.839.

Becker, G. S. (1964), Human Capital: A Theoretical and Empirical Analysis, with Special Reference to Education. New York, National Bureau of Economic Research.

Berger, K. and Walden, G (2002). Trends in public funding for in-company training in Germany: from a dual to a plural system in G. Burke and J. Reuling (eds), Vocational training and lifelong learning in Australia and Germany, Adelaide, NCVER.

Bishop, J. (1991), On-the-J ob Training of New Hires, in Market Failure in Training? edited. by David Stern and Jozef MM Ritzen, pp. 61-98. New York: Springer Verlag.

Bishop, J. (1993), Underinvestment in Employer Training: a Mandate to Spend? Human resources development Quarterly, 4, 3, 223-241.

Bishop, J. (1997), What We Know about Employer-Provided Training: A Review of the Literature, in Polachek, e Solomon, W., eds., Research in Labor Economics. London, JAl Press, pp. 19-87. 
Black S. and Lynch L. (1998), Determinants of Employer-Provided Training, Industrial and Labor Relations Review, vol. , pp

Black, S. and Lynch, L. (2001), How to Compete: The Impact of Workplace Practices and Information Technology on Productivity, The Review of Economics and Statistics, 83, pp. 434-445.

Blanchard, O., and Giavazzi, F. (2003), Macroeconomic effects of regulation and deregulation in goods and labor markets, The Quarterly Journal of Economics, 879-907.

Blanchard, O. and Wolfers, J. (2000), The role of shocks and institutions in the rise of European unemployment, the aggregate evidence, The Economic Journal, $110, \mathrm{C} 1 / 33$.

Blau, F. and Kahn, L. (1983), Job Search and Unionized Employment, Economic Inquiry, Oxford University Press, vol. 21(3), pp. 412-30.

Blinder, A. and Krueger A. (1996), Labor Turnover in the USA and Japan: A Tale of Two Countries, Pacific Economic Review, Vol. 1, pp. 27-57.

Blundell, R., Dearden L., and Meghir C. (1996), The Determinants and Effects of Work-Related Training in Britain, Institute for Fiscal Studies, London

Blundell, R., Dearden, L., and Meghir, C. (1999), Work-related training and earnings, Mimeo, Institute of Fiscal Studies.

Blundell, R., Dearden L., Meghir C., and Sianesi B. (1999), Human Capital Investment: The Returns from Education and Training to the Individual, the Firm and the Economy, Fiscal Studies, 20(1), pp. 1-23.

Boeri T. and Boersch-Supan A. Tabellini G. (2002), Pension Reforms and the Opinions of European Citizens, American Economic Review, 1 May 2002, vol. 92, no. 2, pp. 396-401(6).

Booth, A. (1991), Job-related Formal Training: Who Receives It And What Is It Worth?, Oxford Bulletin of Economics and Statistics, 53, pp. 281-294.

Booth, A. (1993), Private Sector Training and Graduate Earnings, Review of Economics and Statistics, 76, pp. 164-70.

Booth, A. and Bryan M. (2002), Who Pays for General Training? New evidence for British Men and Women, IZA Discussion Paper No. 486, April.

Booth, A. and Bryan, M. (2005a) Testing Some Predictions of Human Capital Theory: New Training Evidence from Britain, Forthcoming Review of Economics and Statistics, May.

Booth, A. and Bryan M. (2005b), Who Pays for General Training in Private Sector Britain?, IZA Discussion Paper No. 486, forthcoming Research in Labor Economics.

Booth, A. and Chatterji M. (1998), Unions and Efficient Training, The Economic J ournal, 108, 447, pp. 328-343

Booth, A. and Coles M. G. (2005), Increasing Returns to Education and the Skills Under-investment Trap, Mimeo, Australian National University.

Booth, A., Francesconi, M., and Zoega G. (1999), Training, Rent-sharing and Unions, CEPR Discussion Paper Series, No. 2200.

Booth, A., Francesconi M. and Zoega G. (2003), Unions, Work-related Training and Wages: Evidence for British Men', Industrial and Labor Relations Review, Vol. 57, No. 1, pp. 68-91.

Booth, A., Francesconi M. and Zoega G. (2005), Oligopsony, Institutions and the Efficiency of General Training, Forthcoming Chapter 2 of Proceedings of the 2004 ECB/CEPR Labour Market Workshop, Edward Elgar Publishers. Ed. J Messina, C. Michelacci, J. Turunen and G. Zoega.

Booth, A. and Zoega G. (1999), Do Quits Cause Under-Training?, Oxford Economic Papers, 51, pp. 374-386, February. 
Booth A. and Zoega G. (2000), Why do Firms Invest in General Training? 'Good' Firms and 'Bad' Firms as a Source of Monopsony Power, Institute for Labour Research, working papers n. 058, University of Essex.

Booth A. and Zoega G. (2004), Is Wage Compression a Necessary Condition for Firm-financed General Training?, Oxford Economic Papers, 56, pp.88-97.

Brown, J. N. (1989), Why do wages increase with job tenure? On-the-job training and life-cycle wage growth observed within firms. American Economic Review, 79(5): $971-991$.

Brunello, G. (2003), On the Complementarity between Education and Training in Europe, in Checchi and Lucifora, (eds.), Education, Training and Labour Market Outcomes in Europe, Palgrave, McMillan.

Brunello, G. (2004), La formazione continua nelle grandi imprese italiane: un'analisi dei risultati della seconda indagine ISFOL, ISFOL, Rome.

Brunello, G. and Checchi, D. (2005), Family Background and School Quality in Italy, forthcoming Economics of Education Review.

Brunello, G. and De Paola, M. (2004a), Training and the Density of Economic Activity: evidence from Italy, IZA Discussion Paper 1073.

Brunello, G. and De Paola, M. (2004b), Market Failures and the Under-provision of

Training, CESIFO Discussion Paper.

Brunello, G. and Gambarotto, F. (2004), Agglomeration Effects of Employer Provided Training: evidence from the UK, IZA Discussion Paper 1055.

Brunello, G. and Giannini, M. (2004), Stratified or comprehensive? The economic efficiency of school, in The Scottish J ournal of Political Economy, 2004, 156-173.

Brunello, G. , Giannini, M. and Ariga, K. (2004), The Optimal Timing of School Tracking, forthcoming in Petersen, P. and Woessmann, L., eds., Schools and Equal Opportunity, MIT Press.

Brunello G. and Medio A. (2001), An Explanation of International Differences in Education and Workplace Training, European Economic Review, vol.1, pp.307322.

Brunello, G. and Topo A. (2005), Dalla formazione apparente alla formazione effettiva? II nuovo apprendistato professionalizzante, Rivista Italiana di Diritto del Lavoro, pp.33-58.

Burdett, K. and Smith E. (1996), Education and Matching Externalities, in: A.L. Booth and D.J. Snower (ed.), Acquiring Skills. Market Failures, Their Symptoms and Policy Responses, Cambridge: Cambridge University Press, 65-80.

Bruyneel, D. (1999), Tax and Accounting Treatment of Vocational Training, OECD, Paris.

Cameron, S. and Taber, C. (2000), Borrowing Constraints and the Returns to Schooling, NBER Working Paper No. W7761.

Campanelli P. and Channell J., with contributions from L McAulay, A Renouf and R. Thomas (1994), Training: An Exploration of the Word and the Concept, Employment Department Research Series No. 30, July.

Card, D. (1999), The Causal Effect of Education on Earnings, in Handbook of Labor Economics, ed. by O. Ashenfelter and D. Card, vol. 3A, chap. 30, pp. 18011863, Elsevier, Amsterdam et al.

Card, D. (2000), Estimating the Return to Schooling: Progress on Some Persistent Econometric Problems, NBER Working Paper No. 7769, Cambridge, MA.

Carneiro P. and Heckman J. (2004), The Evidence on Credit Constraints in PostSecondary Schooling, Economic Journal, 112, pp.705-34.

Carneiro, P. and Heckman J. (2004) Human capital policies, in A. B Krueger, J. Heckman, B. Friedman (editor) Inequality in America: what role for human capital policy? MIT Press, Cambridge Mass. 
Caroli, E. and Van Reenen, J . (2001), Skill-Biased Organizational Change? Evidence from a Panel of British and French Establishments, Quarterly Journal of Economics, Volume 116, Issue 4, pp. 1449-1492.

Chapman. B. (2002), Credit Constraints and Training after J ob Loss, mimeo,

Chang, C. and Wang Y., (1996), Human Capital Investment under Asymmetric Information: The Pigovian Conjecture Revisited", Journal of Labor Economics, 14, pp. 505-519.

Colardyn, D. (ed.) (2002), Lifelong learning: Which ways forward?, Kenniscentrum EVC, Utrecht: Lemma Publishers.

Collier, W., Green, F., Perison, J. and Wilkinson, D. (2003), Training and Establishment Survival, mimeo, Kent University.

Conlon, G. (2000), The Marginal effect of Vocational Qualifications on Labour Market Performance and Earnings", D.Phil. Thesis, Nuffield College, University of Oxford.

Croce G. (2005), An economic evaluation of "interprofessional" Funds as training Policies,University of Rome La Sapienza.

Croce G. (2005), Limiti e prospettive della formazione continua in Italia, in Economia \& lavoro,2, forthcoming.

Crouch, C. (1997), Skills-based Full Employment: the Latest Philosopher's Stone, British Journal of Industrial Relations, pp. 367-391.

Crouch, C. (1998) Skills-based full employment: the latest philosoper's stone, British Journal of Industrial Relations 35 (3), pp. 367-291.

Currie, J. and Fallick, B. (1996), The Minimum Wage and the Employment of Youth, J ournal of Human Resources, 31, pp. 404-28.

Dearden, L., Reed H. and Van Reenen J. (2000), Who gains when workers train? Training and corporate productivity in a panel of British industries, Centre for Economic Policy Research Discussion, Paper No. 2486.

De la Fuente, A. and Ciccone, A., (2002), Human capital in a global and knowledgeBased economy, The European Commission.

Duncan, G. and Stafford, F. (1980), Do union members receive compensating differentials, American Economic Review, 70, 3, pp. 355-71.

Dustmann, C. and Schonberg, U. (2004), Training and Union Wages, Mimeo, UCL.

Duval, R. (2004), Retirement behaviour in OECD countries: impact of old-age pension schemes and other social transfer programmes, OECD Economic Studies, 37.

Epple, R., Newlon, E. and Romano R. (2004), Ability tracking, school competition and the standardization of educational benefits, J ournal of Public Economics.

Eurostat (2000), Continuing Vocational Training Survey (CVTS2): European Union Manual, Eurostat Population and Social Conditions Working Paper 3/2000/E/N¹7, Luxembourg.

European Commission (2005), Progress Towards the Lisbon Objectives in Education and Training, Commission Staff Working Paper.

Fougère, D., Goux, D., and Maurin, E. (2001). Formation continue et carriers salariales. Une évaluation sur données individuelles, Annales d'Économie et de Statistique, 62:49-69.

Frazis, H., and Loewenstein M. A. (1999), Reexamining the Returns to Training: Functional Form, Magnitude, and Interpretation, United States Bureau of Labor Statistics, Office of Employment Research and Program Development, Working paper 325.

Frazis, H., Gittleman, M., Horrigan, M., and Joyce, M. (1996), Formal and informal training: Evidence from a matched employee-employer survey. Paper prepared 
for the conference "New empirical research on employer training: Who pays?" held at Cornell University, November 15-17, 1996.

Freeman, R. and Medoff J. (1984), What Do Unions Do? New York: Basic Books.

Galindo-Rueda, V. and Vignoles, A. (2004), The Heterogeneous Effect of Selection in Secondary Schools: Understanding the changing role of ability, mimeo.

Garibaldi, P. and Violante, L. (2002), The employment effects of severance payments with wage rigidities, New York University.

Gasskov, V. (2001), Government Interventions In Private Financing Of Training, ILO, Geneva

Gerfin, M. (2003), Work-related training and wages - an empirical analysis for male workers in Switzerland. Mimeo, Volkswirtschaftliches Institut, Universität Bern.

Gersbach, H., and Schmutzer, A. (2004), A product market theory of training, IZA Discussion Paper 327

Golden, L., and Appelbaum, E. (1992), What was driving the 1982-88 boom in temporary employment? American Journal of Economics and Sociology, 51(4), pp. 473-493.

Gospel, H. (1995), The decline of apprenticeship training in Britain, Industrial Relations J ournal, 26, 1, pp. 32-44.

Gospel, H. (1997), The revival of apprenticeship training in Britain? Centre for Economic Performance, Discussion Paper, n. 372.

Goux, D. and Maurin E. (2000), Returns to Firm Provided Training: Evidence from French Worker-Firm Matched Data, Labor Economics, 7, pp. 1-19.

Green, F. (1993), The Determinants of Training of Male and Female Employees in Britain, Oxford Bulletin of Economics and Statistics, 55 (1), pp. 103-22.

Green, D., and Lemieux, T. (2001), The impact of unionization on the incidence of the sources of payment for training in Canada: a study based on the adult education and training survey, mimeo.

Green, F., Machin, S. and Wilkinson D. (1999), Trade Unions and Training Practices in British Workplaces, Industrial and Labor Relations Review, 52, 2, pp. 179195.

Greenhalgh, C. (1999), Adult Vocational Training and Government Policy in France and Britain, Oxford Review of Economic Policy, Oxford University Press, vol. 15(1), pp. 97-113.

Greenhalgh, C. (2002), Does an Employer Training Levy Work? The Incidence of and Returns to Adult

Greenhalgh, C. and Mavrotas G. (1994), The Role of Career Aspirations and Financial Constraints in Individual Access to Vocational Training, Oxford Economic Papers, 46, pp. 579-604.

Greenhalgh, C. and Stewart, M. (1987), The Effects and Determinants of Training, Oxford Bulletin of Economics and Statistics, 49 (2) pp. 171-90.

Grossberg A. J. and Sicilian P. (1999), Minimum Wages, On-the-job Training and Wage Growth, Southern Economic Journal, 65(1).

Hannah, F., Raffe, K. and J. Smyth, (1996), Cross-National research in school to work transition: an analytical framework, OECD, mimeo.

Hashimoto, M. (1981), Firm-specific Human Capital as a Shared Investment, American Economic Review, 71, pp. 475-82.

Hashimoto, M. (1982), Minimum Wage Effects on Training on the Job, American Economic Review, 72, pp. 1070-1087.

Hausman, J. A. and Taylor, W. (1981), Panel data and unobservable individual effects, Econometrica, 49, pp. 1377-1398.

Heckman, J. (1999), Policies to Foster Human Capital, NBER Working Paper, No. 7288. 
Håkanson, C, Johanson S., Mellander E.(2003), Employer-sponsored training in stabilisation and growth policy perspectives, IFAU Woking Paper 2003: 8.

Hall, R. E. (2000), Reorganization, Carnegie-Rochester Conference Series on Public Policy, Volume 52, pp. 1-22.

Holzer, H. J., Block, R. N., Cheatham, M., and Knott, J. H. (1993). Are training subsidies for firms effective? The Michigan experience, Industrial and Labor Relations Review, 46(4), pp. 625-636.

ISFOL (2001), Rapporto 2001, F. Angeli.

Johnson, G. (1984), Subsidies for Higher Education, Journal of Labor Economics, 2(3), pp. 303-18.

Jovanovic, B. (1979a), Firm-specific capital and turnover, Journal of Political Economy, 87, pp. 1246-1260.

Jovanovic, B. (1979b), J ob matching and the theory of turnover, J ournal of Political Economy, 87, pp. 972990.

Kaldor, N. (1963), Capital Accumulation and Economic Growth, in Friedrich A. Lutz and Douglas C. Hague, eds., Proceedings of a Conference Held by the International Economics Association, London, Macmillan.

Kane T. and Rouse C. (1999), The Community College: Training Students at the Margin Between College and Work, Journal of Economic Perspectives, Vol. 13, No. 1, pp. 63-84.

Katz, L. and Autor, D. (1999), Changes in the wage structure and earnings inequality, in Handbook of Labor Economics, ed. by O. Ashenfelter and D. Card, vol. 3A

Katz, L. and Murphy K. (1992), Changes in Relative Wages, 1963-1987: Supply and Demand Factors, Quarterly J ournal of Economics, 107, 35-78.

Katz, E. and Zderman, A. (1990), Investment in General Training: The Role of Information and Labour Mobility, Economic J ournal, vol. 100, pp. 1147-58.

Kennedy, S., Drago, R., Sloan, J. and Wooden, M. (1994), The Effect of Trade Unions on the Proand Humanities Research Council of Canada. vision of Training: Australian Evidence, Journal of Industrial Relations, 32, 4, pp.565580.

Krueger, A. (1993), How Computers Have Changed the Wage Structure: Evidence from Micro Data, 1984-1989, Quarterly Journal of Economics, Vol. 108, no. 1 (February 1993), pp. 33- 60.

Krueger, A., and Rouse, C. (1998), The effect of workplace education on earnings, turnover, and job performance, J ournal of Labor Economics, 16(1), 61-94.

Kuckulenz, A. and Zwick, T. (2003), The impact of training on earnings-differences between participant groups and training forms. Mimeo, ZEW Mannheim.

Laing, D, Palivos T. and Wang P. (1995), Learning, Matching and Growth." Review of Economic Studies, 62, 115-129.

Lazear, E. (1979), Why is there mandatory retirement?, Journal of Political Economy.

Lazear, E. (2003), Firm-Specific Human Capital: A Skill-Weights Approach, NBER Working Paper, No. 9679, May.

Lazear, E. and Miller F. (1981), Minimum Wages Versus Minimum Compensation, in Report of the Minimum Wage Study Commission, vol. 5, Washington, DC: US Government Printing Office.

Leighton, L. and Mincer, J. (1981), The Effects of Minimum Wages on Human Capital Formation, in Rottenberg, Simon (ed), The Economics of Legal Minimum Wages, American Enterprise Institute, Washington DC, pp. 155- 173.

Leuven, E. (2004), The economics of private-sector training, Journal of Economic Surveys, forthcoming. 
Leuven E., Oosterbeek H., Sloof R. and Van Klaveren C. (2003), Worker Reciprocity and Employer Investment in Training, Economica, forthcoming.

Leuven, E. and Oosterbeek H. (1999), The Demand and Supply of Work-Related Training: Evidence from Four Countries, in Polacheck S. and J. Robst (eds), Research in Labor Economics, 18, pp. 303-330.

Leuven, E. and Oosterbeek H. (2001), Firm-specific human capital as a shared investment: Comment, American Economic Review, 91. (2001), pp. 342-347.

Leuven, E. and Oosterbeek, H. (2002), A new method to estimate the returns to work-related training, Unpublished working paper, Department of Economics, University of Amsterdam.

Leuven, E. and Oosterbeek, H. (2004), Evaluating the effects of a tax deduction on training. J ournal of Labor Economics, 22(2):461-488.

Levin, H. (1998), Financing a system of lifelong learning, Education Economics 6, pp. 201-218.

Lindbeck, A. and Snower, D. (1988), The Insider-outsider theory of employment and unemployment, Cambridge University Press.

Linneman, P. (1982), The Economic Impact of Minimum Wage Laws: A New Look at an Old Question, Journal of the Political Economy, 90(3), pp. 443-69.

Loewenstein, M. and Spletzer, J. (1997), Delayed Formal On-the-Job Training, Industrial and Labor Relations Review, Volume 51, Issue 1, pp. 82-99.

Lowenstein M. and Spletzer J. (1998), Dividing the Costs and Returns to General Training, Journal of Labor Economics, 16(1), pp. 142-171.

Loewenstein, M. and Spletzer, J. (1999a) Formal and Informal Training: Evidence from the NLSY, Research in Labor Economics, Vol. 18, pp. 403-438.

Lowenstein, M. and Spletzer J. (1999b), General and Specific Training: Evidence and Implications, J ournal of Human Resources, 34(4), pp. 710-733.

Lucas, R. (1988), On the mechanics of economic development, Journal of Monetary Economics, 22, pp. 3-42.

Lynch, L. (1991), The Role of Off-the J ob vs. On-the-J ob Training for the Mobility of Young Women Workers, American Economic Review, 81, pp. 151-156.

Lynch, L. (1992), Private Sector Training and the Earnings of Young Workers, American Economic Review, vol. 82, pp. 299-312.

Lynch, L. (1994), Training and the Private Sector: International Comparisons, Chicago, University of Chicago Press.

Malcomson, J., Maw, J., e McCormick B. (2002), General Training by Firms, Apprentice Contracts, and Public Policy, European Economic Review, Vol. 47, No. 1, pp. 197-227.

Marhuenda Fluixà F. (2000), The rebirth of apprenticeship in Europe: linking education to work? Leonardo SPES- NET. Final report.

Marsden, D. and Ryan P. (1990), Institutional aspects of youth employment and training policy in Britain, British Journal of Industrial Relations, 28, 3, pp. 35170.

Medoff, J. and Abraham, K. (1980), Experience, performance, and earnings. Quarterly J ournal of Economics, 85, pp. 703-736.

Medoff, J. and Abraham, K. (1981), Are those paid more really more productive? The case of experience. J ournal of Human Resources, 16(2), pp. 186-216.

Middleton, J., Ziderman A. and Adams A. (1993), Skills for Productivity, New York: Published for the World Bank by Oxford University Press.

Mincer, J. (1983), Union effects on wages, turnover and job training, Research in Labor Economics, 2, pp. 217/52.

Mincer J. (1996), Training: Costs, Returns, and Wage Profiles, The economics of training, Theory and measurement, in Ashenfelter, O., LaLonde, R.,(eds), Elgar 
Reference Collection, International Library of Critical Writings in Economics, vol. 65, 105-23, Cheltenham, U.K.

Moen, E. and Rosen, A. (2002), Does Poaching Distort Training?, CEPR Discussion Paper No. 3468.

Mortensen, D. T. (1978), Specific capital and labor turnover, Bell Journal of Economics, 9, pp. 572-585.

Mortensen, D. and Pissarides, C. (1999), New developments in models of search in the labour market, in Handbook of Labor Economics, ed. by $\mathrm{O}$. Ashenfelter and D. Card, vol. 3A.

Nestler, K. and Kailis, E. (2002), Disparities in Access to Continuing Vocational Training in Enterprises in Europe, Eurostat Statistics in Focus No. 22/2002.

Neumark D. and Wascher W. (2001), Minimum Wages and Training Revisited, J ournal of Labor Economics, Vol. 19, No. 3, pp. 563-595.

Nicoletti, G. and Scarpetta, S. (2003), Regulation, productivity and growth: OECD evidence, Economic Policy, pp. 9-72.

Nickell, S., Nunziata, L., and Ochel, W. (2005), Unemployment in the OECD since the 1960s. What do we know?, The Economic Journal,

OECD (1993), Employment Outlook, Paris.

OECD (1999), Employment Outlook, Paris.

OECD (2002), Employment Outlook, Paris.

OECD (2003), Employment Outlook, Paris.

OECD (2004), Employment Outlook, Paris.

OECD and Statistics Canada (2000), Literacy in the Information Age, Paris and Ottawa.

OECD (2001), The Economics and Finance of Lifelong Learning, Paris.

OECD (2003a), Upgrading Workers' Skills and Competencies, chapter 5, Employment Outlook, Paris.

OECD (2003b), Beyond Rhetoric: Adult Learning Policies and Practices, Paris.

OECD (2003c), Descriptions and Evaluations of Recent Experience with Mechanisms for Co-financing Lifelong Learning: Reports Prepared by National Authorities and Members of the ELAP Network, prepared for the "Second International Seminar: Mechanisms for the Co-finance of Lifelong Learning", London, 27-29 November, OECD, Paris.

OECD, (2004), The 2003 PISA Study, Paris.

Oi, W. (1962), Labour As a Quasi-Fixed Factor, J ournal of Political Economy, 70, pp. 538-55

Ok W. and Tergeist, P. (2003), Improving Workers' Skills: Analytical Evidence and the Role of the Social Partners, OECD Social, Employment and Migration Working Papers.

Oosterbeek, H. (1998), Unravelling Supply and Demand Factors in Work-Related Training, Oxford Economic Papers, Vol. 50, No. 2, pp. 266-283.

Parent, D. (1999), Wages and mobility: The impact of employer-provided training. J ournal of Labor Economics, 17(2), pp. 298-317.

Parent, D. (2003), Employer-supported training in Canada and its impact on mobility and wages. Empirical Economics, 28, pp. 431-459.

Piore, M. (1968), On-the-Job Training and Adjustment to Technological Change, J ournal of Human Resources, Vol 3, pp. 435-449.

Pischke, J. (2001), Continuous training in Germany, Journal of Population Economics, 14:523548.

Redding S. (1996), The Low-Skill, Low-Quality Trap: Strategic Complementarities between Human Capital and R\&D, The Economic J ournal, 106, pp. 458-70.

Roemer, J. (1998), Equality of Opportunity, Cambridge: Harvard University Press. 
Romer, P. (1986), Increasing Returns and Long Run Growth, Journal of Political Economy, n. 94.

Rosen, S. (1972), Learning and Experience in the Labor Market, Journal of Human Resources, 7, pp. 326-342.

Rubenson, K. and Schuetze H. (1999), Lifelong Learning for the Knowledge Society: Demand, Supply and Policy Dilemmas, in K. Rubenson and H. Schuetze, eds., Transition to the Knowledge Society: Policies and Strategies for Individual Participation and Learning, Human Resources Development Canada and The Institute for European Studies, Vancouver, British Columbia: 1999.

Ryan, P. (1994), Training quality and trainee exploitation, in R. Layard, K. Mayhew and G. Owen (eds), Britain's Training Deficit, Aldershot: Avebury.

Ryan, P. (1998), Is apprenticeship better? A review of the economic evidence, J ournal of Vocational Education and Training, Summer; 50,2; 289-325.

Ryan, P. (2000), The institutional requirements of apprenticeship: evidence from smaller EU countries, International Journal of Training and Development, 4, (1), 42-65.

Schiller, B. R. (1994), Moving Up: The Training and Wage Gains of Minimum Wage Entrants, Social Science Quarterly, 75(3), 622-36, September.

Schøene, P. (2002), Why is the return to training so high? Mimeo, Institute for Social Research, Olso, Norway.

Sepulveda, F., (2002), Training and Business Cycles, Michigan State University, mimeo

Snower, D. (1996), The Low-Skill, Bad-Job Trap, 1996, in Acquiring Skills (ed. with A. Booth), Cambridge: Cambridge University Press, pp.109-124.

Steedman G. (2001a), Five years of the modern apprenticeship initiative: An assessment against continental European models, National Institute Economic Review, No. 178.

Steedman, H. (2001b) Benchmarking Apprenticeship: UK and Continental Europe Compared," CEP Discussion Papers 0513, Centre for Economic Performance, LSE.

Stevens, M. (1994), A Theoretical Model of On-the-Job Training with Imperfect Competition, Oxford Economic Papers, Vol. 46, No. 4, pp. 537-562.

Stevens, M. (1996), Transferable Training and Poaching Externalities, in A.L. Booth and D.J. Snower (eds.), Acquiring Skills: Market Failures, Their Symptoms and Policy Responses, Cambridge University Press, Cambridge, UK.

Stevens, M. (1999), Human Capital Theory and UK Vocational Training Policy, Oxford Review of Economic Policy, 15, 1, pp. 16-32.

Story, A. and Redman, T. (1997), Training agreements: resolving under-investment in training?, International Journal of Training and Development, 1(3), pp. 144176.

Topel, R. (1986), Job mobility, search, and earnings growth: A reinterpretation of human capital earnings functions. Research in Labor Economics, 8, pp. 199-233.

Topel, R. (1991), Specific capital, mobility, and wages: Wages rise with job seniority, Journal of Political Economy, 99(1), pp. 145-176.

Veeken, N. 1999. Industrial social funds in the Netherlands. Paper for the ILO, Geneva.

Veum, J. (1995), Sources of training and their impact on wages, Industrial and Labor Relations Review, 48 (4), pp. 812-26.

Veum, J. (1996), Gender and race differences in company training, Industrial Relations, 35, pp. 32-44, Vocational Training in France and Britain, Fiscal Studies, 23(2), pp. 223-263. 
Veum, J. (1997), Training and Job Mobility among Young Workers in the United States, J ournal of Population Economics 10,2, pp. 219-233.

Whalley, J. and Ziderman A. (1990), Financing Training in Developing Countries: The Role of Payroll Taxes, Economics of Education Review, 9, 4.

Winkelmann, R. (1994), Apprenticeship and After: Does it Really Matter?, CEPR Discussion Papers 1034, CEPR Discussion Papers

Wooldridge, J., 2002, Econometric analysis of cross section and panel data, Cambridge MIT Press.

Zwick, T. (2002), Continuous Training and Firm Productivity in Germany, ZEW Discussion Paper.

Zwick, T.(2004), Training - A Strategic Enterprise Decision?, Modern Concepts of the Theory of the Firm - Managing Enterprises of the New Economy, ed. by G. Fandel, U. Backes-Gellner, M. Schluter, and J. Staufenbiel, pp. 355- 366. Springer, Heidelberg. 